\title{
WestVirginiaUniversity
}

THE RESEARCH REPOSITORY @ WVU

Graduate Theses, Dissertations, and Problem Reports

2016

\section{Potential Failure Mode Analysis for Mineral Extraction Near Reservoirs}

Thomas K. Wachtel

Follow this and additional works at: https://researchrepository.wvu.edu/etd

\section{Recommended Citation}

Wachtel, Thomas K., "Potential Failure Mode Analysis for Mineral Extraction Near Reservoirs" (2016). Graduate Theses, Dissertations, and Problem Reports. 6883.

https://researchrepository.wvu.edu/etd/6883

This Dissertation is protected by copyright and/or related rights. It has been brought to you by the The Research Repository @ WVU with permission from the rights-holder(s). You are free to use this Dissertation in any way that is permitted by the copyright and related rights legislation that applies to your use. For other uses you must obtain permission from the rights-holder(s) directly, unless additional rights are indicated by a Creative Commons license in the record and/ or on the work itself. This Dissertation has been accepted for inclusion in WVU Graduate Theses, Dissertations, and Problem Reports collection by an authorized administrator of The Research Repository @ WVU.

For more information, please contact researchrepository@mail.wvu.edu. 


\title{
Potential Failure Mode Analysis for Mineral Extraction Near Reservoirs
}

\author{
Thomas K. Wachtel
}

\author{
Dissertation submitted \\ to the Benjamin M. Statler College of Engineering and Mineral Resources \\ at West Virginia University \\ in partial fulfillment of the requirements for the degree of \\ Doctor of Philosophy in \\ Civil and Environmental Engineering \\ John Quaranta, Ph.D., PE, Chair \\ Joe Donovan, Ph.D. \\ Keith Heasley, Ph.D., PE \\ Hema Siriwardane Ph.D., PE \\ Avinash Unnikrishnan, Ph.D. \\ Department of Civil and Environmental Engineering
}

\author{
Morgantown, West Virginia \\ 2016
}

Keywords: groundwater, seepage, failure mode analysis, event tree, subsidence Copyright 2016 Thomas K. Wachtel 


\title{
ABSTRACT \\ Potential Failure Mode Analysis for Mineral Extraction Near Reservoirs
}

\author{
Thomas K Wachtel
}

This research was performed to develop a method of determining the potential hazard of underground mining near surface bodies of water. Underground mining creates a void within the subsurface that is eventually filled by overburden material. This strain movement perpetrates through the strata layers through fracturing and bedding plane separation, creating a depression above the mined seam (subsidence). The effect of subsidence may occur rapidly over the course of several weeks to months (longwall mining, pillar extraction) or may occur slowly (room and pillar mining); in some cases over one hundred years. These strain movements may affect the physical properties of the overlying rock layers, specifically hydraulic conductivity as it pertains to this research. Hydraulic conductivity is the ability for a medium to transmit water when submitted to a hydraulic gradient. The change in hydraulic conductivity may permanently alter the local groundwater table, or create a pathway from a surface body of water into the mine void. This may lead to erosion around the reservoir rim, potentially causing uncontrolled water loss within the reservoir.

This research was performed to develop a methodology to determine potential seepage failure modes due to changes in hydraulic conductivity in overburden, caused by underground coal mining. The research is separated into four tasks: 1) literature review of mine subsidence prediction and empirical assessment, 2) a method to develop potential seepage failure mode analysis of a mine site, 3) numerical analysis assessing seepage at a field site, and 4) semiquantitative sensitivity analysis of risk based events for seepage mode failure near reservoirs.

Analysis shows that subsidence due to underground mining affects the hydraulic conductivity of the overlying medium, affecting the localized groundwater table and creating a cone of depression where hydraulic conductivity is increased. The extent of the cone of depression from the mine void is referred to as the Angle of Groundwater Influence. If this angle intersects with a reservoir pool level, seepage from the reservoir may cause uncontrolled drawdown or erosion.

Computer model analysis was performed on a field site to show how this methodology is applied. It was analyzed for three different lateral offset distances based on various pool levels. The numerical modeling results show that the reservoir pool has minimal impact if it lies beyond the affected overburden of the mine. However, if the reservoir rim intersects the impacted area, the increased flow rate may initiate erosion in the subsurface potentially leading to a failure mode for the reservoir. Within the subsurface, the controlling factor is the rock layer with the highest initial hydraulic conductivity located above the fractured zone. At the modeled field site, the changes in groundwater flow rate below the reservoir rim increased beyond one order of magnitude at Probable Maximum Flood (PMF) pool level. The findings developed within the sensitivity and field site analyses were used to develop practical application of the methodology to aid in determining the potential hazard from underground mining on surface bodies of water. 


\section{Acknowledgements}

I would like to thank everyone who helped make this research possible. To Dr. John Quaranta, thank you for everything you have done for me over the course of the past six years. You've been a great advisor and a great friend. Thank you to all of the committee members: Dr. Siri Wardane, Dr. Keith Heasley, Dr. Joe Donovan and Dr. Avinash Unnikrishnan. I appreciate all of the time and effort you dedicated in help my along my career. To Harold Russell, thanks for all your help and for making graduate school enjoyable.

Most importantly, thank you mom. You were always there to support me no matter what and none of this would have been possible without you. 


\section{Table of Contents}

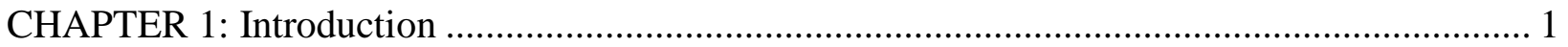

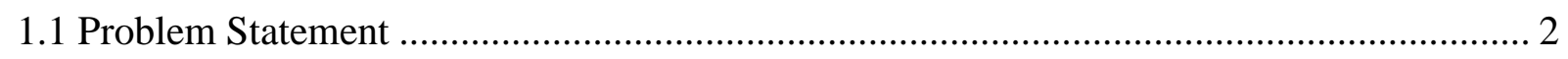

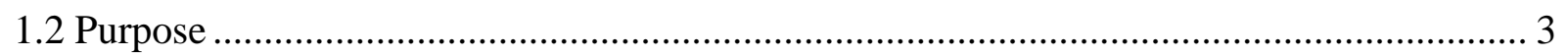

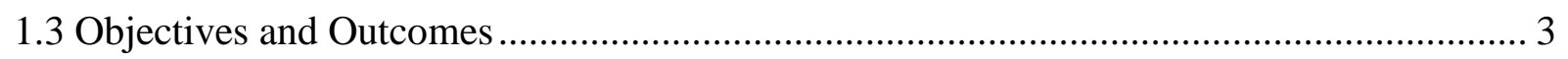

1.4 Scope of Work..................................................................................................... 3

CHAPTER 2: Literature Review for Mineral Extraction Near Surface Bodies of Water ............. 5

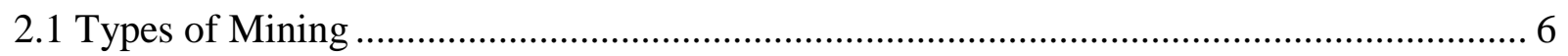

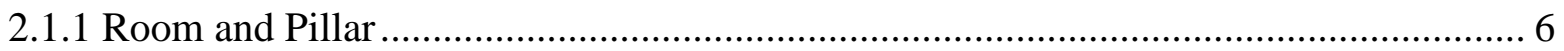

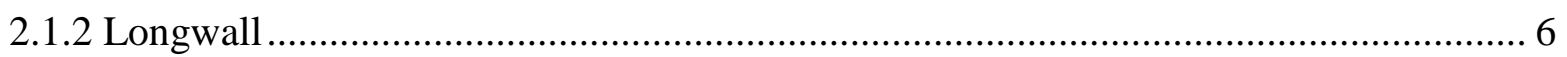

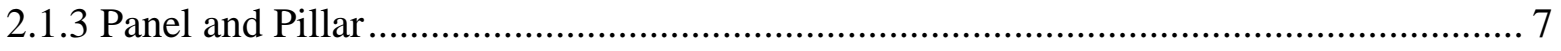

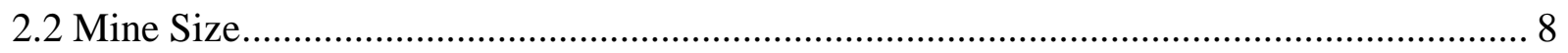

2.3 Guidelines for Mining under Surface Water Phase III and Final Report .......................... 9

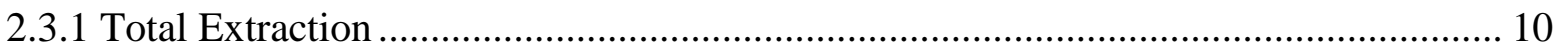

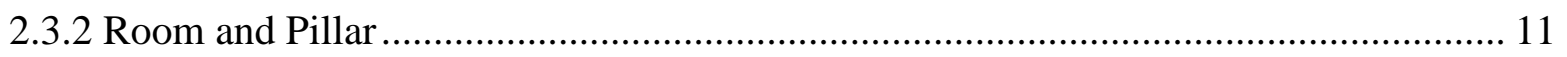

2.3.3 Panel and Pillar Mining ........................................................................................... 12

2.3.4 Safety of Water Bodies............................................................................................. 13

2.3.5 Safety of Important Impounding Structures ......................................................... 13

2.4 Guidelines for Mining near Water Bodies ................................................................. 14

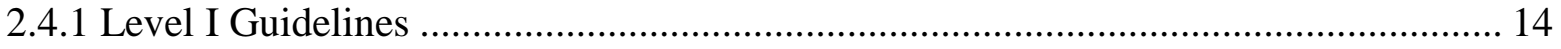

2.5.1 Level II Guidelines ......................................................................................... 16

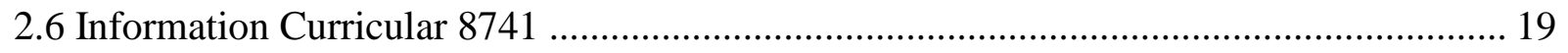

2.6.1 Total Extraction Mining .................................................................................. 20

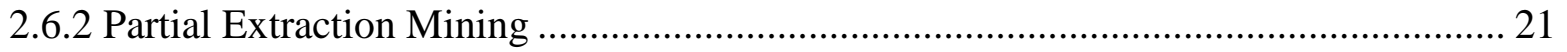

2.6.3 Mining near Surface Structures ....................................................................... 21

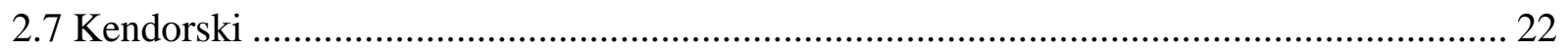

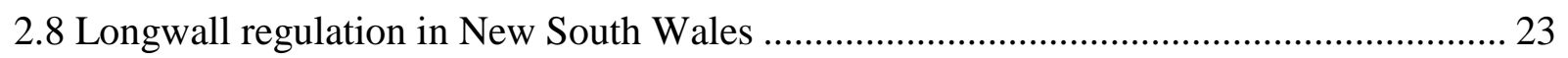

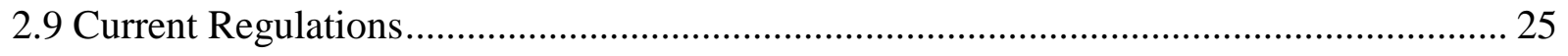

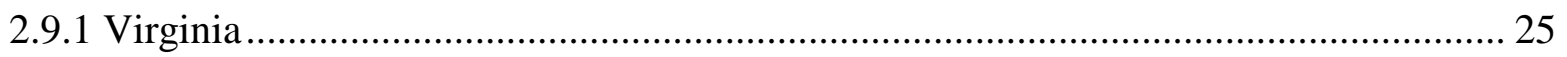

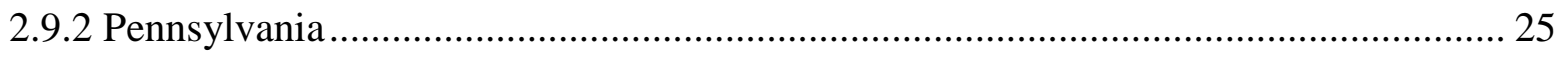

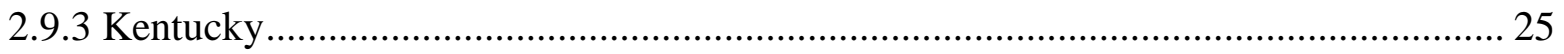

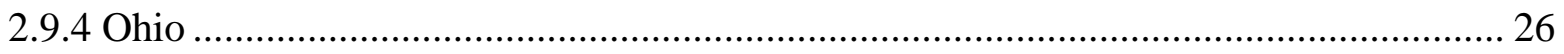

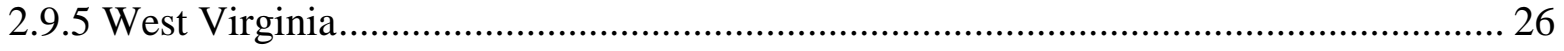

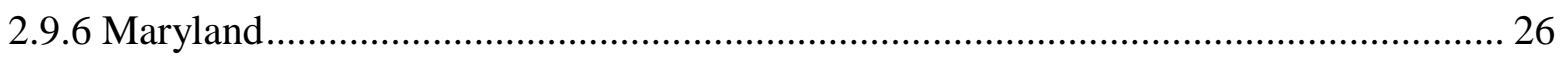

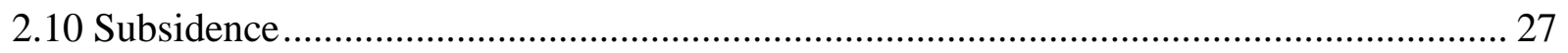

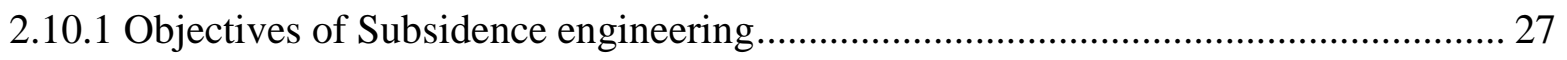

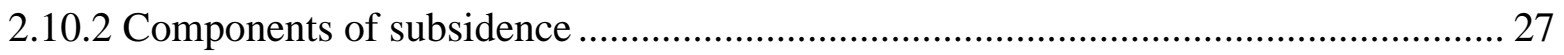

2.10.3 Factors affecting Mine Subsidence.................................................................. 28

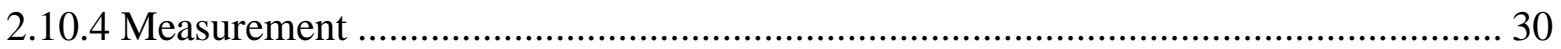

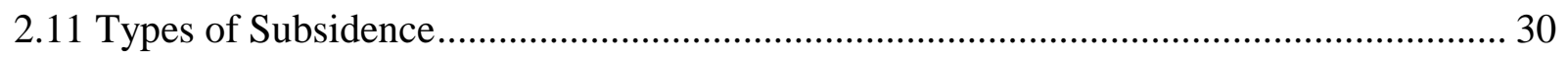




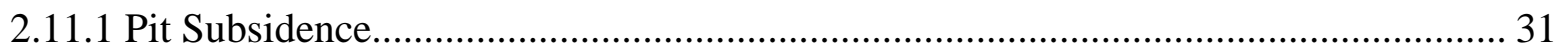

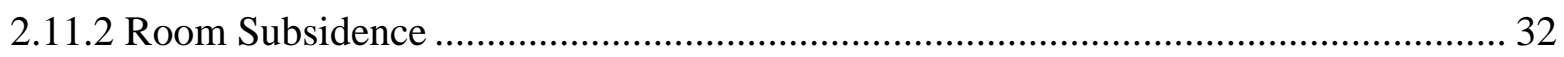

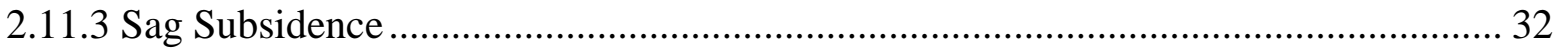

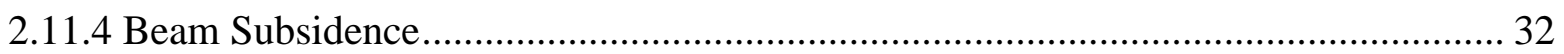

2.12 Surface Subsidence Due to Longwall Mining.............................................................. 33

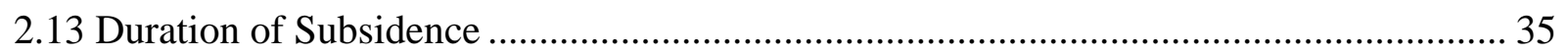

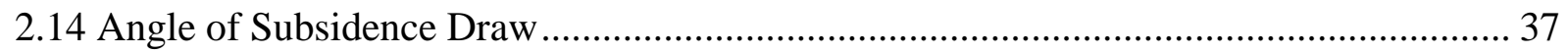

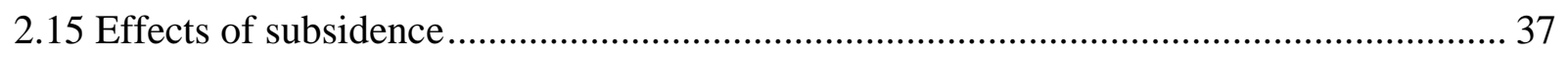

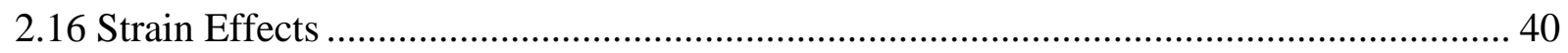

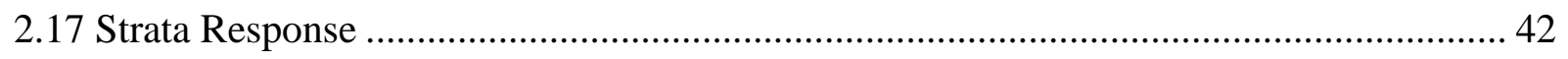

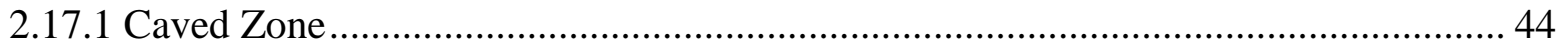

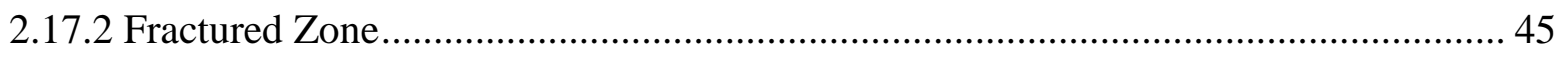

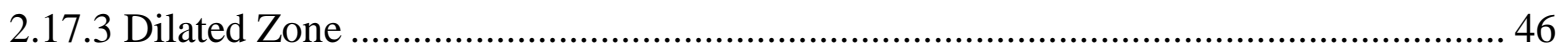

2.17.4 Bending or Constrained Strata Zone .................................................................... 46

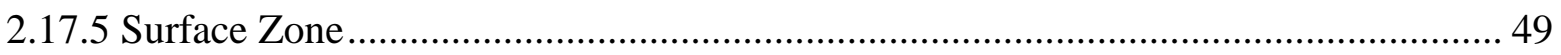

2.18 Analysis of Stress-Relief Fracturing for Modeling Underground Mining near Surface

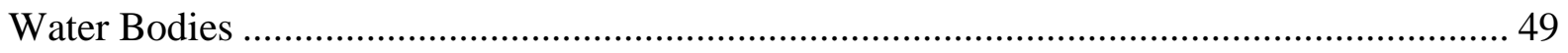

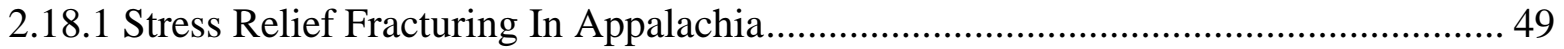

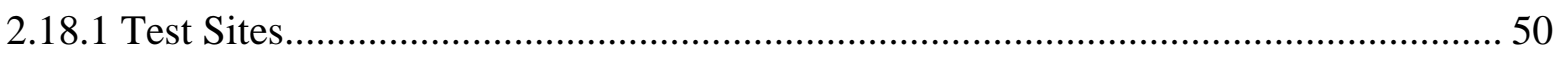

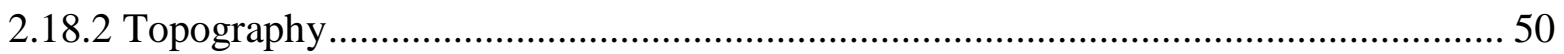

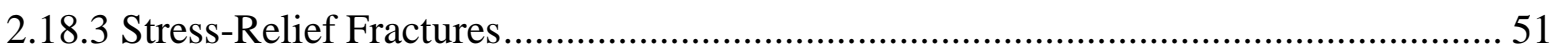

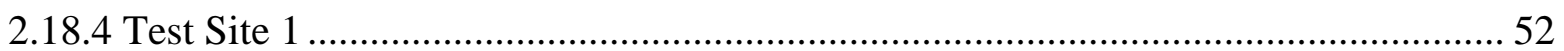

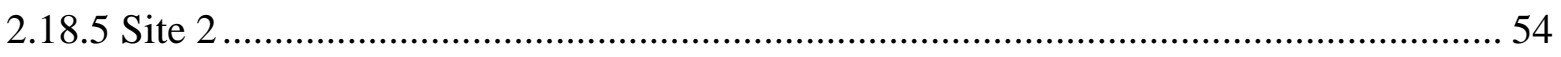

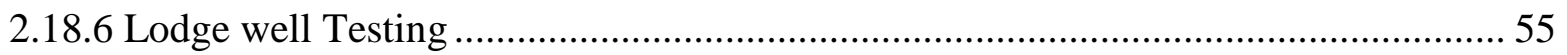

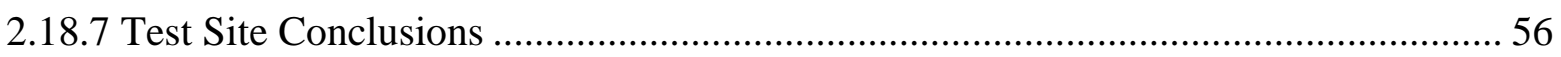

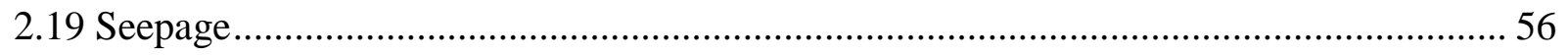

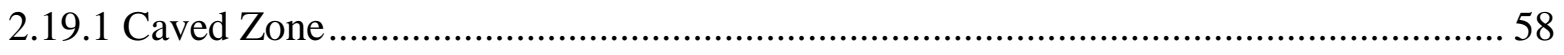

2.19.2 Fractured Zone............................................................................................... 58

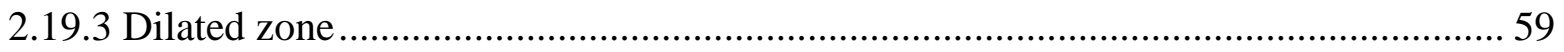

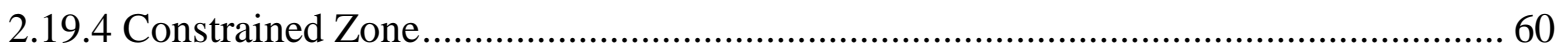

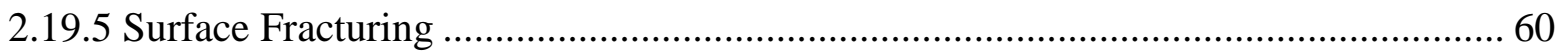

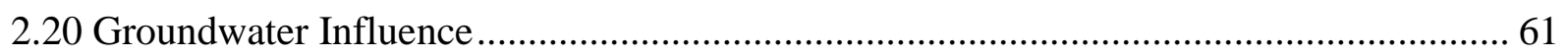

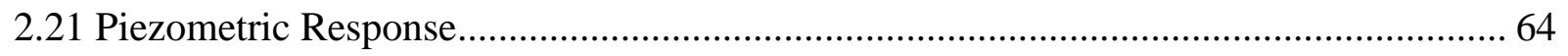

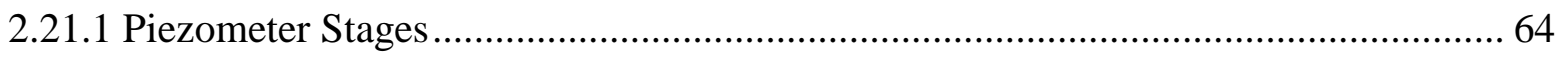

2.21.2 Topographical Permeability Zones...................................................................... 65

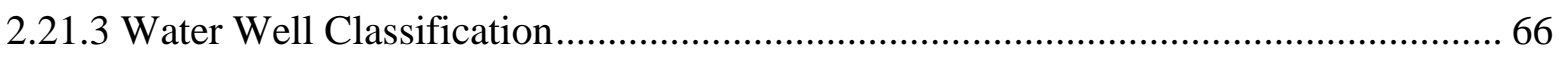

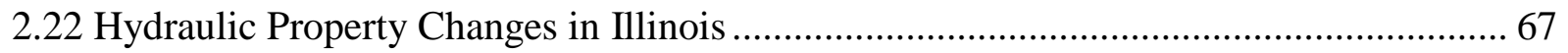

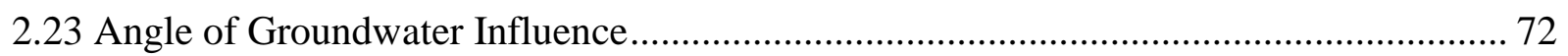

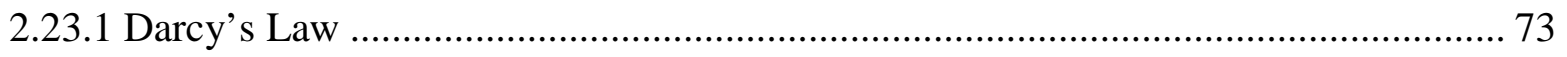

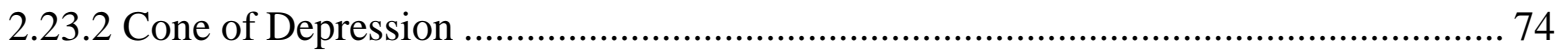




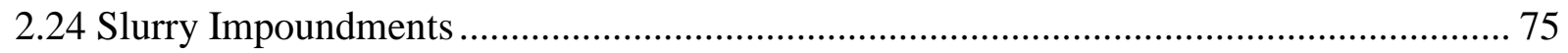

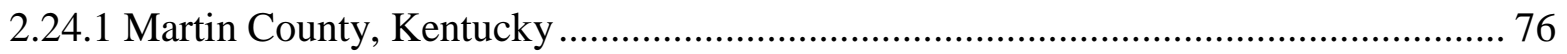

2.24.2 Lee County, Virginia ........................................................................................ 76

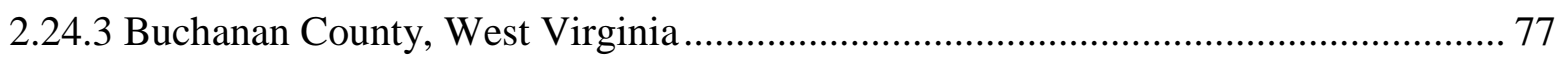

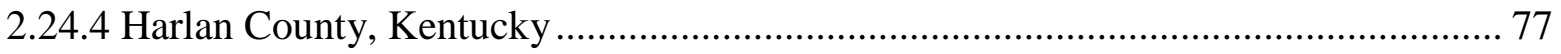

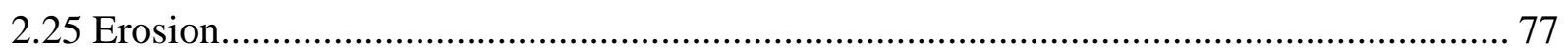

2.25.1 Concentrated erosion ........................................................................................... 77

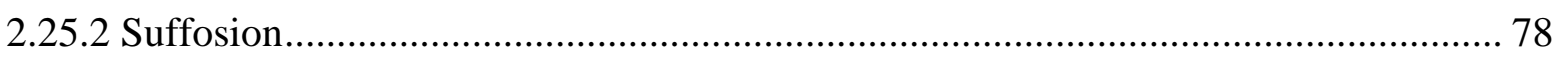

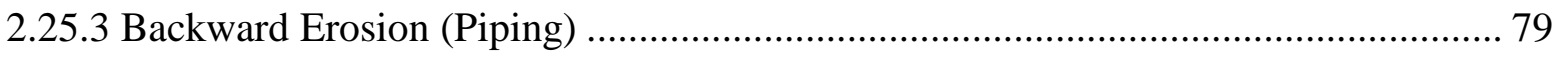

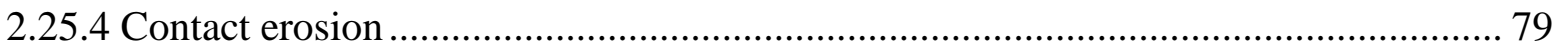

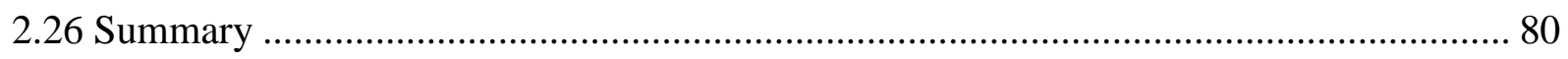

CHAPTER 3: Evaluation and Comparison of Existing Guidelines for Mining Under Water

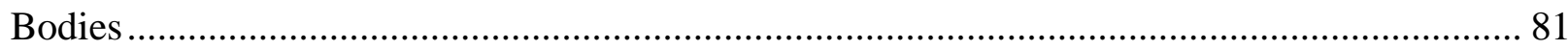

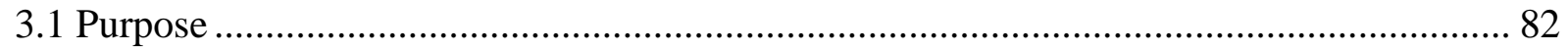

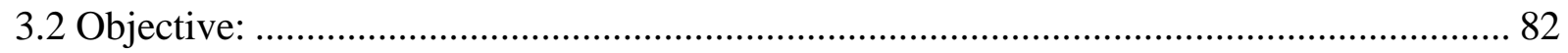

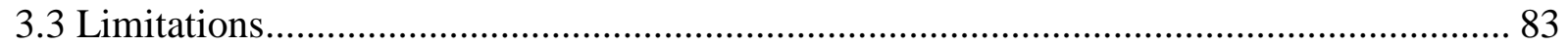

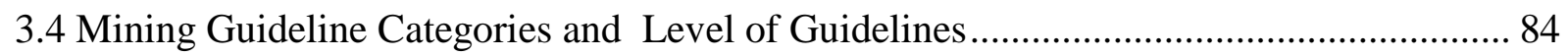

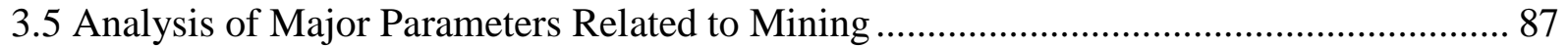

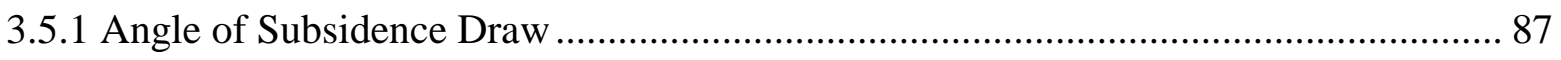

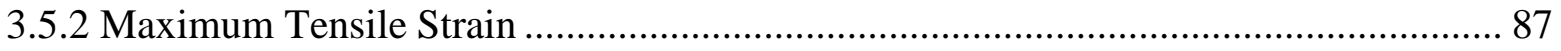

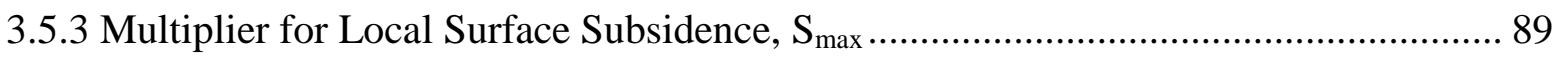

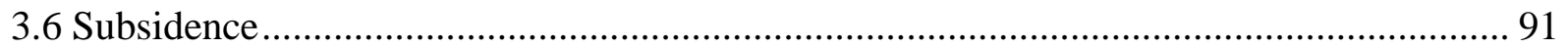

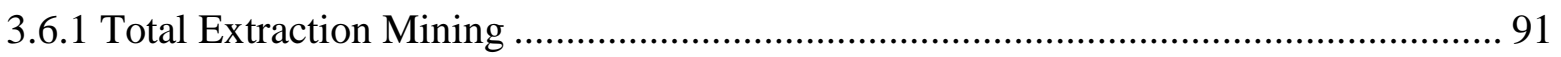

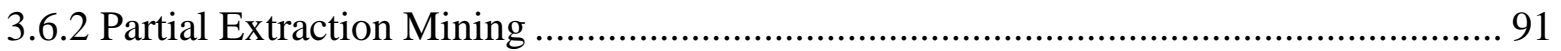

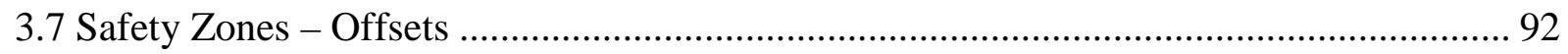

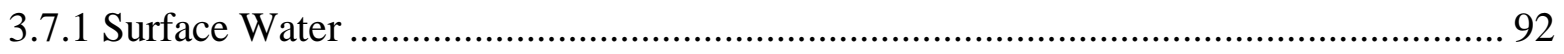

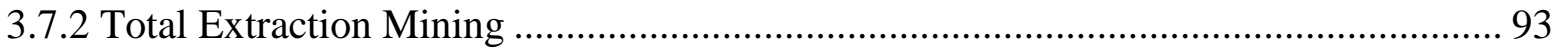

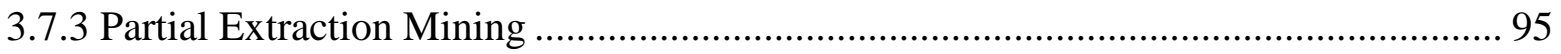

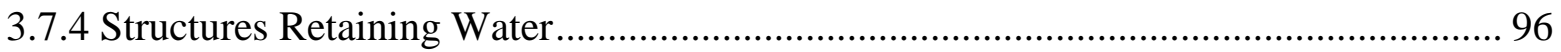

3.8 Comparison Between Pillar Dimensioning for First Workings Room-and-Pillar .............. 97

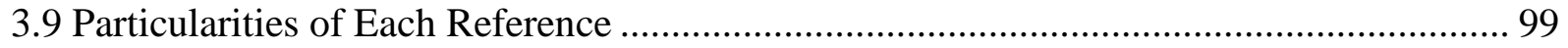

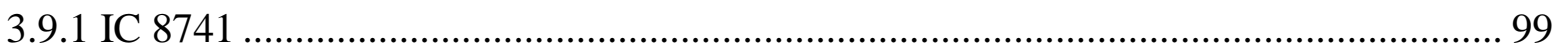

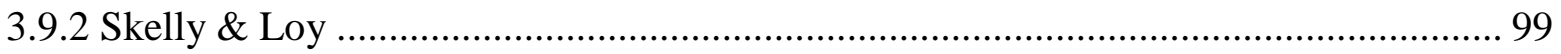

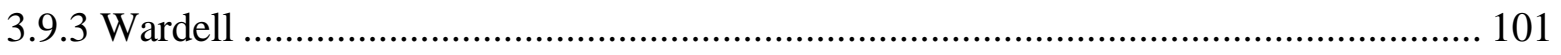

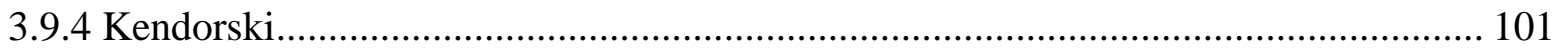

3.10 Dam Safety Classification System ………………................................................ 102

3.11 Summary of Reports for Offset Guidelines......................................................... 103

CHAPTER 4: Probabilistic Analysis Method for Mineral Extraction Near Surface Water

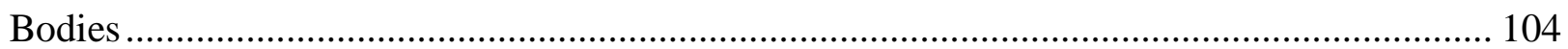

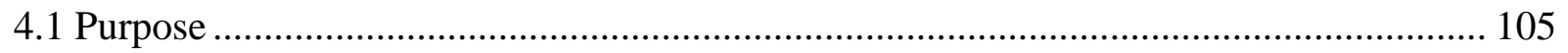




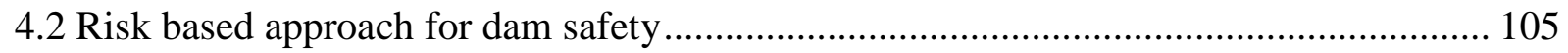

4.3 Factors Affecting Room and Pillar Mining............................................................. 106

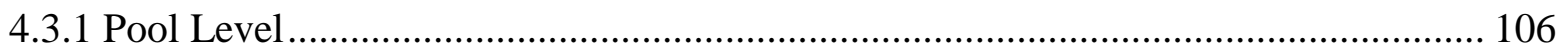

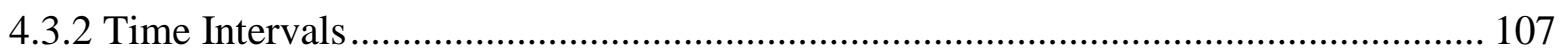

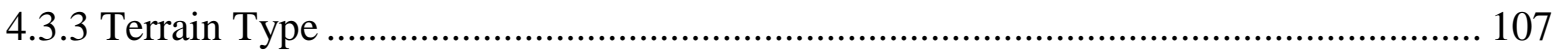

4.3.4 Depth of Coal Seam............................................................................................ 108

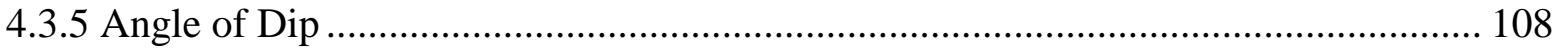

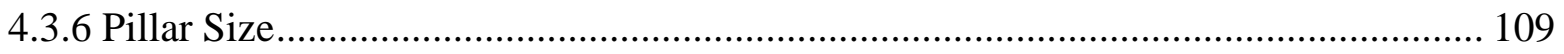

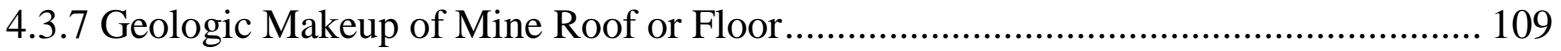

4.3.8 Event Trees for Room and Pillar Mining ............................................................. 109

4.4 Factors Affecting Longwall Mining..................................................................... 112

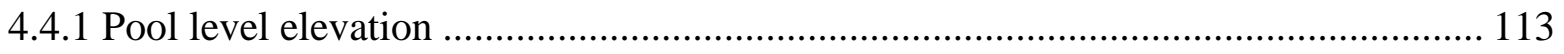

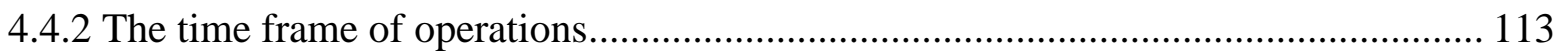

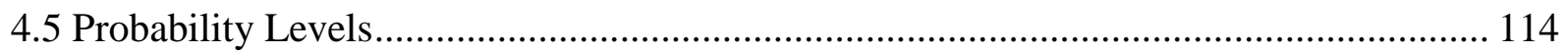

4.5.1 Level 1 Subsidence Angle of Draw .................................................................... 114

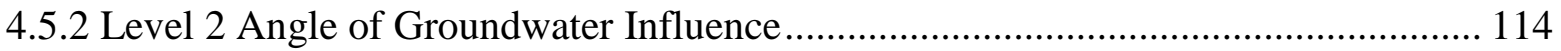

4.5.3 Level 3 Permeability Increase ............................................................................. 115

4.5.4 Conditional Event - Erosion........................................................................ 115

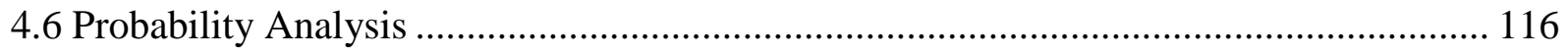

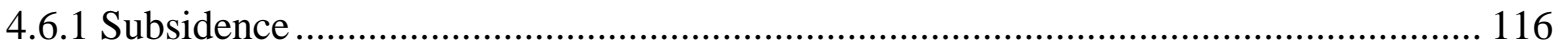

4.6.2 Normal Monte Carlo Distribution ...................................................................... 117

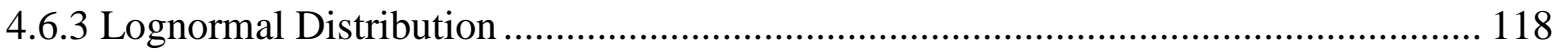

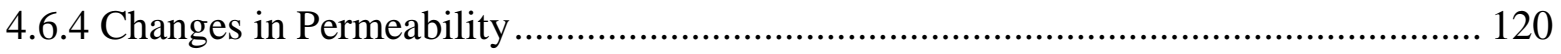

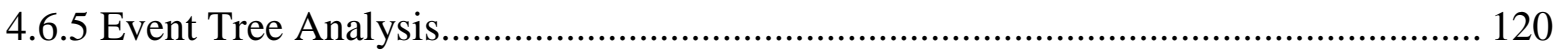

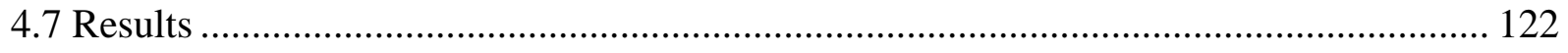

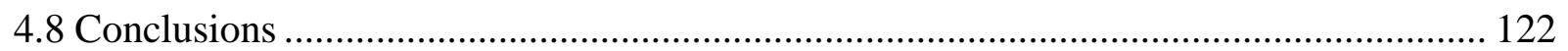

CHAPTER 5: Semi-Quantitative Risk Assessment Analysis Procedure for Mineral Extraction Under Surface Bodies of Water..................................................................................... 124

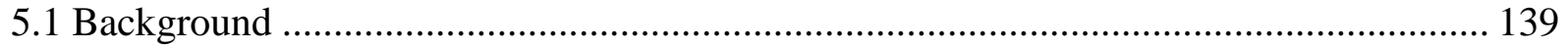

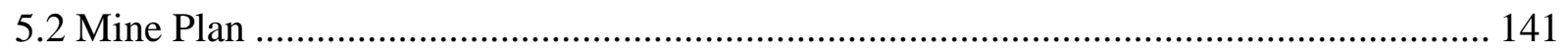

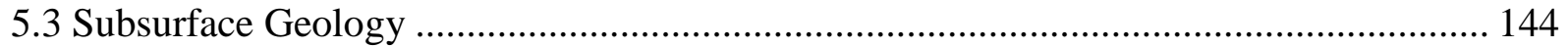

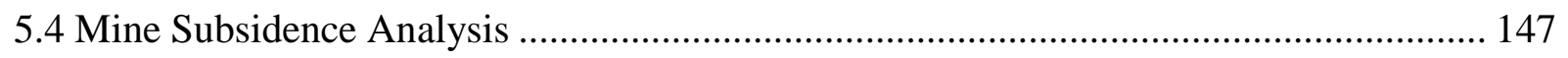

5.4.1 North American Subsidence Analysis \& Calculations ........................................... 147

5.4.2 Chinese Mine Subsidence Analysis..................................................................... 152

5.4.3 Tygart Mine Subsidence .................................................................................... 160

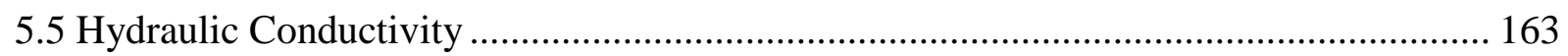

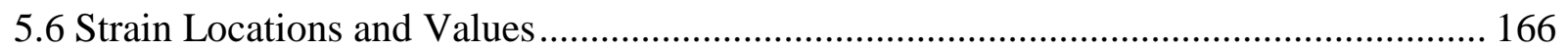

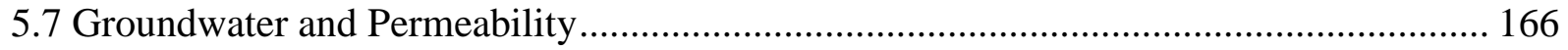

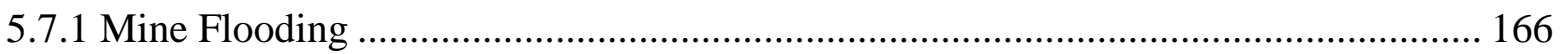

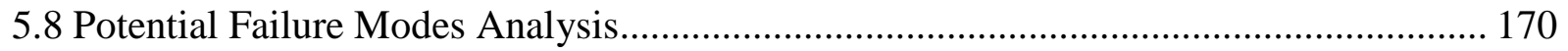




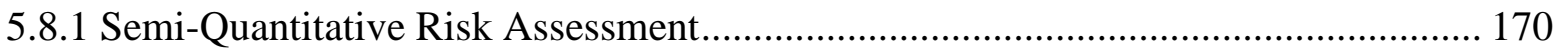

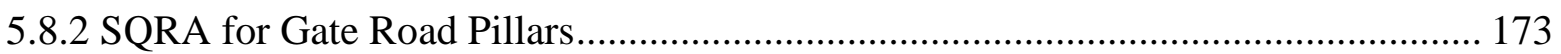

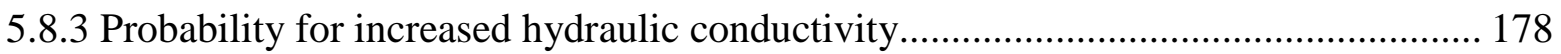

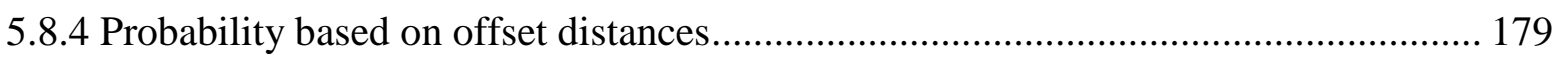

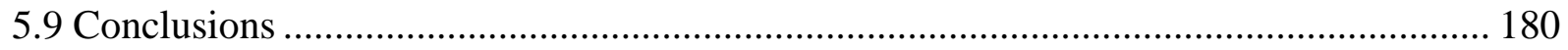

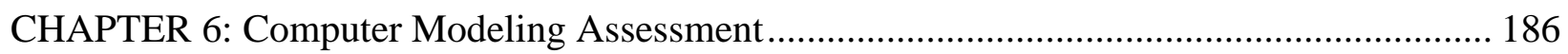

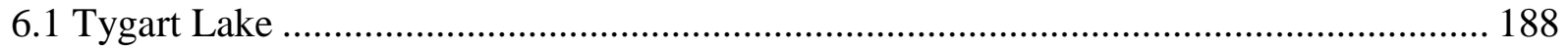

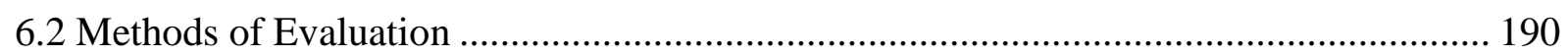

6.2.1 Finite Element Method ..................................................................................... 190

6.2.2 Finite Difference Method ..................................................................................... 190

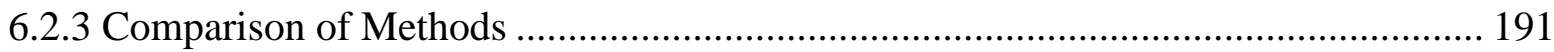

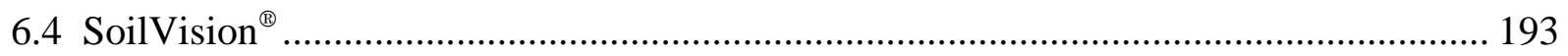

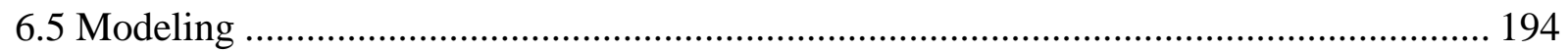

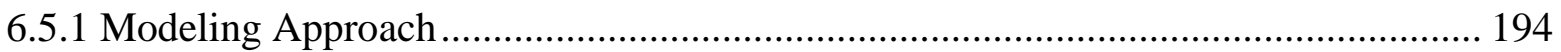

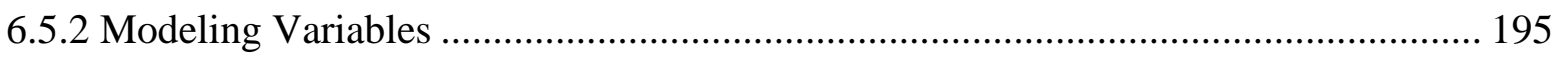

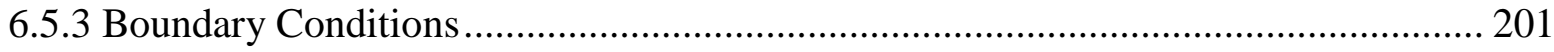

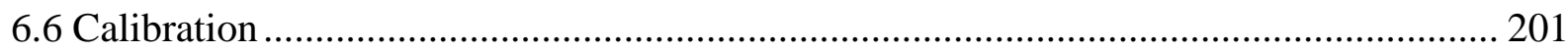

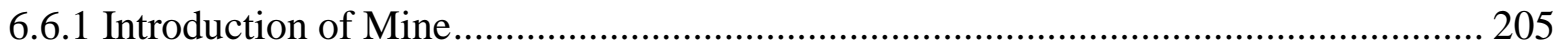

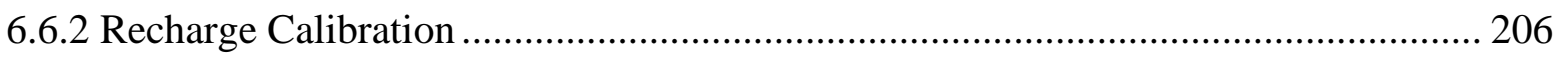

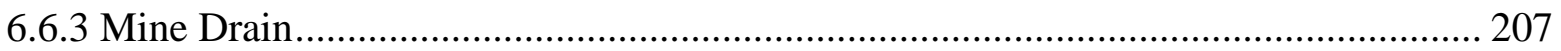

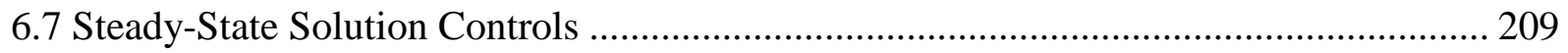

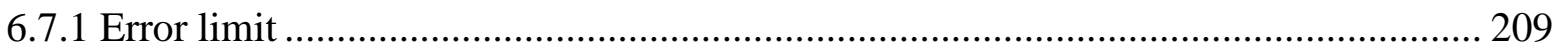

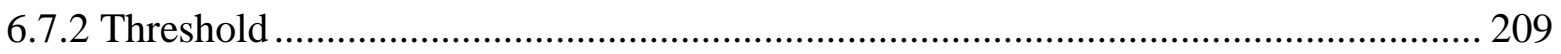

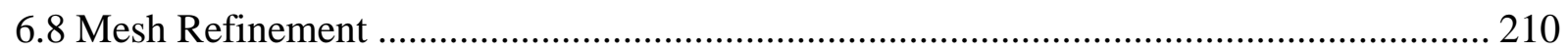

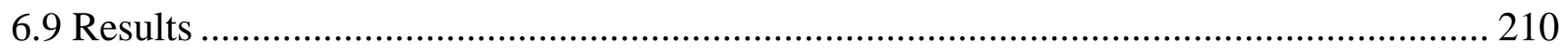

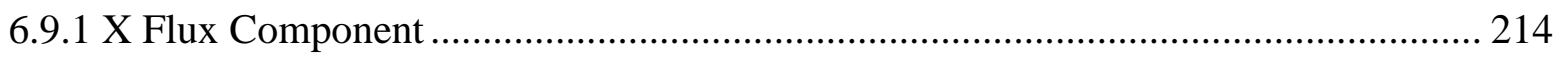

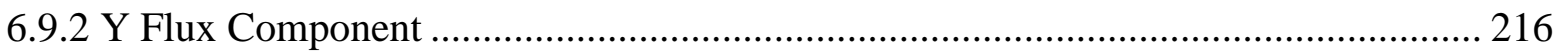

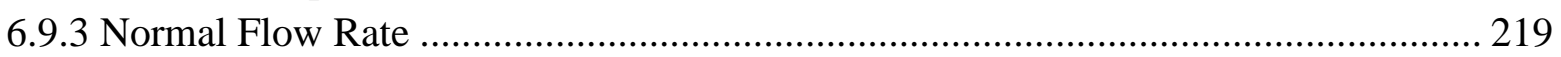

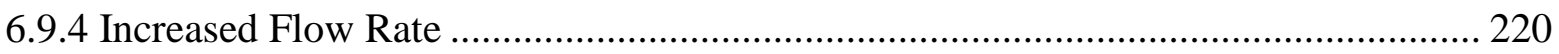

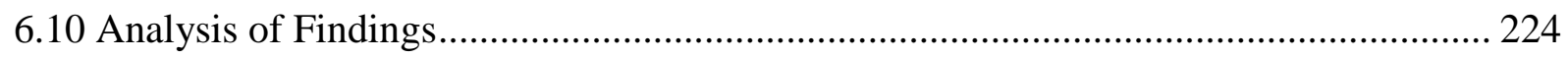

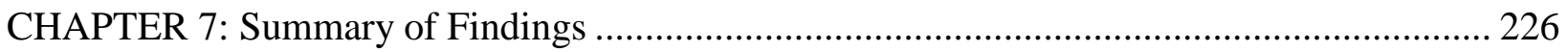

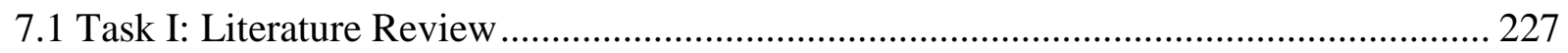

7.2 Task 2: Probabilistic Analysis Method ......................................................................... 228

7.3 Task 3: Semi-Quantitative Sensitivity Analysis........................................................... 230

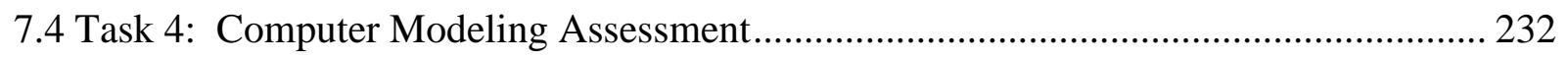

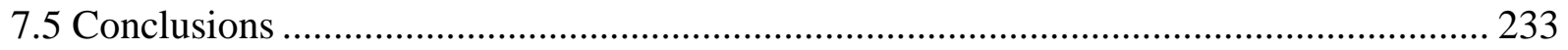

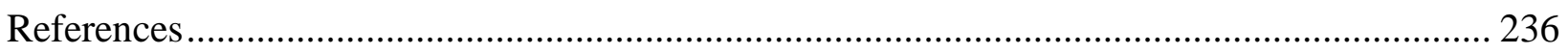




\section{List of Figures}

Figure 2.1: Layout of a longwall mine (Sydney Catchment Authority, 2007)............................. 7

Figure 2.2: Increasing size of coal mines (Alexander, 2006) ................................................... 8

Figure 2.3: Guidelines for mining under surface bodies of water

(after Babcock and Hooker, 1977) ......................................................................... 20

Figure 2.4: Safety zone beneath dam and impounded body of surface water

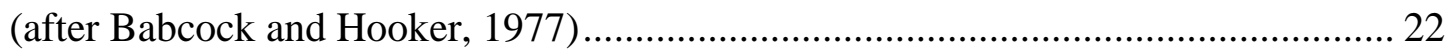

Figure 2.5: Offset distances for mining near water bodies in N.S.W. (Sydney Catchment

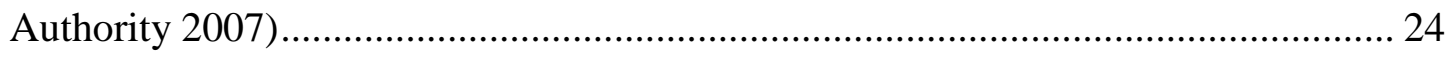

Figure 2.6: Offset distances for mining near dams (Sydney Catchment Authority, 2007)........... 25

Figure 2.7: Regulations for mining near surface water bodies (Roth et al., 1990) ...................... 26

Figure 2.8: Subsidence profiles (Sydney Catchment Authority, 2007)...................................... 34

Figure 2.9: Horizontal stressed zones (Sydney Catchment Authority 2007) .............................. 35

Figure 2.10: Duration of subsidence (Singh, 1992) .............................................................. 36

Figure 2.11: Pressure arch above mine void (Booth, 1986) ..................................................... 38

Figure 2.12: Panel width in relation to subsidence (Singh, 1992) ............................................ 39

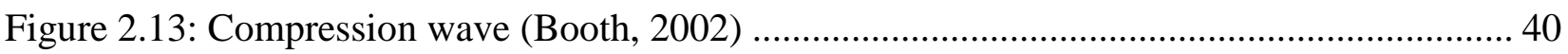

Figure 2.14: Zones of Overburden (After Karmis, 1992) ........................................................ 41

Figure 2.15: Subsidence zones (Bai et al,. 1995) ...................................................................... 43

Figure 2.16: Subsidence zones based on Chinese literature (after Bai et al,. 1995) ..................... 43

Figure 2.17: Types of protective coal layer (Bai et al., 1995).................................................. 48

Figure 2.18: Stress relief fracturing (Wyrick and Borchers, 1981).......................................... 51

Figure 2.19: Test well locations at site 1(Wyrick and Borchers, 1981)..................................... 52

Figure 2.20: Test site 1, water level (Wyrick and Borchers, 1981) ........................................... 53

Figure 2.21: Well A drawdown (Wyrick and Borchers, 1981) ................................................. 55

Figure 2.22: Seepage and groundwater flow observations (Kendorski, 1993) ........................... 57

Figure 2.23: Groundwater level changes based on topography (Elsworth and Liu, 1995) ........... 66

Figure 2.24: Well location based on topography (Elsworth and Liu, 1995) ............................... 67

Figure 2.25: Sandstone peizometric levels for panel \#5 (Booth, et al., 2000) ............................. 70

Figure 2.26: Deep drift water levels for panel \#5 (Booth, 2000) ................................................ 71

Figure 2.27: Total response for panel \#5 (Booth, et al., 2000) ................................................... 71

Figure 2.28: Subsidence Angle of Draw and Angle of Groundwater Influence ........................... 72

Figure 2.29: Cone of depression caused by pumping (Pubs.usgs.gov, 2015) ............................. 74

Figure 4.1: Failure mode event tree for room and pillar mining (After Wachtel, 2012)............. 110

Figure 4.2: Continuation of failure mode event tree for room and pillar mining

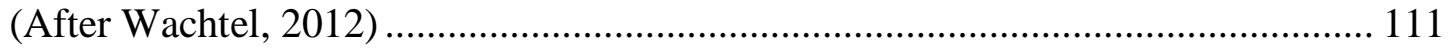

Figure 4.3: Room and Pillar event tree using factor of safety for pillars .................................. 112

Figure 4.4: Failure mode event tree for longwall mining...................................................... 113 
Figure 4.5: Truncated lognormal distribution for twenty to twenty-five degree subsidence range.

Figure 4.6: Example branch of event tree for a 25-30 degree Subsidence Angle of Draw......... 121

Figure 4.7: Probability of increased permeability decreases with offset distance ..................... 123

Figure 5.1: Tygart Lake located in Grafton, WV (Map Data: USDA Farm Service Agency,

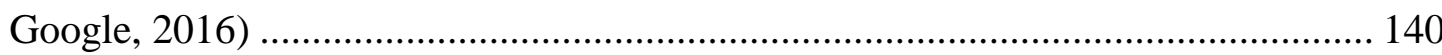

Figure 5.2: Mine plan at Tygart Lake (WVDEP permit \#U-2004-06, 2009)............................. 142

Figure 5.3: Mine location referenced to reservoir pool level conditions (After WVDEP, 2009) 143

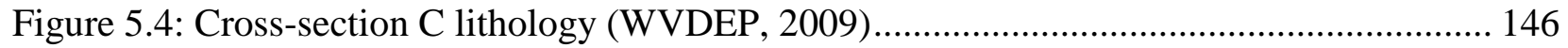

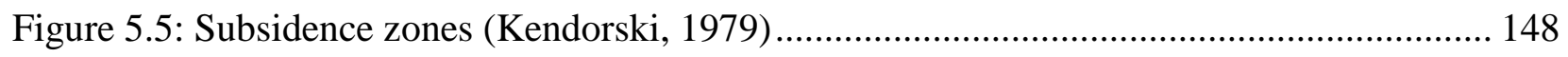

Figure 5.6: North American Analysis ....................................................................... 151

Figure 5.7: Subsidence zones based on Chinese literature (After Bai, et al.,1995) .................... 152

Figure 5.8: Type of protective coal layer (Bai et al., 1995) .................................................... 156

Figure 5.9: Chinese subsidence analysis ............................................................................. 159

Figure 5.10: Mine subsidence angles (After WVDEP, 2009) .................................................. 161

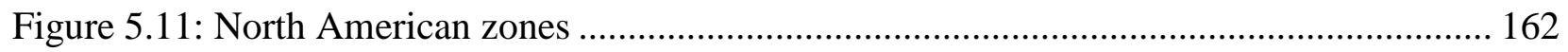

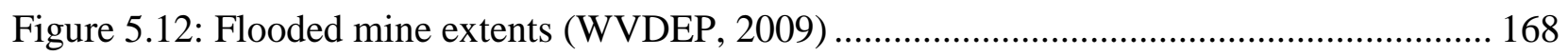

Figure 5.13: Projected seepage outcrop locations (WVDEP, 2009) ......................................... 169

Figure 5.14: Longwall panels near borehole T51-80(WVDEP, 2009) ..................................... 172

Figure 5.15: Event tree for full extraction longwall mining (After Wachtel, 2012) ................... 176

Figure 5.16: Event tree for seepage initiation ............................................................... 177

Figure 5.17: Probability of change in groundwater flow along cross section C-C .................... 178

Figure 5.18: Offset distances to mine based on probability .................................................. 180

Figure 6.1: Probability of Failure at Reservoir Rim Based on Proximity to an Underground

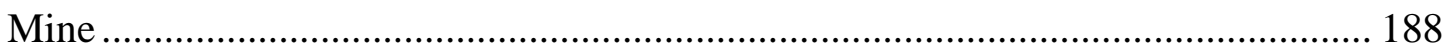

Figure 6.2: Pool Level inundation areas at Tygart Lake (After WVDEP, 2009)....................... 189

Figure 6.3: Basic model of cross-section a Tygart Lake ......................................................... 192

Figure 6.4: Flux model at Tygart Lake................................................................................. 193

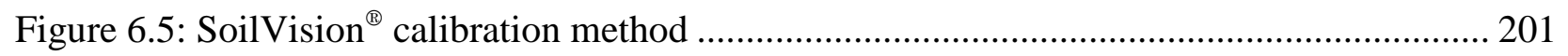

Figure 6.6: Groundwater flowpath adjacent to Tygart Lake (WVDEP, 2009) .......................... 202

Figure 6.7: Basic model setup for Tygart Lake Cross-section ................................................. 203

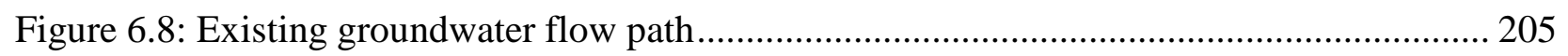

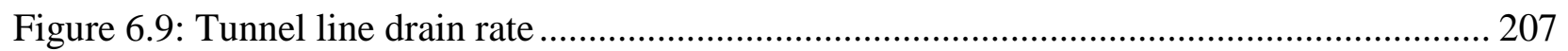

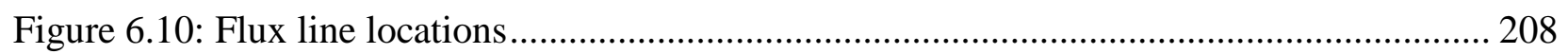

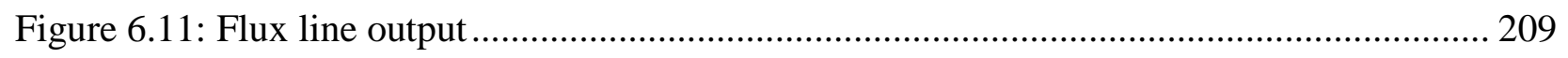

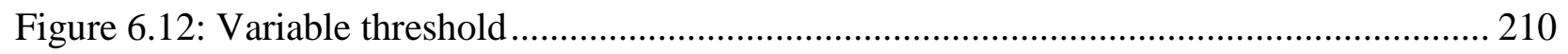

Figure 6.13: Flow path of groundwater into mine................................................................ 212

Figure 6.14: Recharge flow path for Full pool conditions ....................................................... 213

Figure 6.15: Groundwater flow through the Angle of Groundwater Influence at full pool level 219

Figure 6.16: Potential for erosion at Tygart Lake based on lateral offset distance ..................... 225 


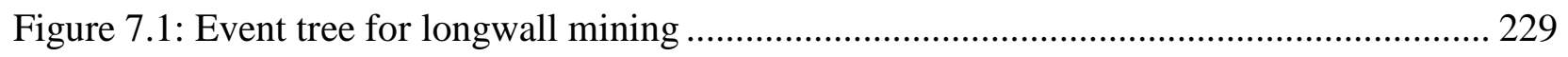

Figure 7.2: Example of PFMA event tree analysis........................................................... 231

Figure 7.3: Potential for erosion at Tygart Lake based on lateral offset distance ....................... 233 


\section{List of Tables}

Table 2.1: Hazards due to underground mining near surface water bodies (after Wardell, 1976) .. 9

Table 2.2: Minimum overburden thickness with respect to coal seam thickness

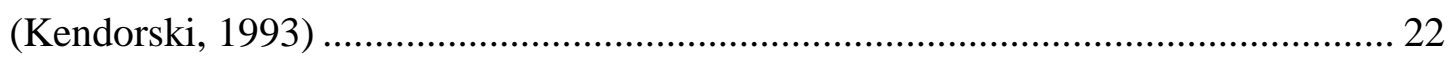

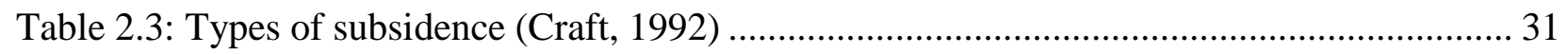

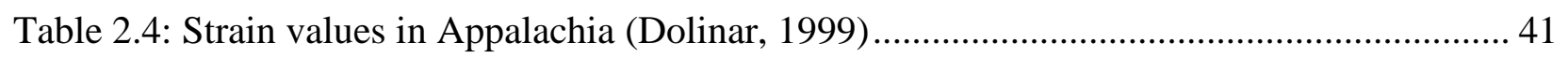

Table 2.5: Strata Lithology versus strength of rock (After Bai et al., 1995)............................... 44

Table 2.6: Coefficients for maximum height in Caving Zone $\mathrm{H}_{\mathrm{c}}$ (after Bai et al., 1995)............. 44

Table 2.7: Coefficients for maximum height of Caving zone Hf (After Bai et al., 1995) ............ 45

Table 2.8: Coefficient for the thickness of the protective layer (After Bai, et al., 1995).............. 47

Table 2.9: Pre- and post-subsidence hydraulic conductivity (Booth and Spande, 1992).............. 63

Table 3.1: Summary of purpose and scope in each reference ................................................. 83

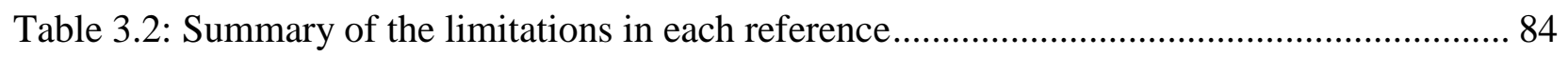

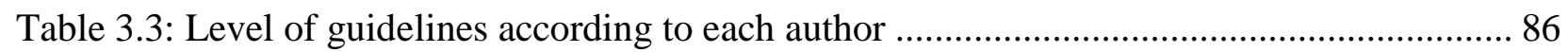

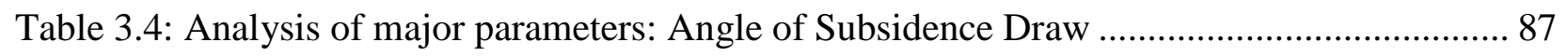

Table 3.5: Analysis of major parameters: maximum tensile strain and $S_{\max }$............................. 90

Table 3.6: Safety zone guidelines according to each compared author - surface water ............... 93

Table 3.7: Safety zone guidelines according to each author - total extraction mining................. 94

Table 3.8: Safety zone guidelines according to each author - partial extraction mining.............. 95

Table 3.9: Safety zone guidelines according to each author - structure retaining water ............... 96

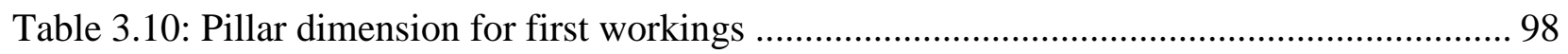

Table 4.1: Typical values of Angle of Subsidence Draw Draw (After Singh, 1992)................. 117

Table 4.2: Normal distribution probabilities for data sets .................................................... 118

Table 4.3: Probability of groundwater draw based on Angle of Subsidence Draw .................... 120

Table 4.4: Changes in permeability based on Angle of Subsidence Draw Draw ...................... 120

Table 4.5: Probability for erosion to occur based on offset distance ....................................... 122

Table 5.1: Distances of reservoir pool levels with mine location .......................................... 143

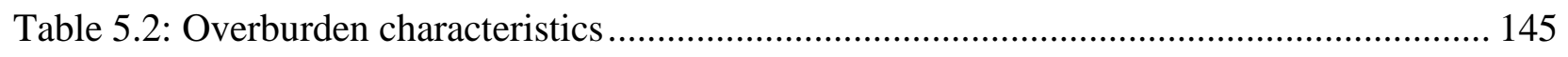

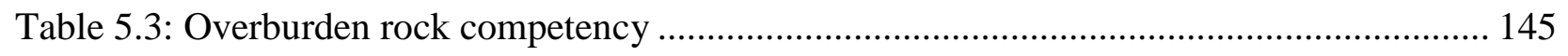

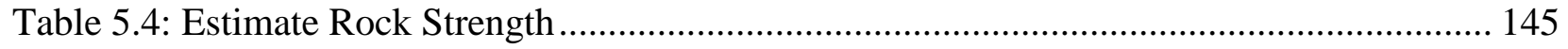

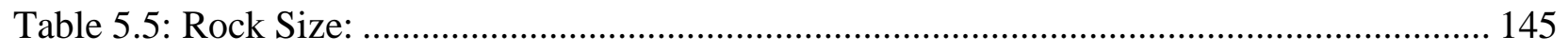


Table 5.6: Strata lithology verses rock strength (Bai, et al., 1995) .......................................... 153

Table 5.7: Coefficients for maximum height of Caving zone Hc (Bai, et al., 1995) .................. 153

Table 5.8: Coefficients for maxium height of Fractured Zone Hf (Bai et al., 1995) .................. 154

Table 5.9: Coefficient $\mathrm{d}$ for the thickness of the protective layer ............................................ 155

Table 5.10: Values determined for Chinese Method............................................................... 157

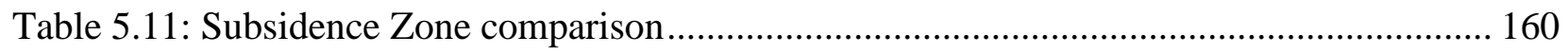

Table 5.12: Hydraulic conductivity for overburden layers at borehole HT16-05 ...................... 163

Table 5.13: Estimated pre-mining hydraulic conductivity at borehole T51-80 ........................ 165

Table 5.14: Approximate hydraulic conductivities pre- and post mining at borehole T51-80 .... 165

Table 5.15: Predicted and actual mine flow rate (WVDEP, 2009) ......................................... 167

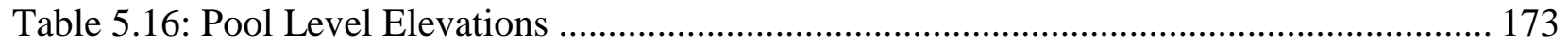

Table 5.17: Likelihood of conditions for pool levels ........................................................... 173

Table 5.18: Likelihood conditions for Subsidence Angle of Draw........................................ 174

Table 5.19: Likelihood conditions for Angle of Groundwater Influence.................................. 175

Table 5.20: Probability of Angle of Groundwater Influence based on Subsidence

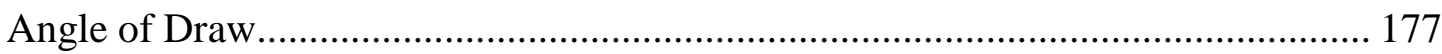

Table 5.21: Probability for erosion to occur based on offset distance .................................... 179

Table 6.1: Hydraulic conductivity for Borehole H13-05 ....................................................... 196

Table 6.2: Hydraulic conductivity for Borehole H16-05 ..................................................... 196

Table 6.3: Approximate hydraulic conductivities at Tygart Lake............................................ 198

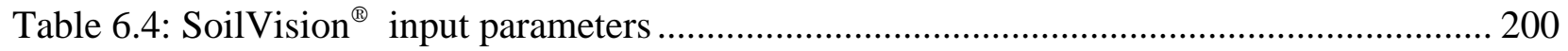

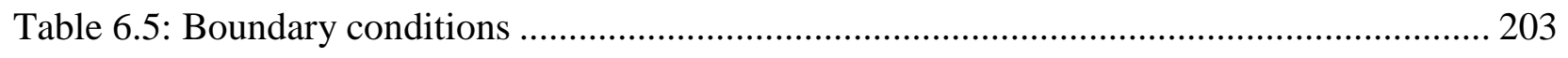

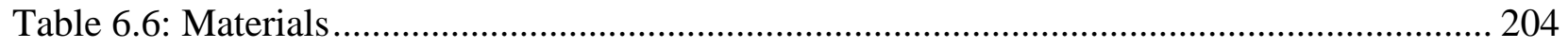

Table 6.7: Hydraulic conductivities for model.................................................................. 206

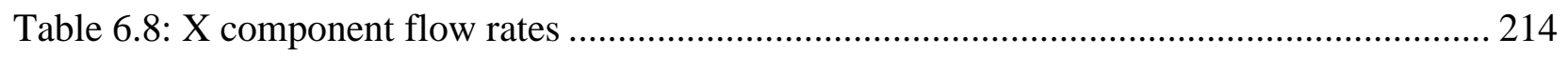

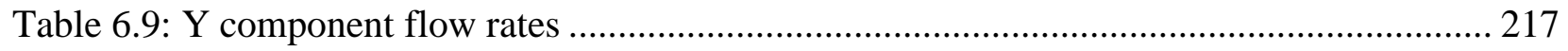

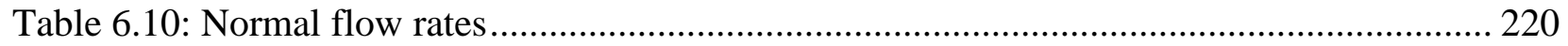

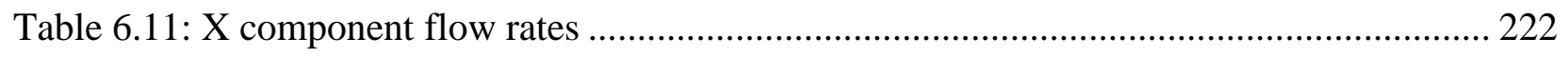

Table 6.12: Y component flow rates .............................................................................. 223

Table 7.1: Probability for erosion given Angle of Subsidence Draw ...................................... 230 


\section{CHAPTER 1: Introduction}




\subsection{Problem Statement}

The need for energy both nationally and internationally often results in mineral extraction encroaching near or beneath publicly owned surface bodies of water. Underground coal reserves often extend into areas outside of traditional surface mine boundaries and mining subsidence effects have been reported to adversely impact surface reservoirs and dams. The vertical and lateral distances between an underground mine and a surface body of water are controlled by potential water inundation or seepage into the mine workings primarily for miners' safety. Underground mining often creates voids that lead to subsidence effects in the overlying strata.

The effects of underground mining result in vertical subsidence which can lead to damage of surface structures within the Subsidence Angle of Draw. Horizontal strains greater than 0.001 in/in may initiate changes in permeability within this zone; altering groundwater flow beyond the Angle of Subsidence Draw. The extent of the flow changes is described as the Angle of Groundwater Influence or Cone of Depression. The methods used by the coal industry for determining safe zones when mining under or near surface bodies of water have predominantly relied upon approaches developed by the Bureau of Mines Information Circular 8741 and others. The major limitation of these studies are that they did not detail the long-term affect mining operations have on changes in groundwater seepage flow due to permeability changes triggered by vertical ground surface subsidence that could lead to increased risk for a reservoir or dam.

In the United States, the frequency of occurrence for underground mining near public surface bodies of water has been increasing and adverse impacts to dams and reservoirs have been reported. In 2008, a mine company was sued by the state of Pennsylvania for 58 million dollars when mining related surface movement damages caused the failure of Ryerson Dam (Hopey, 1992). In 2011 two additional dams and reservoirs in West Virginia are reported to have nearby underground mining either proposed or in progress.

The scope of this research investigates development of a methodology for a probability based semi-quantitative seepage failure mode analysis incorporating event trees. The analysis method presented and discussed incorporates published empirical studies with numerical computer modeling investigating relationships of subsurface soil and rock permeability that impact 
seepage changes. The research culminates by identifying probability of seepage changes with respect to the horizontal offset of an underground mine.

\subsection{Purpose}

The purpose of this research project is to develop a sequential analysis method for performing a risk based semi-quantitative failure mode analysis. This method is intended to identify and quantify risk hazard levels in terms of offset distances when an underground mine is located near a surface water reservoir.

\subsection{Objectives and Outcomes}

The research objectives are to incorporate risk-based event tree sequencing that incorporate empirical analysis and analytical based computer modeling to determine parametric failure probability ranges, sensitivities, and relationships of permeability and strain impacts on the near surface soils and rock. The expected outcomes will include a methodology for a semiquantitative seepage failure mode analysis correlated to the horizontal offset distances between underground mines and public reservoirs for mines at depths up to $350 \mathrm{ft}$. The methodology will include an event tree probability tool identifying key parameters and ranges of values to quantify risk probabilities of seepage changes and hazards.

\subsection{Scope of Work}

The research for this project will be separated into four tasks: 1) literature review of mine subsidence prediction and empirical assessment, 2) semi-quantitative sensitivity analysis of riskbased events for seepage mode failure near reservoirs, 3) numerical analysis assessing seepage at a field site, and 4) a method to develop potential failure mode analysis of the mine site.

Task 1: A literature review will be performed pertaining to underground mineral extraction near surface water bodies. The review will include current guidelines, both domestic and international, used for mining. It will detail changes in overburden due to subsidence and potential effects to groundwater flow.

Task 2: A sensitivity analysis will be performed for longwall, and room and pillar mining near surface water bodies. This will include development of event trees to show pathways 
leading to increased seepage. Probabilistic analysis will be performed using normal and lognormal distribution of field data gained from the literature.

Task 3: A potential failure mode analysis (PFMA) will be performed for underground mining based on United States Army Corps of Engineers (USACE) templates. The PFMA will be constructed for determination of which physical properties should be examined for hazard to the reservoir or dam. These properties are what are used in event tree analysis and the computer modeling. The results will show potential areas of concern and recommended guidelines.

Task 4: This task involves using SoilVision ${ }^{\circledR}$ for Finite Element computer modeling of a field site where longwall mining will occur. The lithology of the mine site will be determined by borehole samples as well as initial rock properties and permeability. The computer program modeling will be calibrated by using an existing location with known groundwater flow properties. A model will then be developed to show the current and mined conditions of Tygart Lake under various reservoir pool levels.

The goal of this research is to provide empirical and numerical analysis of seepage effects on surface bodies of water due to underground mineral extraction. The following outlines are provided as an initial basis for background information that may be used to determine the potential effects.

\section{Background Information}

1. Background of Reservoir and Dam

1.1. Location of reservoir to population: Hazard Potential (High, Significant, Low)

1.2. Reservoir characteristics:

1.2.1. Water levels (elevations): winter pool, summer pool, full pool (spillway elevation), Probable Maximum Flood (PMF).

1.2.2. Capacity: acreage, depth, storage capability (precipitation)

1.2.3. Inflow/supply streams

1.3. Properties of dam structure:

1.3.1. Authorized purpose (USACE)

1.3.2. Type of dam construction: earthen, concrete, gravity, arch, spillway 


\subsubsection{Size: proportional to risk}

1.4. Landform profiles: slopes, ravines, compound profiles and characteristics.

2. Overview of mine

2.1. Basic: lateral distances from reservoir and dam structure, appurtenances.

2.2. Type of mining: permitted/proposed; longwall, room and pillar, (combination of)

2.3. Overburden depth elevations; overburden depths (average, max., min.)

2.4. Location and thickness ( $\mathrm{t}$ ) of coal seam (inter-burden characteristics) over-mining of roof; determine how big of a hole may be put in.

2.5. Coal seam dip and strike.

2.6. Proximity to other historical mines.

\section{Mine Design Features \& Specifications}

3.1. Longwall panel properties: width, length;

3.1.1. Determine critical and super-critical width of longwall panels to calculate subsidence size.

3.2. Room and Pillar: width to height ratios;

3.3. Subsidence: planned / proposed by approved permit and mine consultants

3.3.1. Subsidence angle of draw extents based on mine design calculations;

3.3.2. Locate extents of Subsidence Angle of Draw with respect to reservoir and dam.

4. Subsurface Geology

4.1. Evaluate borehole lithology

4.2. Identify overburden properties (strength, permeability)

4.3. Locate competent rock (sandstone) layer thicknesses and locations - elevations.

4.3.1. Surface rock weathering, depth, extent.

4.3.2. Layer homogeneity, continuity, number of layers

4.4. Locate impermeable layers, aquiclude layers

4.5. Locate aquifer layers, groundwater table

4.6. Natural fracturing and faults

5. Subsidence

5.1. Determine subsidence factor based on equations: "S" used to determine maximum subsidence due to mining.

5.2. Determine calculated and potential ground surface elevation changes (maximum Smax)

5.3. Find type of "percent solid rock": percentage of sandstone, shale, anything that is competent rock. Identify what's solid and what's fractured.

5.4. Identify inflection points of changes in subsidence trough profile (slope) 


\section{Risk Based Semi-Quantitative Analysis}

1. Effects due to Subsidence

1.1. Discuss subsidence effects in subsurface based on the North American (empirical method) and Chinese Zone (analytical method).

\subsection{North American Subsidence Calculations}

1.2.1. Calculate the five zones, identify maximum and minimum elevation locations, plot with correlation to bore hole geologic lithology. Identify and discuss zone locations, presence, rationale, characteristics. (Caved, Fractured, Dilated, Constrained, Surface)

1.2.2. Identify zones with regards to subsidence angle of draw and offset distance relative to reservoir and dam.

1.3. Chinese Zone Calculations

1.3.1. Calculate zones based on overburden properties

1.3.2. Identify zones with regards to subsidence angle of draw and offset distance relative to reservoir and dam.

2. Strain Profile

2.1. Determine maximum tensile strain locations

2.1.1. Near edge of subsidence trough

2.1.2. Tensile strain locations above pillars which may cause extensive vertical fracturing

2.2. Determine Compression strain locations inside subsidence trough

2.3. Estimate changes due to strain

2.4. Determine layers in which strain will increase permeability

3. Groundwater Flow

3.1. Identify current groundwater properties in area (constrained/unconstrained aquifers, perched aquifers, water wells, head level, flow direction)

3.2. Determine change in gradient due to subsidence

3.2.1. Which layers dip toward reservoir

3.3. Identify locations within subsidence zone where pooling may occur

3.4. Determine expected well or surface stream head loss

3.4.1. Determine if temporary or permanent

3.5. Identify limestone layers for potential of karst

3.6. Determine the potential for mine flooding

3.6.1. Locate outcrops for exit flow and head level for exit flow to occur

4. Additional Details

4.1. Determine location of any oil/gas wells around location

4.2. Most current analysis has been done using flat terrain analysis 


\section{CHAPTER 2: Literature Review for Mineral Extraction Near Surface Bodies of Water}


A review of literature on the geological and hydrological impacts of underground mining was performed. This research was performed to determine the extent of effects mining has on the strata layers as well as the groundwater flow regime. It details a review of prior reports and guidelines, both foreign and domestic, for hazard to dams and surface bodies of water. Additionally it encompasses research on subsidence effects at distances both vertically and laterally from a mine void. Literature on groundwater effects was reviewed to provide information on potential changes in hydraulic conductivity and head loss due to underground mining.

\subsection{Types of Mining}

\subsubsection{Room and Pillar}

Room and pillar mining, also called bord and pillar, is the most common method of underground mining in the United States. In the past, this form of mining constituted $90 \%$ of all coal extraction (Farmer, 1992). The main benefit of room and pillar mining is the relative low initial cost compared to longwall mining (Farmer, 1992). This method, broadly called partial extraction, leaves pillars of coal in a checkerboard or grid fashion that supports the roof of the mine during operation (Singh, 1992). The percentage of coal that is extracted is generally between 50 and $70 \%$. This method is suitable for moderately thick deposits (6ft to 20ft) ranging from horizontal up to 30 degrees of dip. However as the depth of the mine increases, the width of the support pillars must increase to support the increased load. Due to this effect, room and pillar mining is limited to shallower coal seams. In addition, the productivity of workers in room and pillar mining is generally less than longwall mining (Wagner, 1980). Productivity is dependent on depth due to larger pillars needed to support greater amounts of overburden. The coal that remains in the pillars could be recovered using a method of pillar robbing; however, this practice is now discouraged. If recovery is greater than $70 \%$, the subsidence caused by the mine void may occur almost immediately (Farmer, 1992).

\subsubsection{Longwall}

Longwall mining is a full extraction method removing large panels of coal between 400 to $960 \mathrm{ft}$ wide and 3000 to $14000 \mathrm{ft}$ long (Peng and Chiang, 1992). The panels are mined from the far end towards the main entry of the mine. The roof of the panels is supported above the shearer by hydraulic supports. As the mine face moves forward, the roof above the void is no longer 
supported causing fracturing and caving into the extracted area. In the longwall mining method, multiple panels are typically excavated side by side, separated by chain pillars, as shown in Figure 2.1 (Sydney Catchment Authority, 2007). Longwall mining is considered much safer than room and pillar mining due to the protection provided by the hydraulic supports.

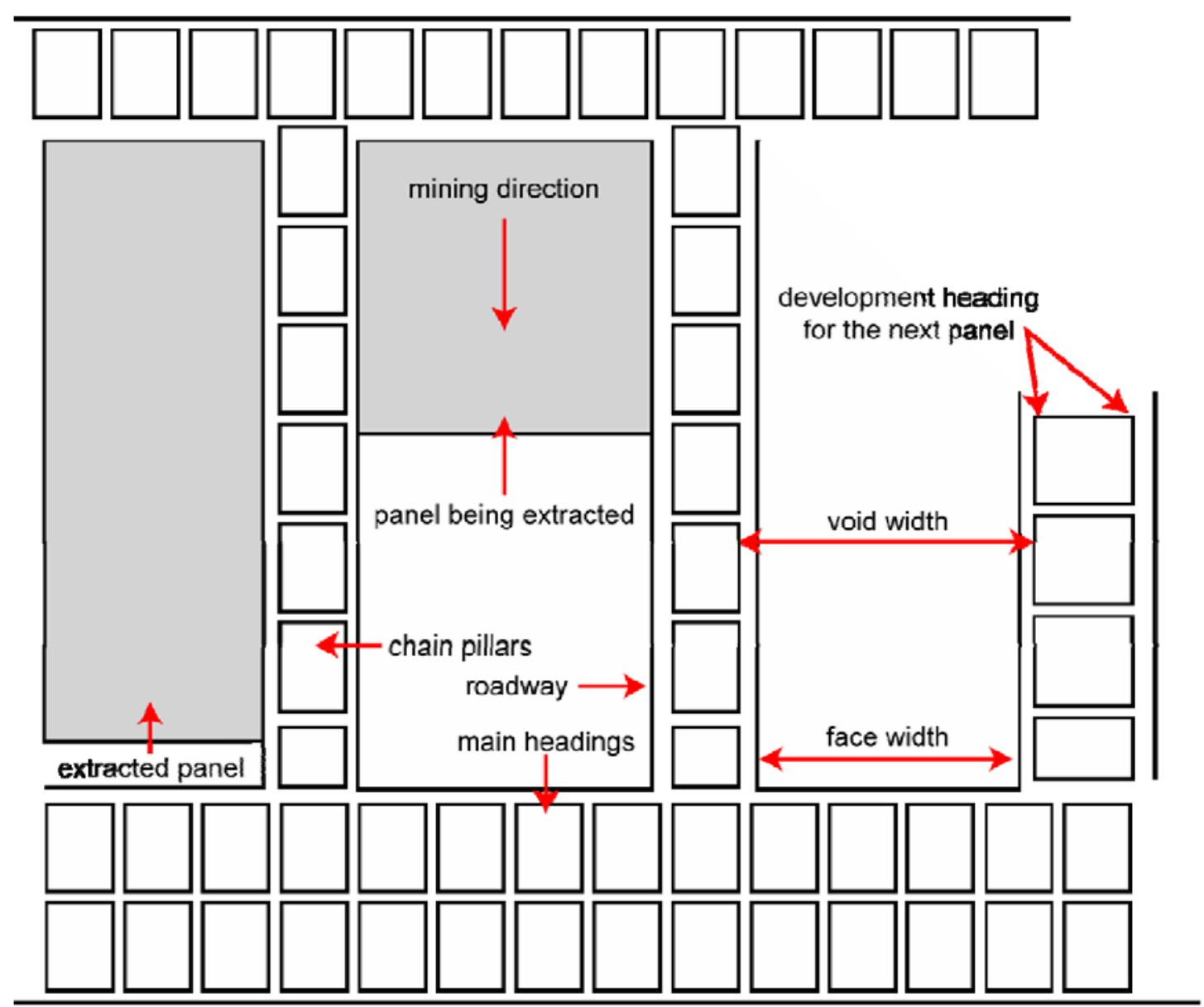

Figure 2.1: Layout of a longwall mine (Sydney Catchment Authority, 2007)

\subsubsection{Panel and Pillar}

Panel and Pillar mining is similar to longwall mining, encompassing fairly wide extraction panels. Between the panels are barrier pillars that support the roof of the mine. The width to depth ratio of the panels is such that there is little deflection in the overburden (Wardell, 1976). This method is generally used at greater depth. Because of the depth required, this method is not common in the United States for coal extraction but is used in England, China and Australia. 
However, as the need for mineral extraction increases, it may become utilized more as deeper coal deposits need to be accessed.

\subsection{Mine Size}

Over the years, there have been two common trends in underground coal mines: mine size and the total number of mines in production. These may be interrelated as the number of mines required to produce the same amount of coal tonnage decreases. This may also be representative of an increase in longwall mining. In 1980, approximately 6\% of all coal mines in the United States were longwall (Peng, 1980). In 1992 that number increased to 8\% (Farmer, 1992) and has continues to increase. As of 1999, longwall mining accounted for $40 \%$ of all coal production (MSHA, 1999). Figure 2.2 (Alexander, 2006) illustrates the number of coal mines in the United States as well as the size based on tonnage from 1959 thru 2002. In 1960 there were approximately 8,200 mines that produced an average of 50,000 tons of coal a year. In 1980, the number of mines decreases to 3,000 while production increased to 120,000 tons per year. This is represented in the level area of Figure 2.2 before the second increasing trend in mine size began. Towards the end of this study in 2000, the annual tonnage per mine had increased to approximately 490,000. The number of mines had dropped to approximately 900 . In total, thru years 1959 to 2002, the total number of underground coal mines in the United States decreased by approximately $90 \%$ while the average size of a mine (by tonnage) increased $980 \%$.

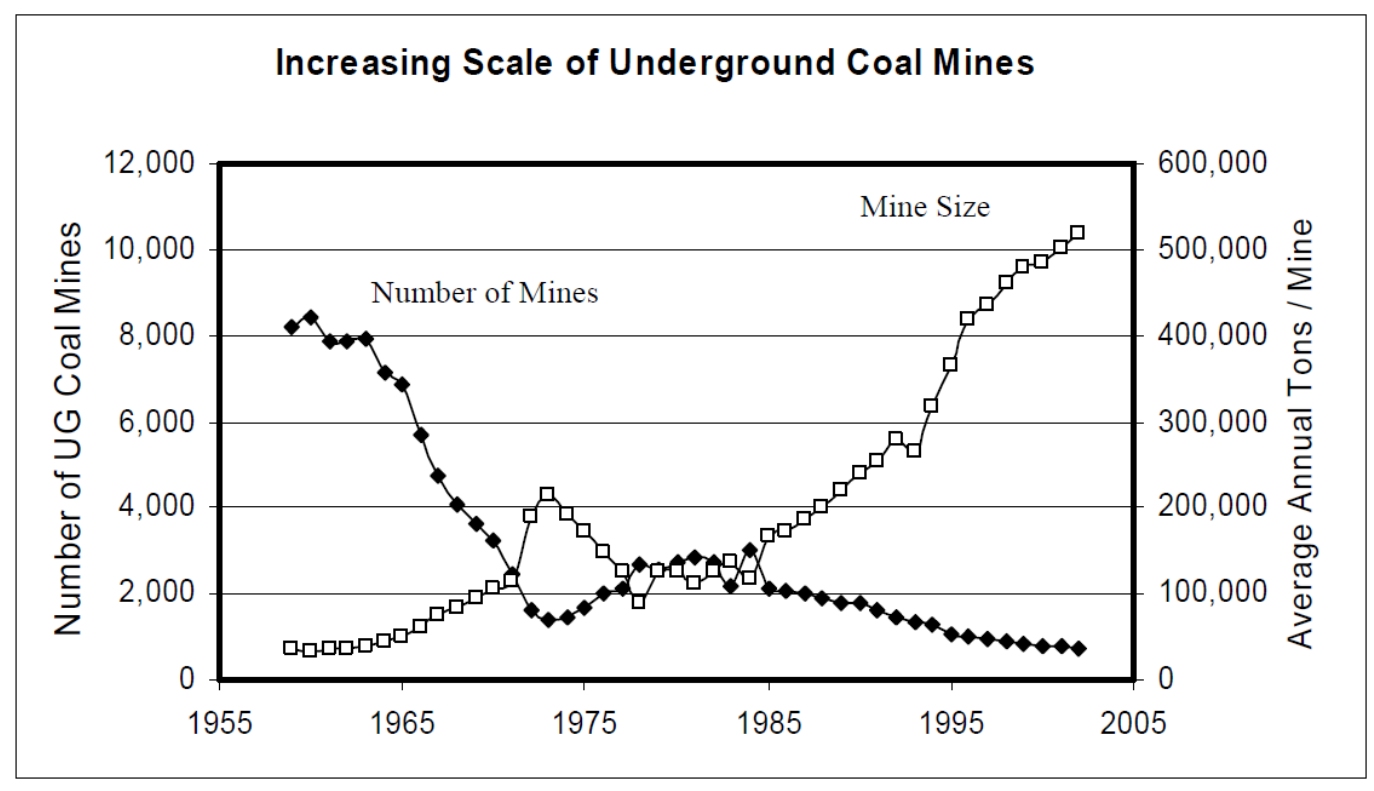

Figure 2.2: Increasing size of coal mines (Alexander, 2006) 


\subsection{Guidelines for Mining under Surface Water Phase III and Final Report}

In the 1970's the US Bureau of Mines contracted two separate groups to develop guidelines for mining near dams and reservoirs. The purpose of these contracts was to protect the mine workers from water inundation. The two research groups Wardell (London, U.K.), which is discussed within this section, and Skelley and Loy (Pittsburgh, U.S.) each developed separate recommendations. Combined, these two reports became Information Curricular (IC) 8741, which guidelines are still used today for offsets to mining near surface bodies of water. The findings for Skelly and Loy (1976) is discussed in Section 2.4.

This research was performed for maximum coal extraction around surface bodies of water while avoiding inundation hazards. There are two types of hazards considered; subsurface hazard where the mine is flooded and surface hazards where water bodies are affected. These are shown in Table 2.1.

Table 2.1: Hazards due to underground mining near surface water bodies (after Wardell, 1976)

\begin{tabular}{|c|c|c|c|c|c|}
\hline \multirow[b]{3}{*}{$\begin{array}{c}\text { Bodies of Surface } \\
\text { Water }\end{array}$} & \multicolumn{5}{|c|}{ Hazards } \\
\hline & \multirow{2}{*}{$\begin{array}{c}\text { Mine } \\
\\
\text { Passage } \\
\text { of water } \\
\text { into mine }\end{array}$} & \multicolumn{4}{|c|}{ Surface } \\
\hline & & $\begin{array}{l}\text { Impairment } \\
\text { or failure of } \\
\text { impounding } \\
\text { structures }\end{array}$ & $\begin{array}{c}\text { Impaiment } \\
\text { or failure } \\
\text { of function } \\
\end{array}$ & \begin{tabular}{|c}
$\begin{array}{c}\text { Encroachment } \\
\text { of land surface } \\
\text { by water }\end{array}$ \\
\end{tabular} & $\begin{array}{l}\text { Instability due } \\
\text { to adverse } \\
\text { changes in } \\
\text { hydrogeology }\end{array}$ \\
\hline \multicolumn{6}{|l|}{ Natural } \\
\hline Sea \& Tidal Waters & $*$ & --- & --- & $*$ & --- \\
\hline Lakes \& Ponds & $*$ & --- & $*$ & $*$ & $*$ \\
\hline Marshes & $*$ & --- & --- & $*$ & $*$ \\
\hline Rivers \& Streams & $*$ & --- & $\begin{array}{c}* \text { (where } \\
\text { navigable) }\end{array}$ & $*$ & $*$ \\
\hline \multicolumn{6}{|l|}{ Artifical } \\
\hline Impounded Waters & $*$ & --- & $*$ & $*$ & $*$ \\
\hline Canals & $*$ & --- & $*$ & --- & $*$ \\
\hline
\end{tabular}

Table 2.1 shows that there is potential for a pathway into the mine from any type of surface water body. On the surface, lakes, rivers and ponds as well as artificially impounded waters may lose functionality if mining occurs within too close of a proximity to the mine. All of the water 
body types are at risk to changes in hydrogeology. However none of the impounding structures were expected to be adversely affected by sub-surface mining.

\subsubsection{Total Extraction}

Total extraction mining allows for the highest percentage of coal to be extracted. This method does also cause the maximum subsidence effects from fracturing, bedding separation and slippage and collapse.

According to Wardell (1976) increased permeability due to sub-surface mining was only directly investigated at the time of Wardell's report in the U.S.S.R. and New South Wales. In the former case the increased permeability was at a height of 15 times the thickness of the coal seam. In New South Wales this distance was 35 times the thickness. Cracking develops at the surface which may lead to increased permeability in the top 50ft. These changes are located in the tension zones at the edges of the panel.

For protection from mine inundation, the suggested vertical distance from the surface to the mine seam is approximately 50 times the seam thickness. This is for a distance of 30 times the thickness of the coal seam for increased permeability directly above the mine and 20 times the thickness for surface fracturing. The type of rock in the overburden may also play a part in limiting mine inundation. Shale and clay may prevent surface waters to drain into the mine.

Based on studies in the United Kingdom, maximum tensile strain may be a determining factor for potential pathways for surface water to flow. In undersea mining operations where no sea water entered the mine, the maximum tensile strain was kept between $5.0 \mathrm{~mm} / \mathrm{m}$ and $15.0 \mathrm{~mm} / \mathrm{m}$. Therefore the National Coal Board in the United Kingdom determined a maximum sea bed tensile strain of $10.0 \mathrm{~mm} / \mathrm{m}$ for full extraction under water bodies.

Based on the strain values provided above, the minimum overburden thickness would therefore be between $45 t$ and $135 t$ where $(t)$ is the thickness of the coal seam. However this is based on studies performed in the United Kingdom where maximum subsidence is approximately 0.90 times the seam thickness. In the United States, the maximum subsidence would be expected to be $0.60 \mathrm{t}$ to $0.70 \mathrm{t}$. Therefore the recommendations for full extraction mining are as follows: 
i. For total extraction mining near or under a body of surface water there must be a minimum of 60ft of cover for every one $\mathrm{ft}$ of seam extraction.

ii. If more than one seam of coal exists, there must $60 \mathrm{ft}$ of cover for every one $\mathrm{ft}$. of all the seams extracted between the water body and the uppermost seam. This distance may be encroached upon provided the maximum tensile strain does not exceed 0.00875 . This is for seams in close proximity to another.

iii. For multiple seams where the top seam has already been mined by full extraction, an underlying seam cannot be fully mined unless there is, at minimum, $60 \mathrm{ft}$ for every one $\mathrm{ft}$ of the lower seam between the two. If it is less than this distance, partial extraction may be performed under the guidelines given for partial extraction mining and as if the upper seam represented a surface water body.

iv. Any deposits (natural and artificial) or wash (loose sediment or material) in the overburden shall be excluded from the aforementioned thicknesses unless it can be demonstrated that the layer is impermeable.

v. If a fault with a displacement of $10 \mathrm{ft}$ vertically or a dyke with $10 \mathrm{ft}$ horizontal displacement exists, no total extraction may occur within 50ft laterally on either side.

These guidelines require field testing to provide the thickness of solid rock and permeability of any non-solid materials for use in the separation thickness.

\subsubsection{Room and Pillar}

Failure of partial extraction mining is not expected to be greater than full extraction even if complete failure occurred. This case (full extraction) would represent the extreme minimum overburden thickness for room and pillar mining. The other boundary would be the absolute minimum where no mining could occur. This was determined to be associated with the height and thickness of the seams provided the pillars and floor remained stable.

The recommendations for Room and Pillar mining under these conditions are as follows:

i. Partial extraction mining may occur under or in proximity to a surface water body if the thickness of the overburden is at least 5 times the thickness of the entry width or 10 times the thickness of the entry height, whichever is greater. If a sandstone layer exists that a 
minimum 1.75 times the thickness of the entry, mining may occur where the overburden is less than described above

ii. For any drifts or tunnels that exist, the same criteria listed above shall be followed unless permanently supported and maintained. If a sandstone layer exists, a minimum 1.75 times the entry width shall be required

Determination of pillar width in these mines was based on the room width and the allowable pillar loading of the coal. The guidelines set are available in tables provided by Wardell (1976) and utilized in IC 8741. However in cases where the strength of the floor or roof beds is lower than the coal, those strengths should be used in determining the appropriate pillar width.

\subsubsection{Panel and Pillar Mining}

Panel and Pillar mining is an effective method of subsidence control and can be used with multiple types of coal extraction. It also has a high amount of stability due to the barrier or abutment pillars. In Europe it has been successfully used to mine under towns and undersea in the United Kingdom.

The key factor in determining overburden thickness for Panel and Pillar mining is referred to the "Height of Affection". This is the distance above each panel that is affected by fracturing and bedding plane separation. While in cases there may be no caving or major fracturing above the panel, this height can be used as a worst case scenario. For seam thicknesses up to $12 \mathrm{ft}$, the Height of Affection is not likely to exceed the width of the extraction panel.

The guidelines for the panel and pillar mining state:

i. Panel and Pillar mining may occur under or in proximity to a surface water body if the thickness of the overburden is at least $270 \mathrm{ft}$

ii. The width of the extraction panels must be less than one-third the depth. The widths of the panels must be 15 times the height of the extracted seam or one-fifth the depth, whichever is greater

iii. For multiple seams, the panel widths shall be determined using the depth of the upper seam and the pillar widths using the thickest or deepest seam, whichever gives the greater dimension 
iv. Mining of a seam below a Panel and Pillar mined seam can be performed by using the total extraction method. Guidelines under total extraction shall be followed with the uppermost seam considered as if it were a surface water body

\subsubsection{Safety of Water Bodies}

Lateral safety zones were developed for surface water bodies so mine operators and regulatory agencies would give proper consideration. These offset zones are to prevent areas of increased tensile strain and permeability from intruding upon the surface water body. If this were to occur, surface water may flow laterally and potentially vertically into the mine.

The recommended guidelines for Safety of Surface water bodies are:

i. The lateral offset distance for mining around a surface water body is a minimum of onehalf the depth of the mine seam. This equals approximately $26.5^{\circ}$. It is not detailed which pool level this line would intersect

ii. If partial extraction mining occurs within the safety zone it must extend a distance of two pillars outside of such zone for room and pillar mining and one pillar for panel and pillar mining

iii. The lateral offset distance may be extended or decreased at the discretion of those authorized

\subsubsection{Safety of Important Impounding Structures}

The guidelines for mining near impoundments differ. An important structure is one that could cause catastrophic consequences if failure were to occur. In this instance the guidelines are to totally protect the structure and not allow any mining to occur within the safety zones.

The recommended guidelines for Safety of Important Impounding Structures are:

i. If a structure is impounding a substantial body of water and subsidence may cause failure, no mining should be permitted within the safety zone for structures

ii. The perimeter of the structure should be determines by those responsible for its safety The offset distance from the perimeter shall be 0.7 times the depth of cover to the seam

iii. A greater or lesser distance may be used if determined by those authorized 
There are additional hazards that are not covered under the guidelines. These include failure of function of a reservoir and encroachment of water onto land. There is currently no way to determine the effects these will have on the mine site and therefore no formal guidelines were implemented.

\subsection{Guidelines for Mining near Water Bodies}

Guidelines for Mining near Water Bodies (Skelly and Loy, 1976) was the second report used as the basis for IC 8741. While the recommendations were similar to the previously discussed research, it differed in that it accounted for field testing. Therefore, the recommendations are split between Level I guidelines where no preliminary testing is performed and Level II where field testing was performed. Using this method Level I offsets would be considered to cover all potential hazard. Level II is used if data shows those offsets could be encroached.

\subsubsection{Level I Guidelines}

These guidelines require little or no surface or subsurface exploration. The offsets are designed to prevent water inrushes and maintain the integrity of the surface water bodies. Three major categories are recognized in the guidelines;

\section{1). Mining under continental surface waters}

2). Mining near abandoned workings and natural subsurface hazards

3). General mine planning procedures

These guidelines are for partial and total extraction mining.

\subsubsection{Mining Under Continental Surface Waters}

For mining under surface water bodies the lateral offset distance is $200 \mathrm{ft}$ from the high water mark (probable maximum flood) perimeter. This is applicable for mine depths up to $350 \mathrm{ft}$. For mining at greater depths, the offset distance is $200 \mathrm{ft}$ plus 25 degrees from vertical at the $350 \mathrm{ft}$ mark. Within this area is termed the zone of no extraction. The angle is designed to protect against subsidence inbreak due to roof falls. In one case, $344 \mathrm{ft}$ of cover did not prevent mine flooding when a safety barrier pillar underlying a stream was breached (Skelly and Loy, 1976). 


\subsubsection{Mining Near Abandoned Workings}

No mining may occur within 200ft laterally of abandoned workings according to the guidelines. If the workings are inspected and verified to be free of dangerous accumulations of water, the offset distance can be encroached. Under these circumstances, mining would be permitted up to a distance corresponding to the greater of: a pillar width to thickness ration of 10:1 or a boundary pillar based on the equation:

$$
P_{b}=10+2 T+5 D
$$

Where:

$\mathrm{T}=$ thickness of the seam

$\mathrm{d}=$ depth of coal seam in hundred foot increments

This should be utilized on both sides of the property line to create a distance of $2 \mathrm{~Pb}$. If natural faults are known to occur in the area, additional pillar width may be required.

\subsubsection{Oil and Gas Wells}

When mining near oil and gas wells, a 300ft diameter barrier shall be left if the well passes through the coal seam. The well should be within $30 \mathrm{ft}$ of the center of the pillar.

\subsubsection{Mining Near Shafts or Other Mine Openings}

A barrier of 300 feet between the mine and shafts or mine openings shall be left around the opening provided at least a $100 \mathrm{ft}$ radius of coal is left around the most extensive dimension. If these can be inspected to be safe and certified, a pillar of width to thickness ratio of 10:1 should be left around each opening.

\subsubsection{Mining Under Unconsolidated Deposits}

Unconsolidated or natural reservoirs are locations of water flow. To prevent inrushes into the mine seam the guidelines require a minimum overburden thickness of 180ft. Generally if there is hard rock such as sandstone in the overburden, this distance may be reduced. However in the Level I guidelines it is assumed that there is no prior testing. If the reservoirs or unconsolidated material intersects the coal bed, a pillar of $200 \mathrm{ft}$ should be left between the working. 


\subsubsection{General Guidelines}

The generally guidelines pertain to the lifespan of the mine. They are designed for protection of the mine workers. They include management procedures, and water control. They include: during operation, the mine is required to be well drained of water; No body of water is to be restrained which may cause risk to the miners and: maps and information pertaining to the mine are located at a fire safe location on the surface

\subsubsection{Level II Guidelines}

The Level II guidelines are designed for when pre-mine field testing is performed at the mine site. Data collection of geology and permeabilities may allow for maximum coal extraction while minimizing risk to mine inundation. If the data collected allows, the offset guidelines detailed in Level I may be encroached. The guidelines are applicable for beds that are inclined less than 30 percent. Some of the requirements include:

1) Extent, location and thickness of unconsolidated and cohesive strata that overlie and underlie the coal seam

2) Locations of old workings and protected areas should be known

3) Reservoir beds and zones of high permeability along with fault zones or impermeable zones should be known

4) Water issues from prior mining should be known and determined if applicable

\subsubsection{Mining Under Continental Surface Waters}

For partial mining under surface water bodies, the thickness of cohesive overburden is required to be a minimum of 5 times the thickness of the heading. The guidelines for determining cohesiveness falls under 3 categories:

1 )Strength of water saturated specimen is equal to or greater than 4000psi

2) Rock quality designation (RQD) must be determined

3) The thickness of strata that qualifies under category 1 multiplied by the RQD must be greater or equal to 5 times the thickness of the mine heading 
An RQD of 50\% will allow for a width of 20 to 40 feet without requiring additional heavy support. If the RQD is less than 50 percent, beams, support arches or cribbing is required.

Pillars must be designed for stability based on the following formula:

$$
S=\frac{(K \times L)}{T}
$$

Where:

$\mathrm{S}=$ unit strength

$\mathrm{L}=$ the least width of the pillar

$\mathrm{T}=$ the pillar thickness

$\mathrm{K}$ = permeability, determined by the laboratory testing of the core sample

A factor of safety of 2 must be applied for the pillar thickness. Core samples should also be taken from the floor of the coal seam. The bearing strength of the pillar cannot exceed the load strength of the floor. When mining for the first time, 2 headings should be kept as narrow as possible; not to exceed $15 \mathrm{ft}$.

Under full extraction guidelines the thickness of the overburden to the surface water body must be a minimum of $100 \mathrm{ft}$ for every foot of seam thickness. The maximum allowable tensile strain in the base of the water body is 0.001 .

The minimum overburden between the water body and the mined seam shall not be less than $700 \mathrm{ft}$ unless monitoring for microseismic activity is performed, in which case the overburden thickness shall be no less than 350ft. Monitoring will detect fractures in the strata and allow the mining to be halted before a hazardous situation occurs.

\subsubsection{Mining Near Abandoned Workings}

Abandoned workings are located through borehole samples. Maps of abandoned mines tend to be unreliable and potentially incomplete. If the mine is dry, Level I guidelines shall be used to determine appropriate offset distances. If the mine is flooded, Level I guidelines may be applied if properly drained. 
In instances where the mine cannot be drained a barrier pillar with a factor of safety of 4 is required. Water can be drained from the abandoned working through the barrier pillar. Property boundary barrier pillars should not be altered from Level I guidelines.

When mining under flooded abandoned workings, strata of no less than $100 \mathrm{ft}$ of cohesive material (as defined in guidelines for mining under continental surface waters) shall be maintained.

\subsubsection{Oil and Gas Wells}

Level II regulations are the same as Level I for oil and gas wells. The exception is when the well can be sealed. If properly sealed, the barrier pillar can be mined through.

\subsubsection{Mining Near Shafts or Other Mine Openings}

Inspection of shafts and mine openings are required before being mined through. If inspection is not feasible, borehole tests need to be performed to determine the presence of water. If present, water must be drained and the shaft verified for no further leakage. If leakage is present, the opening of the mine or shaft must be plugged and then tested again. If no further leakage occurs, normal pillar recovery operations can be conducted.

\subsubsection{Mining Under Natural Subsurface Hazards}

For partial mining under natural subsurface hazards there needs to be cohesive roof rock of no less than 5 times the width of the heading. The pillars are to be designed under the specifications given in 5.2.1. Pillar load cannot exceed the bearing capacity of the floor.

A minimum of 100 feet of strata is required for each foot of seam thickness for full extraction mining. The maximum allowable tensile strain in the base of the water body is 0.001 .

The minimum overburden between the water body and mined seam shall not be less than $700 \mathrm{ft}$ unless monitoring for microseismic activity is performed, in which case the overburden thickness shall be no less than 350ft. Monitoring will detect and fractures in the strata and allow the mining to be halted before a hazardous situation occurs. 


\subsubsection{Future Research}

Based on the conclusions of the report, future research and evaluations were determined to be needed when dealing with abandoned mines. There needs to be a reliable method to determine the location of these mines as well as determining potential water levels in the mines. In addition, future research was suggested be conducted on alternate methods of water drainage, and isolation of abandoned mines so they no longer present a hazard to future mines.

\subsection{Information Curricular 8741}

The two afore mentioned contracts were combined to create Information Curricular 8741 (IC 8741) for the Bureau of Mines by Clarence Babcock and Verne Hooker (Babcock and Hooker 1977). When mining occurs near surface bodies of water the guidelines set by IC8741 (See Figure 2.3) require a minimum offset of $200 \mathrm{ft}$ from the high water mark for depths up to $350 \mathrm{ft}$. The high water mark is considered the probable maximum flood pool level. However there is no indication as to the time frame considered for the maximum flood. If a mined seam lies below the 350ft depth, and additional offset zone extending 65 degrees from horizontal is required.

Under the guidelines, mining is permitted below surface bodies of water under certain circumstances. They are determined based on the type of mining that occurs. The types considered are full extraction (longwall) mining and partial extraction (room and pillar and panel and pillar) mining. Room and pillar mining is only considered partial extraction if retreat mining does not occur. Retreat mining involves removal of pillars, either fully or partially after initial mining has occurred. If retreat mining is performed, the mine is considered full extraction.

Panel and pillar mining is a hybrid of room and pillar and longwall mining. The extraction panels are much smaller in width than longwall mining. The width-to-depth ratio is key in this method so that the main strata can span the panels with little or no deflection. If the pillars are extracted, it will be considered full extraction. The guidelines for these methods are detailed in Figure 2.3. 


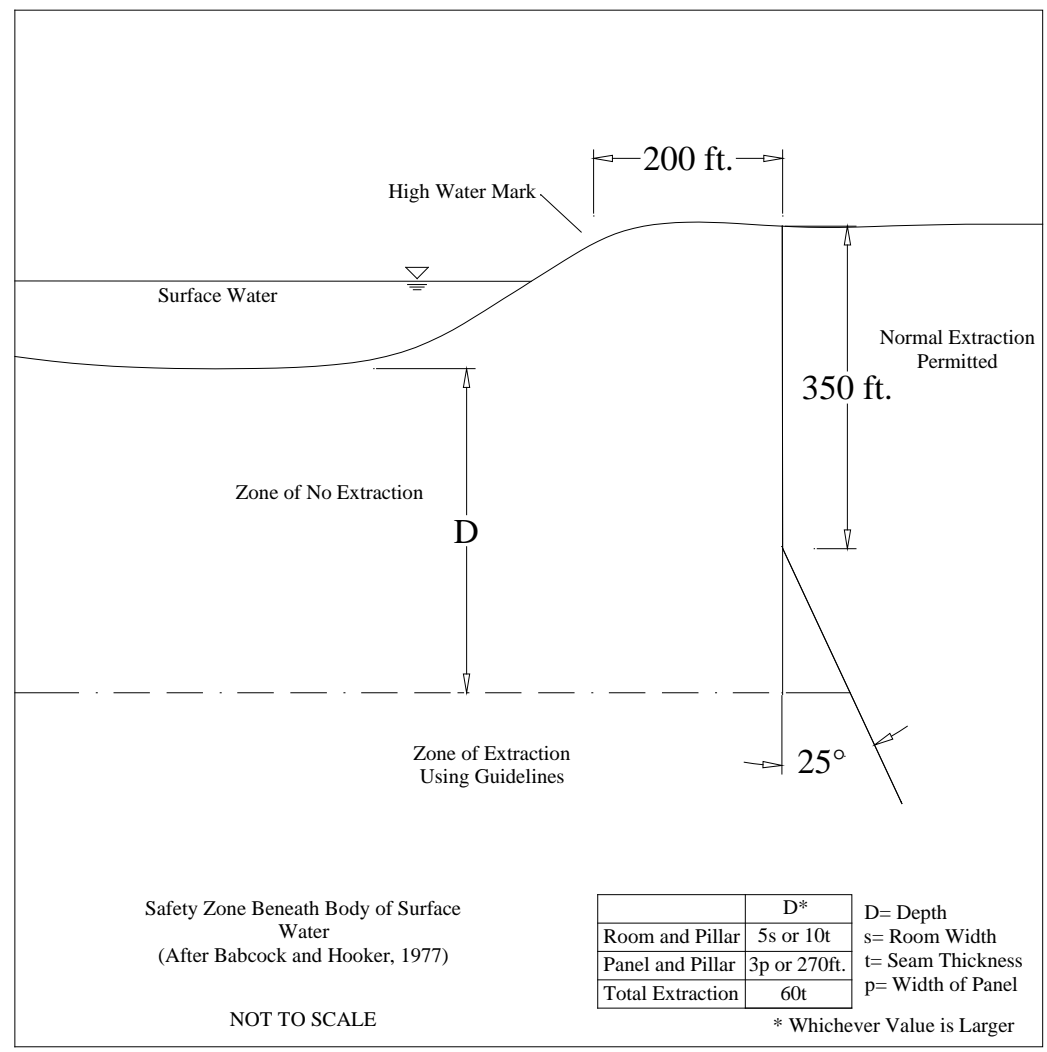

Figure 2.3: Guidelines for mining under surface bodies of water (after Babcock and Hooker, 1977)

\subsubsection{Total Extraction Mining}

For total extraction mining, the guidelines determined that for each foot of coal extracted, a minimum of 60 feet of solid cover (rock) must be between the seam and the water body. If there are other materials located above the seam, they can be included in the $60 \mathrm{ft}$ if proper permeability tests are performed. If they cannot be considered impermeable, that depth should be excluded. In cases where surface strain calculations can be made, the maximum tensile strain cannot exceed $8.75 \mathrm{~mm} / \mathrm{m}$. In cases of multiple seams, the lower seam should be partially extracted as if the upper seam was a water body. If a fault lies in the extraction zone that has a vertical displacement of over $10 \mathrm{ft}$, no seam should be totally extracted within $50 \mathrm{ft}$. There is no mention of partial extraction in this zone. 


\subsubsection{Partial Extraction Mining}

\subsubsection{Room and Pillar}

The room and pillar mining method, in which pillars of coal are left to add support to the overlying surface, has stipulations based on the size of the room and the depth under the body of water. These guidelines state the intervening strata must be no less than 5 times the entry width or 10 times the entry height, whichever is greater. If sandstone or a similar material with a thickness of at least 1.75 times the entry width is present, mining below these guidelines may be considered. There is no mention of how far below guidelines they can go. These guidelines apply to tunnels and drifts as well, unless permanently supported; in which case the strata cover should be no less than 1.75 times the tunnel width.

This work lists multiple tables which determine the minimum width the pillars must meet. This is determined based on the depth of the seam, height of the pillar and the width of the room. If the pillar height is not listed in the charts provided in IC8741, a formula for determining the width is given.

\subsubsection{Panel and Pillar}

The guidelines set for panel and pillar mining are set where there is minimal deflection of the overlying strata. This states that the strata cover must be $270 \mathrm{ft}$ or 3 times the width of the panel, whichever is greater. In addition, the widths of these panels should not exceed one-third the mining depth. The pillar widths should be 15 times their height or one-fifth the mining depth, whichever is greater. When multiple seams are mined, the pillar widths should be determined by the thickest or deepest seam, whichever will give the greater pillar width.

\subsubsection{Mining near Surface Structures}

IC 8741 considers risk to a surface structure if its failure would cause "loss of life, property damage, or damage to water supplies needed for the public welfare.” It recommends that the offset perimeter be designed by those who are in charge of maintaining the integrity of the structure itself. However it has developed guidelines for these zones. Similar to mining under surface bodies of water, the offset zones for mining near a dam require a horizontal barrier of $200 \mathrm{ft}$ for depths up to $350 \mathrm{ft}$. For depths greater than $350 \mathrm{ft}$, and additional offset extending 65 degrees from horizontal is required. The difference for surface structures is that IC 8741 does not 
allow mining to occur within this zone under any condition. These zones are detailed in Figure 2.4 .

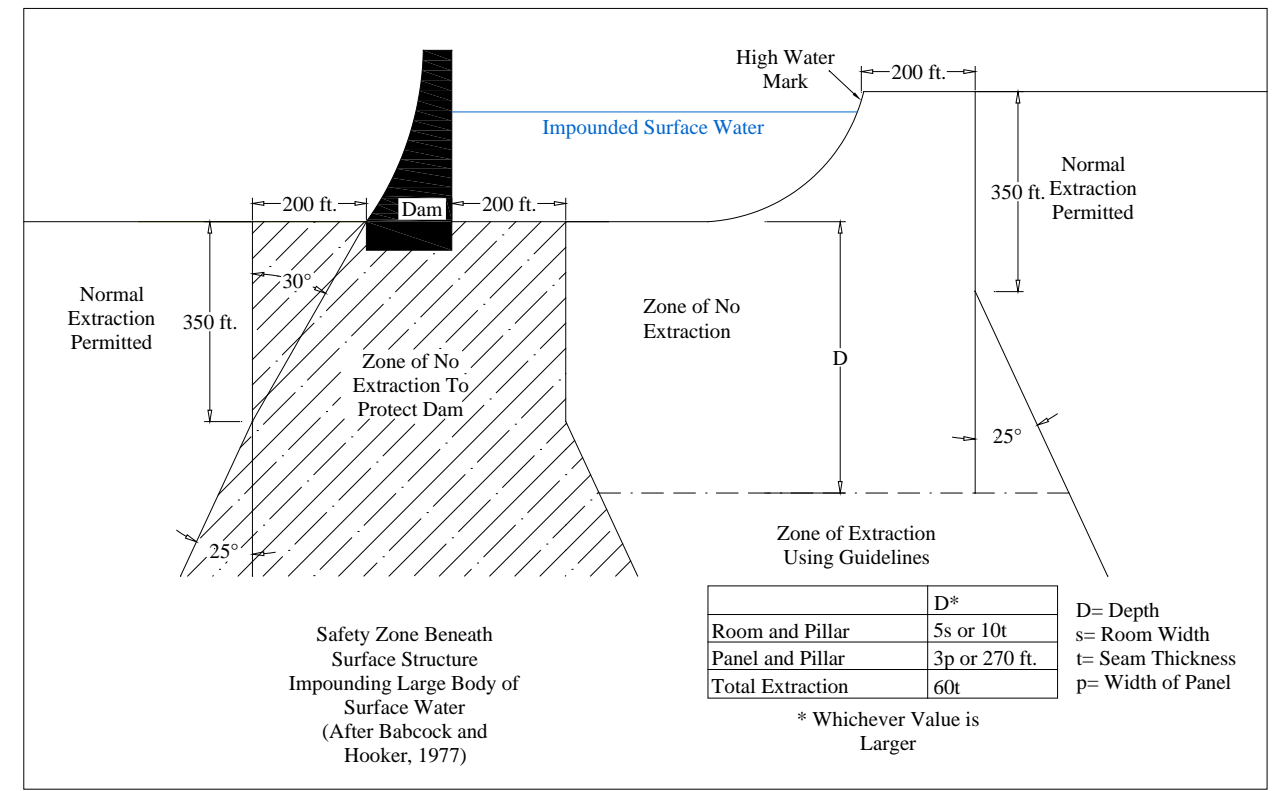

Figure 2.4: Safety zone beneath dam and impounded body of surface water (after Babcock and Hooker, 1977)

\subsection{Kendorski}

The following is a Table (2.2) showing the minimum cover required for total extraction below bodies of water based on Kendorski (1993). Tension and extension cracks form at trough edges and areas of local extension. The Angle of Draw is dependent on strata conditions.

Table 2.2: Minimum overburden thickness with respect to coal seam thickness (Kendorski, 1993)

\begin{tabular}{|c|c|c|}
\hline \multicolumn{3}{|c|}{\begin{tabular}{|c}
$\begin{array}{c}\text { Minimum Cover Required for Total Extraction below Water } \\
\text { Bodies of Catastrophic Potential Size }\end{array}$ \\
\end{tabular}} \\
\hline $\begin{array}{c}\text { Thickness of Seam } \\
\mathrm{ft}\end{array}$ & \multicolumn{2}{|c|}{ Minimum Total Thickness of Cover } \\
\hline $\mathrm{t}$ & $\mathrm{t}$ & $\mathrm{f}$ \\
\hline 3 & $117 \mathrm{t}$ & 351 \\
\hline 4 & $95 \mathrm{t}$ & 380 \\
\hline 5 & $80 \mathrm{t}$ & 400 \\
\hline 6 & $71 \mathrm{t}$ & 426 \\
\hline 7 & $63 t$ & 441 \\
\hline 7.5 & $60 \mathrm{t}$ & 450 \\
\hline$>7.5$ & $60 \mathrm{t}$ & - \\
\hline
\end{tabular}


If a high extraction mine is within 24 to $30 t$ of the surface, temporary surface fracturing may be manifested. If within 24 to 30t plus 50ft, Fractured zone features will merge with the surface fracture zone causing a possible continuous pathway.

Seams less than $6 \mathrm{ft}$ in thickness usually result in ratios thicker than $40 \mathrm{t}$.

\subsection{Longwall regulation in New South Wales}

In New South Wales (NSW) Longwall regulation began with the Mine Subsidence Compensation Act in 1961. This Act allows for compensation due to subsidence for structures that were built prior to mining or designed with approval by the Mine Subsidence Boards postmining. The Act only provides compensation due to settlement and not vibration. In addition, it does not cover economic loss, only compensation for structures (Sydney Catchment Authority, 2007).

In 1982 the Coal Mines Regulation Act stipulated the method of mining for coal allowed and the thickness of pillars and boards based on depth. According to the Sydney Catchment Authority (2007) longwall mining was required for most cases.

Recommendations for mining under bodies of water, known as the Reynolds inquiry, were reviewed in 1977. This commission created a regulatory zone around and below a water body called a marginal zone (Sydney Catchment Authority ,2007). Under these guidelines the marginal zone extended down and laterally out from the full supple (pool) level at an angle of $26.5^{\circ}$ from vertical. Within this zone no full extraction mining was permitted and partial extraction was only allowed in areas with cover greater than $60 \mathrm{~m}$.

Bord and pillar mining guidelines required 5.5m wide bords and pillars a minimum of 15 times the thickness of the seam or one-tenth of the cover, whichever is greater (Sydney Catchment Authority, 2007).

Longwall mining is permitted within the marginal zone provided it is a minimum of $120 \mathrm{~m}$ below the water body. The panel widths are required to be less than one-third of the cover. Pillars around the longwall panels must be one-fifth of the cover or 15 times the seam thickness, whichever is greater (Sydney Catchment Authority, 2007). 
In 1978 the Dam Safety Act was passed which did not include these guidelines. Regulation for mining near and under surface water bodies and dams was not created until 1992 under the Mining Act. These regulations, while similar to the Reynolds Inquiry, create additional zones for mining to limit risk to dams and water bodies.

The Regulations for mining near a surface water body (storage) create a $35^{\circ}$ from vertical marginal zone (Figure 2.5). The restricted zone comprises the area beneath the water body, the marginal zone, plus one-half the depth of the coal seam as it intersects the $35^{\circ}$ angle.

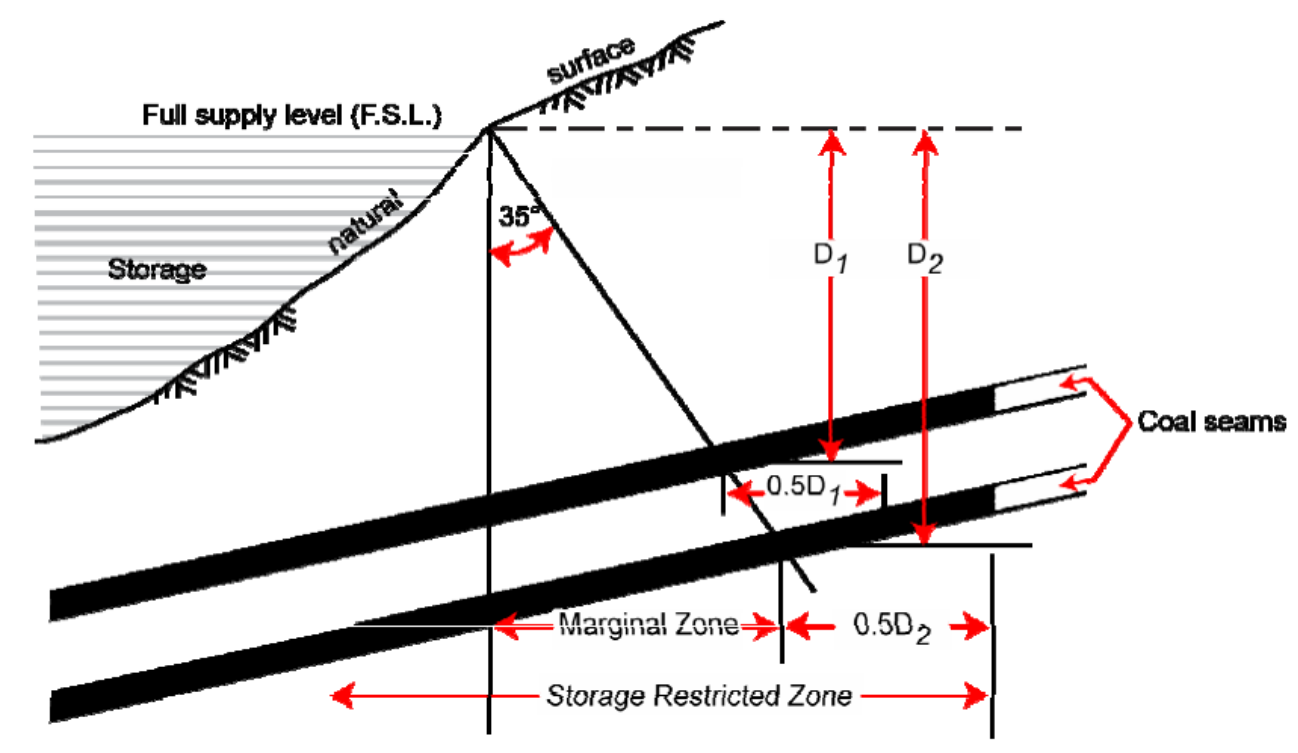

Figure 2.5: Offset distances for mining near water bodies in N.S.W. (Sydney Catchment Authority 2007)

The Restricted Zone for mining near dams is dependent on the type of dam. This is shown in Figure 2.6. The offset distance is based on the depth of the coal seam that is to be extracted. For concrete or masonry dams $(\mathrm{X}=1)$ the Restricted Zone is 1.7 times the depth. For non-rigid dams $(\mathrm{X}=0.5)$ the offset distance is 1.2 times the depth of the coal seam (Sydney Catchment Authority, 2007). 


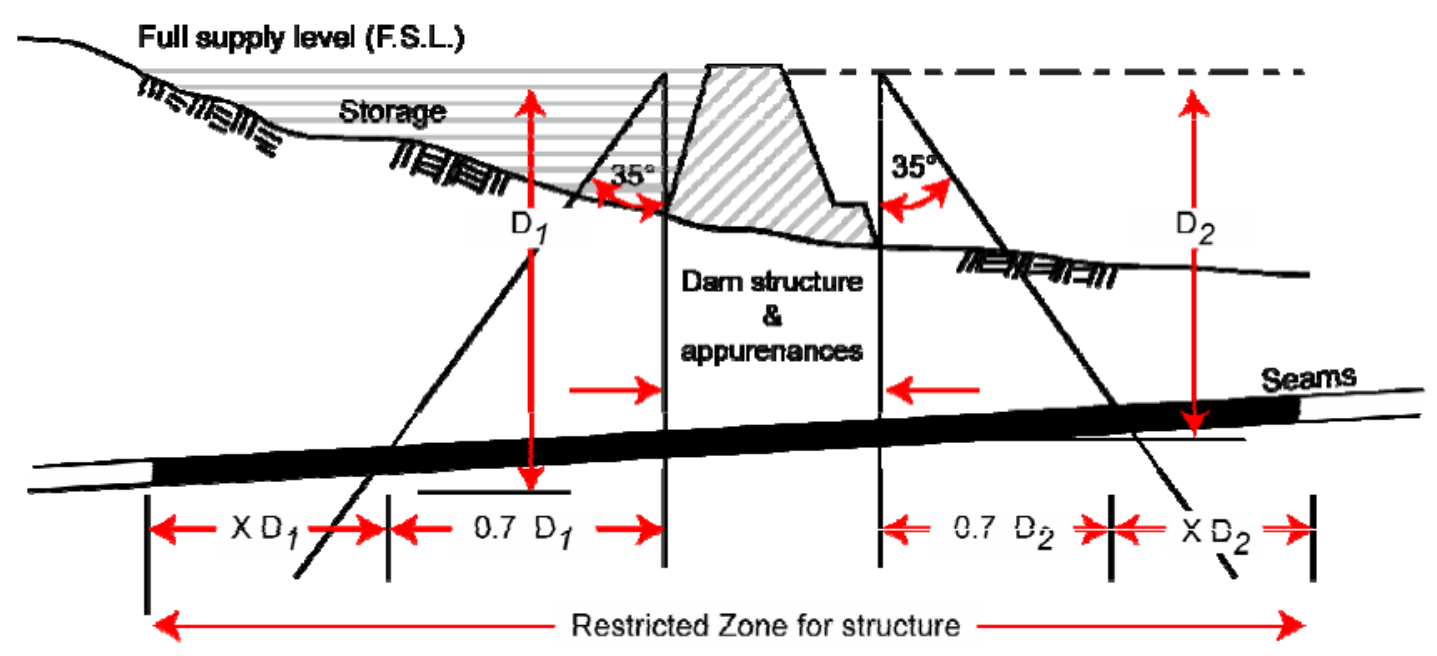

Figure 2.6: Offset distances for mining near dams (Sydney Catchment Authority, 2007)

\subsection{Current Regulations}

These are regulations for six states and the Office of Surface Management based on Roth et al. (1990).

\subsubsection{Virginia}

Virginia requirements include gathering information related to potential hydraulic consequences within a 28 degree angle of draw. For streams within this angle of draw instream monitoring is required to begin 6 months prior to mining and continue during active mining.

\subsubsection{Pennsylvania}

Pennsylvania requirements include mine planning to prevent damage to aquifers, perennial streams and public water supplies. The water supplies must be maintained or restored to premining conditions.

\subsubsection{Kentucky}

Prohibited to mine under any aquifer that serves as a significant source of supply. If damage to a water supply is expected, and alternate water source must be utilized for the public. 


\subsubsection{Ohio}

The requirements for mining in Ohio include repairing any damage to a perennial stream caused by the mining operation. The actual ability to repair damaged sources is unknown. Water levels in wells must be tested one year prior to mining.

\subsubsection{West Virginia}

High extraction or longwall mines must provide pre-mining data for anticipated subsidence area. These include descriptions of "significant aquifers. However significant is not clearly defined. If the overburden is at least 250-300ft and 60 times seam thickness, stream damage is considered unlikely. West Virginia’s regulations include the right to subside, limiting responsibility.

\subsubsection{Maryland}

In Maryland, only partial extraction up to $50 \%$ is allowed under perennial streams. Any loss of water supplies must be replaced by the mining company until pre-existing flows are restored.

\begin{tabular}{|c|c|c|c|c|c|c|c|}
\hline \multicolumn{8}{|c|}{$\begin{array}{l}\text { TABLE 6: FEATURES OF SUBSIDENCE REGULATION IN SIX STATES AND THE } \\
\text { FEDERAL GOVERNMENT }\end{array}$} \\
\hline & osM & KENTUCKY & MARYLAND & ОНIO & PENNSYLVANIA & VIRGINIA & WEST VIRGINIA \\
\hline No. of longwalls (1989) & n.a. & 5 & 1 & 3 & 12 & 13 & 29 \\
\hline $\begin{array}{l}\text { Standards for } \\
\text { protection of } \\
\text { perennial } \\
\text { streams }\end{array}$ & $\begin{array}{l}\text { No adverse effect } \\
\text { on water quantity } \\
\text { on quality or envir. } \\
\text { resources }\end{array}$ & $\begin{array}{l}\text { No material } \\
\text { damage }\end{array}$ & $\begin{array}{l}\text { Discretion } \\
\text { of regulatory } \\
\text { authority }\end{array}$ & $\begin{array}{l}\text { Repair } \\
\text { any } \\
\text { damage }\end{array}$ & $\begin{array}{l}\text { Maintain or } \\
\text { restore premining } \\
\text { condition }\end{array}$ & $\begin{array}{l}\text { Discretion } \\
\text { of DMLR }\end{array}$ & Unknown \\
\hline $\begin{array}{l}\text { Individual water : } \\
\text { supplies }\end{array}$ & $\star$ & $\begin{array}{l}\text { Identify } \\
\text { alternative } \\
\text { supply }\end{array}$ & $\begin{array}{l}\text { Replace, } \\
\text { repair, or } \\
\text { compensate }\end{array}$ & $\begin{array}{l}\text { Replace, } \\
\text { repair, or } \\
\text { compensate }\end{array}$ & $\star$ & $\star$ & $\begin{array}{l}\text { Provide } \\
\text { alternative } \\
\text { water source }\end{array}$ \\
\hline $\begin{array}{l}\text { Coal operator } \\
\text { liablity for } \\
\text { damage to } \\
\text { surface structures }\end{array}$ & $\star$ & Yes & Yes & Yes & $\star$ & $\star$ & Yes \\
\hline $\begin{array}{l}\text { Subsidence damage } \\
\text { waivers recognized }\end{array}$ & Yes & No & Yes & No & $\begin{array}{l}\text { Yes, if } \\
\text { waived by } \\
\text { current owner }\end{array}$ & Yes & Yes \\
\hline
\end{tabular}

Figure 2.7: Regulations for mining near surface water bodies (Roth et al., 1990) 


\subsection{Subsidence}

\subsubsection{Objectives of Subsidence engineering}

Subsidence is an inevitable effect of underground mining (Singh, 1992). These effects may be immediate during the operation of the mine (active subsidence) or may slowly occur for years and decades after mining has occurred (residual subsidence). Subsidence engineering is the process of minimizing surface structural damage by ground movement prediction. Potential surface effects are determined by changes in the strata overlying mine voids.

\subsubsection{Components of subsidence}

There are five major components of subsidence. These components are the root cause of damage to the surface and renewable resources (Singh, 1992). These five components are:

1. Vertical Displacement: Settlement or lowering of the overburden. This alone may cause little damage to surface structures

2. Horizontal Displacement: Lateral movement of the overburden. This may include slippage between the rock layers

3. Slope: also referred to as tilt. The slope is the derivative of the vertical displacement with respect to the horizontal displacement

4. Horizontal Strain: Horizontal displacement with respect to the horizontal. This effect causes the most damage to surface structures through tension and shear initiating fracturing and potential failure

5. Vertical Curvature: The derivative of the slope. Curvature creates shear strain which may distort surface structures and bending which creates strain.

There are three aspects to surface subsidence (Singh, 1992);1) cracking or fracturing, 2) pits or sinkholes and 3) troughs or sags. Changes in tension and stresses within the overburden are caused by cracks, fissures and step fractures. Small areas of overburden that collapse and manifest at the surface are called pitting or sinkholes; this effect is normally associated with room and pillar mining. The depth of the pits or sinkholes is generally limited to $100 \mathrm{ft}$ or 10 to 15 times the thickness of the coal seam (Singh, 1992). The third aspect of subsidence is the 
occurrence of a trough or sagging effect. This is primarily associated with longwall mining due to the larger voids but may occur with room and pillar mining as the pillars deteriorate and collapse or due to Room and Pillar retreat mining.

\subsubsection{Factors affecting Mine Subsidence}

The following is a list of factors detailed in the SME Handbook (Singh, 1992) that can affect subsidence due to underground mining.

\section{Effective seam thickness: extraction thickness}

\section{Multiple seams}

\section{Seam depth}

4. Dip of seam: the subsidence trough is skewed which causes the angle to be greater on the dip side. The strains decrease on the dip side. Pillars are less stable.

5. Competence of roof and floor: the properties of the strata and the floor affect the subsidence. In weak strata, punching from pillars is more likely to occur due to moisture. Stronger strata will delay subsidence.

6. Nature of overburden: Strong strata layers will delay subsidence

7. Near-surface geology: unconsolidated soils and rocks will induce more subsidence near the surface. Intrusion from water will cause more fissures and form gullies. This has a direct affect on structures. Water from a filled mine can seep upwards and increase the chance for soil collapse.

8. Geologic discontinuities: mining may cause movement in a fault plane due to change in forces. Structures overtop of a fault can be severely damaged.

9. Fractures and lineaments: Naturally occurring breaks in the strata will affect subsidence

10. In situ stresses: Surface subsidence is limited where high horizontal stresses occur. However when these area fail they are generally violent collapses. The stability of the strata is correlated to the ratio of horizontal and vertical stresses. 
11. Degree of extraction: the more coal that is extracted, the more likely subsidence is to occur.

12. Surface topography: hillsides and uneven terrain will tend to cause more movement in the ground due to gravity.

13. Groundwater: water will seep in to crack and fissures causing larger formations. Groundwater will pool in aquifer zones and create reservoirs or flow into the mine itself. If limestone is present, groundwater can cause caverns to form.

14. Water elevation and Fluctuations: will cause deformation of the pillars. It will also soften the roof and floors allowing for punching from the pillars. Water in the bedding planes will also induce movement due to lubrication.

15. Mined area: maximum subsidence will occur if the critical width of the mine is exceeded in both directions. Subsidence will occur at a smaller scale if only one axis is exceeded.

16. Method of working: type of mine (room and pillar, longwall, ...). The subsidence in a longwall mine begins to occur almost immediately.

17. Rate of face advance: the speed of extraction directly affects the strains in the overburden. A quick even pace is recommended.

18. Backfilling the gob: this helps reduce subsidence depending on the method used.

19. Time elapse: the amount of time affects the amount of subsidence depending on the type of mine. Room and pillar mining will have limited subsidence effects in the short term. However the subsidence will increase over the long term due to punching and deterioration. Longwall mining affects will cease in a few years except when pillars are left behind. In this instance the affects can last for decades until the pillars fail.

20. Structural characteristics: the damage caused to a surface structure is dependent on its properties. Larger or older structures are more likely to be damaged due to subsidence. 


\subsubsection{Measurement}

Measurement is determined through monitoring stations that undergo the same vertical and horizontal changes as the ground.

The monuments need to be anchored below the frost zone and be able to withstand surface conditions that could potentially skew the data. The distances between the monuments must be close enough to be able to detect strains of 0.001 , about $1 / 10$ the strain level for structural damage (Singh, 1992). The general standard in the United States is a distance of 0.05D to 0.1D; where $\mathrm{D}$ is the depth of the mined bed. International standards are stricter; however cost is a consideration when determining the appropriate distances. Once the monuments are in place the vertical strains in the ground is measured by optical or laser leveling.

\subsection{Types of Subsidence}

Subsidence is the vertical displacement of the ground surface caused by a void in the underlying strata. For the purpose of this report, the voids discussed are developed due to mining operations, either longwall or room and pillar. As a mine is formed, the overlying strata bend and fracture, creating vertical movement at the ground surface. This movement is critical in determining the effects of mining because it not only can cause damage to surface structures but creates strain in bed layers, both vertically and horizontally. Increased strain is the determining factor that leads to increased hydraulic conductivity and seepage erosion progression.

There are 4 types of subsidence due to underground mining (Table 2.3) (Craft, 1992). These are pit subsidence, room subsidence, sag subsidence and beam subsidence. Each type of subsidence develops based on the geological setting around the mine itself. The key factors in determining the subsidence are depth of mine, overburden and the topography. 
Table 2.3: Types of subsidence (Craft, 1992)

\begin{tabular}{|c|c|c|c|c|c|c|c|}
\hline \multirow{2}{*}{\begin{tabular}{c|} 
Types of \\
Subsidence
\end{tabular}} & \multirow{2}{*}{\multicolumn{3}{|c|}{ Pit }} & \multirow{2}{*}{ Room } & \multirow{2}{*}{ Sag } & \multicolumn{2}{|c|}{ Beam } \\
\hline & & & & & & Arch & Cantilever \\
\hline Orerburden & Shale & $\begin{array}{l}\text { Unconsolid ated } \\
\text { sediments - Dry }\end{array}$ & \begin{tabular}{|l|} 
Unconsolidated \\
sediments - \\
Wet \\
\end{tabular} & $\begin{array}{l}\text { Shale with } \\
\text { interbedded } \\
\text { silts tone }\end{array}$ & $\begin{array}{l}\text { Shale with } \\
\text { limestone and } \\
\text { siltstone }\end{array}$ & $\begin{array}{l}\text { Predominately silts tone } \\
\text { and sands tone }\end{array}$ & $\begin{array}{l}\text { Predominately sands tone } \\
\text { with interbedded } \\
\text { silts tone }\end{array}$ \\
\hline Topography & \multicolumn{2}{|c|}{$\begin{array}{l}\text { Flat to rolling } \\
\text { overburden les s than } \\
100 \text { feat }\end{array}$} & \begin{tabular}{|l|} 
Generatly flat \\
overburden any \\
thickenss
\end{tabular} & $\begin{array}{l}\text { Flat to rolling } \\
\text { overburden } \\
\text { less than } 150\end{array}$ & \begin{tabular}{|l|} 
Flat to rolling \\
overburden over \\
150 feat
\end{tabular} & $\begin{array}{l}\text { Flat to rolling and valley } \\
\text { bottons overburden } \\
\text { any thickness }\end{array}$ & $\begin{array}{l}\text { Steep hills ides, high } \\
\text { relief, overburden any } \\
\text { thickness }\end{array}$ \\
\hline $\begin{array}{c}\text { Surface } \\
\text { Expression }\end{array}$ & \multicolumn{2}{|c|}{ Steep sided pit } & $\begin{array}{l}\text { Surface sag } \\
\text { indefinite size }\end{array}$ & $\begin{array}{l}\text { Depression } \\
\text { mimics room in } \\
\text { the mine }\end{array}$ & $\begin{array}{l}\text { Depression } \\
\text { larger than room } \\
\text { in mine }\end{array}$ & $\begin{array}{l}\text { Surface cracks with } \\
\text { graben type block } \\
\text { depressions. Water } \\
\text { loss fromstreams }\end{array}$ & $\begin{array}{l}\text { Large surface cracks, no } \\
\text { depression }\end{array}$ \\
\hline Depth & \multicolumn{2}{|c|}{$\begin{array}{l}\text { Generally only a few feet } \\
\text { can extend to the mine } \\
\text { level }\end{array}$} & $\begin{array}{l}\text { Generally less } \\
\text { than two feet }\end{array}$ & \multicolumn{2}{|c|}{$\begin{array}{l}\text { Generally less than } 1 / 2 \text { coal seam } \\
\text { thickness }\end{array}$} & $\begin{array}{l}\text { Tension cracks over } \\
\text { coal in place, shallow } \\
\text { depression over panels }\end{array}$ & $\begin{array}{l}\text { Crackwid th and depth } \\
\text { depends on overburden } \\
\text { thickeness, relief and } \\
\text { thickness of beam }\end{array}$ \\
\hline \multicolumn{8}{|c|}{ Remedial Measures } \\
\hline Emergency & \multicolumn{2}{|c|}{$\begin{array}{l}\text { Eucavation and backfill } \\
\text { with stable material }\end{array}$} & \multicolumn{4}{|c|}{ Temporary stabilization of structures to prevent further danage } & $\begin{array}{l}\text { Build fence around larger } \\
\text { cracks }\end{array}$ \\
\hline Long Term & \multicolumn{2}{|c|}{$\begin{array}{l}\text { Excavation and backfill } \\
\text { with s table material }\end{array}$} & \begin{tabular}{|l|} 
Identify piping \\
zone and grout \\
fractures in \\
bedrock
\end{tabular} & \multicolumn{2}{|c|}{$\begin{array}{l}\text { backfll void or build cohm } \\
\text { support sys tems in mine to stop } \\
\text { further faibre }\end{array}$} & $\begin{array}{l}\text { Identify Compression } \\
\text { area, build support in } \\
\text { nine, grout cracks in } \\
\text { streambed }\end{array}$ & Backfall crack \\
\hline
\end{tabular}

\subsubsection{Pit Subsidence}

Pit subsidence is the initiation of a small surface depression directly above the mine that extends varying depths towards the mine. Maximum subsidence generally occurs directly over the mine itself with easing effects extending outwards in all directions. This type of subsidence occurs when mining induces fracturing in the overburden or where the operation disturbs existing fractures. In this instance a steep sided pit is formed. The actual size and shape of the pit is determined by the composition of the overburden and presence of a water table. If the overburden contains continuous layers of solid rock such as shale, the fractures will extend through the broken (fractured) zone to the surface due to local caving effects from the mine. If unconsolidated material is present, fracturing will cease at the contact point. However the unconsolidated material may be susceptible to hydraulic transport into the mine void or other types of erosion due to strain effects. The three typical settings for this type of subsidence to occur are where; 1) thin-bedded shale is present, 2) a perched water table with unconsolidated material exists or 3 ) in areas of a seasonal water table. 
When either water table type is present the sediment may travel through the fractured material into the mine void. If the fractured zone lies in contact with unconsolidated material, hydraulic transport of fines can occur. This will in effect lower the water table and draw water from outlying areas not directly influenced by subsidence.

\subsubsection{Room Subsidence}

Room subsidence occurs in overburden directly over the mined region extending upwards in converging towards directly above the center of the mine void. Due to this, the area affected is generally less than or equal to the area of the mine. This type of subsidence occurs in shallow mines generally less than $100 \mathrm{ft}$ deep and in predominately shale. According to Craft (1992), the maximum vertical displacement of this type of subsidence is less than half the thickness of the original mine void and occurs very rapidly. After such an instance occurs, there is minimal movement at the edges of the depression.

\subsubsection{Sag Subsidence}

This type of subsidence is limited to partial extraction mining where the pillars fail from crushing causing roof failure. It occurs in areas where overburden consists of limestone, shale and siltstone at depths greater than $150 \mathrm{ft}$. Although the surface cracks are generally small (several inches) the angle of draw diverges towards the surface extending past the mined seam. When the pillars begin to fail, subsidence occurs rapidly and will continue to occur over a long period of time. Surface structural damage is common with this type of subsidence, especially at the edge of the subsiding area.

\subsubsection{Beam Subsidence}

Beam subsidence can occur in two ways: cantilever and arch beam failure. Cantilever beam subsidence occurs when a layer of hard rock lies above a coal seam but outcrops overtop of the coal seam. For full extraction mining the entire weight of the remaining overburden is placed on this seam. If pillars are left as in partial extraction, the weight extends to them. As the pillars fail, the overburden acts on the cantilever beam dropping the opposite end of the beam. This type of subsidence causes a large fissure in the overburden directly above the support structure on the supported side of the beam. This type of subsidence occurs in areas of steep terrain. 
Arch beam failure occurs when a large area of coal is left between two room and pillar areas. This potentially may occur between longwall mining. Over time the pillars will slowly crush or fracture causing settling directly above the mined areas. As both sides settle, the overburden in the middle will arch creating high zones of tension directly above the untouched coal extending outward to the mined sections. This type of subsidence will occur slowly and under all types of terrain.

\subsection{Surface Subsidence Due to Longwall Mining}

Surface subsidence due to longwall mining is dependent on the depth of the coal seam. The relationship between the panel and chain pillar widths to the depth creates different profiles (Figure 2.8). If the longwall extraction is performed using thin panels (W/H ratio less than 0.33) and large pillars (W/H ratio greater than 0.2 ) the profile (b) will be shallow and smooth (Sydney Catchment Authority, 2007). Under these conditions the subsidence troughs over the panels will be shallow and relatively uniform. Under the same panel conditions with smaller pillars (W/H equal to 0.6), the subsidence trough depth will increase but maintain a smooth profile. As the width of the longwall panels increases, the subsidence profile will take on a wavy shape. Troughs will appear over each individual panel. This is show as (d) in Figure 2.8.

Topography is an important factor in longwall mining below streams and valleys. Maximum subsidence occurs in areas of high relief. The horizontal stresses on either side are transferred to the valley or stream floor (Figure 2.09). The unconfined material in the floor is pushed up vertically creating a hump, reducing subsidence and increasing strain (Sydney Catchment Authority 2007). 


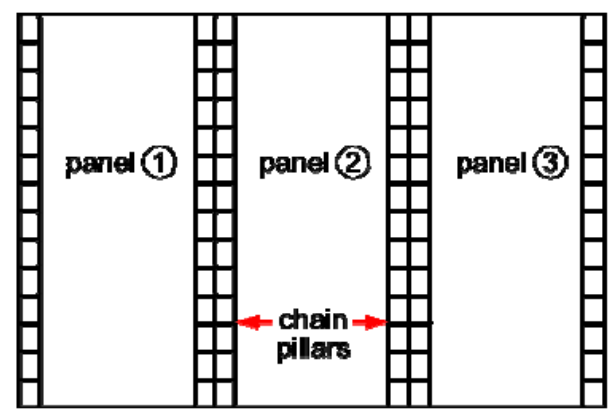

(a) Plan of longwall layout

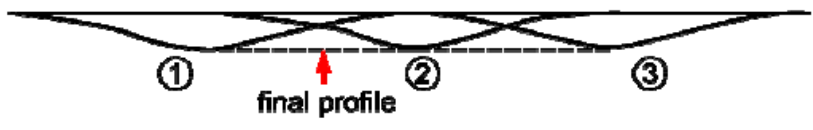

(b) Subsidence profile - shallow and smooth

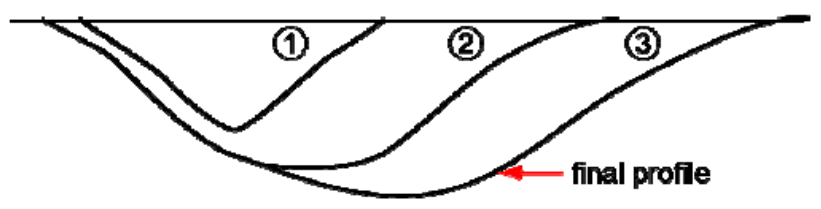

(c) Subsidence profile - deep and smooth

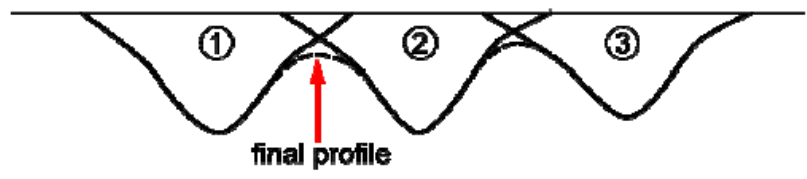

(d) Subsidence profille - deep and wavy

Figure 2.8: Subsidence profiles (Sydney Catchment Authority, 2007) 


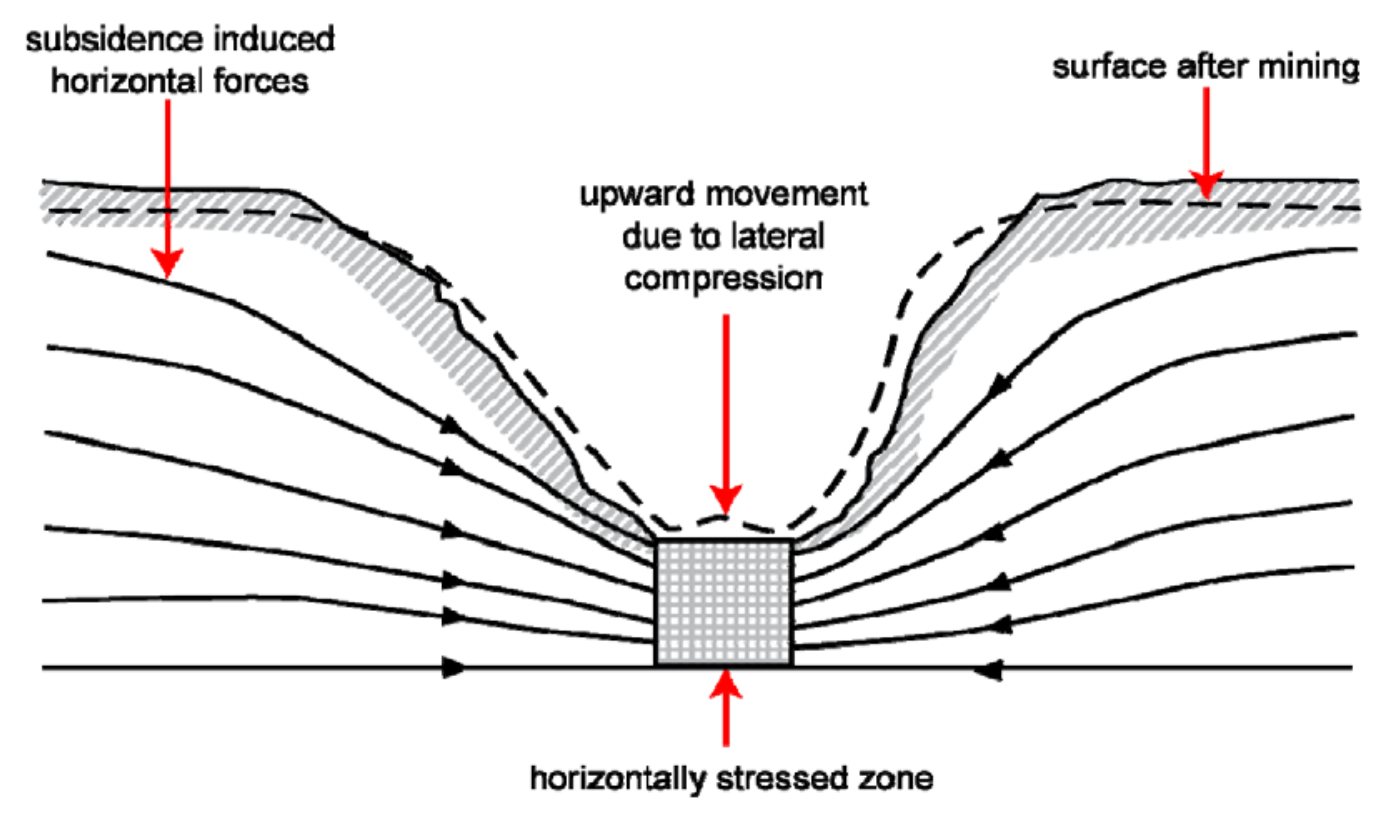

Figure 2.9: Horizontal stressed zones (Sydney Catchment Authority 2007)

\subsection{Duration of Subsidence}

There are two types of subsidence due to underground coal mining; active and residual. Active subsidence occurs during the mining operation. This type of subsidence is associated with longwall mining once critical width is reached. Residual subsidence is the surface deformation that occurs after mining has ceased. This is generally associated with the deformation and collapse of pillars causing the settling of overburden. In several case histories, residual subsidence has continued to occur over one hundred years after closure of the mine (Singh, 1992).

The timeline for subsidence to occur is directly dependent on the type of mining that occurs. Major occurrences of surface subsidence from Room and Pillar mining may not occur for decades until the support structures have deteriorated or failed (Singh, 1992). Full extraction such as Longwall mining causes subsidence to begin begins almost immediately. Figure 2.10 shows estimated timeframes for residual (post mining) subsidence occurrence due to Longwall mining (Singh, 1992). 


\begin{tabular}{|c|c|c|}
\hline Reference & $\begin{array}{l}\text { Countryl } \\
\text { Coalfield }\end{array}$ & $\begin{array}{c}\text { Residual Subsidence } \\
\text { Duration }\end{array}$ \\
\hline $\begin{array}{l}\text { institution of Municipal } \\
\text { Engineers (Anon., } \\
\text { 1947) }\end{array}$ & UK & 2 to 10 years \\
\hline Orchard \& Allen (1974) & UK & $\begin{array}{l}\text { Several months to } 3 \text { to } \\
6 \text { years (strong } \\
\text { overburden) }\end{array}$ \\
\hline Collins (1977) & UK & 2 to 4.5 years \\
\hline Grard (1969) & France & 6 to 12 months \\
\hline Brauner (1973) & Germany & $\begin{array}{l}1 \text { year (Cretaceous } \\
\text { overburden) } \\
2 \text { years (sandstone } \\
\text { overburden) }\end{array}$ \\
\hline Brauner (1973) & USSR & $\begin{array}{l}2 \text { years (shallow } \\
\text { mines) } \\
4 \text { to } 5 \text { years (deep } \\
\text { mines, > } 1300 \mathrm{ft} \text { or } \\
400 \mathrm{~m} \text { ) }\end{array}$ \\
\hline $\begin{array}{l}\text { Shadrin and Zamotin } \\
(1977)\end{array}$ & USSR & 2 to 25 months \\
\hline Gray et al. (1977) & US/Appalachian & $\begin{array}{l}\text { Few months to few } \\
\text { years }\end{array}$ \\
\hline Hood ef al. (1981) & US/Illinois & 12 months \\
\hline
\end{tabular}

Figure 2.10: Duration of subsidence (Singh, 1992)

In general, initial subsidence occurs when a void is created in the subsurface. As the overburden begins to fracture and sag, the subsidence effects will continue to increase. As long as the overburden cannot support itself, the effects will continue.

Duration time for subsidence due to room and pillar mining is much more complicated to predict. Unlike full extraction mining, the pillars will support the overburden as long as they are intact. Some initial subsidence will occur but generally in localized areas and only minimal effects will be seen. Overtime, the pillars will begin to fail. Once one begins to crush or fracture, the weight supported by that pillar will be transferred to the other surrounding pillars. With additional weight placed upon them, these pillars will begin to fail as a faster rate creating a domino effect.

The initial failure event for pillars is dependent on multiple factors. The depth of the coal seam affects the overall weight needed to be supported. The width of the pillars and placement affects how much each one is designed to support. The terrain and the dip of the coal seam affects how much overburden each pillar is designed to support and the type of strata dictates how a pillar is likely to fail. Because of all the unknown factors in pillar design and overburden, it is hard to predict the timeframe when subsidence will occur. What is known is that failure will eventually occur and it will be relatively quick when it does (Singh, 1992). Over a long period of time, 
room and pillar mining will have the same extraction ratio effect on the surface as full extraction mining would.

The ultimate likelihood of maximum subsidence is based on field data showing that subsidence can occur for decades to over one hundred years after mining (Singh, 1992).

\subsection{Angle of Subsidence Draw}

Subsidence reaches its maximum displacement directly above a mine. However it extends horizontally past the mine void in a range called the angle of draw. In the United States the average angle of draw is expected to be less than 35 degrees in coal fields (Singh, 1992).

Data for the Appalachian coal fields indicate that the subsidence angle of draw can extend more than 40 degrees. The Mining Engineering Handbook listed typical values of angle of draw ranging between 10 to 38 degrees for the eastern United States (Singh, 1992). For case history data the range for Appalachia and Illinois subsidence generally falls between 20 to 40 degrees (Booth, 2006). Peng discussed that the range of angle of draw has been reported to be between 4 to 45 degrees. However, in the development of a database for subsidence from longwall mining, Peng found the maximum angle of draw for 110 cases was 24 degrees. In 95\% of these cases the subsidence was reported to be less than 20 degrees (Peng et al., 1995).

\subsection{Effects of subsidence}

Longwall mining causes subsidence to occur quickly, which affects the overburden. These changes occur in the form of fracturing and bed separation. At the surface, subsidence can be up to 60-90 percent of the thickness of the coal seam (Booth et al., 2000). As this occurs, groundwater flow and aquifers can be altered due to changes in hydraulic properties. Over time shale in the overburden will self heal or recover; however in most cases there is permanent increase in the permeability.

When a void is created in the ground, the overburden pressure is transferred from the roof of the opening to the solid rock around it. This creates a pressure arch above the mine void. Within this zone is an area of de-stressed fractured rock (Figure 2.11). The stability of this opening, however, depends on the beam strength (Booth, 1986). Failure of the beam causes fracturing and sagging of rock into the mine void. The extent of this is dependent on the width of the opening and the strength of the roof rock (Booth, 1986). 


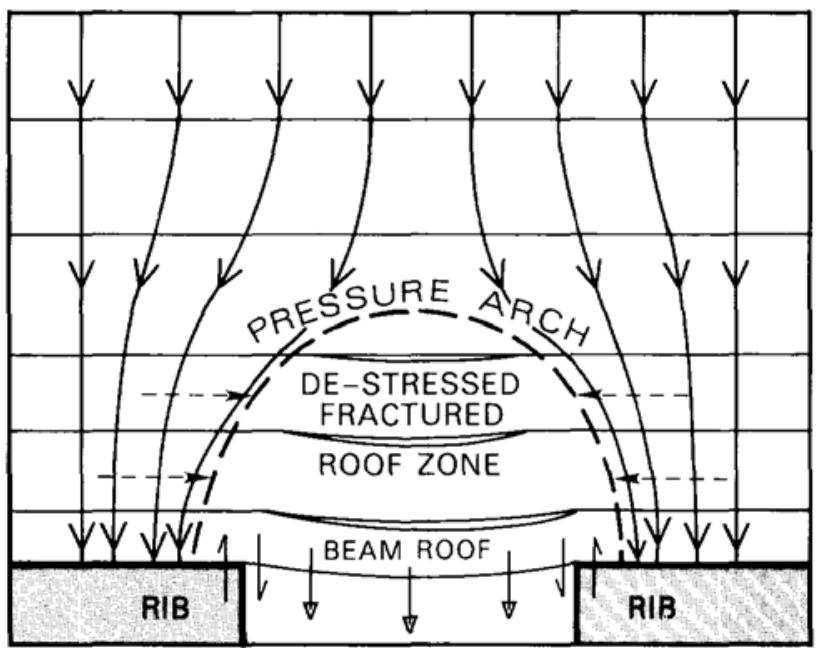

Figure 2.11: Pressure arch above mine void (Booth, 1986)

In longwall mining, this critical width is greatly exceeded during mining and roof material collapses as the mine face passes. The increased pressures peak just in front of the mine face but exist several hundred feet away (Booth, 1986). Behind the face the mine roof breaks apart in a cantilever fashion with vertical fractures (Booth, 1986). The remaining overburden then deforms and becomes supported by the fractured and bulked material (gob). The pressures within the gob increase outwards from the mine face.

Maximum subsidence generally occurs directly above the center of the mine opening (Singh, 1992). The amount of subsidence is dependent on the width of mine (Singh, 1992). This would be the size of the room for partial extraction or the width of the longwall for full extraction. The critical width is the distance necessary for full subsidence to occur. If this width is not reached, subsidence will occur albeit at a lesser degree. Figure 2.12 shows how the room width of the extraction seam can affect the amount of subsidence occurring. 


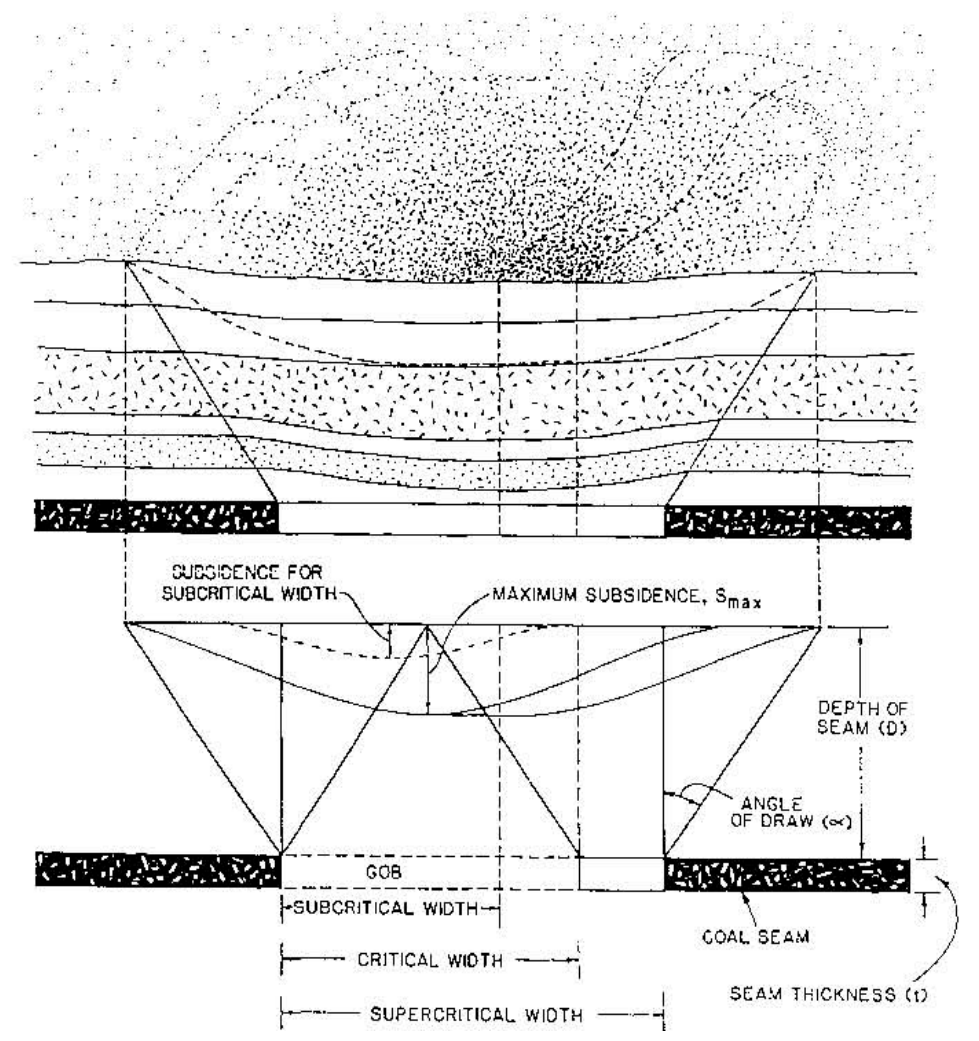

Figure 2.12: Panel width in relation to subsidence (Singh, 1992)

Longwall mining creates rapid subsidence, generally within several days because of the full extraction method (Booth, et al., 2000). As the mine face advances it creates what is known as a "subsidence wave". This is shown in Figure 2.13. The subsidence wave creates zones of tension and compression that create fracturing and separation of the bed layers. The rapid changes are expressed in stages (Booth, 2000).

The initial response is lowering of groundwater head outside of the mining zone. The lateral distance affected is dependent on the transmissivity of the overburden. Recovery of the water levels can occur after mining but the timeframe is hard to predict. In several cases, water levels recovered within several months. In another case study, only 1 out of 19 had any significant recovery (Booth, et al., 2002). 


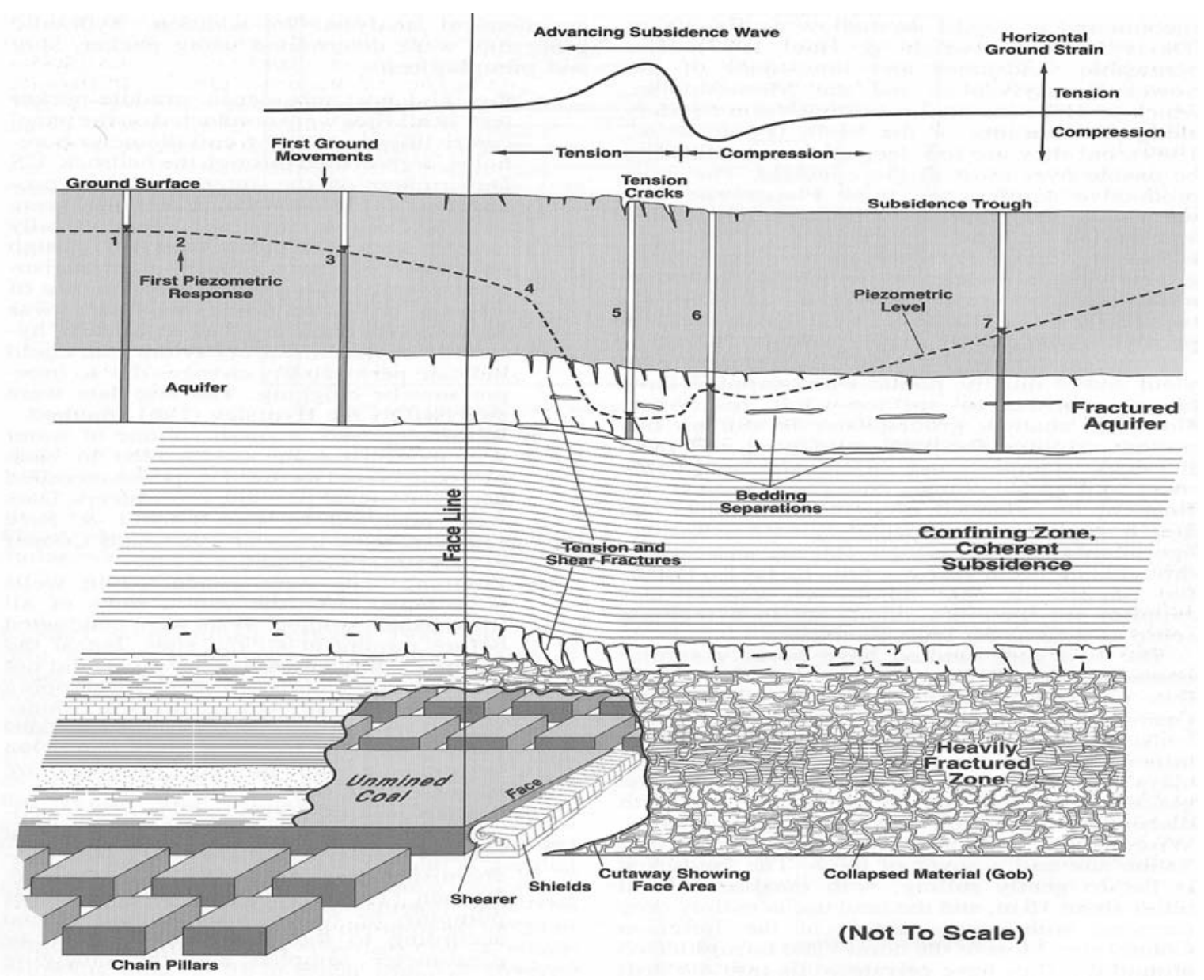

Figure 2.13: Compression wave (Booth, 2002)

\subsection{Strain Effects}

Subsidence creates zones of compression directly above the extracted coal seam with areas of tension beginning near edges and extending outwards. The zones of tension and compression are shown in Figure 2.14 with the inflection point of where the change between the two occurs. Heavy fracturing and compression occur directly above the mine where tensional strains occur past the inflection point outwards to the extent of where the rock is undisturbed. This correlates with the Angle of Subsidence Draw. 


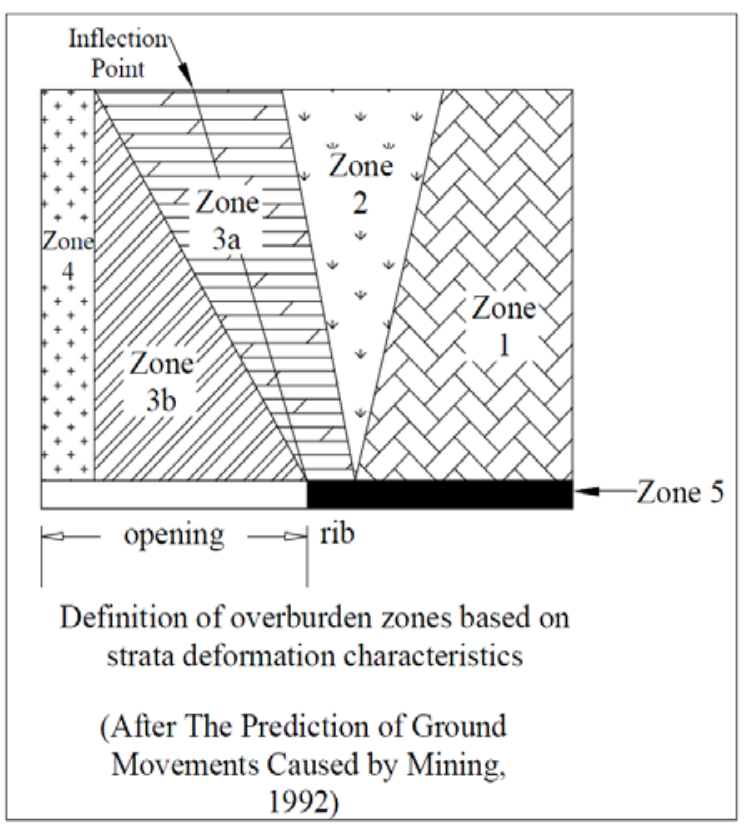

- Zone 1 or Intact Zone- Includes the strata below the seam and the undisturbed rock outside of the influence area

- Zone 2 or Intermediate Zone- Extends between the outermost boundary of Zone 3 and the boundary of Zone 1, over the rib or the excavation. The angle of fracture, when available, is also used to define the right boundary of this zone.

- Zone 3 or Fractured Zone- Includes the high shear area around the inflection point

- Zone 4 or Affected Zone- Extends from the innermost boundary of Zone 3 to the centerline of the panel. In this zone, the strata is assumed to be primarily subject to translation, without being exposed to high stresses associated with the high shear zone.

- Zone 5 or Extraction Zone- Represents the coal seam

Figure 2.14: Zones of Overburden (After Karmis, 1992)

The recommended tolerable strain for groundwater aquifers and surface bodies of water is 0.005 (Singh, 1992). However, research has shown that increased permeability can occur with extensional strains of only 0.001 (Bai et al., 1995). This is 5 times less than the recommended guidelines. IC 8741 recommends strains not to exceed 0.00875 which is far greater than both of these values.

Field data from the eastern United States shows excess strain ranging from 300 to 970 micro strains (Dolinar, 1999). Excess strain is the strain after gravitational affects are removed. These values are shown in Table 2.4. For the 36 sites examined, all showed maximum strain values above what can initiate increased permeability based on Bai et al. (1995).

Table 2.4: Strain values in Appalachia (Dolinar, 1999)

\begin{tabular}{lccccccc}
\hline \multicolumn{1}{c}{ Region } & $\begin{array}{c}\text { Number of } \\
\text { Sites }\end{array}$ & $\begin{array}{c}\text { Maximum } \\
\text { Strain Micro } \\
\text { strain }\end{array}$ & $\begin{array}{c}\text { Standard } \\
\text { Deviation }\end{array}$ & $\begin{array}{c}\text { Range of Site } \\
\text { Maximum Strain } \\
\text { Microstrain }\end{array}$ & $\begin{array}{c}\text { Minimum } \\
\text { Strain Micro } \\
\text { strain }\end{array}$ & $\begin{array}{c}\text { Standard } \\
\text { Deviation }\end{array}$ & $\begin{array}{c}\text { Strain Ratio } \\
\text { Max/Min }\end{array}$ \\
\hline $\begin{array}{l}\text { Northern Appalachian } \\
\text { Central Appalachian }\end{array}$ & 7 & 440 & 90 & $300-540$ & 260 & 70 & 1.69 \\
$\quad$ Low Strain Zone & 7 & 370 & 60 & $300-480$ & 170 & 70 & 2.17 \\
$\quad$ High Strain Zone & 12 & 760 & 130 & $550-970$ & 410 & 130 & 1.85 \\
Eastern Mid-Continent & 10 & 370 & 90 & $240-530$ & 80 & 90 & 4.6 \\
\hline
\end{tabular}


At a study site in Jefferson County, Illinois maximum tensile strains were located 22m inside a 183m panel. The maximum compressive strains were located 60m inside the panel (Booth, 2002). The interior contained vertical extensional separations while the panel edges showed fracturing at the surface.

\subsection{Strata Response}

Bai et al. (1995) identified multiple layers in which changes in the overburden occur. In the overburden layers, the rock will lose strength from either tension or compression. The loss of strength results in fracturing and allows for increased permeability. These break down the strata layers from the mine to the ground surface into 5 separate layers. These layers are:
1.) Caved Zone
2.) Fractured Zone
3.) Dilated Zone
4.) Constrained Zone
5.) Surface Fracture Zone

Figure 2.15 shows the zones and the approximate thickness of each layer above a mine. The Chinese method is similar, however, it only has three representative zones: Caving, Fractured and Bending Zones. The thickness of these zones is based on mathematical formulation, rather than empirical analysis. The Chinese zones are detailed in Figure 2.16. 


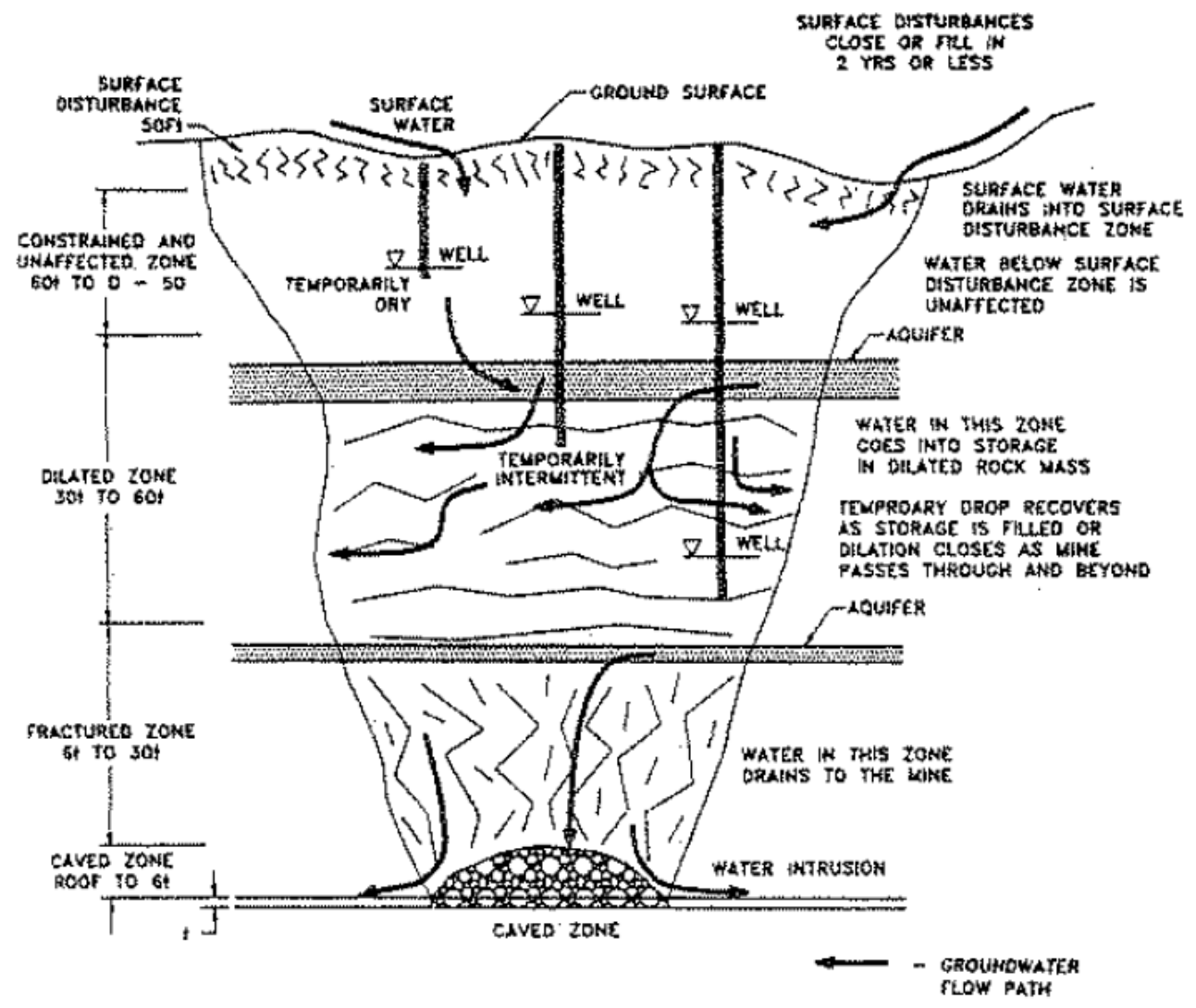

Figure 2.15: Subsidence zones (Bai et al,. 1995)

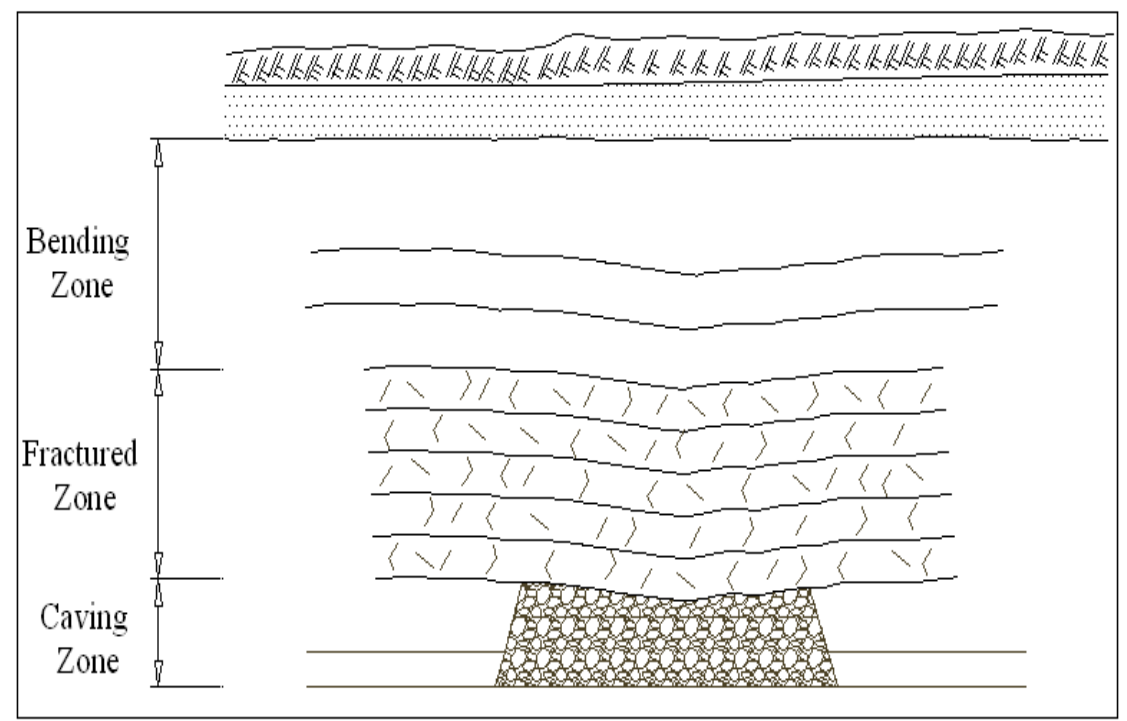

Figure 2.16: Subsidence zones based on Chinese literature (after Bai et al,. 1995) 


\subsubsection{Caved Zone}

The caved zone exists from the roof of the mine to approximately 6 times the thickness of the mine (Bai et al. 1995). Booth (2002) described this zone as approximately 2 to 8 times the thickness of the seam. The amount of fracturing or caving in this zone is dependent on the rock dilation. This differs depending on the type of rock that is present in this zone. The average coefficient for rock dilation is usually less than 1.5 and decreases under multiple seams due to repeated compression. The report lists a table of these approximate coefficients. The Chinese have developed a formula for determining the extent of this zone.

$$
H_{c} \text { or } H_{f}=\left(\frac{(100 \times M)}{(a \times M+b))}+C\right.
$$

Where:

$H_{c}$ or $H_{f}=$ the extent of the caving zone in total height

$\mathrm{M}=$ the coal seam thickness

$\mathrm{a}$ and $\mathrm{b}=$ the coefficients of rock dilation (listed below)

$\mathrm{c}=$ the mean square deviation (listed below)

Table 2.5: Strata Lithology versus strength of rock (After Bai et al., 1995)

\begin{tabular}{|l|c|}
\hline Strata Lithology & Uniaxial Compressive Strength \\
\hline Strong & $>40 \mathrm{Mpa}(5,800 \mathrm{psi})$ \\
\hline Medium Strong & 20 to $40 \mathrm{Mpa}(2,900$ to $5800 \mathrm{psi})$ \\
\hline Weak & $<20 \mathrm{Mpa}(2,900 \mathrm{psi})$ \\
\hline
\end{tabular}

Table 2.6: Coefficients for maximum height in Caving Zone $H_{c}$ (after Bai et al., 1995)

\begin{tabular}{|l|c|c|c|}
\hline Strata Lithology & $a$ & $b$ & $c$ \\
\hline Strong & 2.1 & 16 & 2.5 \\
\hline Medium Strong & 4.7 & 19 & 2.2 \\
\hline Weak & 6.2 & 32 & 1.5 \\
\hline Weathered & 7.0 & 63 & 1.2 \\
\hline
\end{tabular}


Table 2.7: Coefficients for maximum height of Caving zone Hf (After Bai et al., 1995)

\begin{tabular}{|l|c|c|c|}
\hline Strata Lithology & $\mathrm{a}$ & $\mathrm{b}$ & $\mathrm{c}$ \\
\hline Strong & 1.2 & 2.0 & 8.9 \\
\hline Medium Strong & 1.6 & 3.6 & 5.6 \\
\hline Weak & 3.1 & 5.0 & 4.0 \\
\hline Weathered & 5.0 & 8.0 & 3.0 \\
\hline
\end{tabular}

Field tests have shown that the caved zone does fall into the criteria of the report. The studies have shown that the caving zones fell between 2 and 10 times the seam height. The field tests also have shown that weaker strata actually cave less than stronger strata. This is because the weaker strata will sag rather than break apart. The Chinese guidelines follow this pattern.

\subsubsection{Fractured Zone}

The fractured zone consists of the area above the caving zone to an aquifer layer. This zone ranges from $6 \mathrm{t}$ to up to $30 \mathrm{t}$ (where $\mathrm{t}$ is the seam thickness) depending on the geologic profile of the overburden (Bai et al., 1995). Booth (2002) describes this zone as being a maximum of 30 to 40 times the thickness of the coal seam. It is identified by vertical fracturing and horizontal bedding plane separations. Within this region, the ground water will eventually drain into the mine. There are several types of fractured zones according to Chinese reports (Bai et al., 1995). The severely fractured zone consists of large separation of the strata with flow rates greater than 1 liter $/ \mathrm{sec} / \mathrm{m}$. The moderately fractured zone has only partial separation with ground flows ranging from 0.1 to 1 liter/sec/m. The slightly fractured zone has only small fractures. The flow rates in this region are less than $0.1 \mathrm{liter} / \mathrm{sec} / \mathrm{m}$.

The following equation can be used for determining the height of this zone. This also includes the caved zone;

$H_{f}=((100 \times M) /(a \times n+b))+c$

Where;

a, b and c $=$ coefficients of the strata

$\mathrm{n}=$ the number of lifts 
As with the caved zone, weaker strata have a smaller fractured zone. In North America the fractured zone is approximately $24 t$ for strong strata and decreases to $19-20 t$ for weaker strata and even down to 10t in certain instances (Bai et al., 1995).

The fractured zone does not remain constant. According to the report, the fractured zone will reconsolidate over time (Bai et al., 1995). The length of time is also a function of the type of overburden. Stronger strata will remain constant for a least a month and remain up to 20 years before reconsolidation occurs. Weak strata will remain unconsolidated for only 6 months to 17 months. At this point the zone will decrease at an average rate of $0.4 \mathrm{~m}$ per month. Field experience has shown that the fractured zone will also from a saddle shape due to compaction.

\subsubsection{Dilated Zone}

The dilated zone reaches from approximately 30 times to 60 times the coal seam thickness above the mine. This zone is not recognized in the Chinese empirical zones (Bai et al., 1995). The strata in this area acts as multiple thin beams that bend which ultimately cause surface fracturing. There is little fracturing in this zone because the rock beds act differently under stresses and tend to separate. This does however increase the water storage volume of this zone. The bending causes tension on the lower portion of the beams and compression on the upper portions. This can be a result of the saddle formation in the lower zones. Due to the different stiffness of the beams, there is considerable shear present in the dilated zone. This will cause larger deformations in the zone but will not increase (actually lower) the vertical transmission of groundwater. In three layer subsidence, this zone is included in the fractured zone. It lies above an aquifer zone and therefore cannot increase the volume of water flowing into the mine.

\subsubsection{Bending or Constrained Strata Zone}

This zone lies between the dilated and surface zones. It does not allow increased flow into the fractured zone and ultimately into the mined area. According to Bai et al. (1995), this zone is a barrier that provides a measure of safety for the water bodies above.

This zone only exists when the mine lies deeper than the combination of the surface and fractured zones. It is characterized by having tensile strains less than $1 \mathrm{~mm} / \mathrm{m}$ where there is no increased permeability. However Bai et al. (1995) expresses that localized excessive strains may 
occur in this zone. Kendorski (1979) determined that this zone should be comprised of shale to limit fracturing and become "self-healing".

The Chinese have a similar aquiclude zone that allows for clays, shale, and crystalline rocks. Their equation for the thickness of this zone is;

$$
H_{p}=d\left(\frac{M}{n}\right)
$$

Where:

$M=$ the seam thickness

$\mathrm{n}=$ the number of lifts

$\mathrm{d}=$ the coefficient for thickness of the protective layer

The coefficient is based on the presence of clay material at the bottom of unconsolidated layer (Figure 2.17 and Table 2.8). The amount present dictates the coefficient used.

Table 2.8: Coefficient for the thickness of the protective layer (After Bai, et al., 1995)

\begin{tabular}{|l|c|c|c|c|}
\hline Strata Lithology & Case $\mathrm{a}$ & Case $\mathrm{b}$ & Case c & Case d \\
\hline Strong & 4 & 5 & 7 & 6 \\
\hline Medium & 3 & 4 & 6 & 5 \\
\hline Weak & 2 & 3 & 5 & 4 \\
\hline Weathered & 2 & 2 & 5 & 3 \\
\hline
\end{tabular}




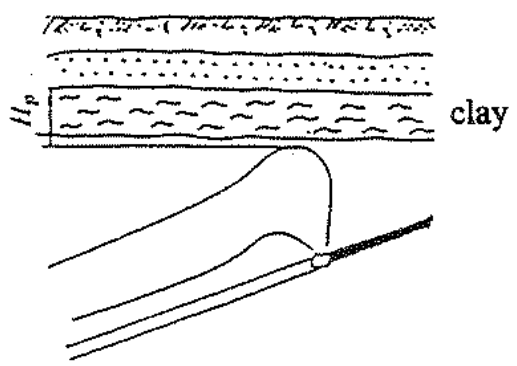

a: Thick Clay at Bottom of Unconsolidated Strata.

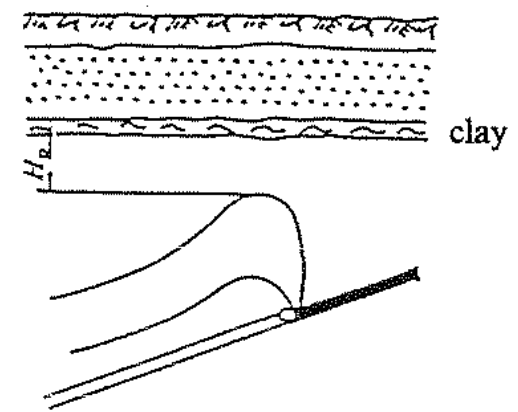

b: Thin Clay at Bottom of Unconsolidated Strata.

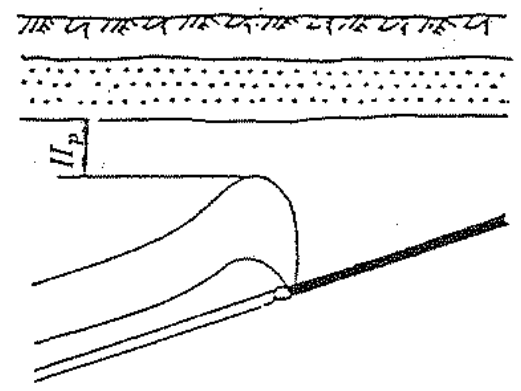

C: No Clay at Bottom of Unconsolidated Strata.

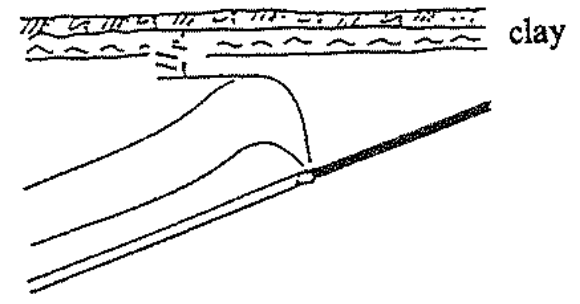

d; Uniform Clay Distribution in Unconsolidated Strata.

Figure 2.17: Types of protective coal layer (Bai et al., 1995) 


\subsubsection{Surface Zone}

There is no real data to express the depth of this zone. In Figure 2.15, Bai et al. (1995) lists the extent of surface zone to $50 \mathrm{ft}$. However the actual depth is reliant on the type of properties in the strata. Soils are plastic in nature and will show very little fracturing but will show subsidence. Rock layers in this zone will show fracturing but natural fractures already exist in this zone. This will not cause any additional effects. The fractures in this zone are not expected to cause any additional water transfer into the fractured zone except in shallow mined areas.

Booth (2002) describes a shallow zone of open fracturing. This is due to the unconstrained properties of the material.

\subsection{Analysis of Stress-Relief Fracturing for Modeling Underground Mining near Surface Water Bodies}

Natural stress-relief valley fracturing occurs when the load conditions on a valley floor are removed or eased. The release causes upheaval within the underlying layers which causes fracturing and patterns of high transmissivity. This pattern may be similar to man made conditions created by underground mining. This report provides a discussion of the similarities between the two and how finite element modeling may be used to effectively reproduce these conditions.

\subsubsection{Stress Relief Fracturing In Appalachia}

In Twin Falls State Park, WV, a hydrologic study was performed by Wyrick and Borchers (1981) to determine how fracture systems affect the occurrence and movement of groundwater. The study area was a 3 mile long valley approximately $400 \mathrm{ft}$ to $600 \mathrm{ft}$ wide. The geology of the area is sandstone with interbedded thin coal and shale layers. Research was performed to gain understanding of how fractures within rock layers affect groundwater flow.

Twin Falls State Park, while located in a heavily mined part of the state, has not been mined under. Coal mining may create unnatural stresses and fracturing within the overburden which could manipulate the research results. Additionally, all pumping within the valley is maintained by the park service, allowing for controlled testing. The closest tectonic feature, an anticline, is approximately 5 miles northeast. Anticlines have fracturing along the axis and which affects groundwater infiltration. However given the proximity, it was unlikely to have a significant 
effect on the study location. The park is also very similar both topographically and geologically to other regions within the Appalachian Plateau.

The geologic profile of this location allowed for the study of aquifers as they relate to fractures within the rock.

The system used for study of this location was referred to as the STOP (Sequential Thematic Organization of Publications) system. Benefits of understanding the hydrologic effects of stressrelief fracturing are (Wyrick and Borchers, 1981):

- Better well site locations can be selected

- Better understanding of dispersion of contaminants from landfills and injections wells into aquifers

- Understanding of water losses from reservoir and seepage from locks and dams

- Inflow into deep mines underlying valleys may be estimated

- More effective monitoring design for strip mine benches. Strip mine benches may expose slump fractures and allow more surface water to seep into aquifers. Conversely, impermeable material may reduce the inflow of surface water.

\subsubsection{Test Sites}

There were two sites tested in the study by Wyrick and Borchers (1981); one in the upper region (Test Site 1) and one in the lower central region (Test Site 2). Initially, three wells were drilled at Test Site 1 for observation and aquifer testing. However, as research continued, more holes were drilled. Additionally, geophysical testing and stream fluctuation studies were performed. As the State Park owned the test locations, pumping of the wells was able to be performed under controlled conditions.

\subsubsection{Topography}

Black Fork, a tributary of Cabin Creek, is a 3 mile long stream that flows through a $400 \mathrm{ft}$ wide valley in Twin Falls State Park. The valley floor of Black Fork is composed of two sections; above and below Black Fork Falls. Above the falls the valley floor is composed of mainly sand and clay, grading to a dense clay layer at depth. It is gently flowing with a gradient of approximately $25 \mathrm{ft}$ per mile or 0.0047. Below Black Fork Falls, the gradient is 18 times as steep 
(approximately 0.085) and flows over a hard sandstone layer, unlike the alluvium found above the falls.

\subsubsection{Stress-Relief Fractures}

Compressional stress in rock is caused by the weight of overlying rock layers and sediment. When the overlying rock is removed due to surface water flow or other forms of erosion, this compressional stress is reduced. However, in locations such as valley floors, the overburden is only removed within a portion of the bedding plane; the rest remains under compression. This may cause the reduced stress location to heave or arch in the valley floor (Figure 2.18).

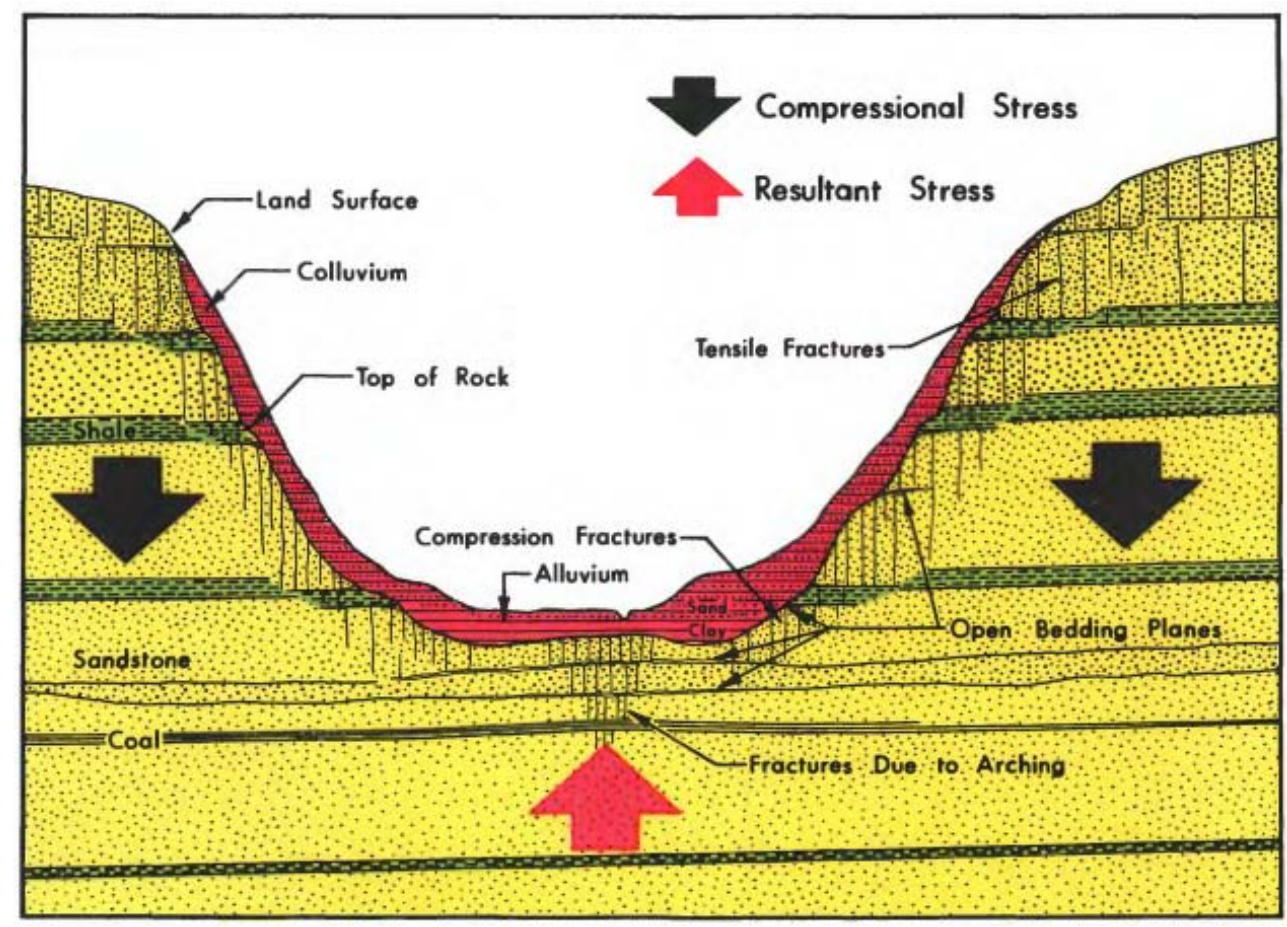

Figure 2.18: Stress relief fracturing (Wyrick and Borchers, 1981)

The arching of the upper layers of the valley floor creates fracturing and separation between the bedding planes as well as minor fractures at the crown of the arch. On the valley walls, reduced horizontal stress creates tensile fractures and slumping. The slump creates compressional fractures at the base where the walls meet the valley floor. 


\subsubsection{Test Site 1}

Test site 1 was located in the upper region of Black Fork Valley. Four wells were drilled in a diamond formation into similar geologic profiles to determine the permeability changes parallel and perpendicular to stress fractures in the valley (Figure 2.19). Wells J68, 002 and 003 were drilled into the confined bedding plane fractures beneath the valley floor. Well 001, is located within the slump fractures of the valley walls which are unconfined. Well J68, located on the western portion of the site was pumped at a rate of 70 gallons per minute and 20 gallons per minute. The effects were observed at the other wells. The permeability was determined to be approximately equal in observation wells 002 and 003 based on drawdown. However, the actual transmissivity and storage coefficient could not be determined.

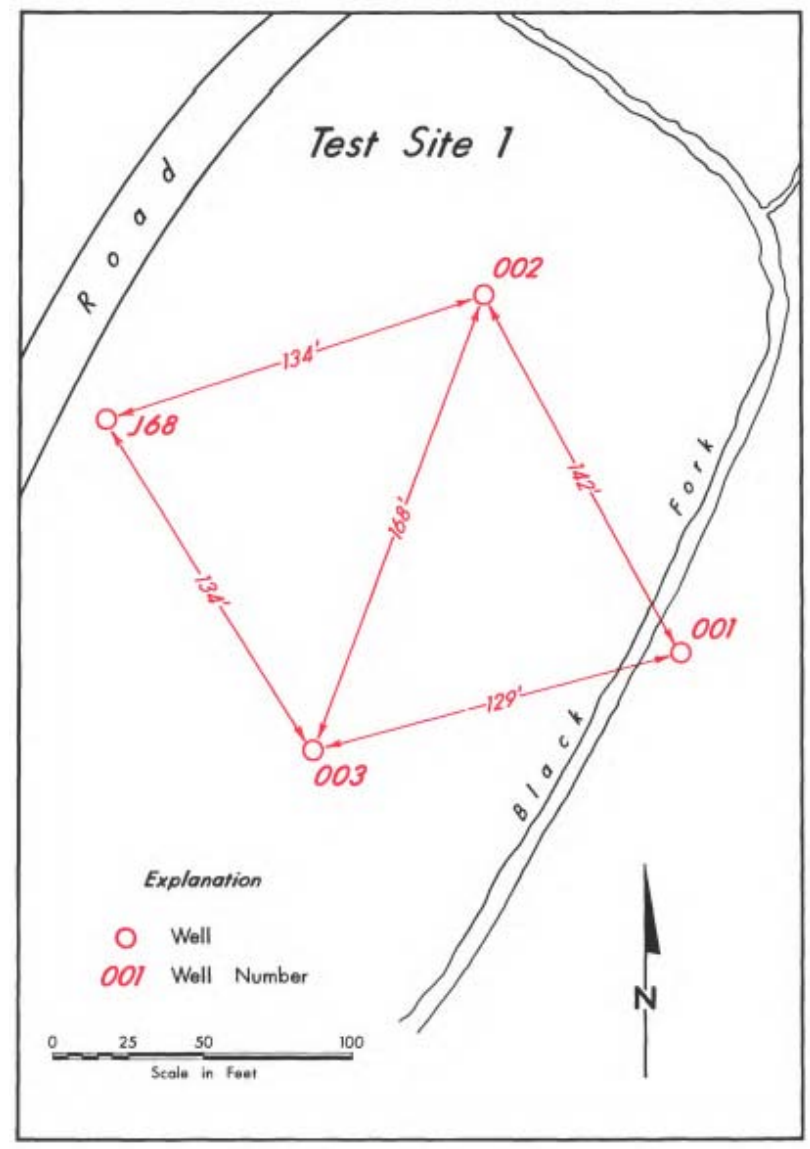

Figure 2.19: Test well locations at site 1(Wyrick and Borchers, 1981) 
Relative velocity is the flow rate within a well to a pump intake. If the well is in an isotropic location with uniform permeability, the relative velocity would gradually increase from the bottom of the well to the intake. However, if fractures are adjacent, the velocity would spike when reached by the water level. At well locations 002 and 003, this occurred between 50 and 60 $\mathrm{ft}$, indicating stress relief fracturing. At 40 to $45 \mathrm{ft}$, the flow velocity decreased indicating caving within the well. At 001, no groundwater flow was observed below $30 \mathrm{ft}$. This showed that fracturing that located at observation well 001 was different that that of 002 and 003 . From this comparison, it could be determined that there were different forms of stress-relief fracturing occurring; shallow at well 001 and deeper bedding plane separation at 002 and 003.

On October 27, 1977, Well 003 was pumped at a rate of 6 gallons per minute. Observation of the Wells 003 and J68 showed drawdown occurred within 35 seconds while Well 001 didn’t show drawdown until approximately 4 minutes. The delayed drawdown was due to the shallow, unconfined slump fractured aquifer it penetrates at the intersection of the valley wall and floor. Once the drawdown was observed at all three observation wells, the rate was uniform indicating high transmissivity throughout the test location (Figure 2.20).

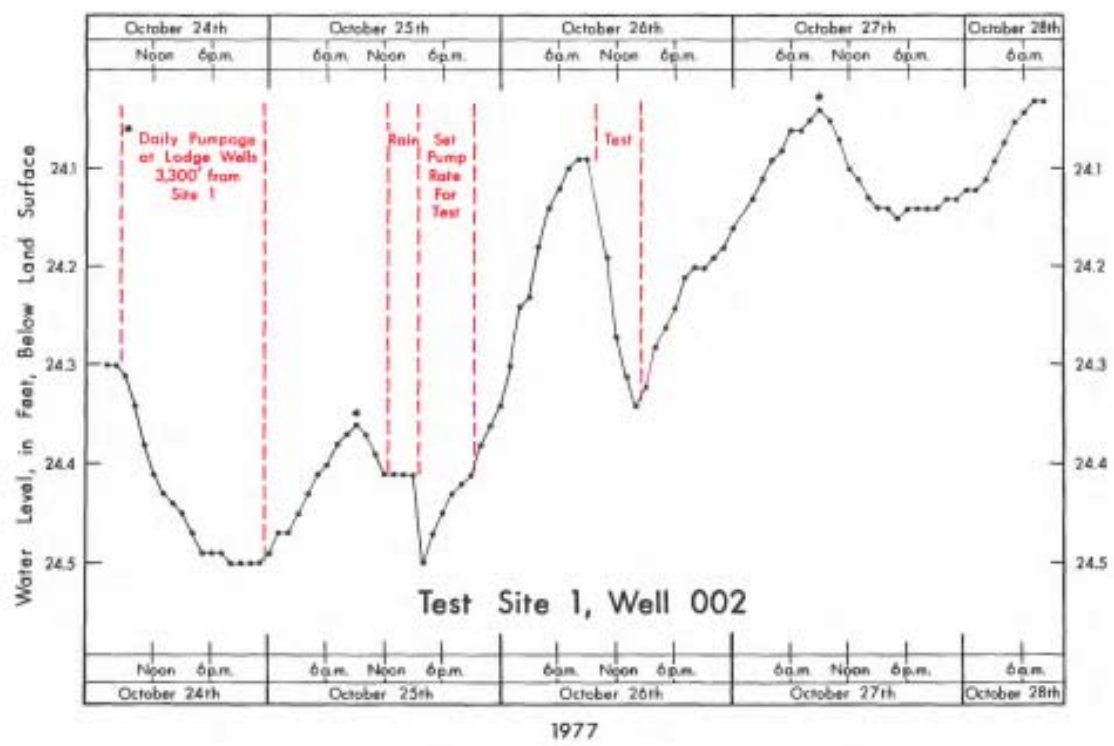

Figure 2.20: Test site 1, water level (Wyrick and Borchers, 1981) 
While the actual transmissivity of the test site could not be conclusively determined, the results show the area to be highly transmissive bounded by lower transmissive aquifers and impermeable layers. This profile accurately depicts the hydrogeology caused by stress-relief fracturing where the valley floor is under confined aquifer conditions while the walls are unconfined.

\subsubsection{Site 2}

Located in the lower central part of the Black Fork Basin above Black Fork Falls, two wells were drilled at Test Site 2. This location was in a narrow strip of the valley approximately $200 \mathrm{ft}$ wide. Well A was drilled near the center of the valley while Well B was drilled about halfway between Well A and the valley wall.

Pumping tests were performed on Well A at a rate of 20 gallons per minute. As with Test Site 1, large increases in relative velocity indicate locations of stress relief fracturing and bedding plane separation; which occurred at 22, 33 and $52 \mathrm{ft}$. This indicated that the hydrologic system at Test Site 2 was similar in nature as that of Test Site 1.

On November 28, 1978, slug tests were performed on both wells. Slug tests consist of adding a pre-determined amount of water into a well and measuring the amount of time taken for the fluid to transmit into the bedding layers. It essence it is the opposite of a pumping test but is used to determine the same values; transmissivity and storage coefficient. At Test Site 2 the results showed a local impermeable boundary affecting the type curve. When no impermeable boundary conditions exist, the type curve will be an even and consistent. However, if the added water reaches an impermeable boundary, it can no longer seep into that location. This results in the head loss in the well occurring gradually over a longer period of time. This also makes it more difficult to determine transmissivity and storativity. At the time that this site was analyzed, these values were not able to be determined. However, advances have been made through research and technology and these values could be closely estimated using computer software of today. As with Test Site 1, it was determined that the region was highly transmissive; though the exact extent was not known. 


\subsubsection{Lodge well Testing}

On October 26, 1977 pumping occurred from a lodge well $3300 \mathrm{ft}$ away from Well 002. The pumping occurred at a rate of 17 gallons per minute and lasted for 9 hours. Over the course of this timeframe, a drawdown of $0.2 \mathrm{ft}$ was observed. On February 21, 1979 the well was pumped at the same rate for 5 hours in which Well 002 experienced a drawdown of approximately $0.1 \mathrm{ft}$. During this event, Well A, located approximately $2400 \mathrm{ft}$ away, showed a drawdown of approximately $0.8 \mathrm{ft}$ (Figure 2.21). Given that both wells were affected by the same pump test, the entire research site is identified as being located on a continuous aquifer. It also showed that in areas of stress relief fracturing, drawdown can have a far reaching effect on groundwater levels.

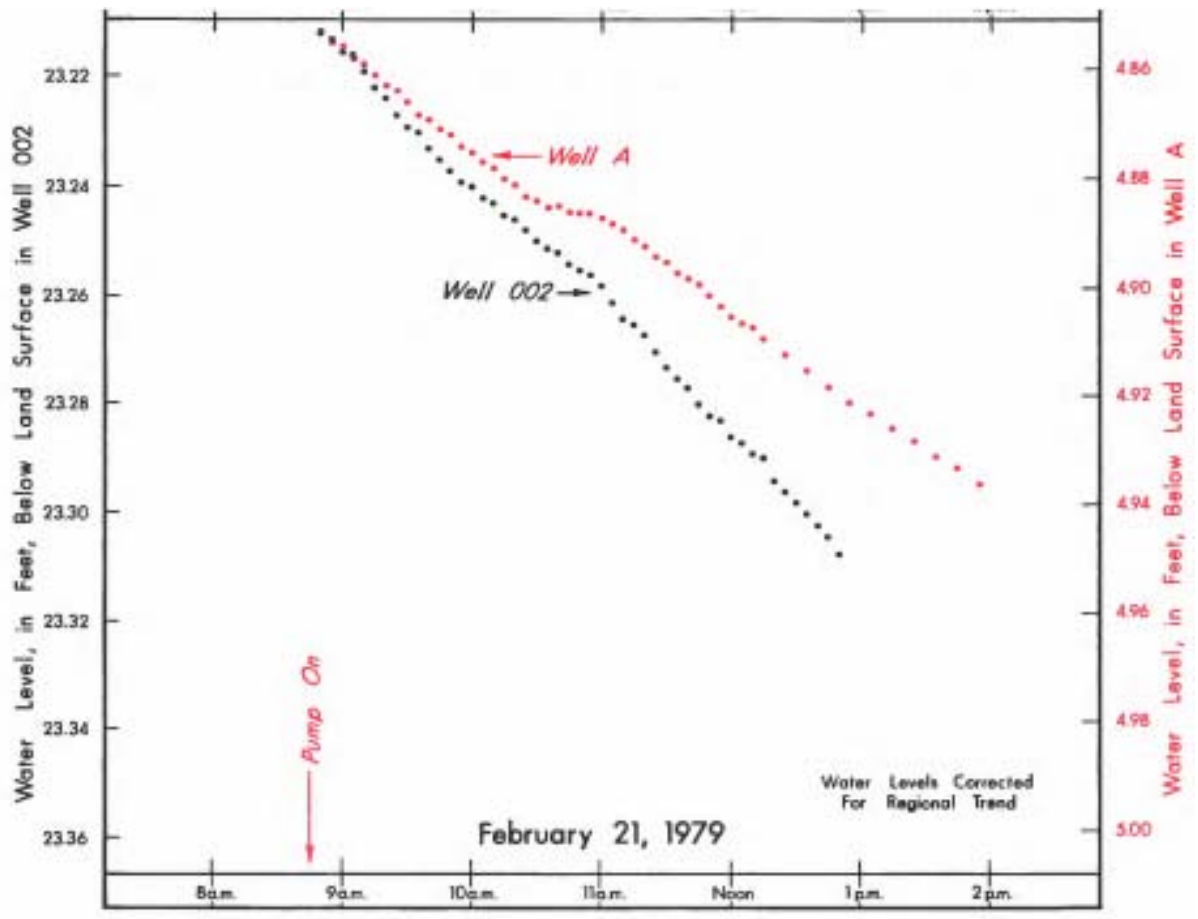

Figure 2.21: Well A drawdown (Wyrick and Borchers, 1981)

Below the falls, the bedding plane fractures outcrop into the streambed. The added fractured flow created stream runoff at a rate of 6 to 11 times the flow above the falls. However, this rate was directly affected by the head levels within the confined aquifer zone. It was observed that the 
level of increased flow from the fractured zones changes proportionally to the head levels in Wells A and 002.

\subsubsection{Test Site Conclusions}

The tests performed at Twin Falls State Park showed the entire valley floor region above Black Fork Falls to be a stress relief fractured, confined aquifer overlain by clay and silts. The fractured bedding planes were highly transmissive and could be affected from the entire aquifer region. The valley walls are exposed to slump fracturing and create shallow unconfined aquifers where the walls intersect the valley floor. Below the falls, the fractured beds outcrop into an unconfined state. This greatly increases the stream flow due to the permeable nature of the fractured rock (Wyrick and Borchers, 1981).

\subsection{Seepage}

Kendorski (1993) described the methods taken to develop the 5 zones (See Section 2.17) that are used. The scope is based on his 1979 report that investigates the hazards of mining to surface bodies of water using over 65 case histories that show how strata behavior was projected and reported. It became clear that the behaviors were determined differently depending on whether the researcher was looking at it as water intrusion into the mine or water loss from surface or ground waters.

In the 65 studies performed, the surface cracking was measured to be shallow at 2 mines (16ft and 30ft) but eight others that had this measurement showed at least $50 \mathrm{ft}$ of surface fracturing. The angle of influence (thought to be approximately 23 degrees (DEP, 2009)) was actually in excess of 40 degrees in some regions.

The surface subsidence is almost imperceptible and is seen as a trough with fracturing occurring generally at the edges. Below the surface, there will be bending and fracturing of the strata. The extent is dependent on the proximity, both horizontally and vertically, to the mine. The extent of the angle of influence is dependent on the strata conditions. 


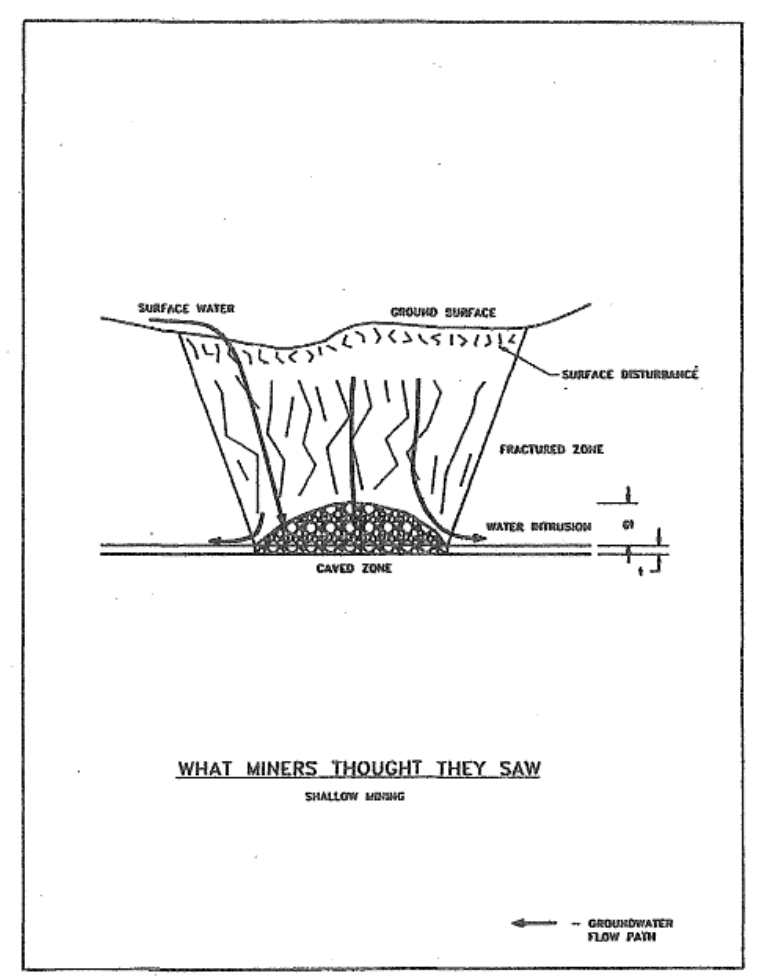

Figure 2a. Mining Viewpoint - Shallow Works.

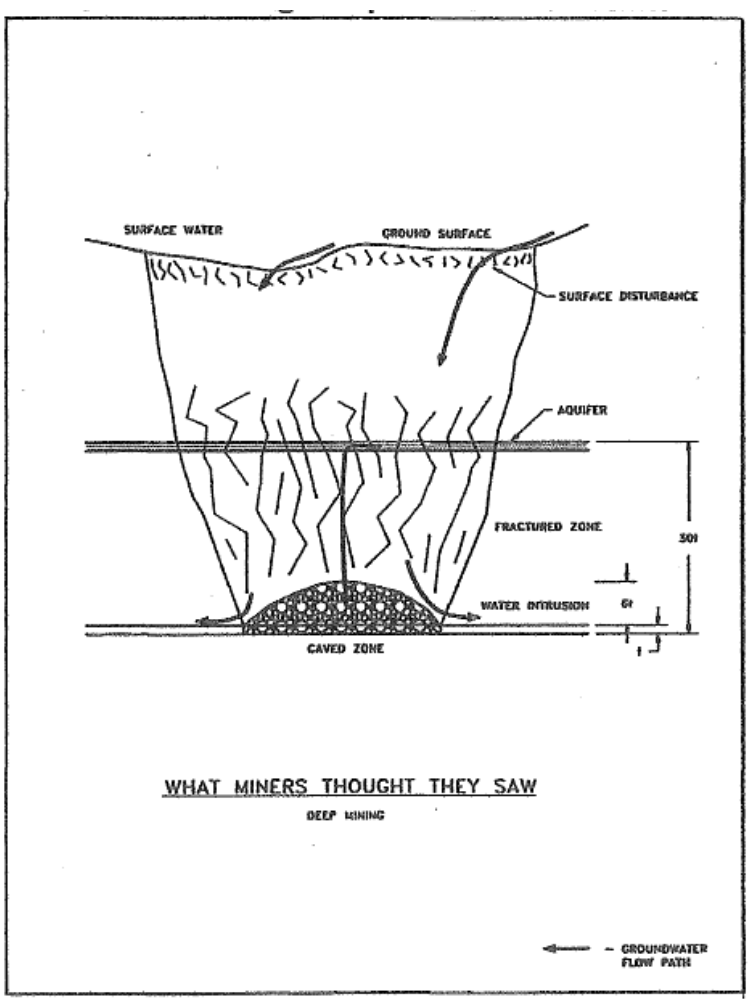

Figure 2b. Mining Viewpoint - Deep Works.

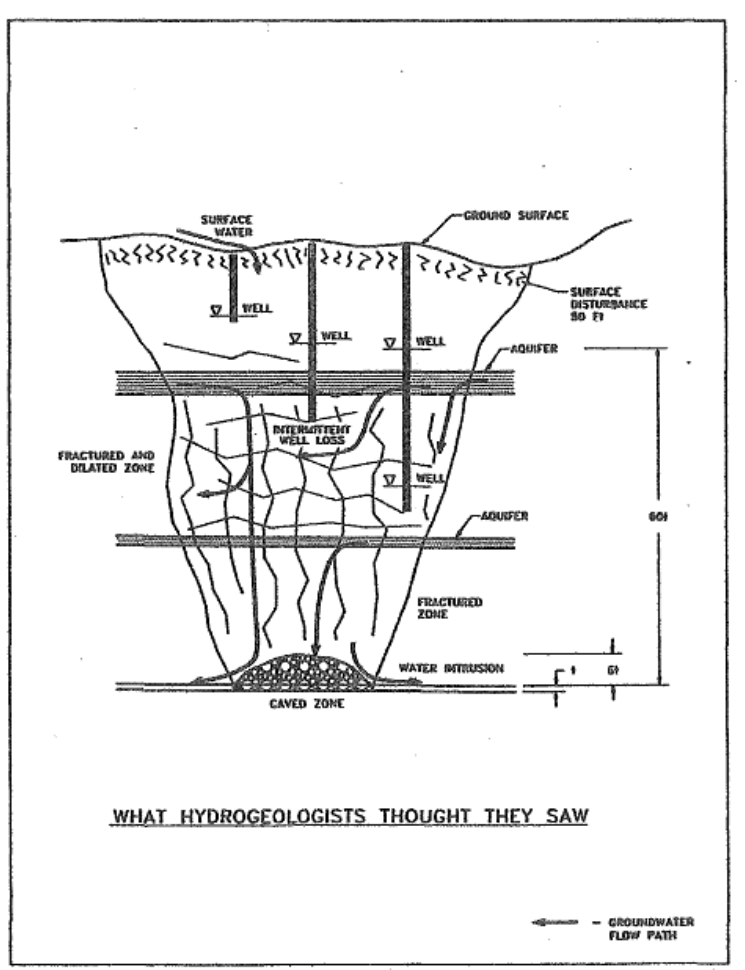

Figure 3. Well Observation Viewpoint.

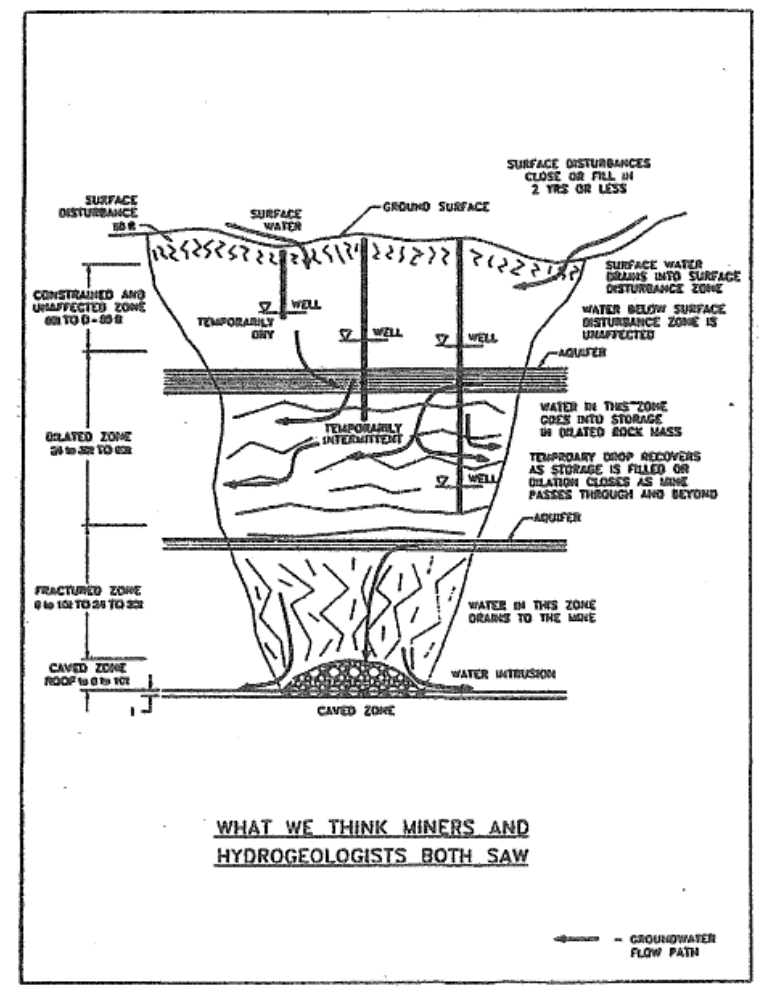

Figure 4. Present Concept of Strata Disturbance Zones.

Figure 2.22: Seepage and groundwater flow observations (Kendorski, 1993) 
Kendorski (1993) identified that literary resources came from two perspectives;

Protecting mines from inrushes of surface waters and ground waters so that the tendency was to look "up" the strata until the problem became minimal (Figure 2.22).

Protecting surface and shallow ground waters from the effects of mining so that the tendency was to look "down" the strata until the problem became minimal (Figure 2.22).

The result of these two different viewpoints is that the fractured zone was determined to be far greater in size than in actuality.

\subsubsection{Caved Zone}

The caved zone is shown as being 2 to 10 times the seam height. In weaker strata such as shale it is closer to 10 times where in stronger strata such as sandstone or limestone is generally 6 or less times the seam height. The paper also mentions that shale tends to encourage cave development by minimizing void space. Surface collapse can occur in shallow mines if the depth is less than the predicted cave zone. If within the Caved zone plus $50 \mathrm{ft}$ surface fracturing will occur creating a continuous path for water to flow into the mine.

\subsubsection{Fractured Zone}

The fractured zone is where the strata "crack and settles". It is in this zone that separation, vertical fracturing through entire beds and shearing occur. In the sites that were used, the top of this zone was generally in the 24 to 30 times the seam thickness range. If the fractured zone is within $50 \mathrm{ft}$ of the surface, there will be a direct link to the surface water and the mine for flow to occur. There have been reports of greater ratios than $30 t$ but these results are open to interpretation as to how the data was collected.

The mine seam height is usually less than $6 \mathrm{ft}$ when high ratios fracturing occur. Seams less than $6 \mathrm{ft}$ in thickness usually result in ratios thicker than 40t. Kendorski (1993) determined a straight line approximation to define this. 
$\mathrm{R}=75-14.3 \mathrm{t}$ (in meters)

$\mathrm{R}=75-9.2 \mathrm{t}$ (in feet)

Where

$\mathrm{R}=$ ratio of height of disturbance to mine seam height.

$\mathrm{T}=$ mined seam height

The relationship shows that the fractured zone is dependent on mined seam height but is approximately 120-140ft for all seams up to $6 \mathrm{ft}$ in height. They therefore concluded that the range will extend upwards to $24 \mathrm{t}$ above the mined seam height.

\subsubsection{Dilated zone}

The dilated zone or aquiclude zone is the region within the strata layer that has the ability to “prevent or minimize the intrusion of ground or surface waters into mines” (Kendorski, 1993). The dilated zone occurs through bending or sagging. The beds in this zone separate due to vertical strains. The dilation occurs laterally by elastic strains deforming the strata with little or no fracturing. Kendorski (1993) reported that sandstone will fracture at $0.1 \%$ extensional strain or $0.001 \mathrm{ft} / \mathrm{ft}$. Below this level of strain the layers will behave elastically with significant pathways opening up. The data shows that this region has an extent to $30 \mathrm{t}$ to $60 \mathrm{t}$, even up to $100 \mathrm{t}$. The sagging in this zone allows for water to be stored but not flow vertically. Wells and streams will see a drop in water level as the water fills this region. However, once the dilated zone is filled with water the surface levels will go back to normal. If the mine is within 24 to $60 t$ plus $50 \mathrm{ft}$ of the surface, water could drain into the dilated zone.

The projection is that the water loss from the shallow overburden will pool in the dilated region and not seep vertically downward. Water will seldom seep into the mine through this zone. It also explains that the water can eventually be recovered (water levels return to normal) through "closing of dilations by mine subsidence progression away from the area, or filling the additional void space created, or both”. 


\subsubsection{Constrained Zone}

The constrained zone occurs when the mine is deeper than $60 \mathrm{t}$ plus $50 \mathrm{ft}$. This is because the strain in this area is not sufficient to dilate and increase storage potential. The strains in this region are characterized as less than $0.1 \%$ (0.001 in/in). This is the point that rock masses are not disrupted enough to increase their permeability. Kendorski (1979) determined that this zone should be made of mostly shale so "fracturing is more difficult to develop and is to some extent self-healing”.

To separate surface water bodies or shallow aquifers from the fractured zone a minimum aquiclude zone must exist. The aquiclude zone consists of the dilated and confined zones. The critical thickness of this zone depends on topography, structure and lithology (Booth, 2002).

Using finite element modeling, Elsworth and Liu (1995) determined for separation between shallow aquifers and highly permeable fractured material the distance should be $90 \mathrm{~m}$ under valleys and 150m under hilly terrain. In a shale dominated region of Illinois this was found to be only 60m (Booth, 2002).

\subsubsection{Surface Fracturing}

There are few actual measurements for surface fracturing. This fracturing generally occurs at the edges of the subsidence trough in the tensile zone. The most reliable determinations of the depth of this zone are approximately 50-60ft. This zone is considered continuous for fracturing and water flow from the surface.

In the Illinois basin there were found to be no changes in water levels or permeability in glacial materials but found widely-spaced surface cracking developed parallel to mine panel edges with strain of 0.006 to 0.009 in/in. The cracking occurred to depths of 20-30ft and did not provide sufficient pathways for water to reach the subsurface (Kendorski, 1993).

Studies on surface cracking have shown the impacts may persist up to 3 years. This occurs from natural weathering or stream sediment. In Utah the closing occurred at a rate of 1/16in a day (Kendorski, 1993).

Higher levels of the fractured zone might have been suggested because there is some minor fracturing occurring in the dilated zone (Kendorski, 1993). If samples from drilling show 
fracturing in this area it might be considered to be part of the fractured zone. However these fractures are generally small and do not penetrate the length of the strata layers.

\subsection{Groundwater Influence}

The hydrological response to underground coal mining can be separated into three zones (Booth, 2002, 2006):

- Lower heavily fractured zone creating high permeability. In this zone, wells lose their water as the groundwater drains directly into the mine through vertical fractures. This corresponds to the Caved and Fractured Zones detailed previously. Thickness of this zone is $1 / 3$ to $1 / 2$ the width of the panel or 20 to 60 times the thickness of the coal seam.

- Intermediate zone containing little fracturing. The strata in this zone subside uniformly maintaining a low permeability region; typically found in shale.

- The near surface zone contains in situ fracturing. In this zone, aquifers are affected but groundwater does not flow into the mine. Head loss in this zone is often significant but temporary.

Pervious mining under lakes and seas have been successful due to the presence of an intermediate zone (Booth, 2002). It creates a buffer between the surface water and the highly permeable fractures directly above the mine void.

Studies have shown that the typical response from underground mining to potentiometric heads is a rapid, but often temporary decline. These changes are caused by the increase in fracture porosity and the change in hydraulic gradients (Booth, 2002).

The head drop in the overburden is transmitted further and occurs gradually in more transmissive units, whereas in poorly transmissive units it occurs suddenly and closer to the site and time of undermining (Elsworth and Liu, 1995). 
According to Bai et al. (1995) there are several fractured zones to be considered:

Severely: In the severely fractured zones, the flow rate is greater than $1.0 \mathrm{~L} / \mathrm{sec} / \mathrm{m}$

Moderately: In the moderately fractured zone, the flow rate is between $0.1 \mathrm{~L} / \mathrm{sec} / \mathrm{m}$ and $1.0 \mathrm{~L} / \mathrm{sec} / \mathrm{m}$

Slightly: Only small fractures occur in the strata. Flowrates are less than $0.1 \mathrm{~L} / \mathrm{sec} / \mathrm{m}$

There is a hydraulic division of the overburden, broken into three layers. Corresponding to the Caved and Fractured zones is a heavily fractured and highly permeable zone. This layer is expected to drain into the mine through voids and vertical fractures.

In the intermediate zone, there is less fracturing and the strata generally maintain low permeability conditions. The presence of this zone is critical in longwall hydrology.

In shallow aquifers, the changes are generally due to in situ property changes that do not drain into the mine. This is due to the intermediate zone of low permeability strata that maintains its pre-mining properties, separating the mine void with the shallow aquifers. Due to this, there will be changes in the hydraulic properties within the shallow strata that may not perpetrate into the mine (Booth, 2002).

In modeling simulation, Elsworth and Liu (1995) simulated a zone of vertical separation in the lower strata directly over the panel and zones of shear failure and increased permeability in the abutment region and the near-surface zone at the sides of the panel.

As the longwall face passes, the layers of the overburden begin to separate and permeability increases. The interior of the longwall trough undergoes tension then compression, causing the fractures to partially close, decreasing permeability from the tensional peak down. On the outer edge of the trough, the overburden only undergoes tension as the subsidence wave passes (Elsworth and Liu, 1995). This creates an area of increased permeability regardless of the interior compression The actual permeability changes within the strata depend on the location, both vertically and laterally, to the mine.

Two sites were measured for permeability changes as the longwall face approached (Elsworth and Liu, 1995). At one site (Lynemouth) permeability changes began when the mine face was 
70m away. Hydraulic conductivities were initially $1 \times 10^{\wedge}-7 \mathrm{~m} / \mathrm{s}$, increased by an order of magnitude, then settled at about $2 \times 10^{\wedge}-7 \mathrm{~m} / \mathrm{s}$. This mine was at a depth of $207 \mathrm{~m}$ with permeabiltiy changes tested between $15 \mathrm{~m}$ and $55 \mathrm{~m}$ above the mine. At the Wentworth site $(54 \mathrm{~m}$ mine depth, $20 \mathrm{~m}-47 \mathrm{~m}$ above mine) permeability fluctuations increased from $2 \times 10^{\wedge}-9 \mathrm{~m} / \mathrm{s}$ to $9 \times 10^{\wedge}-8 \mathrm{~m} / \mathrm{s}$ then declined to $2-5-5.2 \times 10^{\wedge}-8 \mathrm{~m} / \mathrm{s}$.

In a study conducted in Illinois the hydraulic conductivity in a sandstone aquifer approximately $650 \mathrm{ft}$ above a $10 \mathrm{ft}$ coal seam increased one order of magnitude (Booth and Spande,1992). These results are shown in Table 2.09. The normal responses of a shallow aquifer due to subsidence include rapid decline with partial recovery of head levels and increased permeability

Table 2.9: Pre- and post-subsidence hydraulic conductivity (Booth and Spande, 1992)

\begin{tabular}{cccccc}
\hline & \multicolumn{2}{c}{$\begin{array}{c}\text { Presubsidence tests } \\
\text { Duration } \\
\text { (mins) }\end{array}$} & $K$ & \multicolumn{3}{c}{$\begin{array}{c}\text { Postsubsidence tests } \\
\text { Duration } \\
(\mathrm{cm} / \mathrm{s})\end{array}$} & No. & $\begin{array}{c}K \\
\text { (mins) }\end{array}$ & $(\mathrm{cm} / \mathrm{s})$ \\
\hline 2 & 13 & $2.0 \times 10^{-6}$ & 6 & 32 & $4.9 \times 10^{-5}$ \\
4 & 68 & $1.7 \times 10^{-5}$ & 7 & 66 & $3.4 \times 10^{-5}$ \\
5 & 239 & $3.3 \times 10^{-6}$ & 8 & 258 & $3.7 \times 10^{-5}$ \\
\hline
\end{tabular}

Changes in permeability are related to subsidence both spatially and temporally; however, topographic relief and lithological variation affect this. The changes due to subsidence create one of two conditions: when the permeability is increased by subsidence related fracturing, the hydraulic gradient in the affected area must decline or the specific discharge must increase. Up gradient of the affected area will see a decline in head while down-gradient area may see an increase in head or groundwater discharge. Within the discharge areas, there will likely be an increase in spring and stream flow; up-gradient there will be head loss and decrease in stream flow (Booth, 2002).

Unlike porosity, changes in permeability permanently affect groundwater flow.

In field tests, hydraulic conductivity increased 2-3 orders of magnitude in shale and 1 order of magnitude in sandstone (Kelleher, 1991). This caused the head in wells to decrease when the mine was $610 \mathrm{~m}$ away. However these levels recovered after only 3 months. At a second field site head loss occurred $457 \mathrm{~m}$ laterally from the mine. This site contained thin layers of sandstone that 
did not have the storage capacity to return levels to its pre-mining conditions, thus permanently affecting the site.

Subsidence can affect permeability in the subsurface in multiple ways. It can create an area of compression above the mine causing an area of pooling. In areas of tension located within the area of draw, strain values will increase permeability. Both of these instances will allow for changes on subsurface water flows outside the angle of draw. The area affected is called the angle of groundwater influence. Like the angle of draw, this range develops at an angle extending outwards from the extents of the mine.

\subsection{Piezometric Response}

\subsubsection{Piezometer Stages}

The approach of a longwall mine is detailed in Figure 2.13. At the face there is substantial fracturing and tension in the overburden with bedding separations. Behind is a confined zone supported by collapsed material. Tension and compression zones are shown laterally within the subsidence wave.

Booth, et al. (2000) describes the stages of the water level in an piezometer as a longwall mine face approaches. These stages are numbered on Figure 2.13.

1. Static Level. At this location the water level is beyond influence of the approaching mine face

2. Initial response. The head level begins to decrease due to potentiometric lows within the subsidence zone. The lateral distance of this response is dependent on the transmissivity of the rock

3. Gradual decline of head level. The decline accelerates as the mine face approaches

4. Phase change. At this point the water level is abruptly influenced by physical changes within the overburden rather than drawdown. The phase change is due to tensional fracturing that occurs immediately after mining

5. Maximum head drop. Subsidence creates large amounts of porosity due to fracturing and bedding separation. The location of this stage is at the area of maximum tensional strain. 
The severity of the change in potentiometric head is influence by the type of overburden and amount of fracture porosity

6. Compression of fractured material creating a rapid partial rise in head levels

7. Gradual recovery of head levels. Timeframe of recovery is hard to predict. Generally several months to several years for full recovery, however recovery may never occur

\subsubsection{Topographical Permeability Zones}

According to Elsworth and Liu (1995) there are three zones for increased permeability. These are described below and used in their modeling techniques.

Zone 1 Suprapanel Zone: Area located directly above the mine panel

Zone 2 Abutment Shear Zone: Area of permeability change located at edges of mine panel where shear occurs. The increase in hydraulic conductivity in this zone is vertical in nature.

Zone 3 Surface Zone: Area of increased hydraulic conductivity at the ground surface above the mine panel. The increased permeability is predominately in the horizontal direction in this area

Figure 2.23 details these three zones given different mining conditions under the same geometric setting (Elsworth and Liu, 1995). In Sub-plateau (a) the mine is beneath a flat or level surface area, (b) is located below a hilltop and (c) is located beneath a valley. Each condition affects the zones of permeability increase as described above.

The range of Zone 1 increases from a flat setting to a rolling terrain setting. At plateau conditions the thickness of Zone 1 is between 20 and 40 times the thickness of the coal seam. Under a hilltop this increases to potentially 60 times the thickness of the coal seam with the range for a valley setting being between 30 and 60 times the seam thickness.

Zone 2 is located in the shear abutment zone. Under plateau and hilltop conditions the vertical range is between 60 and 80 times the seam thickness. For a sub-valley setting this range may extend to 140 to 220 times the panel thickness. 
The surface zone (Zone 3) extends from ground level down. For a flat terrain the zone is between 24 and 30 seam thickness. In hilltop and valley settings this may increase to 60t with a minimum of $40 \mathrm{t}$ and $30 \mathrm{t}$ respectively.

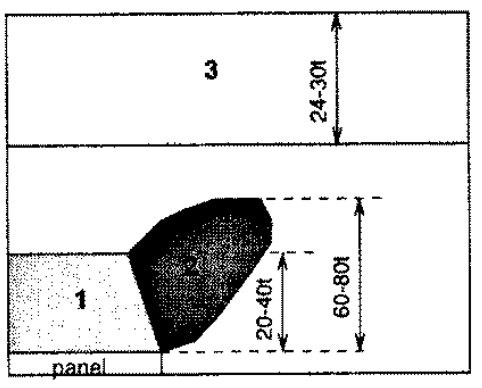

(a). Sub-plateau setting

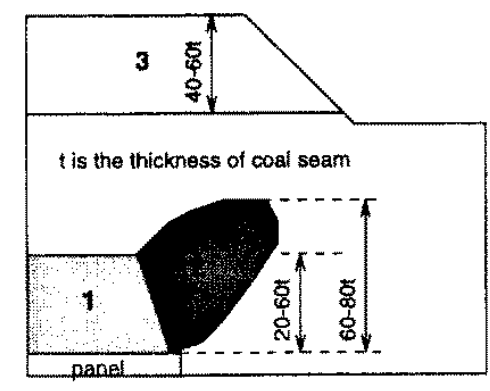

(b). Sub-hilltop setting

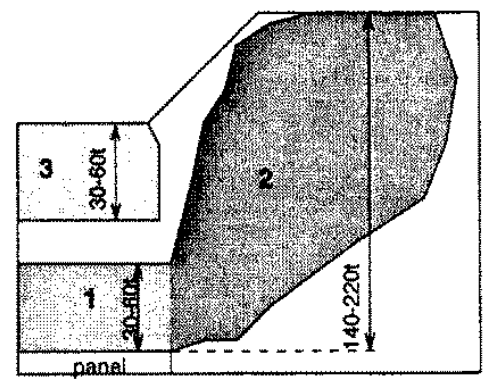

(c). Sub-valley setting

Figure 2.23: Groundwater level changes based on topography (Elsworth and Liu, 1995)

In the sub-plateau setting, increased hydraulic conductivity in Zone 1 and Zone 3 is predominately in the horizontal direction. In Zone 2 the changes are in the vertical direction.

In the sub-hilltop and sub-valley settings Zone 1 will experience increased permeability both horizontally and vertically. The change in Zone 2 is vertical while the change in Zone 3 is in the horizontal direction.

\subsubsection{Water Well Classification}

Water wells within proximity to a longwall panel can be classified into three different categories. These categories are based on the change in hydraulic conductivity and the location relative to charge or recharge based on Finite Element modeling (Elsworth and Liu, 1995).

C1: Wells in this category will show little change in head levels. When only small changes in hydraulic conductivity occur, head elevations may only be affected locally

C2: In this category there is an expectation that phreatic elevations will reduce. In upslope recharge regions where hydraulic conductivities will be increased, the head elevation will be reduced

C3: Wells are expected to remain unaffected or recharged in this category. In downslope of valleys, head elevations will increase when hydraulic conductivity increases 
The location of these well zones with respect to the mine panel and topography are shown in Figure 2.24 for mining below level, hilltop and valley settings. In the sub-plateau setting (a), the separating factor between C1 and C2 is depth. If the well is within 500ft of the mine it is classified as C2, otherwise, C1. If located within 500ft over a mine panel the head loss may be permanent. There is no C3 classification due to lack of slopes to recharge wells. Sub-hilltop classifications are similar to plateau except for the presence of C3 at the bottom of the valley which will experience recharge.

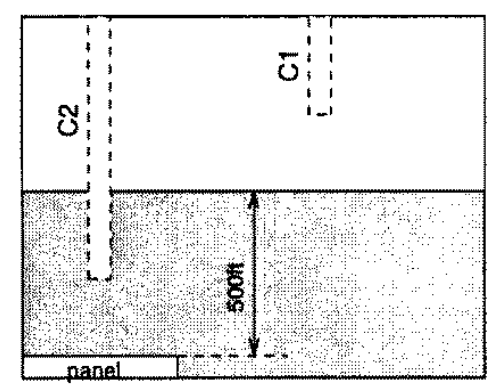

(a). Sub-plateau setting

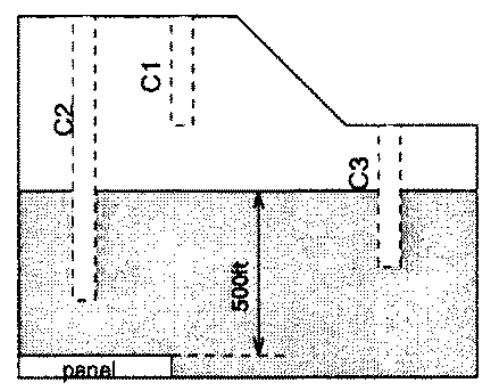

(b). Sub-hilltop setting

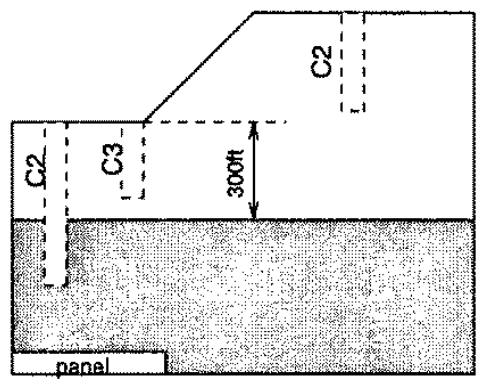

(c). Sub-valley setting

Figure 2.24: Well location based on topography (Elsworth and Liu, 1995)

In the sub-valley setting wells completed uphill of the mine panel are considered C2 wells. In the valley above the panel, wells are considered C2 and likely non-recoverable if the distance from the valley surface is greater than 300ft. If less than 300ft the wells are classified as C3 and will not be affected or likely recharged.

Through the finite Element modeling method, Elsworth and Liu (1995) determined the most likely affected wells were upland class C1 and C2 while the least affected were C3 located in the valley. As the depth of the mine increases, the topographic influence on hydraulic conductivity lessens for sub-hilltop mining. However the other two conditions remained identical between $500 \mathrm{ft}$ and $900 \mathrm{ft}$ depths.

\subsection{Hydraulic Property Changes in Illinois}

In Jefferson County, Illinois a mine site was studied to determine the potential hydrogeologic changes due to subsidence (Booth, 1992). The mine was a 735ft deep active (at time of study) longwall mine with a coal seam of approximately 9 to $10 \mathrm{ft}$ thick. The overburden consisted mostly of shale with a shallow sandstone aquifer. The study site was performed over two 
longwall panels (panels 3 and 4), each 600ft wide and 5,000ft long. Between the panels are 200ft of barrier pillars. Above the mines exists local streams that drain into a man-made lake.

The lithography of the mine site includes mostly shale and siltstone. The shallow aquifer is located in the Mt. Carmel sandstone approximately 75 to 80ft below ground surface. Above the sandstone layer is 40 to $60 \mathrm{ft}$ of shale covered by surface materials.

The study consisted of monitoring existing wells and piezometers for a period of two years (Booth, 2002). Within approximately 2 and one half months, subsidence at the center of the trough was approximately $6 \mathrm{ft}$. Surface fractures approximately one foot wide temporarily opened due to tension. Within the overburden, bedding plane separation occurred between stronger and weaker strata.

During the mining operation, water levels at the center and barrier pillar of panel \#3 declined approximately 20ft and 40ft as the mine face passed to 50 to $100 \mathrm{ft}$ beyond (Booth 1992). These levels increased to approximately $10 \mathrm{ft}$ below the original water levels approximately 3 months later.

The water levels in panel 4 declined from $70 \mathrm{ft}$ to $80 \mathrm{ft}$ to approximately $110 \mathrm{ft}$ below ground level as panel \#3 was mined (Booth, 1992). The piezometers tested were at the centerline of panel 4, representing approximately 500ft from the \#3 panel edge. When panel \#4 was mined, the water levels decreased to $140 \mathrm{ft}$ below ground level, or approximately $60 \mathrm{ft}$ to $70 \mathrm{ft}$ below initial ground conditions. The water levels eventually recovered to preliminary conditions, approximately two and a half years after mine panel \#3 made its closest approach. However stable pre-mining conditions were not reached until 4 years later (Booth, et al., 2000).

A piezometer within the shale at approximately $300 \mathrm{ft}$ deep with a head $60 \mathrm{ft}$ below ground surface initially rose $20 \mathrm{ft}$ before subsidence occurred; after which the water levels fell below $300 \mathrm{ft}$.

The only wells affected during the study period were located either directly above or adjacent to the mine panels. At the conclusion of the study, they had not recovered. However wells using the same aquifer 500ft. away were not affected (Booth, 1992). 
A similar study was performed in Saline County in Southern Illinois on a 122m deep Panel (panel 1). At this site, the piezometric head of a well located 300m laterally from the longwall panel declined 22.5m from pre-mining conditions (Booth, et al., 2000). After 5 years, the well had only recovered $1.5 \mathrm{~m}$. However, wells in glacial till at the same distance had no major head losses.

Panel 1 at the Saline site differed from the site in Jefferson County with less direct fracturing and more localized permeability increases (Booth et al., 2000). The sandstone was deeper and less able to recover through recharge sources.

Panel 5 at the Saline site had no major increases in permeability during the study period. Head level did change significantly in the sandstone. At panel 5, the Travoli sandstone (representing a shallow aquifer) was approximately $20 \mathrm{~m}$ deep and locally outcropped. The piezometers, located above the panel, all showed significant drops in head (Figure 2.25) (Booth, et al., 2000). The approximate drop over the panel was $17 \mathrm{~m}$ and $12 \mathrm{~m}$ over the barrier pillars. These heads did not recover by the end of the study, 2 and a half years later. Piezometer P54, located above a barrier pillar did recover quickly after the mine face passed and settled at approximately $5 \mathrm{~m}$ below premining conditions. Over 2 years later, at the end of the study period, the head in P54 dropped 12m for unknown reasons (Booth, et al., 2000). 


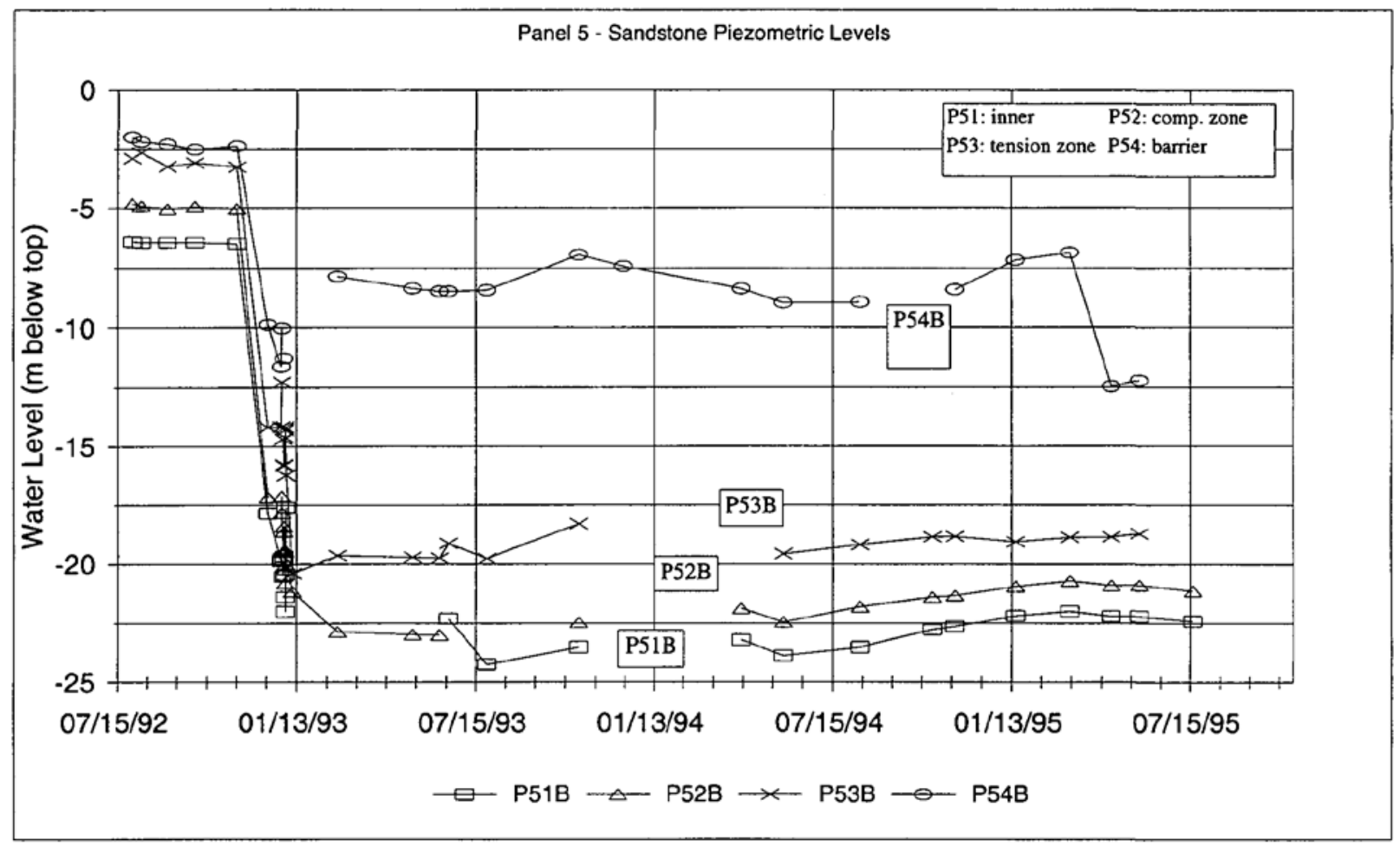

Figure 2.25: Sandstone peizometric levels for panel \#5 (Booth, et al., 2000)

In the deep drift water wells, the piezometer head levels differed depending on the location with respect to the mine (Figure 2.26). In the inner compression zones the head levels overflowed the ground surface, due to compression, immediately before being undermined then settling to a depth of 4.5m (Booth, 2002). The piezometer head at the tensional edges of the panel stabilized at lower depths of $12 \mathrm{~m}$ and $7.6 \mathrm{~m}$ during the study period, approximately $9.5 \mathrm{~m}$ and $5.5 \mathrm{~m}$ below pre-mining conditions.

The total response of head levels over panel \#5 and the barrier pillar is shown in Figure 2.27. The figure shows the pre-and post mining heads for the deep drift ( $\left.d-d^{\prime}\right)$ and sandstone (b -b') subsidence. The levels did not recover to normal conditions. The gradient between P54B and P53B is thought to be due to low transmissivity of the sandstone layer (Booth, et al., 2000). The impact of the stream is not referenced. 


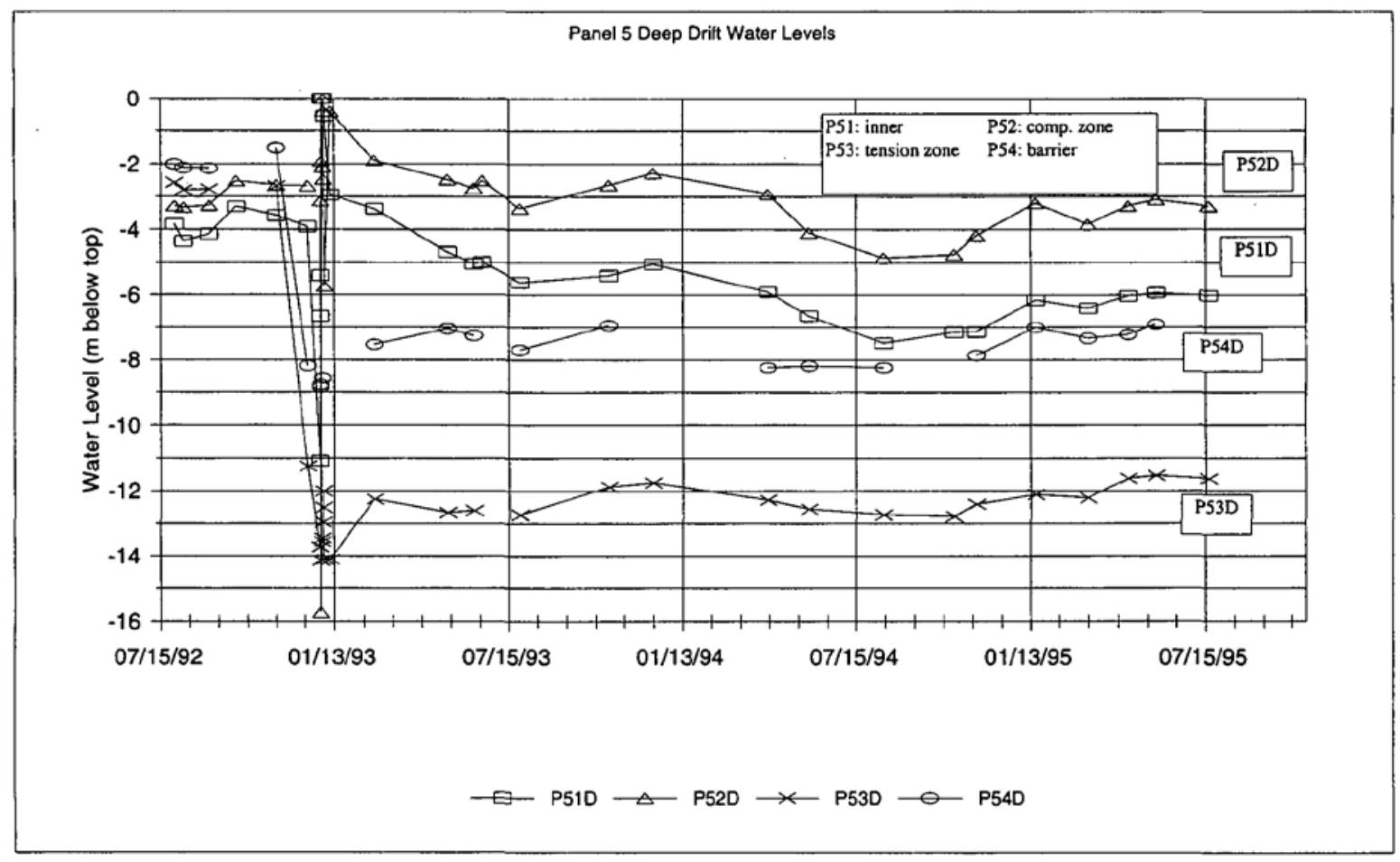

Figure 2.26: Deep drift water levels for panel \#5 (Booth, 2000)

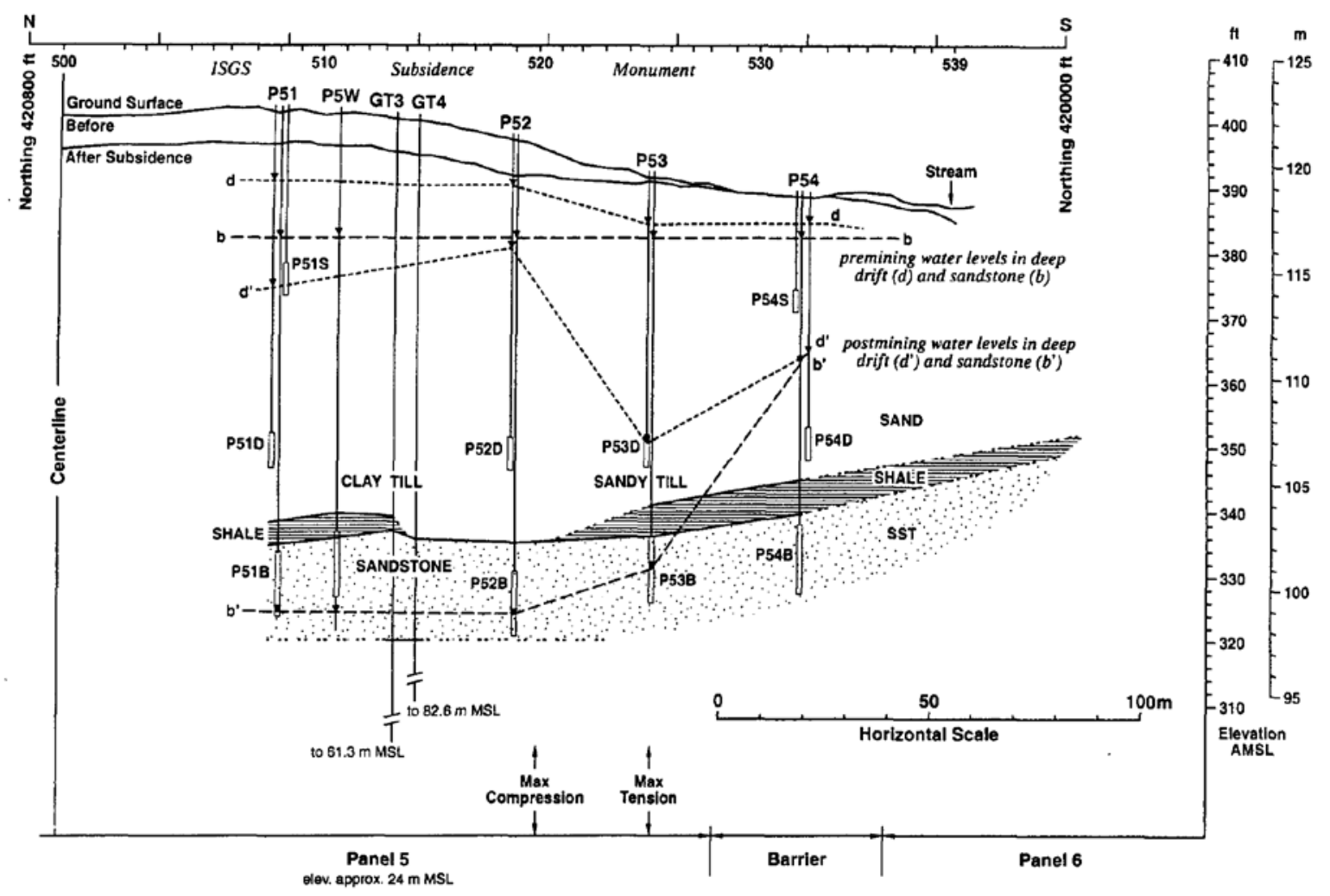

Figure 2.27: Total response for panel \#5 (Booth, et al., 2000) 


\subsection{Angle of Groundwater Influence}

The Angle of Groundwater Influence (Draw) is the region where head loss occurs due to subsidence affects. While related to the Subsidence Angle of Draw, it is not directly correlated to this. The Subsidence Angle of Draw only shows the areas where fracturing causes hydrologic responses. The groundwater changes can extend much farther past this zone. The angle of groundwater influence correspondingly ranges from 16 to 60 degrees (Booth, 2006). Generally groundwater influence is within 40 degrees unless in areas of steep terrain. However, in one case study, the range of groundwater or "dewatering” influence reached 70 (60 \pm 20$)$ degrees (Reed and Rauch, 2001).

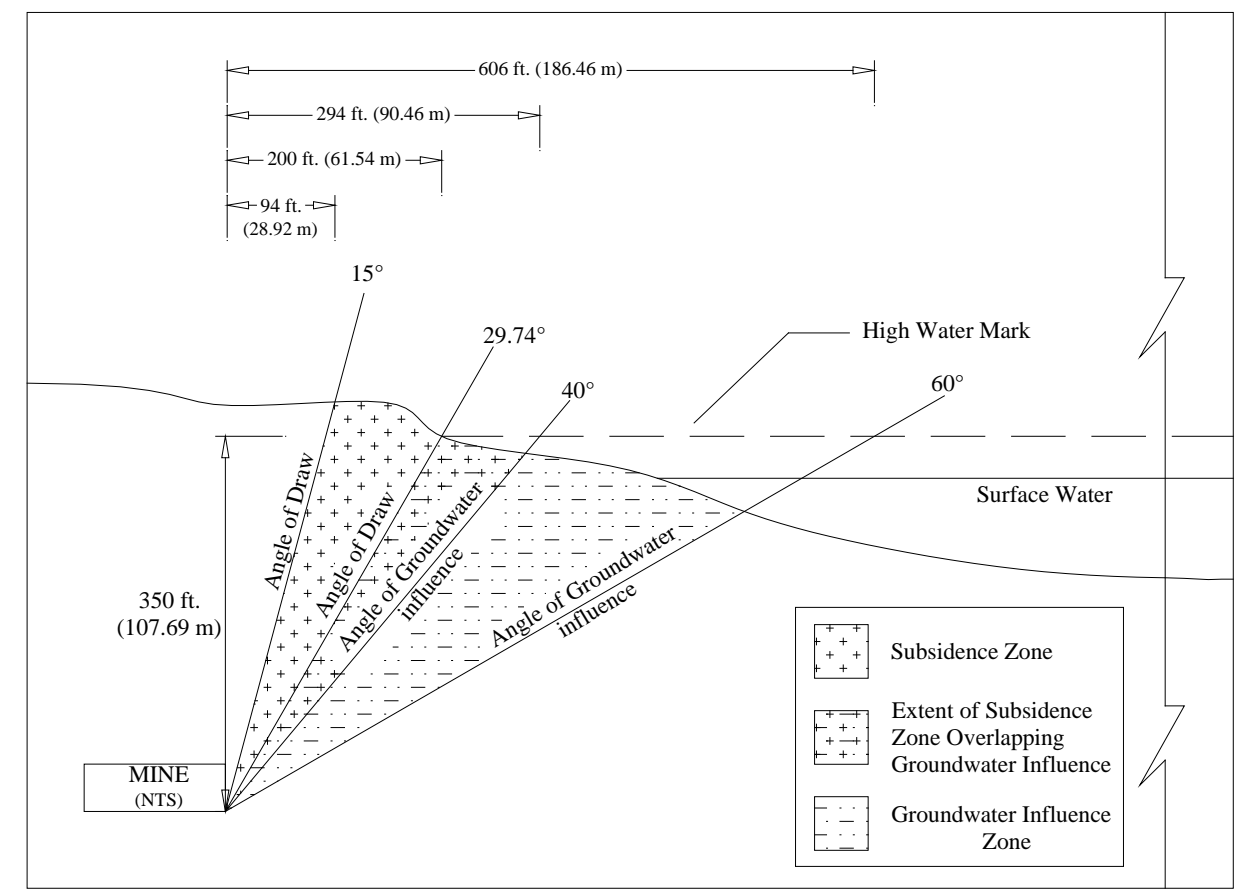

Figure 2.28: Subsidence Angle of Draw and Angle of Groundwater Influence

There is an interrelationship of these two effects, specifically the subsidence strain causing surface deformation changing strata permeability. Figure 2.28 illustrates that at an approximately $200 \mathrm{ft}(61.54 \mathrm{~m})$ offset, the angle of groundwater influence will extend into the surface water reservoir at the high water mark elevation for the full range of influence.

Kendorski (1993) identified that the subsurface strata permeability increases when strains due to mining are greater than $0.001 \mathrm{in} / \mathrm{in}$, or $0.1 \%$. Ground surface cracking develops parallel to mine 
edges directly above the mine with extensional strains ranging 0.006 to 0.009 in/in. Field measurements indicate maximum tensile strains of 0.0134 and 0.021(Kelleher, 1991).

From the hydrogeology perspective, Booth presented research on the effects of mine subsidence related to issues including the advance of the subsidence wave which induces tension and compression strains leading to zones of subsidence extension, compression, and fractured zone (Booth et al., 2000). The overburden strata strain effects culminate in permeability changes occurring in the near surface soils. The changes occurring during mining are the highest. Booth reports that reductions in the subsidence compression have been shown at approximately -10x. While the permeability increases in the extension (dilation) zones range from $+10 \mathrm{x}$ to $+1,000 \mathrm{x}$. These changes have permanent effects on the groundwater system.

\subsubsection{Darcy's Law}

Groundwater flow through a medium is governed by Darcy's law. It is based on the idea that the flow rate of a fluid in a porous material is proportional to the head loss and inversely proportional to the flow path length. The difference in head loss over a particular distance is called the hydraulic gradient. Darcy's law is expressed as:

$Q=K i A$

Where:

$Q=$ Volumetric flow rate of liquid through a porous medium (V/T)

K=Hydraulic conductivity $(\mathrm{L} / \mathrm{T})$

$i=$ hydraulic gradient, head loss over distance in flow direction (L/L), unitless

$A=$ Cross-sectional area of flow $\left(\mathrm{L}^{2}\right)$

Darcy’s law assumes laminar flow occurring across the entire cross-sectional area of a saturated porous medium. An increase in hydraulic conductivity due to subsidence will proportionally increase the flow rate through a particular bedding layer. If the flow rate is greater than the rate of recharge, drawdown of the water table will occur, decreasing the hydraulic gradient until equilibrium between inflow (recharge) and outflow (Q) is re-established. 


\subsubsection{Cone of Depression}

The Angle of Groundwater Influence may be compared to a Cone of Depression. A Cone of Depression, roughly conical in shape, is produced in the water table by the pumping of water from a well (Figure 2.29). As pumping from a well occurs, the water table is drawdown so that areas that are normally saturated become unsaturated. The extent of these effects is dependent on pumping rate, lithology (porosity, faults, etc) and water storage within the aquifer. Reduction in groundwater levels around the well decreases the hydraulic gradient and reduces pore pressure. The cone is created as the effects from the well decrease with distance (i.e. water table drawdown).

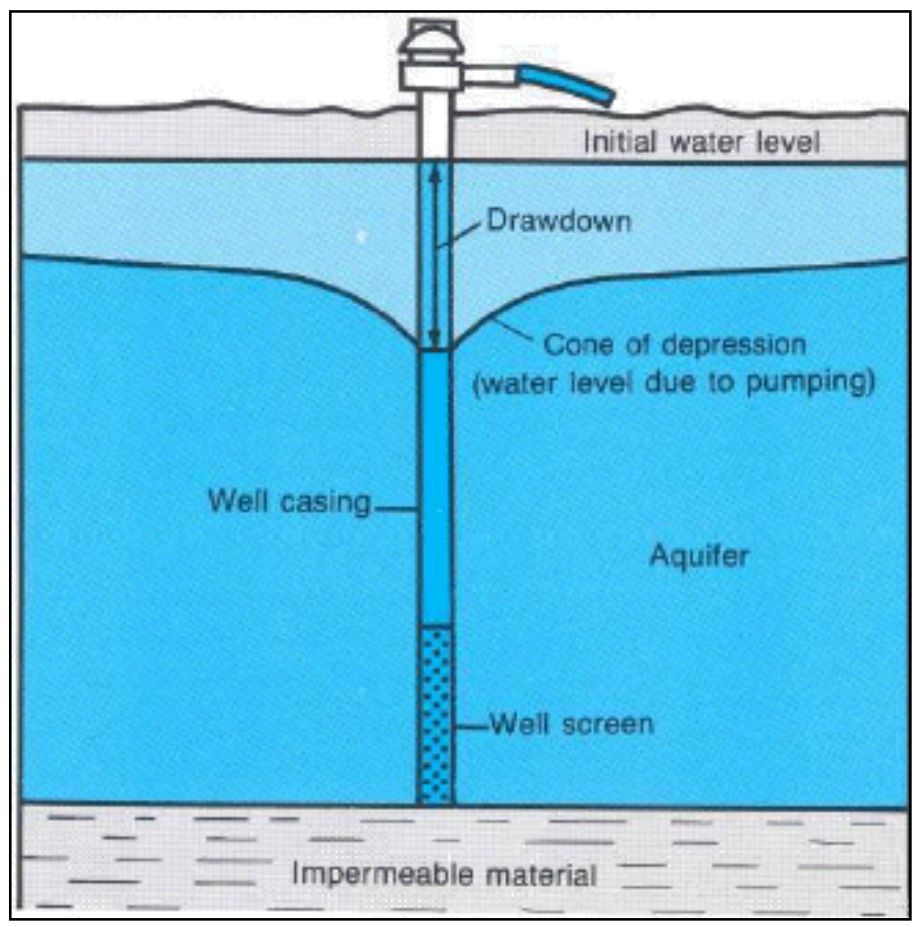

Figure 2.29: Cone of depression caused by pumping (Pubs.usgs.gov, 2015)

An underground mine would act in a similar fashion as a well to the groundwater table. Mining creates a subsurface area of higher localized permeability and fracturing. As groundwater flow takes the path of least resistance, the mine void would draw the groundwater table down until the mine is flooded or pressure is equalized. The primary extent of this lies within the Subsidence Angle of Draw where fracturing and tensional strain is most prevalent. However, this will continue to affect the surrounding areas to a lesser degree as the increased hydraulic conductivity 
reduces the surrounding water table. The maximum horizontal extents of these changes determine the Cone of Depression.

\subsection{Slurry Impoundments}

Michael (2010) discussed the effects on breakthrough potential of slurry cells on adjacent mines. This concern was raised in 2000 after 306 million gallons of water and slurry broke through the bedrock barrier and into a mine in Martin County, Kentucky. Approximately 260 million gallons discharged from the mine affecting 75 miles of streams in Kentucky and West Virginia causing 56 million dollars in damage and affecting 6 public water intakes.

The requirements for the design and maintenance of the slurry impoundments are provided in Title 30 of the Code of Federal Regulations (Michael, 2010). Additionally regulations concerning the identification of underground mines and prevention of breakthrough are available in MSHA's Engineering and Design Manual- Coal Refuse Facilities. These regulations are designed to ensure horizontal and vertical barriers exist. Most inactive impoundments are capped if there is a public safety hazard. Others are converted into lakes. However of the 110 impoundments in West Virginia, only a handful have been capped and only 6 out of 113 in Kentucky have done so (Michael, 2010).

The main cause for the breakthroughs into mines is from weak horizontal barriers or sinkholes in vertical barriers. The concerns related to these breakthroughs are based on the location of the mine with regard to the impoundment and whether the slurry remains a liquid or can be changed into one due to liquefaction.

The response of slurry to barrier failure is directly related to the characteristics of the refuse, the depth of the impoundment and the location of the mine. The major property of the refuse that affects stability is consolidation. Unconsolidated fine coal refuse has high moisture content potential. Insufficient drainage during the consolidation process could cause liquefaction. The consolidation period is long for coal refuse. During this time there is high pore pressure which reduces shear strength. In certain tests, it was determined that consolidation slows considerably after a void ratio of 6 was reached and in large scale tests there was no effective stress build up after almost 15 years. Additionally a change in moisture content of only 1 percent may cause large change in undrained strength. 
Coal slurry is thixotropic in nature. This means it will act as a semisolid at rest and a fluid when moved. During testing, it was determined that at low water content there was no consolidation strength development. At high water content, changes were prominent, indicating consolidation.

Comparisons done in 1977 showed that the failed impoundments had high phreatic surfaces and overly steep downstream slopes. The stable impoundments had pervious foundations. There are recommendations that allow for the flow of groundwater discharge. Other methods also include adding polymers to tailings slurry to keep it flowing.

The following are slurry breakthrough events that occurred between 1994 and 2000 as reported by OSM (2006).

\subsubsection{Martin County, Kentucky}

In 1994 approximately 50 million gallons of water/slurry drained into an underground mine in Martin County, Kentucky through an opening at the edge of workings (OSM, 2006). The water/slurry discharged through two portal openings and a coal barrier approximately 2-3ft wide. The vertical distance between the water/slurry and the mine void was $28 \mathrm{ft}$ at the time of the breakthrough, fifteen of which was overburden. A seepage barrier was created around the workings.

In 2000, slurry from the impoundment drained through the seepage barrier into an underground mine due to a subsidence fracture (OSM, 2006). The vertical distance between the slurry and the roof of the coal seam was approximately $100 \mathrm{ft}$. The outcrop was approximately $65 \mathrm{ft}$ wide, containing weathered material.

\subsubsection{Lee County, Virginia}

In August of 1996, slurry drained into a formerly unknown mine entry (OSM, 2006) through an opening in a highwall. The coal barrier between the underground mine and the surface mine was less than five feet. The majority of the leak was contained within the mine and impact was minimal. An earthen liner was created along the mine bench.

In October of 1996, after the impoundment level rose above the height of the earthen liner, the slurry drained into the aforementioned underground mine through a subsidence crack (OSM, 2006). The slurry discharged through an open portal at an initial rate of 3thousand gallons per 
minute before the leak was sealed. Drainage from the underground mine continued for approximately one week after containment.

\subsubsection{Buchanan County, West Virginia}

Approximately 4 million gallons of slurry drained through old auger holes or a mine portal along a highwall into an underground mine in 1996 (OSM, 2006). The slurry discharged approximately 900ft of the impoundment. When the drainage threatened to enter an active mine downstream, the flow was diverted into a nearby creek (OSM, 2001).

\subsubsection{Harlan County, Kentucky}

In 1994 approximately 23 million gallons of water and slurry drained into a mine through a previously sealed mine opening (OSM, 2006). Both active and inactive parts of the mine were flooded. The overburden thickness was approximately $26 \mathrm{ft}$ at the breakthrough location.

\subsection{Erosion}

Internal erosion is a progressive event in the failure mode process. It connects the physical changes in the soil structure and the final events that lead to failure. The erosion process occurs when subsidence and changes in groundwater flow cause the particles in the strata to begin to move. There are 4 types of internal erosion; concentrated, suffusion, backward erosion and contact erosion (Brown, 2008).

\subsubsection{Concentrated erosion}

Concentrated erosion occurs within cohesive soils that can contain open cracks or a continuous voids either horizontally or vertically. For erosion to occur, the shear stress of the soil must be exceeded by the shear stress of the water flow. The shear stress in soils varies in several orders of magnitude (Brown, 2008), generally from 0 to $150 \mathrm{~Pa}$. The rate of erosion will also vary by several orders of magnitude. The sides of the opening will erode creating larger fractures and increased voids. As the openings increase, there will be an increase in permeability within the strata. 
The shear stress and the flow velocity can be determined by using the formula;

$$
\tau=\gamma R i
$$

Where:

$\tau=$ Shear stress

$\gamma=$ Specific weight of water $\left(9.8 \mathrm{kN} / \mathrm{M}^{3}\right)$

$\mathrm{R}=$ Hydraulic radius

$\mathrm{i}=$ Hydraulic gradient

Concentrated erosion will likely occur in the failure mode identification when permeability changes allow for increased transmissivity and hydraulic conductivity. For this type of erosion to occur the soil must have cohesion that can withstand fracturing. In the surface fracture zone (Bai et al., 1995) this will occur when clays and mudstones are present. However, this type of erosion is more likely to occur in the dilated zone where strains are greater than 0.001 . The common geologic profile for this region above a mining operation is limestone and sandstones. However shale, mudstone and clay materials are also prevalent in this region making the potential for erosion likely in the dilated zone.

\subsubsection{Suffosion}

Suffosion is the process where flow velocity is sufficient to transport finer particles between the larger particles. As the finer particles as removed the void ratio and permeability of the soil increases. This increase will cause further particles to be removed in the soils. This type of erosion occurs in soils that are internally unstable making fracturing within the soil unlikely and found in the surface fracture zone rather than the dilated zone. The loss of fines within the layers will cause an increase in transmissivity both vertically and horizontally. Vertically the increased seepage will allow water to infiltrate the underlying strata layers and allow for conditions causing increased head and pore pressure. According to Brown, the mean pore velocity $\left(\mathrm{V}_{\mathrm{pav}}\right)$ due to seepage can be determined by the following equation: 


$$
V_{p a v}=\frac{V}{n T}
$$

Where:

$\mathrm{n}=$ porosity

$\mathrm{T}=$ tortuosity $(2 / \pi$ or 0.64$)$

\subsubsection{Backward Erosion (Piping)}

Backward erosion results from pore pressures within the strata. As the water flows through the soil it releases at an exit point where there is little pore pressure. If the soil is cohesive, a "pipe" will begin to form and transmit back against the groundwater flow. This type of erosion occurs when the seepage gradient exceeds the floatation gradient of the soil. The critical average gradients are $0.34,0.28,0.24$ and 0.14 for gravel, coarse medium and fine sand all with a uniform coefficient of 3 (Brown, 2008).

\subsubsection{Contact erosion}

Contact erosion is where fine soils are washed into a coarse soil due to horizontal flow. The methodology for this is similar to concentrated erosion with adjustment for pore size and crack width. Time for Development of Internal Erosion and Piping in Embankment Dams:

- Backward erosion will be rapid with a concentrated leak and slow in a non concentrated leak

- Crack/hydraulic fracture will be rapid and occurs when the reservoir level reaches the crack or a point in which a hydraulic fracture is induced

- High permeability processes will occur rapidly once the reservoir reaches an area of high permeability and or other critical gradients to initiate erosion

- Suffosion occurs slowly 


\subsection{Summary}

Literature has shown that strains induced by subsidence can cause changes in groundwater flow. While the average Angle of Subsidence Draw in Appalachia is 23 degrees, literature shows that subsidence may extend beyond 40 degrees from the mine extents. Changes in permeability may affect groundwater flow greater than 60 degrees from the edge of mining. Hydraulic conductivity changes have been shown to increase 2 orders of magnitude for sandstone and three orders of magnitude in shale. The increased hydraulic conductivity within the overburden may lead to erosion and potential risk to the integrity of reservoirs and dams. 


\section{CHAPTER 3: Evaluation and}

\section{Comparison of Existing Guidelines for Mining Under Water Bodies}


Mining under water bodies is a significant issue due to subsidence and water intrusion and flooding in underground mines. Guidance in the design of underground mines near water bodies are included in the Bureau of Mines document Information Curricular (IC) 8741. This document presents a comparison of four publications on guidance for mining under water bodies. The Federal guidelines are included in IC 8741. The other authors who suggest guidelines which were compared are Skelly \& Loy (1976), Wardell and Partners (1976), and Kendorski (1979).

\subsection{Purpose}

This chapter is intended to compare and contrast literature which has complemented the federal guidelines for mining under water bodies. All subsurface coal mining guidelines focus on miner's safety. The miner safety information in IC 8741 is limited, but is complemented by other

authors. Skelly \& Loy’s guidelines consider miner's safety while realizing maximum coal recovery. Wardell and Partners are concerned about mine flooding, danger to Mineworkers and to mine property, environmental effects, and public safety. Kendorski divided his work purpose into two focus areas:

- For industry (design the mine for working below surface water bodies ensuring maximum resource utilization) and

- For regulatory agencies (to ensure that all operations are carried out with safety and precaution).

\subsection{Objective:}

The objective of this chapter is to compare and contrast references which include guidelines for avoiding potential hazards for mining under water bodies. The references included for comparison are listed below. Table 3.1 presents a summary highlighting the common points among the references.

1. Kendorski, F. S., Singh, M.M. (1979). Criteria for Determining When a Body of Surface Water Constitutes a Hazard to Mining. Downers Grove, Ill, Engineers International, INC: 364.

2. Skelly and Loy (1976). "Guidelines for Mining Near Water Bodies, Phase III - Final Report.” U.S. Department of Interior, Bureau of Mines, Project No. HO252083, Denver, CO. 
3. Wardell, K., and Partners (1976). Guidelines For Mining Under Surface Water. Phase III and Final Report, U.S. Bureau of Mines - Contract No. HO.25201, K. Wardell \& Partners, Newcastle Staffs [England].

4. United States Army Corps of Engineers (USACE) (1994). Authorized and Operating Purposes of Corps of Engineers Reservoirs, Hydraulics \& Hydrology Branch, PR-19, November 1994.

Table 3.1: Summary of purpose and scope in each reference

\begin{tabular}{|l|l|l|l|l|}
\hline & \multicolumn{1}{|c|}{ IC 8741 } & \multicolumn{1}{c|}{ Skelly \& Loy } & Wardell and Partners & \multicolumn{1}{c|}{ Kendorski } \\
\hline Purpose & Miners' safety. & $\begin{array}{l}\text { Developing practical } \\
\text { guidelines for mining in } \\
\text { close proximity to bodies } \\
\text { of water to assure } \\
\text { adequate protection to } \\
\text { coal miners while } \\
\text { realizing maximum coal } \\
\text { recovery. }\end{array}$ & $\begin{array}{l}\text { Mine flooding (danger } \\
\text { to mineworkers and to } \\
\text { mine property), } \\
\text { environmental effects } \\
\text { and public safety. }\end{array}$ & $\begin{array}{l}\text { For industry: design the mine for } \\
\text { working below surface water } \\
\text { bodies ensuring maximum } \\
\text { resource utilization; } \\
\text { For regulatory agencies: ensure } \\
\text { that all operations are carried out } \\
\text { with safety and precaution. }\end{array}$ \\
\hline \multirow{5}{\text{Scope}}{} & $\begin{array}{l}\text { Maximum } \\
\text { efficient utilization } \\
\text { of underground } \\
\text { coal resources } \\
\text { consistent with } \\
\text { minimizing } \\
\text { inundation } \\
\text { hazards. }\end{array}$ & $\begin{array}{l}\text { Development of } \\
\text { recommended guidelines } \\
\text { for underground coal } \\
\text { mining under water } \\
\text { bodies. }\end{array}$ & $\begin{array}{l}\text { Determine guidelines for } \\
\text { maximum coal } \\
\text { extraction while } \\
\text { avoiding potentials } \\
\text { hazards; } \\
\text { Focus on total extraction } \\
\text { due to maximizing the } \\
\text { amount of coal to be } \\
\text { mined. }\end{array}$ & $\begin{array}{l}\text { Determine what sizes of such } \\
\text { water bodies do not constitute a } \\
\text { hazard to mining and how their } \\
\text { sizes depend on the special } \\
\text { mining plans and procedures. }\end{array}$ \\
\end{tabular}

\subsection{Limitations}

Due to the limited available data when these guidelines were developed, there are many gaps the authors highlighted and left as suggestions for future research and improvement.

IC 8741 develops its recommendations based on an “empirical approach to data collection”. It states that, "when there are sufficient engineering data or mining experience available, these conservative recommendations should be modified”.

Skelly \& Loy (1976) recognizes that "the guidelines do not offer protection against mining into unknown and unexpected water-filled abandoned workings or glacial and alluvial deposits”. Additionally, "the Level II Guidelines are just applicable to flat lying beds and beds that are inclined less than 30\%. Level II Guidelines are not directly applicable to mining steeply inclined 
beds". That is, all testing and evaluation are only effective if the beds are flat or inclined less than $30 \%$; for steep beds, the results will not be accurate.

Wardell (1976) shows the necessity of Level II guidelines in order to maximize coal extraction. He states, "the recommended guidelines should require little or no sub-surface exploration or testing by miner operator. However, it might be too conservative and sterilize too much coal. In that case, alternate guidelines were to be proposed indicating additional required investigation, but permitting more coal extraction". The author also says, "there are additional hazards that are not covered under the guidelines. These include the failure of dams and encroachment of land surface by water".

Kendorski (1979) did not state any limitation in his recommendations. A summary highlighting the contrasts can be found in Table 3.2.

Table 3.2: Summary of the limitations in each reference

\begin{tabular}{|l|l|l|l|l|}
\hline & \multicolumn{1}{|c|}{ IC 8741 } & \multicolumn{1}{c|}{ Skelly \& Loy } & \multicolumn{1}{c|}{ Wardell and Partners } \\
\hline & $\begin{array}{l}\text { Empirical approach to } \\
\text { data collection was } \\
\text { used in developing } \\
\text { these } \\
\text { recommendations. }\end{array}$ & $\begin{array}{l}\text { The guidelines do not offer } \\
\text { protection against mining } \\
\text { into unknown and } \\
\text { unexpected water-filled } \\
\text { abandoned workings or } \\
\text { glacial and alluvial deposits; }\end{array}$ & $\begin{array}{l}\text { The recommended guidelines should } \\
\text { require little or no sub-surface } \\
\text { exploration or testing by miner } \\
\text { operator. However, it might be too } \\
\text { conservative and sterilize too much } \\
\text { coal. In that case, alternate guidelines } \\
\text { were to be proposed indicating } \\
\text { additional required investigation, but } \\
\text { permitting more coal extraction. } \\
\text { There are additional hazards that are not } \\
\text { covered under the guidelines. These } \\
\text { include the failure of dams and } \\
\text { encroachment of land surface by water. }\end{array}$ \\
$\begin{array}{l}\text { When there are } \\
\text { sufficient engineering } \\
\text { data or mining } \\
\text { experience available, } \\
\text { these conservative } \\
\text { recommendations } \\
\text { should be modified. }\end{array}$ & $\begin{array}{l}\text { The Level II Guidelines are } \\
\text { just applicable to flat lying } \\
\text { beds and beds that are } \\
\text { inclined less than 30\%. } \\
\text { Level II Guidelines are not } \\
\text { directly applicable to mining } \\
\text { steeply inclined beds. }\end{array}$ & $\begin{array}{l}\text { Not found. } \\
\end{array}$ & \\
\hline
\end{tabular}

\subsection{Mining Guideline Categories and Level of Guidelines}

The categories for IC 8741 are based on the water location; surfaces and underground waters.

The sections are then subdivided into total extraction and mining extraction mining for the first (surface waters), and mine maps, property boundary barrier pillars, abandoned workings, abandoned areas, and adjacent mines, oil and gas well pillars, shaft and vertical opening barrier 
pillars, mining under abandoned flooded workings for the second (underground waters), respectively.

Wardell only considers total extraction and partial extraction mining without any subcategory.

Skelly \& Loy divided their categories in accordance with the causes of mine inundation:

i. mining under continental surface waters

ii. submarine mining

iii. mining near abandoned workings and

iv. water bearing zones, and situations in which general mine planning was at fault

Most of their work is focused on category i. and iii., which is subdivided in total extraction mining, partial extraction mining, mine maps, property boundary barrier pillars, abandoned workings, abandoned areas, and adjacent mines, oil and gas well pillars, shaft and vertical opening barrier pillars, and mining under abandoned flooded workings. The authors say, “each technique presented includes a discussion of its applicability, reliability, benefits, utilization, and factors of safety” . Category ii. is described in Appendix C, as well as its recommendations.

Kendorski's division is based on the critical size of the water body. The categories are: catastrophic potential, major potential and limited potential. Each category is subdivided in total extraction and partial extraction mining.

Related to the level of guidelines, Skelly \& Loy are the unique authors and are concerned about maximizing coal extraction by doing tests and evaluation of the strata. They developed two levels of guidelines. The first is designed to provide maximum protection to the miners (require little or no surface or subsurface exploration). The second illustrates methods of testing and evaluating specific conditions, which allows for the greatest possible coal extraction while still promoting a safe environment.

IC 8741 mentions about first and second workings for room-and-pillar method, but only provides guidelines for first workings. 
Wardell recognizes that additional coal may be extracted with testing, but his guidelines are to require little or no testing by the mine operator, that is, the guideline only recommends Level I. He additionally states, "we have tended to the view that where detailed exploratory information, testing or experience would be essential to justify a departure from guidelines, it should be the responsibility of the mine operator to obtain and present such information. We hope this is a view which recommends itself to you. On the basis of this approach we have not felt it necessary to suggest any alternate guidelines”

Kendorski only presents Level I guidelines. A summary highlighting the contrasts can be found in Table 3.3.

Table 3.3: Level of guidelines according to each author

\begin{tabular}{|c|c|c|c|c|}
\hline & IC 8741 & Skelly \& Loy & Wardell and Partners & Kendorski \\
\hline $\begin{array}{c}\text { Level of } \\
\text { Guidelines }\end{array}$ & $\begin{array}{l}\text { Mentions about first } \\
\text { and second } \\
\text { workings for room- } \\
\text { and-pillar method, } \\
\text { but only provides } \\
\text { guidelines for first } \\
\text { workings }\end{array}$ & $\begin{array}{l}\text { Developed two levels of } \\
\text { guidelines. The first is designed } \\
\text { to provide maximum protection } \\
\text { to the miners (require little or } \\
\text { no surface or subsurface } \\
\text { exploration) and the second } \\
\text { illustrates methods of testing } \\
\text { and evaluating specific } \\
\text { condition, allowing for the } \\
\text { greatest possible coal extraction } \\
\text { while still promoting a safe } \\
\text { environment. }\end{array}$ & $\begin{array}{l}\text { The guidelines are to require } \\
\text { little or no testing by the mine } \\
\text { operator but recognize that } \\
\text { additional coal may be } \\
\text { extracted with testing. } \\
\text { Additionally, "we have tended } \\
\text { to the view that where detailed } \\
\text { exploratory information, } \\
\text { testing or experience would be } \\
\text { essential to justify a departure } \\
\text { from guidelines, it should be } \\
\text { the responsibility of the mine } \\
\text { operator to obtain and present } \\
\text { such information. We hope } \\
\text { this is a view which } \\
\text { recommends itself to you. On } \\
\text { the basis of this approach we } \\
\text { have not felt it necessary to } \\
\text { suggest any alternate } \\
\text { guidelines”. }\end{array}$ & $\begin{array}{l}\text { Only Level I } \\
\text { Guidelines. }\end{array}$ \\
\hline $\begin{array}{l}\text { Additional } \\
\text { comments }\end{array}$ & Not found. & $\begin{array}{l}\text { "Each technique presented } \\
\text { includes a discussion of its } \\
\text { applicability, reliability, } \\
\text { benefits, utilization, and factors } \\
\text { of safety”. }\end{array}$ & Not found. & $\begin{array}{l}\text { The author states } \\
\text { that all guidelines } \\
\text { have limitations } \\
\text { because of } \\
\text { "problems in } \\
\text { defining both water } \\
\text { bodies of concern } \\
\text { and the nature of the } \\
\text { strata". }\end{array}$ \\
\hline
\end{tabular}




\subsection{Analysis of Major Parameters Related to Mining}

\subsubsection{Angle of Subsidence Draw}

All references report the same value for the Angle of Subsidence Draw; what varies is the context. IC 8741, Wardell and Kendorski use: “at a depth of 350 feet, outward and angle of $65^{\circ}$ with the horizontal”, Skelly \& Loy write: “the continuation of the safety zone at a $25^{\circ}$ inclination from the 350 foot level vertically is intended as a protection against the subsidence inbreak angle due to roof falls and full extraction mining”. Also, Skelly \& Loy say that the subsidence inbreak angle "is influenced by the type of overlying rock, the dip and thickness of the coal seam, and also the direction, rate, and type of mining being conducted" ... "workings at depths of 350 feet or greater usually do not induce surface subsidence effects as a result of localized roof failures”

Table 3.4: Analysis of major parameters: Angle of Subsidence Draw

\begin{tabular}{|c|c|c|c|c|}
\hline & IC 8741 & Skelly \& Loy & $\begin{array}{c}\text { Wardell and } \\
\text { Partners }\end{array}$ & Kendorski \\
\hline $\begin{array}{l}\text { Angle of Subsidence } \\
\text { Draw }\end{array}$ & $\begin{array}{l}\text { At a depth of } 350 \text { feet } \\
\text { outward, and angle of } \\
65^{\circ} \text { with the } \\
\text { horizontal. }\end{array}$ & $\begin{array}{l}\text { "The continuation of the } \\
\text { safety zone at a } 25^{\circ} \\
\text { inclination from the } 350 \\
\text { foot level is intended as } \\
\text { a protection against the } \\
\text { subsidence inbreak } \\
\text { angle due to roof falls } \\
\text { and full extraction } \\
\text { mining". }\end{array}$ & Same as IC 8741. & Same as IC 8741. \\
\hline
\end{tabular}

\subsubsection{Maximum Tensile Strain}

Wardell bases his recommendation about the maximum tensile strain in the British guidelines. In item 2.8 and 2.9, he reports "the National Coal Board has adopted a criterion of $10.0 \mathrm{~mm} / \mathrm{m}$ of calculated maximum tensile strain as governing the minimum depth for total extraction. The following equation (10) is used:

$$
E_{m}=\frac{k \times S_{\max }}{D} \text {, where } \mathrm{k}=0.75 \text { (in U.K.) }
$$

Moreover, Wardell explains the why of using the above equation to calculate the maximum tensile strain. "The stipulation of a criterion in terms of maximum calculated tensile strain is 
attractive because it allows some account to be taken of the relationship between maximum subsidence and coal thickness extracted, on the one hand and, locally observed values for the coefficient $k$ on the other. The latter value is believed to be related - in some presently unexplained way - to the lithology of the strata between workings and the land surface. Clearly, however, this criterion is of little value if local observed data concerning these variables is not available”.

IC 8741 presents the same equation as Wardell in its Appendix.

Kendorski presents a more detailed evaluation about maximum tensile strain, considering the size of water body and its affect in this parameter:

- Catastrophic potential water bodies: "The maximum cumulative, calculated tensile strain beneath a body of surface water shall nowhere exceed 10,000 $\mu \varepsilon$, and shall be calculated by an approved method".

- Major potential water bodies: "The maximum cumulative, calculated tensile strain beneath a body of surface water of major potential size shall nowhere exceed $15,000 \mu \varepsilon$ as calculated by approved method".

- Limited potential water bodies: no concerns.

Skelly \& Loy defined the tensile strain as a measure of the intensity of disturbance of the surface at the bottom of the water body. Equation 11 represents another version of the British equation reported in Wardell.

$E_{\max }=\frac{K_{2} \times T \times S_{\max }}{D}$

Where:

$\mathrm{K}_{2}=\mathrm{a}$ constant (ranging from 0-1) derived from local observations

$\mathrm{S}_{\max }=$ multiplier for local surface subsidence (ranging from 0-1)

$\mathrm{T}=$ thickness of the seam

$\mathrm{D}=$ depth of the seam 


\subsubsection{Multiplier for Local Surface Subsidence, $S_{\max }$}

According to Wardell, the British guideline stipulates the value of $0.9 t$ for $S_{\max }$ with longwall caving where $t$ is the thickness of the coal seam. IC 8741 uses this value too. However, Wardell and Partners determined that in the United States the value of $S_{\max }$ would be lower than in Europe. "From subsidence observations in the Appalachian Coalfields of the U.S.A. and from coalfields of New South Wales, Australia - it seems probable that the value of $S_{\max }$ is likely to be in order to $0.60 \mathrm{t}$ to $0.70 \mathrm{t}$ compared with the figures of $0.80 \mathrm{t}$ to $0.90 \mathrm{t}$ generally observed in European coalfields”.

Kendorski presented another relation to determine $S_{\max }$. "The maximum possible surface subsidence is given by the equation (12):

$S_{\max }=t \times N$

Where:

$\mathrm{t}=$ the seam thickness

$\mathrm{N}$ is a "subsidence factor which ranges from 0.1 to 0.9 with different gob support methods". shows the typical subsidence factor $(\mathrm{N})$ measured in different countries.

A summary from maximum tensile strain and $S_{\max }$ can be found in Table 3.5. 
Table 3.5: Analysis of major parameters: maximum tensile strain and $S_{\max }$

\begin{tabular}{|c|c|c|c|c|}
\hline & IC 8741 & Skelly \& Loy & $\begin{array}{l}\text { Wardell and } \\
\text { Partners }\end{array}$ & Kendorski \\
\hline $\begin{array}{c}\text { Maximum } \\
\text { tensile strain }\end{array}$ & $*$ & $\begin{array}{l}E_{\max }=\frac{K_{2} \times T \times S_{\max }}{D} \\
\text {,where } \\
\mathrm{K}_{2}=\text { a constant } \\
\text { (ranging from } 0-1 \text { ) } \\
\text { derived from local } \\
\text { observations; } \\
\mathrm{S}_{\max }=\text { multiplier for } \\
\text { local surface } \\
\text { subsidence (ranging } \\
\text { from } 0-1 \text { ); } \\
\mathrm{T}=\text { thickness of the } \\
\text { seam; } \\
\mathrm{D}=\text { depth of the seam. }\end{array}$ & $\begin{array}{l}\text { "The National Coal } \\
\text { Board has adopted a } \\
\text { criterion of } 10.0 \\
\mathrm{~mm} / \mathrm{m} \text { of calculated } \\
\text { maximum tensile } \\
\text { strain as governing } \\
\text { the minimum depth } \\
\text { for total extraction". } \\
\text { The following } \\
\text { equation is used: } \\
E_{m}=\frac{k \times S_{\max }}{D} \text {, } \\
\text { where } \mathrm{k}=0.75 \text { (in } \\
\text { U.K.) }\end{array}$ & $\begin{array}{l}\text { For each size of water body, } \\
\text { Kendorski presents a maximum } \\
\text { tensile strain: } \\
\text { - Catastrophic potential water } \\
\text { bodies: "The maximum } \\
\text { cumulative, calculated tensile } \\
\text { strain beneath a body of surface } \\
\text { water shall nowhere exceed } \\
10,000 \mu \varepsilon \text {, and shall be } \\
\text { calculated by an approved } \\
\text { method". } \\
\text { - Major potential water bodies: } \\
\text { "The maximum cumulative, } \\
\text { calculated tensile strain beneath } \\
\text { a body of surface water of major } \\
\text { potential size shall nowhere } \\
\text { exceed } 15,000 \mu \varepsilon \text { as calculated } \\
\text { by approved method". } \\
\text { - Limited potential water bodies: } \\
\text { no concerns. }\end{array}$ \\
\hline$S_{\max }$ & $*$ & No specific mention. & $\begin{array}{l}\text { They determined } \\
\text { that in the United } \\
\text { States the value of } \\
\mathrm{S}_{\max } \text { would be lower } \\
\text { than in Europe; } \\
\text { It stipulates the } \\
\text { value of } 0.9 \mathrm{t} \text { for } \\
\mathrm{S}_{\max } \text { with longwall } \\
\text { caving; }\end{array}$ & $\begin{array}{l}\text { The maximum possible surface } \\
\text { subsidence is given by the } \\
\text { relation } S_{\text {max }}=t \times N \text {, where } \mathrm{t} \\
\text { is the seam thickness and } \mathrm{N} \text { is a } \\
\text { subsidence factor which ranges } \\
\text { from } 0.1 \text { to } 0.9 \text { with different } \\
\text { gob support methods. } \\
\text { shows the typical subsidence } \\
\text { factor }(\mathrm{N}) \text { measured in different } \\
\text { countries. }\end{array}$ \\
\hline
\end{tabular}

* For tensile strain and $\mathrm{S}_{\max }$, IC 8741 reports the same as Wardell in the Appendix. 


\subsection{Subsidence}

\subsubsection{Total Extraction Mining}

According to IC 8741, "When subsidence observations have been carried out and satisfactory calculations of surface tensile strain can be made, any number of seams may be mined by total extraction provided that the maximum cumulative, calculated tensile strain beneath a body for surface water will nowhere exceed 8.75 mm/m (0.875 percent)” . Skelly \& Loy, Wardell and Kendorski state the same. Wardell adds, "It must be remarked that total extraction will give rise to the maximum surface subsidence effects - and consequently to the greater possibility of inundation hazards at surface - even in circumstances where it may not present a problem so far as mine flooding is concerned”.

\subsubsection{Partial Extraction Mining}

All authors share the idea of no major concern with partial extraction mining because this method will impact less than total extraction mining.

IC 8741 does not mention about subsidence for partial extraction mining. It only provides guidelines for minimum depth of cover and pillar dimensions. In these two aspects, there is no concern related to subsidence. Basically, if the criterion for total extraction is followed, it will also fit for partial extraction.

Wardell affirms that failure in a partially extracted mine would not be greater than in a totally extracted mine. "Where properly designed partial extraction systems are required as a necessary precaution against mine flooding, their use automatically limits subsidence of the land surface and avoid or reduces the possibility of surface inundation hazards”. He also suggests more research in this area. "It appears to us that more extensive empirical studies in relation to surface subsidence ground movements and the stability of partial extraction systems of mining would be an essential pre-requisite to refinement of the guidelines suggested herein”.

“Observations in the United States have revealed that with extraction of pillars, subsidence development over room and pillar panels is similar to that over longwall panels (Dahl and Choi, 1973,1974). Thus, subsidence development can be fairly well predicted on the basis of an average extraction thickness calculated from extraction ratios”. With a deeper analysis, 
Kendorski reports that "rock movement outgoing from the individual excavation in the room and pillar system of mining are usually superimposed to give a uniform overall surface subsidence trough free from any undulations except when the cover is shallow. As reported from several European countries, the surface subsidence ranged from $3 \%$ to $20 \%$ of the seam thickness for an extraction range of $30 \%$ to $70 \%$ (Brauner, 1973). It may be mentioned that the subsidence factor can be reduced to less than 3\% by leaving the pillars unworked and stowing the entries hydraulically".

\subsection{Safety Zones - Offsets}

\subsubsection{Surface Water}

All guidelines state the same offset for mining under surface water with the same figure to illustrate it. In relation to the writing, there are some slight differences.

In IC 8741, "safety zone should extend 200 feet horizontally from the high-water mark, or perimeter of the water body, and vertically downward from this point to a depth of 350 feet, then outward at an angle of dip of $65^{\circ}$ ”. Wardell brings the same text and illustration.

In Kendorski, "Where any body of surface water is present above the potential mine working, a safety zone around the body of surface water should extend $200 \mathrm{ft}$ horizontally from the highwater mark all along the perimeter of the water body, and vertically downward from the perimeter to a depth of $350 \mathrm{ft}$, then outward at an angle of dip of $65^{\circ}$.

In Skelly \& Loy, "Should extend 200 feet horizontally from the high water mark of each bank of such stream or river, or from the known perimeter of any other body of water, and should extend downward to the limit of the workable beds or to 350 feet, whichever is less. At the intersection of 350 foot vertical depth line and the 200 foot horizontal line, the safety zone should continue downward on a line projected 25 degrees from the vertical”.

The difference between Skelly \& Loy and the other authors is that they report the complementary angle ( $25^{\circ}$ from vertical instead of $65^{\circ}$ from horizontal). Also, Skelly \& Loy are more specific about the surface water body. Table 3.6 presents the differences. 
Table 3.6: Safety zone guidelines according to each compared author - surface water

\begin{tabular}{|c|c|c|c|}
\hline IC 8741 & Skelly \& Loy** & $\begin{array}{c}\text { Wardell and } \\
\text { Partners }\end{array}$ & Kendorski \\
\hline $\begin{array}{l}\text { "Safety zone should } \\
\text { extend } 200 \text { feet } \\
\text { horizontally from the } \\
\text { high-water mark, or } \\
\text { perimeter of the water } \\
\text { body, and vertically } \\
\text { downward from this } \\
\text { point to a depth of } 350 \\
\text { feet, then outward at } \\
\text { an angle of dip of } \\
65^{\circ} \text {.' }\end{array}$ & $\begin{array}{l}\text { "Should extend } 200 \text { feet } \\
\text { horizontally from the high water } \\
\text { mark of each bank of such stream } \\
\text { or river, or from the known } \\
\text { perimeter of any other body of } \\
\text { water, and should extend } \\
\text { downward to the limit of the } \\
\text { workable beds or to } 350 \text { feet, } \\
\text { whichever is less. At the } \\
\text { intersection of } 350 \text { foot vertical } \\
\text { depth line and the } 200 \text { foot } \\
\text { horizontal line, the safety zone } \\
\text { should continue downward on a } \\
\text { line projected } 25 \text { degrees from the } \\
\text { vertical" (page } 16 \text { ). }\end{array}$ & Same as IC 8741. & $\begin{array}{l}\text { "Where any body of } \\
\text { surface water is present } \\
\text { above the potential mine } \\
\text { working, a safety zone } \\
\text { around the body of surface } \\
\text { water should extent } 200 \mathrm{ft} \\
\text { horizontally from the high- } \\
\text { water mark all along the } \\
\text { perimeter of the water } \\
\text { body, and vertically } \\
\text { downward from the } \\
\text { perimeter to a depth of } 350 \\
\mathrm{ft} \text {, then outward at an angle } \\
\text { of dip of } 65^{\circ} \text {. }\end{array}$ \\
\hline
\end{tabular}

** Table 3.6 only includes Skelly \& Loy’s Level I Guidelines.

\subsubsection{Total Extraction Mining}

IC 8741, Skelly \& Loy and Wardell recommend for each 1 foot thickness of the coal seam to be extracted, a minimum of 60 feet of solid strata cover exists between the proposed workings and the bed of the body of surface water.

Kendorski is much more specific and divides his recommendation based on the critical size of the water body:

- Catastrophic potential water bodies: "any single seam beneath or in the vicinity of any body of surface water may be totally extracted, whether by longwall mining or by pillar robbing, provided that a minimum thickness of strata cover be present, as (given), between the proposed workings and the bottom of the body of surface water”.

The best point of Kendorski's table for minimum thickness of strata cover is that it sets a different offset according to the seam thickness instead of assuming 60 feet of solid strata cover for each one foot seam thickness. 
- Major potential water: “Any single seam of coal beneath or in the vicinity of any body of surface water of major potential size may be totally extracted, whether by longwall mining or by pillar robbing provided that a minimum strata cover of a suitable nature exists between the proposed workings and the bottom of the body of surface water as (given)”.

- Limited potential water bodies: "where sufficient in-mine pumping capacity equivalent to the mine life flood discharge of all small surface streams affected is available, any number of seams may be totally extracted at any thickness of cover between the uppermost seam and the bottom of the surface water and at any thickness of parting between the seams”.

Table 3.7 presents the safety zone guidelines proposed according to the authors compared for this report.

Table 3.7: Safety zone guidelines according to each author - total extraction mining

\begin{tabular}{|c|c|c|c|}
\hline IC 8741 & Skelly \& Loy** & $\begin{array}{c}\text { Wardell and } \\
\text { Partners } \\
\end{array}$ & Kendorski \\
\hline $\begin{array}{l}\text { For each } 1 \text { foot thickness } \\
\text { of the coal seam to be } \\
\text { extracted, a minimum of } \\
60 \text { feet of solid strata } \\
\text { cover exists between the } \\
\text { proposed workings and } \\
\text { the bed of the body of } \\
\text { surface water. }\end{array}$ & Same as IC 8741. & Same as IC 8741. & $\begin{array}{l}\text { Catastrophic potential water bodies: "any single seam } \\
\text { beneath or in the vicinity of any body of surface water } \\
\text { may be totally extracted, whether by longwall mining or } \\
\text { by pillar robbing, provided that a minimum thickness of } \\
\text { strata cover as (given) exists between the proposed } \\
\text { workings and the bottom of the body of surface water” } \\
\text { - Major potential water: “Any single seam of coal } \\
\text { beneath or in the vicinity of any body of surface water } \\
\text { of major potential size may be totally extracted, whether } \\
\text { by longwall mining or by pillar robbing provided that a } \\
\text { minimum strata cover of a suitable nature exists } \\
\text { between the proposed workings and the bottom of the } \\
\text { body of surface water as (given)”. } \\
\text { - Limited potential water bodies: "where sufficient in- } \\
\text { mine pumping capacity equivalent to the mine life flood } \\
\text { discharge of all small surface streams affected is } \\
\text { available, any number of seams may be totally extracted } \\
\text { at any thickness of cover between the uppermost seam } \\
\text { and the bottom of the surface water and at any thickness } \\
\text { of parting between the seams”. }\end{array}$ \\
\hline
\end{tabular}

** Table 3.7 only considers Skelly \& Loy’s Level I Guidelines. 


\subsubsection{Partial Extraction Mining}

IC 8741, Skelly \& Loy and Wardell recommend for partial extraction mining that no entry should be driven in any seam lying beneath or in the vicinity of any body of surface water where the total thickness of strata cover above the seam is less than 5 times the maximum entry width (5s) or 10 times the maximum entry height (10t), whichever is greater. Where at least one competent bed of sandstone or similar material is present within the strata and has a thickness at least 1.75 times the maximum entry width, mining at a lesser cover than $5 \mathrm{~s}$ or $10 \mathrm{t}$ may be considered.

Kendorski also bases his recommendation in accordance to the size of water body:

- Catastrophic potential water bodies: Same as IC 8741.

- Major potential water: same as for catastrophic potential size.

- Limited potential water bodies: not mentioned.

Table 3.8 presents a summary of the partial extraction recommendations.

Table 3.8: Safety zone guidelines according to each author - partial extraction mining

\begin{tabular}{|c|c|c|c|}
\hline IC 8741 & Skelly \& Loy** & $\begin{array}{c}\text { Wardell and } \\
\text { Partners } \\
\end{array}$ & Kendorski \\
\hline $\begin{array}{l}\text { No entry should be driven in any } \\
\text { seam lying beneath or in the } \\
\text { vicinity of any body of surface } \\
\text { water where the total thickness of } \\
\text { strata cover above the seam is less } \\
\text { than } 5 \text { times the maximum entry } \\
\text { width (5s) or } 10 \text { times the } \\
\text { maximum entry height (10t), } \\
\text { whichever is the greater. Where at } \\
\text { least one competent bed of } \\
\text { sandstone or similar material is } \\
\text { present within the strata and has a } \\
\text { thickness at least } 1.75 \text { times the } \\
\text { maximum entry width, mining at } \\
\text { a lesser cover than } 5 \text { s or } 10 t \text { may } \\
\text { be considered. }\end{array}$ & Same as IC 8741. & Same as IC 8741 . & $\begin{array}{l}\text { Catastrophic potential water } \\
\text { bodies: Same as IC } 8741 \text {. } \\
\text { - Major potential water: same } \\
\text { as for catastrophic potential } \\
\text { size. } \\
\text { Limited potential water } \\
\text { bodies: not mentioned. }\end{array}$ \\
\hline
\end{tabular}

** Table 3.8 only considers Skelly \& Loy’s Level I Guidelines. 


\subsubsection{Structures Retaining Water}

IC 8741 recommends "The perimeter of the structure requiring protection should be established by those responsible for its maintenance and safety. The safety zone around the perimeter of protection should extend outward $200 \mathrm{ft}$ in all directions, then downward for $350 \mathrm{ft}$, and then outward at a dip of $65^{\circ}$ from the horizontal. This safety zone is designated as a zone of no extraction. This shows the restriction on mining beneath the impounded water”.

Skelly \& Loy and Wardell and Partners recommend the same as IC 8741 with the same text and illustration.

Kendorski subdivides the structures retaining water in two subcategories in order to set recommendations:

- Structures important to the public safety: The text and figure are the same than IC 8741.

- Small structures or embankments impounding water: "the mining of single or multiple seams by total or partial extraction methods may be undertaken beneath or in the vicinity of small structures or embankments impounding water in accordance with the guidelines recommended for other equivalent volume and flow surface water bodies”. Table 3.9 presents a summary of the safety zone guidelines suggested by the authors compared for this report.

Table 3.9: Safety zone guidelines according to each author - structure retaining water

\begin{tabular}{|c|c|c|c|}
\hline IC 8741 & Skelly \& Loy** & $\begin{array}{c}\text { Wardell and } \\
\text { Partners } \\
\end{array}$ & Kendorski \\
\hline $\begin{array}{l}\text { The perimeter of the structure } \\
\text { requiring protection should be } \\
\text { established by those responsible for } \\
\text { its maintenance and safety. The } \\
\text { safety zone around the perimeter of } \\
\text { protection should extend outward } \\
200 \mathrm{ft} \text { in all direction, then } \\
\text { downward for } 350 \mathrm{ft} \text {, and then } \\
\text { outward at a dip of } 65^{\circ} \text { from the } \\
\text { horizontal. This safety zone is } \\
\text { designated as a zone of no } \\
\text { extraction. (This) shows the } \\
\text { restriction on mining beneath the } \\
\text { impounded water”. }\end{array}$ & $\begin{array}{l}\text { The text and figure } \\
\text { are the same than } \\
\text { IC } 8741 \text {. }\end{array}$ & $\begin{array}{l}\text { The text and figure } \\
\text { are the same than } \\
\text { IC } 8741 \text {. }\end{array}$ & $\begin{array}{l}\text { Structures important to the public safety } \\
\text { The text and figure are the same than IC } \\
8741 \text {. } \\
\text { Small structures or embankments } \\
\text { impounding water: "the mining of single } \\
\text { or multiple seams by total or partial } \\
\text { extraction methods may be undertaken } \\
\text { beneath or in the vicinity of small } \\
\text { structures or embankments impounding } \\
\text { water in accordance with the guidelines } \\
\text { recommended for other equivalent } \\
\text { volume and flow surface water bodies". }\end{array}$ \\
\hline
\end{tabular}

** Table 3.9 only considers Skelly \& Loy’s Level I Guidelines. 


\subsection{Comparison Between Pillar Dimensioning for First Workings Room-and-Pillar}

IC 8741, Wardell and Kendorski recommend the use of tables and numerical methods in order to calculate the pillar width for room-and-pillar first workings. However, there are considerable differences among them. Skelly \& Loy recommends the calculated of pillar width be based on its strength.

Wardell studies report several graphs for relating the pillar width with depth for different pillar height at a fixed room width. These results are displayed in tables where the pillar height is fixed. In the tables, information can be obtained on the minimum pillar width, given the depth of the seam, and room width. These tables are broad and the pillar heights considered are 4, 5, 6, 7, 8, 9, 10 and 12 feet.

IC 8741 uses some of Wardell's tables, but they are shorter. The pillar heights considered are 3, 4, 6, 8, 10, 12 and 14 feet. For other pillar height values, there is a note where IC 8741 mentions a numerical method using an equation (13) to calculate the pillar width if seam thickness, room width and depth from surface are known; however, it did not cite the source of this equation.

$$
\left(\frac{W+R}{W}\right)^{2} 1.5 D=\frac{1000}{\sqrt{H}}+20\left(\frac{W}{H}\right)^{2}
$$

where W, R, H and D are pillar width, room width, seam thickness and depth from surface, respectively.

In the Kendorski report, the author states that IC 8741 uses the Wardell equation; however, in Phase III of the report, there is no equation to calculate the pillar width.

Additionally, Kendorski recommends Wardell’s equation. "Where room and pillar first working is to be carried out beneath or in the vicinity of any body of surface water at cover depth greater than the stipulated minimum, the width of the pillar should be determined in accordance with (tables). The minimum width of pillar is required for seam thicknesses other than those given in 
these tables, the width may be calculated using the below relationship” . It's suggested that the empirical relation (Equation 14) (Wardell, 1976) be used:

$$
\left(\frac{W+s}{W}\right)^{2} 1.5 D=\frac{1000}{t+20(W+t)^{2}}
$$

Where:

$\mathrm{W}=$ pillar width

$\mathrm{s}=$ room width

$\mathrm{t}=$ seam thickness

$\mathrm{D}=$ depth from surface

An exception can be made where specific local data (including relevant and comparable mining experience) exist which demonstrate that a lesser width could be used with safety.

Table 3.10: Pillar dimension for first workings

\begin{tabular}{|c|c|c|c|}
\hline IC 8741 & Skelly \& Loy & Wardell and Partners & Kendorski \\
\hline $\begin{array}{l}\text { This guideline uses some of the } \\
\text { Wardell table, but is shorter. The } \\
\text { pillar heights considered are } 3,4 \text {, } \\
6,8,10,12 \text { and } 14 \text { feet. For other } \\
\text { pillar height values, there is a note } \\
\text { where IC } 8741 \text { presents a } \\
\text { numerical method using an } \\
\text { equation to calculate the pillar } \\
\text { width if the seam thickness, room } \\
\text { width and depth from surface are } \\
\text { known; however, it did not cite the } \\
\text { source of this equation. } \\
\qquad\left(\frac{W+R}{W}\right)^{2} 1.5 D=\frac{1000}{\sqrt{H}} \\
\qquad+20\left(\frac{W}{H}\right)^{2} \\
\text { where W, R,H D are pillar width, } \\
\text { room width, seam thickness and } \\
\text { depth from surface, respectively. }\end{array}$ & $\begin{array}{l}\text { They do not use these tables to } \\
\text { dimension the pillar width; } \\
\text { Their pillar dimensioning is based } \\
\text { on Holland \& Gaddy equation } \\
\text { which consists in an estimation of } \\
\text { coal pillar strength: } \\
\text { Pillars should be dimensioned as } \\
\text { needed for stability and to } \\
\text { accommodate the room width. } \\
\text { Estimating strength (S) of coal } \\
\text { pillar: } \\
S=\frac{S_{C} \times D \times L}{T} \text { (psi) } \\
\text { where } \\
\mathrm{L}=\text { least width of the pillar (in) } \mathrm{T} \\
=\text { pillar thickness (in) } \\
\mathrm{S}_{\mathrm{c}}=\text { strength of the specimen } \\
\text { tested in the laboratory } \\
\mathrm{D}=\text { edge dimension of the } \\
\text { cubical specimen being tested. }\end{array}$ & $\begin{array}{l}\text { There are several } \\
\text { graphs for relating } \\
\text { pillar width with depth } \\
\text { for different pillar } \\
\text { height at a fixed room } \\
\text { width;These results are } \\
\text { displayed in tables } \\
\text { where the pillar height } \\
\text { is fixed and obtain the } \\
\text { minimum pillar width, } \\
\text { known the depth and } \\
\text { room width. These } \\
\text { tables are broad and the } \\
\text { pillar heights } \\
\text { considered are } 4,5,6 \text {, } \\
7,8,9,10 \text { and } 12 \text { feet. }\end{array}$ & $\begin{array}{l}\text { "Where room and pillar first } \\
\text { working is to be carried out } \\
\text { beneath or in the vicinity of any } \\
\text { body of surface water at cover } \\
\text { depth greater than the stipulated } \\
\text { minimum, the width of the pillar } \\
\text { should be determined in } \\
\text { accordance with tables. The } \\
\text { minimum width of pillar is } \\
\text { required for seam thicknesses other } \\
\text { than those given in these tables, the } \\
\text { width may be calculated using the } \\
\text { below relationship". It's suggested } \\
\text { that the empirical relation } \\
\text { (Wardell, } 1976) \text { be used: } \\
\left(\frac{W+s}{W}\right)^{2} 1.5 D=\frac{1000}{t+20(W+t)^{2}} \\
\text { Where, W = pillar width; } \mathrm{s}=\text { room } \\
\text { width; } \mathrm{t}=\text { seam thickness; } \mathrm{D}= \\
\text { depth from surface. }\end{array}$ \\
\hline $\begin{array}{l}\text { In Kendorski’s paper, he mentions } \\
\text { IC } 8741 \text { uses Wardell equation; } \\
\text { however, in the Phase III report, } \\
\text { there is no equation to calculate the } \\
\text { pillar width. }\end{array}$ & No additional comment. & $\begin{array}{l}\text { No additional } \\
\text { comment. }\end{array}$ & $\begin{array}{l}\text { An exception can be made where } \\
\text { specific local data (including } \\
\text { relevant and comparable mining } \\
\text { experience) exist which } \\
\text { demonstrate that a lesser width } \\
\text { could be used with safety. }\end{array}$ \\
\hline
\end{tabular}


This comparison only assessed Wardell' Phase III report, which did not demonstrate any equation for pillar width calculation. Table 3.10 presents a summary of the pillar dimension guidelines for the authors compared in this chapter.

\subsection{Particularities of Each Reference}

\subsubsection{IC 8741}

This guideline is a compilation of Skelly \& Loy and Wardell. There is nothing beyond to highlight.

\subsubsection{Skelly \& Loy}

The importance of Skelly \& Loy's work is due to the Level II Guidelines. The major testing for Level II recommendations for continental mining under surface bodies are shown below.

\subsubsection{For Total Extraction Guidelines}

- Core evaluation: obtain the geologic stratigraphy within the safety zone directly below and adjacent to the water body. Frequently, holes for reserve evaluation and mine planning are drilled on 330 foot center; however, this may prove inadequate for proper evaluation of strata under continental surface waters.

- Additional information can be obtained by aerial photography (color or color infrared low level photography would be the most applicable type). 


\subsubsection{Partial Extraction Guidelines}

Wherever cohesive roof rock strata that is equal in thickness to 5 times the width of the mined rooms exists between the workings and the water body:

\section{Roof evaluation:}

The roof rock must:

- Be evaluated to determine the rock quality designation;

- Be equal to or greater than 4,000 psi in compressive strength as determined by uniaxial tests;

- The thickness of the strata that fits requirement ii above must, when multiplied by the rock quality designation, give a resultant roof rock thickness equal to or greater than 5 times the mine room width.

\section{Hydraulics:}

"The most important hydraulic property which must be assessed in estimating water inflows is the permeability of overburden material and coal”.Pump-in-pressure-tests in drill holes conducted at near grade of an underground mine opening or tunnel.

\section{Determining the width of the heading:}

The width of the mined rooms will depend upon the strength and the horizontal stress component of the roof rock and its ability to span the opening. RQD is used as an indicator of roof stability.

Floor Rock evaluation:

Bearing capacity of laboratory tested core samples can be determined based on the theory of elasticity with a factor of safety of 4 by equation 15 :

$P=1.81 S_{o}$

Where:

$\mathrm{P}=$ safe bearing capacity and

$\mathrm{S}_{0}=$ tensile strength of the rock. 
A factor of safety of 4 is recommended due to the scarcity of empirical data to confirm the results of laboratory unconfined compressive tests.

\subsubsection{Wardell}

Definition of safety zones to bodies of surface water, the important points are:

- Illustrates the problem of tensile strains around the perimeter of the body of surface water. This illustration shows the zone of increased permeability (tensile zone) and subsided surface;

- Mentions the concern about the interaction between the unrestricted and restricted mining areas:

- The concern: the pillars towards the edges of the restricted mining zone could be loaded (possibly towards failure) by the effect of the adjacent total extraction. If this occurs, the system would be impaired and subsidence/tensile strain effects would be extended beneath the body of surface water.

- The consequence: water might percolate first into the unrestricted mining zone and thence into the restricted mining zone. If the depth of mining increases, the loading on the edge pillar in the restricted mining zone also increases.

\subsubsection{Kendorski}

"Numerous practical examples of this nature have led to the conclusion that not only the induced fractures are self sealing to some extent on account of weathering, being filled up by clay and silt, and so on, but it also appears that the fracturing is confined to the free surfaces such as the surface and the roof. It appears that for a significant part of the intermediate overburden, natural constraints prevent fracturing; or in other words, the induced stress is absorbed or resisted without any fracturing taking place”.

- Subsidence control plan: "this plan is required to contain a detailed description of the mining and other measures that might affect subsidence” .

- Sinkhole phenomena - surface damage as a result of collapse of the strata overlying old workings at shallow depth. Also called as "piping”. 
- " $81 \%$ of sinkholes in Pennsylvania took place at a cover of less than $100 \mathrm{ft}$. More than $50 \%$ of the incidents noted in Pennsylvania occurred 50 or more years after the completion of the mining operations. A few of the incidents took place even after 100 years and others happened soon after the mining operations. The sinkhole phenomena are generally associated with partially extracted seams by the room and pillar method".

- "A sinkhole is a circular or elliptical type surface subsidence which is usually associated with partial extraction of seams by room and pillar method at shallow cover.” .

\subsection{Dam Safety Classification System}

Regarding to dam safety classification system, the Federal Emergency Management Agency (FEMA) and the United States Army Corps of Engineers (USACE) are the two major entities to consider this aspect. However, they have different purposes. FEMA classification considers the potential hazards due to failure and the USACE classification considers the actions they should do if a dam failure occurs.

According to FEMA, "This hazard potential classification system categorizes dams based on the probable loss of human life and the impacts on economic, environmental, and lifeline interests" (page 5). For this entity, there are three levels of categories: low - no probable loss of human life and low economic and/or environmental losses; significant - no probable loss of human life but can cause economic loss, environmental damage, disruption of lifeline facilities, or can impact other concerns; and high - probable loss of life. 
The USACE classification system is "based on their probability of failure or the individual dam safety risk estimate considered as a combination of probability of failure and potential life safety, economic, environmental, or other consequences”. The classes are:

- Class I (urgent and compelling): dam is almost certain to fail under normal operation;

- Class II (urgent): dam failure could begin under normal operation;

- Class III (high priority): dam have issues which are significantly inadequate;

- Class IV (priority): dams are inadequate with low risks;

- Class V (normal): dam is considered adequately safe.

\subsection{Summary of Reports for Offset Guidelines}

Kendorski was thorough in analyzing the subsidence and fracturing due to mining under bodies of water. However, a considerable part Kendorski’s guidelines followed IC 8741. When considering catastrophic size of water, the author came up with similar recommendations as IC 8741, Skelly \& Loy, and Wardell. Kendorski’s most important contribution was to set less conservative guidelines when considering major potential water body size and limited potential water body size, once there are less risks in these situations. Skelly \& Loy also was thorough in the production of the Level II guidelines which allows more coal extraction if all parameters are reasonable due to investigations, testing and evaluations. 


\section{CHAPTER 4: Probabilistic Analysis \\ Method for Mineral Extraction Near Surface Water Bodies}




\subsection{Purpose}

This chapter serves two purposes: an event tree analysis is developed for quantifying potential changes in subsurface permeability triggered by vertical ground subsidence due to underground mining; and second, a sensitivity analysis is performed that compares and contrasts the probability of increased subsurface permeability in terms of offset surface distances from a reservoir rim.

This chapter frames mining under surface bodies of water with regards to current risk based analysis methods used in dam safety by the US Army Corps of Engineers and the US Bureau of Reclamation, specifically The Practical Application of Risk Assessment to Dam Safety by Gregg Scott (2011).

\subsection{Risk based approach for dam safety}

Literature has shown that strains induced by vertical ground subsidence induced by underground mining can cause changes in groundwater flow. The increased subsurface soil and rock permeability may lead to subsurface erosion and potential increased risk to the integrity of reservoirs and dams. This can occur at distances far beyond the subsidence zone which the current IC 8741 guidelines implement for offset distances. The adverse conditions resulting from underground mining for coal near or under surface bodies of water can affect the intended purpose of the dam or reservoir or, in the case of USACE dams and reservoirs, the Authorized Purposes.

The Authorized and Operating Purposes of USACE reservoirs (also termed projects) refer to the federal laws granting authority, and the purposes for which water is being controlled. Project authorizations are found in a variety of public laws passed by Congress and these are traced back to a series of River and Harbor and Flood Control acts passed by Congress since 1870. Purposes are promulgated by laws passed subsequent to project construction and may only be changed by the amendment of the law(s) which apply to that specific project (USACE, 1994). Specifically for this research, "intended purpose" relates to the ability and integrity of the structures and reservoirs to contain water. 
The US Bureau of Reclamation (USBR) and the US Army Corps of Engineers (USACE) incorporate risk analysis as the primary dam safety decision making tool (USACE, 2008). These organizations define and estimate risk based on understanding and documenting what the major contributors are in initiating a dam failure and why they occur. The USACE risk analysis methodology involves fully describing and evaluating site specific Potential Failure Modes then

applying event trees for a site-specific analysis. Event tree analysis is based on Quantitative Risk Assessment to estimate the probability of failure (Fell, 2000). Quantitative Risk Assessment is used for determining failure mode identification, analysis for probability of failure, and calculation of losses that would occur in case of failure.

\subsection{Factors Affecting Room and Pillar Mining}

The following paragraphs define the initial conditions of the mining operation including the strata and overall type of terrain where mining takes place. The probability of increased permeability is dependent on the type of overburden so that it is site specific. Sandstones tend to increase in permeability in the range of one order of magnitude while shale increases by a magnitude of 2 to 3 times (Van Roosendaal et al., 1995). These are the maximum changes in the permeability of the rock and will decrease over time. However, permanent change for hydraulic conductivity is normally an increase in 1 order of magnitude (10x).

Each of these initial conditions determines the probability of occurrence for each level in the event tree. These probability levels occur for both longwall (full extraction) and room and pillar (partial extraction) mining. Once mining has occurred, pillars will begin to deform due to the transmission of weight (Singh, 1992). As time increases, probabilities of these levels for partial extraction may become similar to longwall mining as pillars fail and maximum subsidence occurs.

\subsubsection{Pool Level}

The pool level of a reservoir is important in determining the risk of erosion occurrence. There are three typical pool levels considered: summer, winter and maximum pool level. Summer pool level, also known as sunny day, is most common for determining risk because it is the lowest normal conditions. However, for this analysis, the maximum pool level should be considered because it generates the greatest potential for failure due to erosion as this condition produces the 
highest hydraulic head. The maximum pool level is the highest peak level a reservoir is expected to reach over its lifespan. However, for specific locations, the maximum pool level could be deemed to be caused by a 100 year, 500 year or 1000 year storm, depending on the severity of the effects and expected outcome. The analysis would not consider the probability of the flood event occurrence only that it could occur during the lifespan of the reservoir. While this provides the greatest chance of seepage failure, summer and winter pool conditions need to be recognized as a constant since these are general conditions. The sunny day analysis would provide the everyday risk to the reservoir while the probable maximum flood would give the maximum risk to the reservoir. These can both be used in considering potential risk at specific locations.

\subsubsection{Time Intervals}

Unlike longwall mining, where subsidence is expected to occur almost immediately, room and pillar subsidence can occur over long periods of time. There is limited initial subsidence during the mining operation but as long as the pillars remain intact there will not be significant surface subsidence. Eventually, after a few pillars begin to fail there can be a domino effect creating subsidence similar to full extraction mining. When this occurs it will affect the likelihood of failure to a reservoir. While the pillars remain intact, changes in the hydrogeology of the strata will remain close to original conditions. If a flood event occurs during this time, the potential for failure due to erosion will be less than under conditions when the pillars had already failed.

Additionally, pillars will lose strength over time. Flood conditions could add additional stress to the pillars causing them to fail more rapidly than under sunny day conditions. This could create full subsidence conditions during the event or could speed up the failure rate of the pillars. In many room and pillar mining operations, retreat mining of pillars is common. In this analysis, retreat mining above $70 \%$ of the total coal seam would create full extraction conditions because the pillars would no longer be able to withstand the weight of the overburden. This scenario would follow the event tree path similar to longwall mining.

\subsubsection{Terrain Type}

The surface terrain directly above a room and pillar mine is important to determine the total stress on an individual pillar. In pillar design, stress is assumed to be evenly distributed throughout the mine plan (Farmer, 1992). However this assumption is based on level surface and 
does not consider steep terrain. In locations, such as the Appalachian mountain chain, there are significant elevation changes within mine locations. Stress on one pillar in a valley may be doubled on a pillar located under a hilltop or plateau. Unless the maximum possible stress is considered for each pillar, there is a potential for underestimation and faster occurrence of pillar failure. Pillar failure occurs when the stress exceeds the compressive strength of the pillar. Reliable measurements of average stress are rare because of the difficulty to obtain them (Farmer, 1992).

\subsubsection{Depth of Coal Seam}

The depth of the extracted coal seam has an effect on the angles of subsidence and accordingly the Angle of Groundwater Influence. In general terms, the deeper a mine is, the greater the potential affected area. In room and pillar mining the depth also has an effect on the pillars designed to support the roof. This has two effects on the potential failure of a pillar; the total weight a pillar must be designed to withstand and the total stress where the pillars contact the floor and roof of the mine. Pillars are designed to withstand the weight of the overburden for the lifetime of the mine for the protection of mine workers. Once they begin to fail, greater weight will be required to be supported by the pillars that remain intact. In deeper mines this weight will be more evenly distributed throughout the mine and into the untouched areas outside of the mine. In shallower mines failure of one pillar will have a greater affect on the surrounding pillars. For depth, the strength of these pillars needs to be able to withstand the stresses applied by the overburden. Failure of pillars can occur regardless of their strength if the contact layers cannot equal the stress applied.

\subsubsection{Angle of Dip}

The angle of dip is the angle in which a coal seam rises or falls with respect to horizontal. Room and pillar mining is not recommended above angles greater than 30 degrees. In the Appalachian mountain range, the angles of dip generally fall less than 10 degrees. The importance of angle of dip when considering the potential for failure is the stress that is placed on individual pillars. In areas of constant surface elevation and no dip in the coal seam, the stress in pillars will be evenly distributed. As previously discussed, changes in surface elevation will affect how much stress each pillar is required to withstand. Likewise the angle of dip will have the same effect. If a coal seam dips over the course of the extraction site, more overburden will be above one end of the 
mine than the other causing additional stress. If the seam dips under an area where the surface terrain rises, extreme conditions compared to normal expectation can occur which must be considered in design.

\subsubsection{Pillar Size}

The width-to-height ratio of pillars affects the likeliness of how the pillars fail. IC 8741 has specific guidelines for pillar design based on depth, height of coal seam and room width. This only applies for the safety of the workers during the operation of the mine. Studies have shown that pillars with a width to height ratio greater than one-third behave in more of a yielding fashion. This means they are prone to compression creating a sagging effect on the roof. This type of failure occurs more slowly than fracturing of a pillar. However, in this type of yielding, the pillars could also push or "punch" through the roof or floor creating a localized zone of vertical and horizontal fracturing. This fracturing diminishes the integrity of the roof layer and its ability to support the overburden. Fracturing in this instance could cause a greater zone of caving and fracturing above the levels investigated in literature. Pillars with width-to-height ratios less than one-third tend to be more brittle in nature. These ratios mean the pillars are more elongated and have a smaller cross sectional area causing them to crack. The effect is a more rapid failure of the pillar and subsidence effect. This type of failure may not manifest for a long period after mining but can occur almost without warning.

\subsubsection{Geologic Makeup of Mine Roof or Floor}

The type of rock found directly above or below a mine seam will impact the ability for support structures to function properly. Pillar design requires that the pillar stress does not exceed the maximum stress capacity of the rock it is in contact with. However, this is determined while all pillars are assumed to be intact. Once pillars begin to fail, the stress on other pillars and their contact with strata increases. If the maximum stress level on the roof or floor is exceeded, the roof will fracture around the pillar creating a punching effect. This leads to vertical fracturing and additional stresses on other pillars creating an immediate domino effect and subsidence zone.

\subsubsection{Event Trees for Room and Pillar Mining}

Figures 4.1 and 4.2 outline a generalized event tree developed for this failure mode due to room and pillar (partial extraction) mining. 


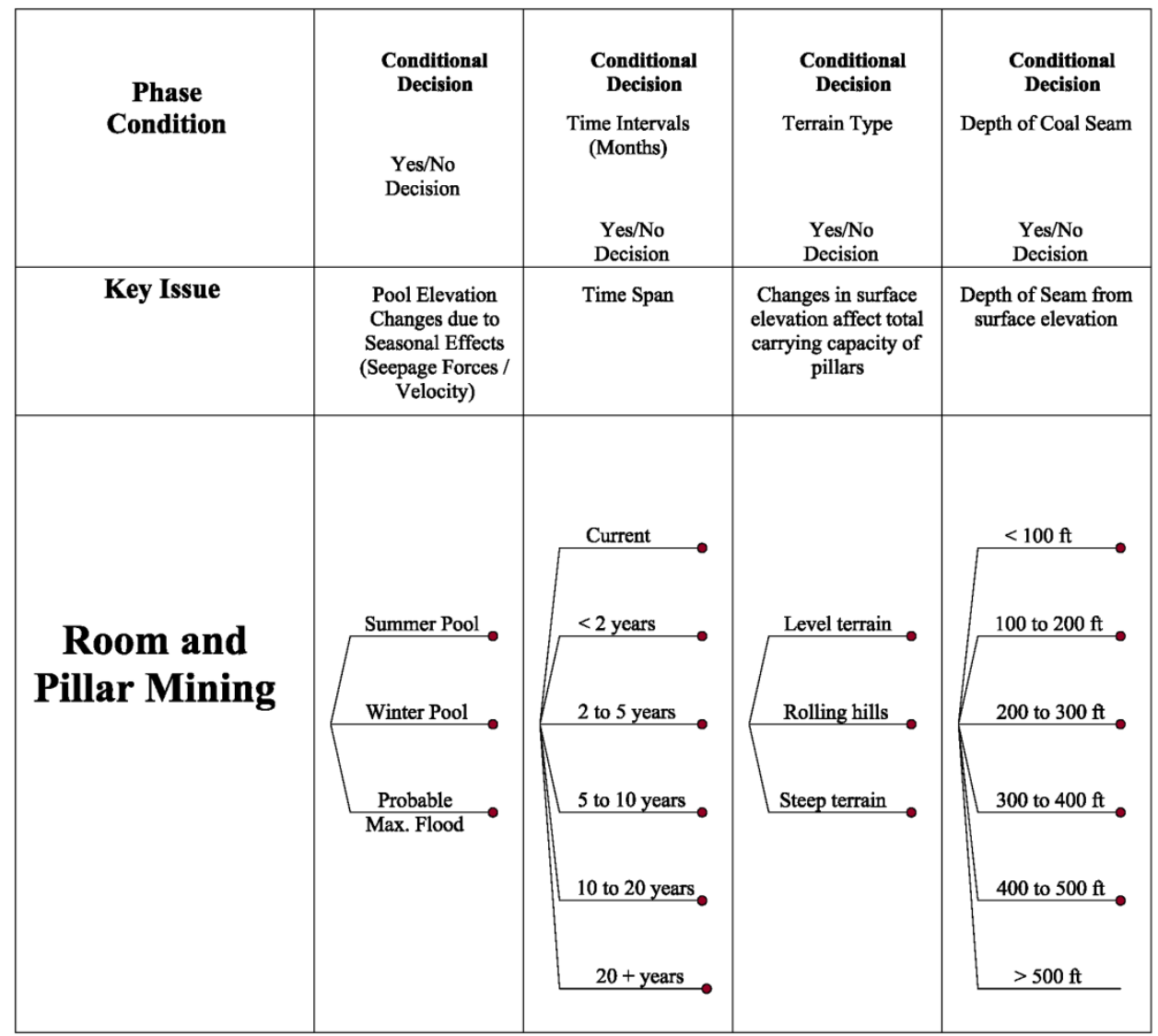

Figure 4.1: Failure mode event tree for room and pillar mining (After Wachtel, 2012) 


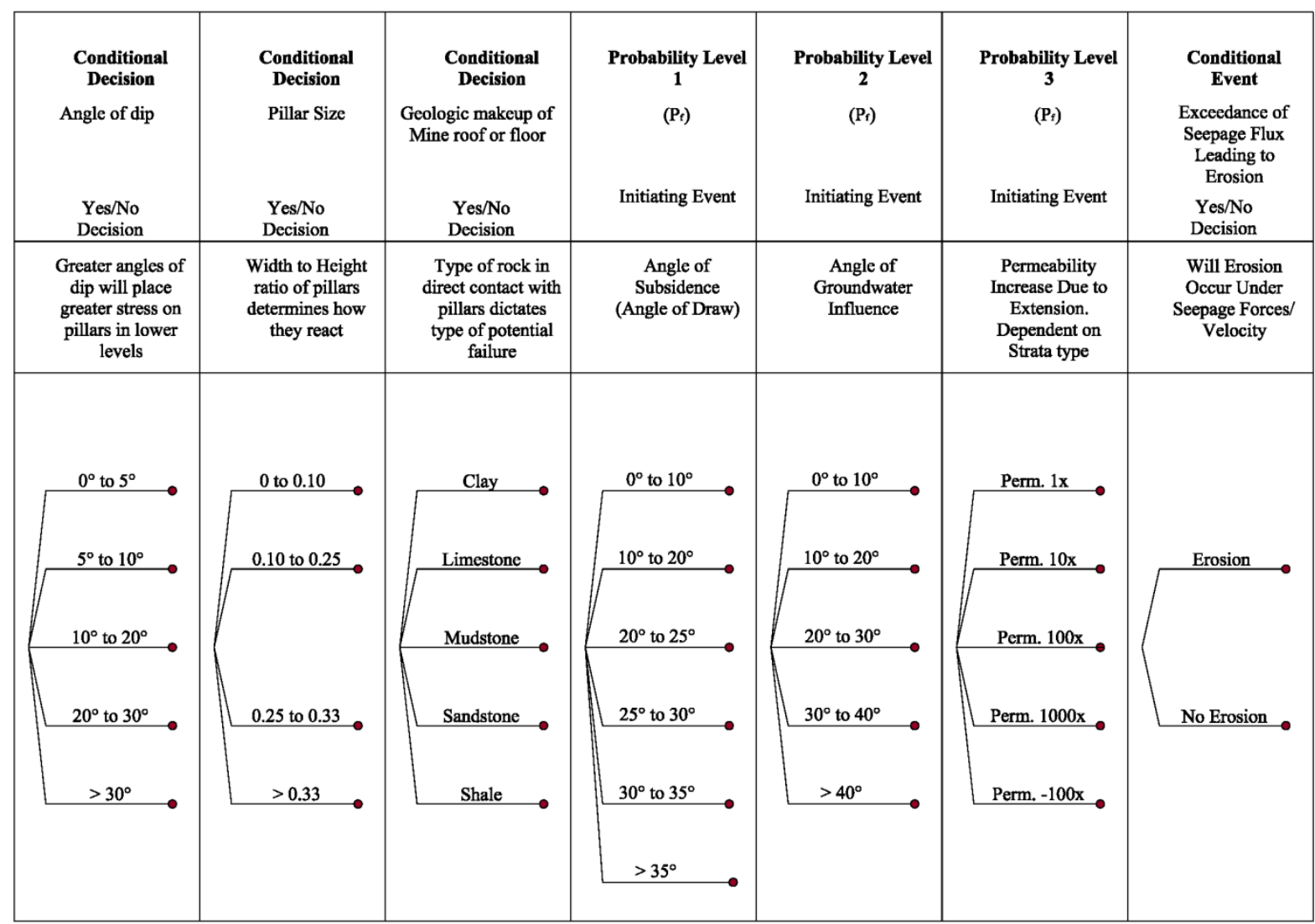

Figure 4.2: Continuation of failure mode event tree for room and pillar mining (After Wachtel, 2012)

The conditional decisions are based on how the pillars may fail, however. A different method of analysis is to use the factor of safety of the pillars for partial extraction, as the parameters described above are generally used in pillar design. An example of an event tree using this method is shown in Figure 4.3. 


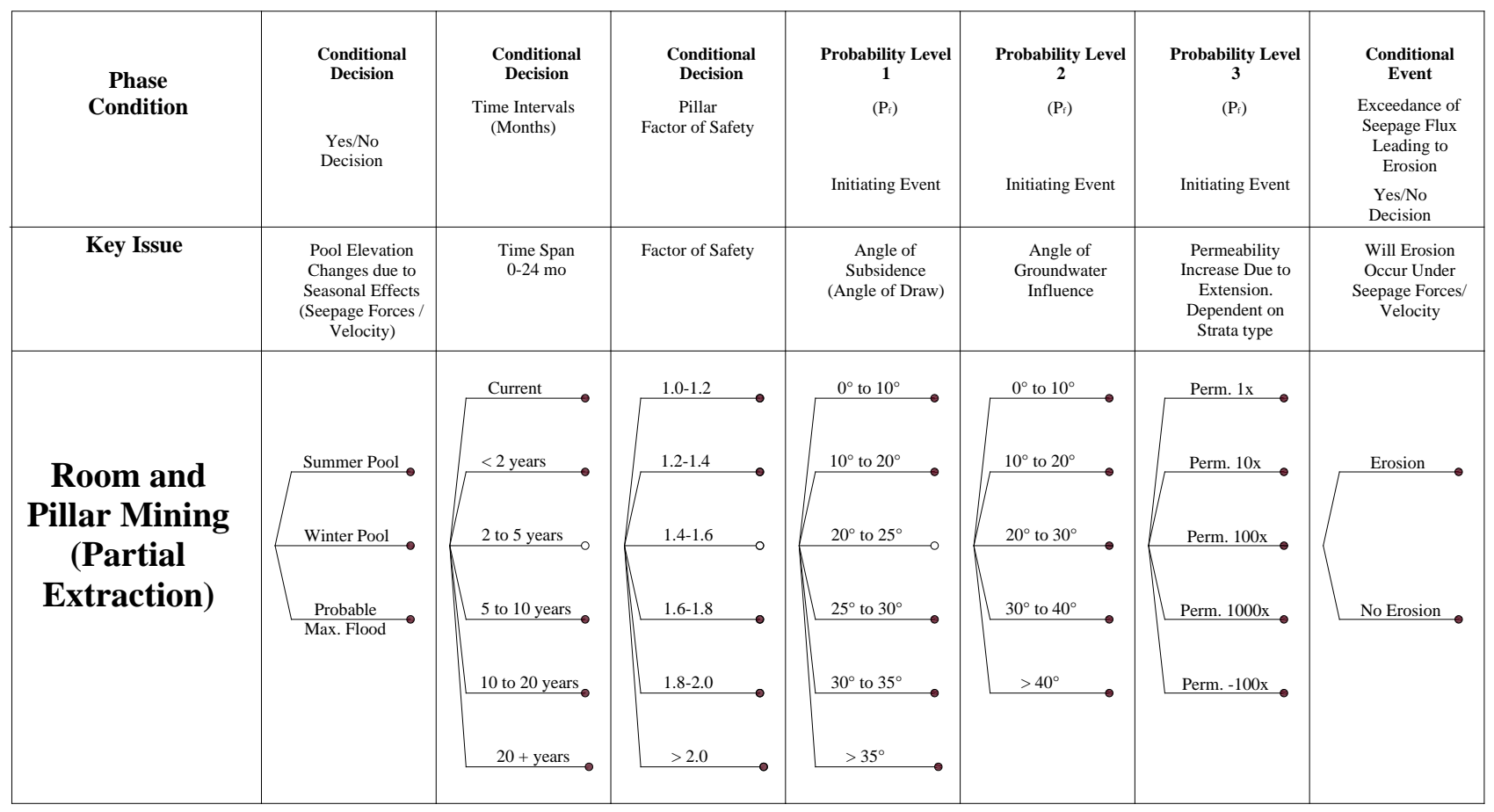

Figure 4.3: Room and Pillar event tree using factor of safety for pillars

The conditional decisions discussed will lead into the probability levels detailed in Section 4.5.

\subsection{Factors Affecting Longwall Mining}

Characteristics of subsidence for longwall mining (full extraction) initiate immediately after the critical width is reached. References cite full subsidence effects occur within a few weeks to 10 years post mining (Singh, 1992). The initial conditions for potential reservoir failure, where failure is considered as uncontrolled reservoir pool level due to seepage, are predetermined based on the following items and are illustrated in an event tree structure in Figure 4.4. 


\begin{tabular}{|c|c|c|c|c|c|}
\hline $\begin{array}{c}\text { Phase } \\
\text { Condition }\end{array}$ & $\begin{array}{c}\begin{array}{c}\text { Conditional } \\
\text { Decision }\end{array} \\
\text { Time Intervals } \\
\text { (Months) } \\
\\
\text { Yes/No } \\
\text { Decision } \\
\end{array}$ & $\begin{array}{c}\text { Probability Level } \\
1 \\
\left(\mathrm{P}_{\mathrm{f}}\right) \\
\text { Initiating Event }\end{array}$ & $\begin{array}{c}\text { Probability Level } \\
\text { 2 } \\
\left(\mathrm{P}_{t}\right) \\
\\
\text { Initiating Event }\end{array}$ & $\begin{array}{c}\text { Probability Level } \\
\mathbf{3} \\
\left(\mathrm{P}_{\mathrm{f}}\right) \\
\\
\text { Initiating Event }\end{array}$ & $\begin{array}{l}\text { Conditional } \\
\text { Event } \\
\text { Exceedance of } \\
\text { Seepage Flux } \\
\text { Leading to } \\
\text { Erosion } \\
\text { Yes/No } \\
\text { Decision }\end{array}$ \\
\hline Key Issue & Time Span & $\begin{array}{c}\text { Angle of } \\
\text { Subsidence } \\
\text { (Angle of Draw) }\end{array}$ & $\begin{array}{l}\text { Angle of } \\
\text { Groundwater } \\
\text { Influence }\end{array}$ & $\begin{array}{l}\text { Permeability } \\
\text { Increase Due to } \\
\text { Extension. } \\
\text { Dependent on } \\
\text { Strata type }\end{array}$ & $\begin{array}{c}\text { Will Erosion } \\
\text { Occur Under } \\
\text { Seepage Forces/ } \\
\text { Velocity }\end{array}$ \\
\hline $\begin{array}{c}\text { Longwall } \\
\text { Mine }\end{array}$ & 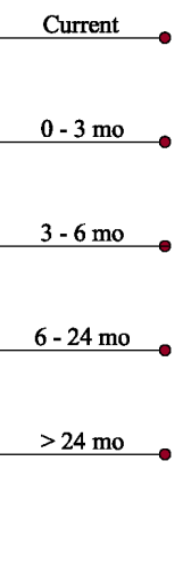 & \begin{tabular}{|l}
$0^{\circ}$ to $10^{\circ}$ \\
$10^{\circ}$ to $20^{\circ}$ \\
$20^{\circ}$ to $25^{\circ}$ \\
$25^{\circ}$ to $30^{\circ}$ \\
$30^{\circ}$ to $35^{\circ}$ \\
$>35^{\circ}$ \\
\end{tabular} & $\begin{array}{l}0^{\circ} \text { to } 10^{\circ} \\
10^{\circ} \text { to } 20^{\circ} \\
20^{\circ} \text { to } 30^{\circ} \\
30^{\circ} \text { to } 40^{\circ} \\
>40^{\circ} \\
\end{array}$ & $\begin{array}{c}\text { Perm. 1x } \\
\text { Perm. 10x } \\
\text { Perm. 100x } \\
\text { Perm. 1000x } \\
\text { Perm. }-100 \mathrm{x}\end{array}$ & No Erosion \\
\hline
\end{tabular}

Figure 4.4: Failure mode event tree for longwall mining

\subsubsection{Pool level elevation}

The change in pool level from summer elevations and the expected frequency of occurrence; for example, the likelihood that a probable maximum flood will occur during mining operations. This must be taken into account to defend possibility of occurrence while theoretically unlikely. Lowering of elevation will cause the probability of seepage to diminish, however it may cause periods of saturation to unsaturated soils breaking up the particles in the soil increasing the likelihood of erosion.

\subsubsection{The time frame of operations}

Determination of whether mining is currently taking place or the length of time that has passed since mining operations have occurred affects the probability of the change in order of magnitude in permeability (order of magnitude $1 \mathrm{x}-3 \mathrm{x}$ ). 
Each of these initial conditions determines the probability of occurrence for each level in the event tree.

These initial conditions are dependent on the strata and overall type of terrain where mining takes place. These conditional decisions show the likely causes of maximum ground subsidence and each will have an impact on the total time frame for maximum subsidence. Maximum subsidence is considered when the mine void is completely filled with rubble, and compaction of the voids can no longer occur (Singh, 1992).

\subsection{Probability Levels}

The following are the probability levels that will affect the potential for seepage. The likelihood of each branch to occur is based on factors determined in the field and discussed previously for room and pillar and longwall mining.

\subsubsection{Level 1 Subsidence Angle of Draw}

The angle of draw determines the horizontal surface distance from the mine that subsidence occurs. The average angle for the Appalachian mountain range is 23-25 degrees, while field tests have shown this angle extending up to 42 degrees. In this range there is an expectancy of surface fracturing and strains greater than $0.001 \mathrm{in} / \mathrm{in}$. The probability of continuation for failure is based on the proximity of this zone to the pool rim. If the reservoir edge lies within the angle of draw the probability of seepage will lie near 1 . If it lies outside of the angle of draw, the probability will become based on the expectancy of groundwater draw.

\subsubsection{Level 2 Angle of Groundwater Influence}

The Angle of Groundwater Influence determines the horizontal distance from the mine that change in groundwater flow is likely to occur. This angle is correlated to the angle of draw but not dependant on it. However, in all conditions it is expected to extend past the Angle of Subsidence Draw. In the Appalachian mountain range this angle generally falls between 30 and 40 degrees with maximum angles up to 60 degrees. If the rim falls within this horizontal range, the probability of seepage and erosion will be near 1 . Studies have shown that water levels have shown to drop outside this range due to locations of aquifers and horizontal groundwater flow. The probability of failure for rims lying outside the Angle of Groundwater Influence is based on 
field studies conducted on the region. As the horizontal distance (L) increases, the probability of continuation to the next level decreases.

\subsubsection{Level 3 Permeability Increase}

The probability of permeability increase at the reservoir rim is based on the distance between the extents of subsidence and groundwater draw to the pool. The closer either of these extents are, the greater the likelihood of continuation for failure. The characteristics of the strata will have an effect on the amount of change in permeability. During mining operations a condition called a subsidence wave occurs that creates zones of tension and compression. Typically compression occurs within the mine trough while tension occurs at the edges extending outwards. However changes from compression to tension, or vice versa, will occur internally to the panel as mining passes or concludes.

Typical changes in permeability range from 10x to 1000x normal conditions in tensional areas and $-10 \mathrm{x}$ in compressional areas. Once mining has concluded, the permeability tends to fall back towards it normal conditions but never fully recover.

\subsubsection{Conditional Event - Erosion}

Based on the reservoir event tree, the probability of erosion is determined based on the preceding factors. The potential for erosion to occur is predicted by determining the likelihood of the initialing events occurring. Each decision and probability level is split into factors that would affect the overall risk. The actual amount of branches for each level would be determined by the overall change in risk from the low end and high end of each branch. For example, if a 10 degree Angle of Groundwater Influence poses minimal risk to a reservoir but a 20 degree angle

represents considerable risk, the range of that branch would be to great and required to be broken down into several branches. For this analysis, only generalized values were used and would need to be detailed further. 


\subsection{Probability Analysis}

\subsubsection{Subsidence}

\subsubsection{Timeframe of subsidence}

Room and pillar mining has shown that subsidence will continue to occur as the pillars fail and the overburden caves. Maximum subsidence occurs when the pillars completely fail and the roof collapses into the mine void. This is highly dependent based on factors such as rock strength, degree of fracturing and water presence (Singh, 1992).

Studies have shown that this can occur over long periods of time and in several cases, subsidence from room and pillar mining was continuing to occur over one hundred years (Singh, 1992). There is no common trend for the time frame of pillar collapse. Therefore analysis for this method of mining cannot be easily generalized and would require site specific information. However, when considering in perpetuity, likelihood of pillar failure and maximum subsidence becomes great and could be treated similar to full extraction mining under this analysis. The only exception would be that, because it occurs over a longer period of time, shale and clays found in the overburden may potentially self heal and total increase in hydraulic conductivity may not be as dramatic as longwall mining.

Unlike room and pillar mining which can take decades for maximum subsidence to occur, subsidence from longwall mining occurs over a short period; generally 2 to 3 years. Subsidence from full extraction mining occurs within the lifespan of the mine, making it more identifiable. As previously discussed, multiple variables in the geologic profile above a mine can affect the timeframe of subsidence in room and pillar mining due to pillar failure. Full extraction mining does not have the same qualifications since panel rooms are completely mined.

\subsubsection{Typical Subsidence Values}

The probability event tree analysis is based on the condition that maximum subsidence has occurred and considers increased post-mining time frames greater than 50 years. These time frames are generally within the intended purpose periods of most dams and reservoirs or the Authorized Purpose periods for USACE projects. Reference data from the SME Handbook (Singh, 1992) provides ranges for Angle of Subsidence Draw. No field data was used in the 
event tree analysis. The data was collected between 1936 and 1981. While the data may appear to be potentially outdated, no significant databases were available providing recent information ( $<20$ years) beyond information on a few specific sites. The data ranges shown here are from what has been referred to as the "Golden Age” for subsidence research. The data is illustrated in Table 4.1.

Table 4.1: Typical values of Angle of Subsidence Draw Draw (After Singh, 1992)

\begin{tabular}{|c|l|c|}
\hline Range \# & \multicolumn{1}{|c|}{ Eastern Coalfield } & $\begin{array}{c}\text { Angle of } \\
\text { Draw } \\
\text { (Degrees) }\end{array}$ \\
\hline 1 & Southwestern, PA (after Newhall and Plein (1936)) & $10-25$ \\
\hline 2 & Appalachian (after Cortis (1969)) & $15-27$ \\
\hline 3 & Appalachian (after Peng and Chyan (1981)) & $22-38$ \\
\hline 4 & Northern Appalachian (after Adamek and Jeran (1981)) & $12-17$ \\
\hline 5 & Illinois (after Wade and Conroy (1977)) & $23-29$ \\
\hline 6 & Illinois (after Conroy 1979)) & $15-30$ \\
\hline 7 & Illinois (after Bauer and Hunt (1981)) & $12-26$ \\
\hline
\end{tabular}

Changes in the angle of groundwater influence and permeability are dependent on terrain type and the geologic makeup of the overburden. While assumptions can be made to determine the probabilities of occurrence for the event tree, they are site specific. However, these changes are expected to extend past the subsidence angle of draw. Therefore the subsidence angle of draw is used as the minimum offset distance where permeability changes will occur.

\subsubsection{Normal Monte Carlo Distribution}

The normally distributed random numbers used in this research were created for each data set in Table 4.1 based on the mean and standard deviation. The probability of the normally distributed numbers to fall within each range was calculated by counting the number of values that fall within the range and dividing by ten thousand, the total number of values calculated for each data set and provided in Table 4.2. The average is the probability given equal weight for each set of the data ranges. These are the probabilities used for Angle of Subsidence Draw in this analysis. The probability for Subsidence Angle of Draw values greater than 29.74 degrees was also calculated in Table 4.2. This represents the potential for subsidence to reach the rim of a reservoir at a depth of $350 \mathrm{ft}$. This is the maximum depth for the $200 \mathrm{ft}$ minimum lateral offset based on IC 8741 guidelines. 
Table 4.2: Normal distribution probabilities for data sets

\begin{tabular}{|c|c|c|c|c|c|c|c|c|}
\hline \multicolumn{9}{|c|}{ Results } \\
\hline Data Set \# & 1 & 2 & 3 & 4 & 5 & 6 & 7 & Average \\
\hline $\mathrm{P}(>29.74)$ & 0.002 & 0.006 & 0.517 & 0.000 & 0.015 & 0.045 & 0.004 & 0.000 \\
\hline $\mathrm{P}(0-10)$ & 0.042 & 0.000 & 0.000 & 0.001 & 0.000 & 0.002 & 0.014 & 0.008 \\
\hline $\mathrm{P}(10-20)$ & 0.680 & 0.387 & 0.016 & 0.999 & 0.000 & 0.278 & 0.581 & 0.420 \\
\hline $\mathrm{P}(20-25)$ & 0.236 & 0.485 & 0.126 & 0.000 & 0.286 & 0.435 & 0.332 & 0.271 \\
\hline $\mathrm{P}(25-30)$ & 0.041 & 0.122 & 0.365 & 0.000 & 0.703 & 0.246 & 0.070 & 0.221 \\
\hline $\mathrm{P}(30-35)$ & 0.002 & 0.006 & 0.357 & 0.000 & 0.011 & 0.038 & 0.003 & 0.059 \\
\hline $\mathrm{P}(>35)$ & 0.000 & 0.000 & 0.137 & 0.000 & 0.000 & 0.002 & 0.000 & 0.020 \\
\hline Total & 1.000 & 1.000 & 1.000 & 1.000 & 1.000 & 1.000 & 1.000 & 1.000 \\
\hline
\end{tabular}

Normal (Gaussian) distribution was used for determining the probability of the extents of the Angle of Subsidence Draw. This method of distribution was used as there was limited data available on the measured subsidence extents in the field for this report. While the data indicates a series of ranges, it does not detail whether the distribution of that data is skewed to the left or the right and cannot be justified. Therefore it is assumed that the data sets represent and even or normal distribution over the extents. This assumes that $68.3 \%$ will fall within one standard deviation of the mean, 95.4\% within 2 standard deviations, and 99.7\% within 3; known as the 3sigma rule.

The data used was a set of 7 ranges of values for subsidence extents. An individual set of ranges may skew the data as one outlier would unnaturally increase the mean. However, by using multiple sets of ranges, the effect of outliers is limited.

\subsubsection{Lognormal Distribution}

Table 4.3 shows the probability for the angle of groundwater influence based on subsidence ranges from Table 4.2. These values are based on literature showing an average range to be 20 to 40 degrees, with greater angles possible in areas of steep terrain (Booth, 2006). There is no direct correlation between this angle and the angle of draw from subsidence except that it extends past the angle of draw. The method used for this analysis was a lognormal distribution due to the ability to return only positive values. The mean expected value for groundwater angle of influence was 30 degrees except for where low subsidence angles occurred. The lognormal distribution was truncated using the minimum values given in each subsidence range. An example is shown in Figure 4.5 representing the probability of a thirty to forty degree angle of 
groundwater influence given a 20 to 25 degree subsidence angle of draw. This also allowed for the minimal potential of extreme cases that occur in the field. For example Booth (2006) and Reed and Rauch (2001) indicate angles of groundwater influence exceeding 60 degrees. In this analysis such cases were only present where large angles of subsidence occurred. However the majority of these cases still provided groundwater influence angles within the 40 degree range provided in literature.

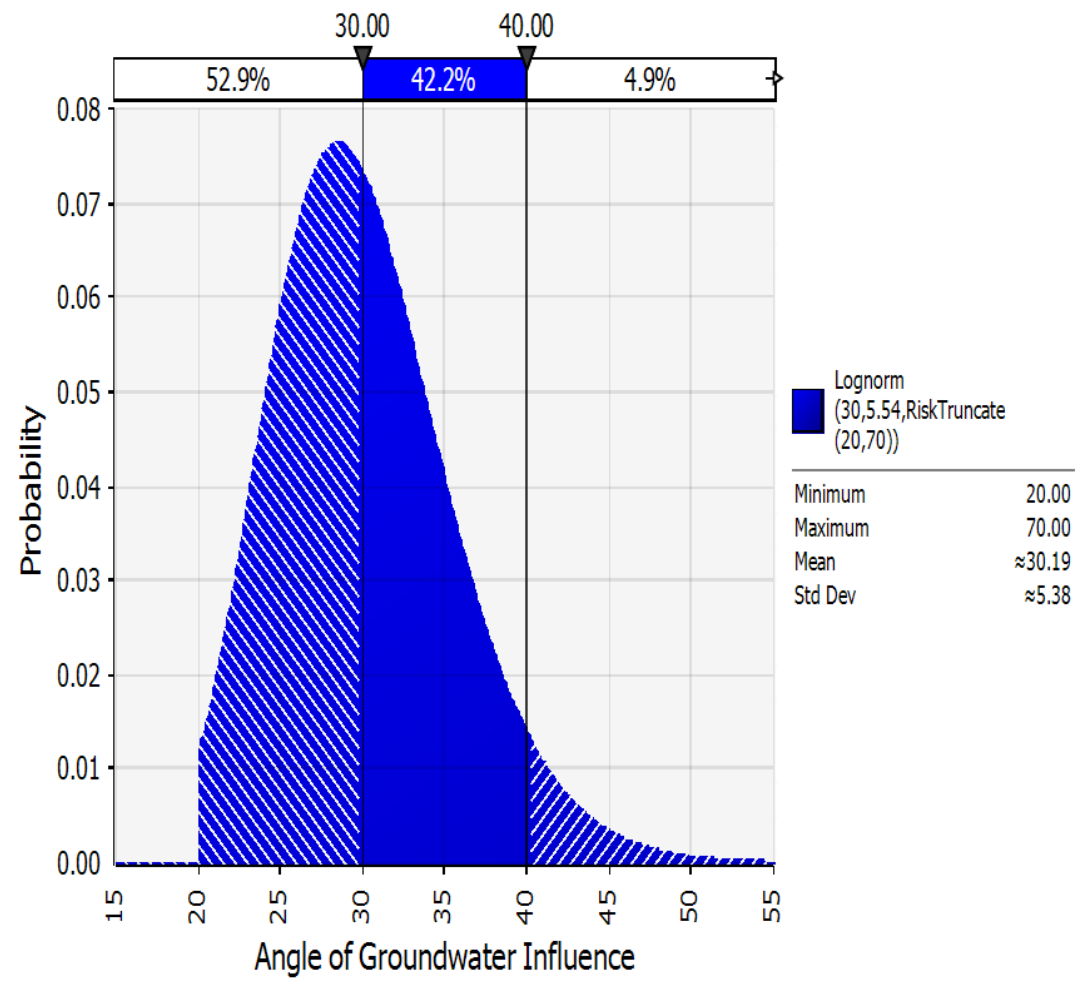

Figure 4.5: Truncated lognormal distribution for twenty to twenty-five degree subsidence range

More conservative values for the mean groundwater angle of influence were used as the expectancy for changes in the subsurface were less in these cases. A 40 degree angle of groundwater influence would be unlikely if the mine void only caused a minimal Angle of Subsidence Draw (10 degrees); this was accounted for by lowering the mean of groundwater influence to minimal values. The values in Table 4.3 depict groundwater being affected beyond the Angle of Subsidence Draw. 
Table 4.3: Probability of groundwater draw based on Angle of Subsidence Draw

\begin{tabular}{|c|c|c|c|c|c|c|}
\hline \multirow{2}{*}{ Groundwater Draw } & \multicolumn{7}{|c|}{ Angle of Subsidence Draw } \\
\cline { 2 - 7 } & $\begin{array}{c}0-10 \\
\text { Degrees }\end{array}$ & $\begin{array}{c}10-20 \\
\text { Degrees }\end{array}$ & $\begin{array}{c}20-25 \\
\text { Degrees }\end{array}$ & $\begin{array}{c}25-30 \\
\text { Degrees }\end{array}$ & $\begin{array}{c}30-35 \\
\text { Degrees }\end{array}$ & $\begin{array}{c}35-40 \\
\text { Degrees }\end{array}$ \\
\hline 0-10 Degrees & 0.008 & 0.000 & 0.000 & 0.000 & 0.000 & 0.000 \\
\hline 10-20 Degrees & 0.549 & 0.185 & 0.000 & 0.000 & 0.000 & 0.000 \\
\hline 20-30 Degrees & 0.395 & 0.651 & 0.528 & 0.432 & 0.000 & 0.000 \\
\hline 30-40 Degrees & 0.048 & 0.164 & 0.422 & 0.508 & 0.894 & 0.722 \\
\hline 40-50 Degrees & 0.000 & 0.000 & 0.048 & 0.057 & 0.101 & 0.266 \\
\hline 50-60 Degrees & 0.000 & 0.000 & 0.002 & 0.003 & 0.004 & 0.011 \\
\hline >60 Degrees & 0.000 & 0.000 & 0.00 & 0.00 & 0.001 & 0.001 \\
\hline Total Probability & 1.000 & 1.000 & 1.000 & 1.000 & 1.000 & 1.000 \\
\hline
\end{tabular}

\subsubsection{Changes in Permeability}

Table 4.4 provides estimates for the increase in permeability within the Angle of Subsidence Draw. As detailed previously, the actual change is dependent on strata type, proximity to the mine void, and distributed strain. Since this is site specific, the values are similar for each angle of groundwater influence. Highest probability was given for an increase by two orders of magnitude because both shale and sandstone can fall into this range. For the Angle of Groundwater Influence occurring within 10 degrees of the mine, a higher probability of decreased permeability is expected. For this analysis, any increase in permeability was determined to have the potential for subsurface erosion to occur.

Table 4.4: Changes in permeability based on Angle of Subsidence Draw Draw

\begin{tabular}{|l|c|c|c|c|c|}
\hline \multirow{2}{*}{$\begin{array}{c}\text { Permeability } \\
\text { Change }\end{array}$} & \multicolumn{5}{c|}{ Subsidence Draw } \\
\cline { 2 - 6 } & $\begin{array}{c}0-10 \\
\text { Degrees }\end{array}$ & $\begin{array}{c}10-20 \\
\text { Degrees }\end{array}$ & $\begin{array}{c}20-30 \\
\text { Degrees }\end{array}$ & $\begin{array}{c}30-40 \\
\text { Degrees }\end{array}$ & $\begin{array}{c}>40 \\
\text { Degrees }\end{array}$ \\
\hline No Increase & 0.15 & 0.15 & 0.15 & 0.15 & 0.15 \\
\hline Increase 10x & 0.25 & 0.30 & 0.30 & 0.30 & 0.30 \\
\hline Increase 100x & 0.40 & 0.40 & 0.40 & 0.40 & 0.40 \\
\hline Increase 1000x & 0.15 & 0.14 & 0.14 & 0.14 & 0.14 \\
\hline Decrease 100x & 0.05 & 0.01 & 0.01 & 0.01 & 0.01 \\
\hline Total Probability & 1.00 & 1.00 & 1.00 & 1.00 & 1.00 \\
\hline
\end{tabular}

\subsubsection{Event Tree Analysis}

The values provided in the event tree show the probability that the next step could occur given the prior actions have taken place. For example, once full subsidence has been reached, the 
expectancy for a 25-30 degree Angle of Subsidence Draw is approximately $22 \%$ in this analysis. The angle of groundwater influence is dependent on the subsidence angle of draw and its probability is subject to change. In the example provided in Figure 4.6, there is a $43.2 \%$ likelihood of groundwater influence extending between 20 and 30 degrees for this particular range. This is then multiplied by the potential extent that permeability increases within the groundwater zone of influence. The final number at the right shows the likelihood (in percentage) of this particular branch occurring. This would be added to all other possible branches in the event tree to determine a final probability of subsurface erosion potential.

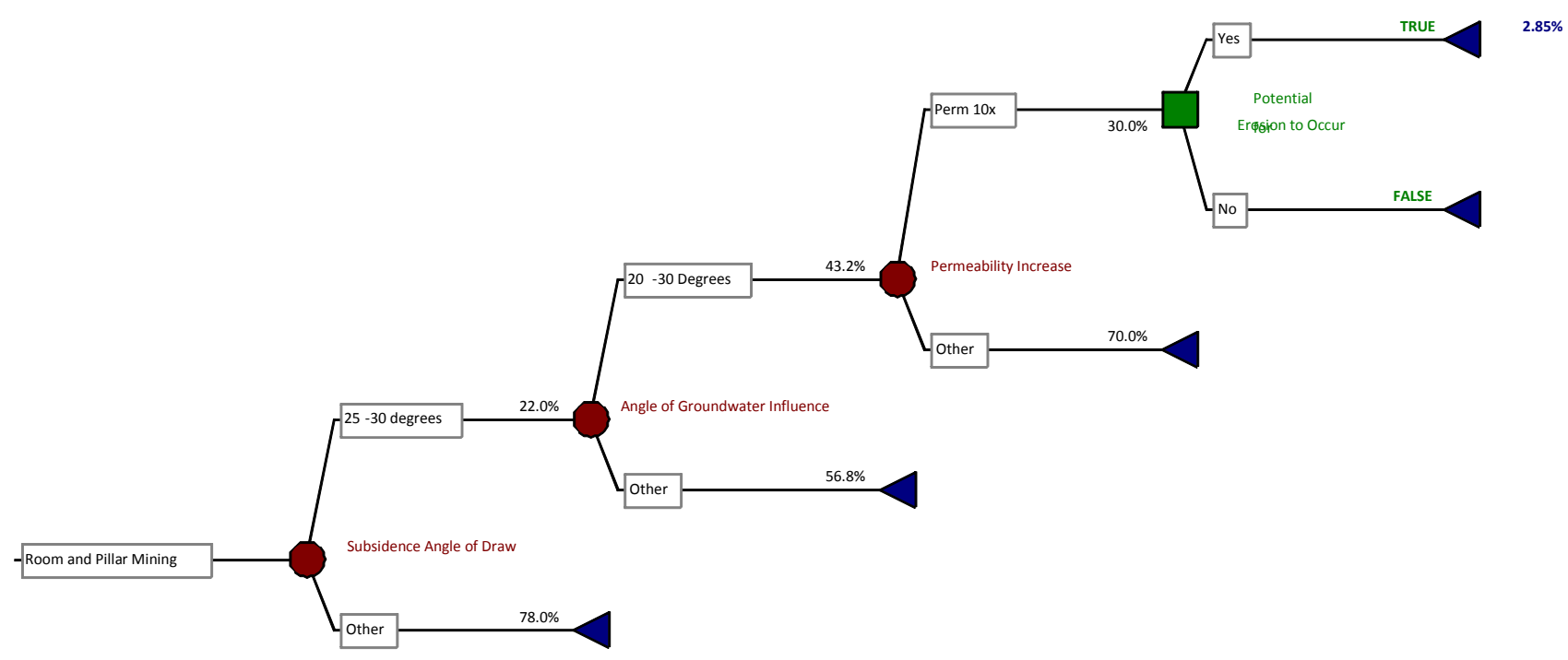

Figure 4.6: Example branch of event tree for a 25-30 degree Subsidence Angle of Draw 


\subsection{Results}

An analysis was performed for longwall mining near a surface body of water given the surface distance ranges of 200, 400, and 600ft (61,122, and 183m). This analysis provides an empirical estimation for probability that permeability will change at the probable maximum flood perimeter potentially triggering subsurface erosion. The analysis assumed a 350ft (107m) deep mine located at offsets of 200, 400 and 600ft $(61,122$, and 183m) respectively. The results of the event tree analysis are that at a $200 \mathrm{ft}(61 \mathrm{~m})$ offset the probability that permeability will increase was approximately $0.41(41 \%)$. At 400ft (122m) the probability decreased to $0.0066(0.66 \%)$ and at $600 \mathrm{ft}(183 \mathrm{~m})$ the probability was calculated at $0.000067(0.0067 \%)$. The values are shown in Table 4.5. They depict the potential for permeability change given the probability for each subsidence range.

Table 4.5: Probability for erosion to occur based on offset distance

\begin{tabular}{|c|c|c|c|c|c|c|c|}
\hline \multirow[b]{2}{*}{ Offset Distance } & \multicolumn{6}{|c|}{ Potential for Erosion Given Angle of Subsidence Draw } & \multirow{2}{*}{$\begin{array}{c}\text { Total } \\
\text { Probability }\end{array}$} \\
\hline & $\begin{array}{c}0-10 \\
\text { Degrees }\end{array}$ & $\begin{array}{c}10-20 \\
\text { Degrees }\end{array}$ & $\begin{array}{c}20-25 \\
\text { Degrees }\end{array}$ & $\begin{array}{c}\text { 25-30 } \\
\text { Degrees }\end{array}$ & \begin{tabular}{|c|}
$30-35$ \\
Degrees
\end{tabular} & \begin{tabular}{|c|}
$35-40$ \\
Degrees
\end{tabular} & \\
\hline $200 \mathrm{ft}$ & 0.001 & 0.096 & 0.127 & 0.118 & 0.050 & 0.017 & 0.41 \\
\hline $400 \mathrm{ft}$ & 0.000 & 0.000 & $2.3 \mathrm{E}-03$ & $2.3 \mathrm{E}-03$ & $1.1 \mathrm{E}-03$ & 9.5E-04 & $6.6 \mathrm{E}-03$ \\
\hline $600 \mathrm{ft}$ & 0.000 & 0.000 & 0.000 & 0.000 & $5.0 \mathrm{E}-05$ & $1.7 \mathrm{E}-05$ & $6.7 \mathrm{E}-05$ \\
\hline
\end{tabular}

\subsection{Conclusions}

Underground mining causes changes in the overburden strain resulting in changes to subsurface permeability. As the horizontal distance between a longwall mine and a reservoir increases, the likelihood that subsidence based changes in permeability (and groundwater flow) will have an impact decreases. The event tree analysis results, shown in Figure 4.7, shows that there can be a significant reduction in the potential for changes in permeability as the offset distances increases from 200ft (40.96\%), 400ft (0.0067\%) and 600ft (0.000067\%). 


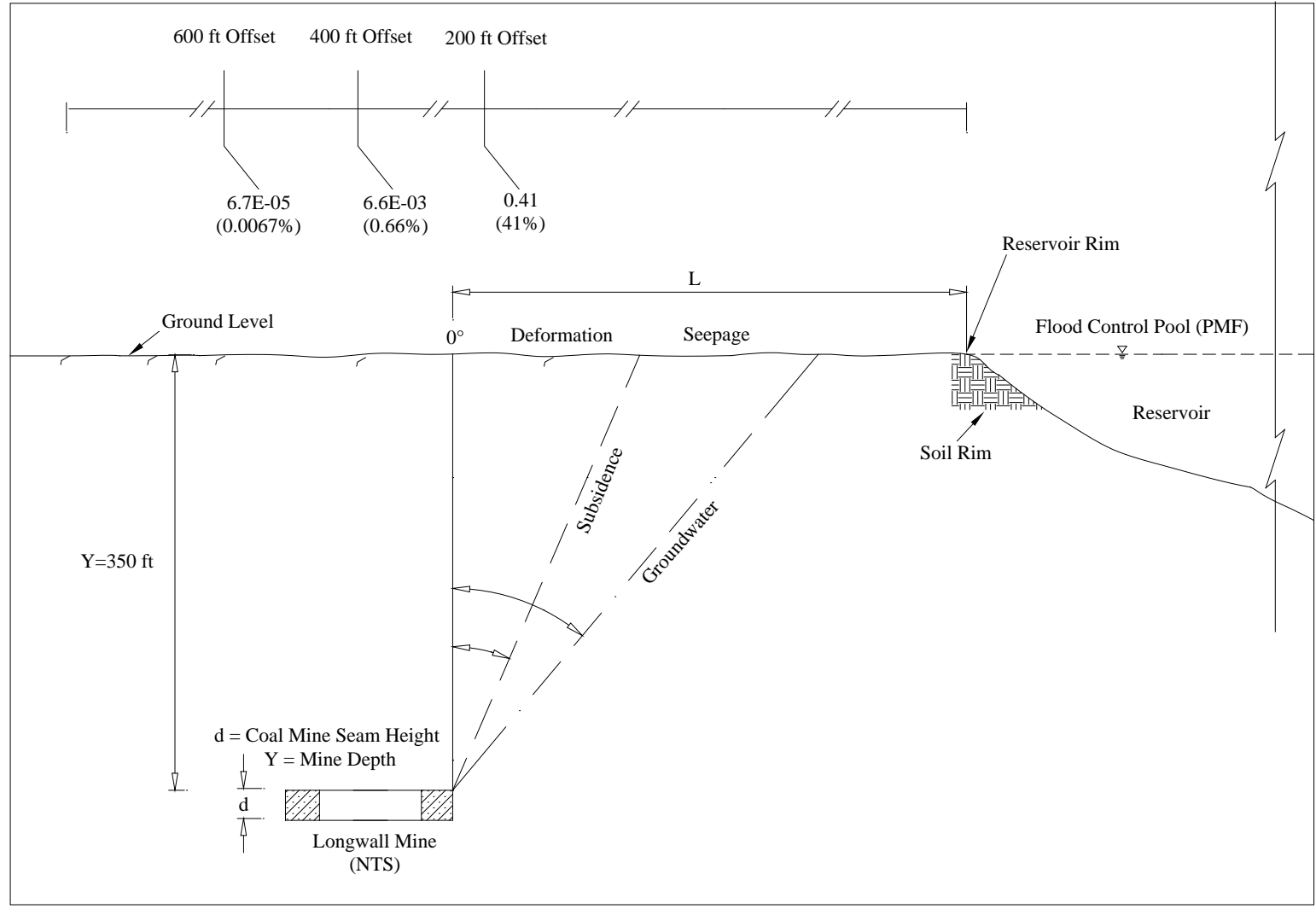

Figure 4.7: Probability of increased permeability decreases with offset distance 


\section{CHAPTER 5: Semi-Quantitative Risk}

Assessment Analysis Procedure for

Mineral Extraction Under Surface Bodies

of Water 
In this chapter, a Semi-Quantitative Risk Assessment was developed and presented for calculating the likelihood of subsurface seepage changes affecting a reservoir due to nearby underground coal mining. This study is only concerned with a qualitative likelihood of increased subsurface seepage leading to internal erosion beneath the study reservoir. The model for this analysis uses the existing Lear underground coal mine located adjacent to the Tygart reservoir in Taylor County, West Virginia (WVDEP, 2009).

This assessment presents a risk based event tree analysis following the U.S. Army Corps of Engineers (USACE) methodology and formulated herein to subsurface mining affects on groundwater seepage culminating with a loss of reservoir pool level control. The USACE method uses a Failure Mode Analysis (FMA) structure consisting of the following elements: 1) identifying the Initiating Event, 2) creation of a Flaw, 3) Initiation of an effect, 4) continual Progression of the effect, 5) the Unsuccessful Detection and Intervention, and 6) the Failure by Uncontrolled Reservoir Level.

\subsection{Background}

The Tygart Dam is located approximately 2.25 miles south of Grafton, WV (Figure 5.1). The dam and reservoir are owned and operated by the U.S. Army Corp of Engineers and serve as flood control on the Tygart River a tributary of the Monongahela River and a major tributary to the Ohio River. Construction for Tygart dam was completed in 1938 and the dam was authorized for flood control, navigation, water supplies, and recreation. It is 1,921ft in length and stands $207 \mathrm{ft}$ above the river bed. The reservoir is approximately 3,430 acres in size. It has the capability to store 4.56 inches of precipitation from a 1,184 square mile drainage area (http://www.Irp.usace.army.mil/Missions/Recreation/Lakes/TygartLake.aspx, USACE, 2016). 


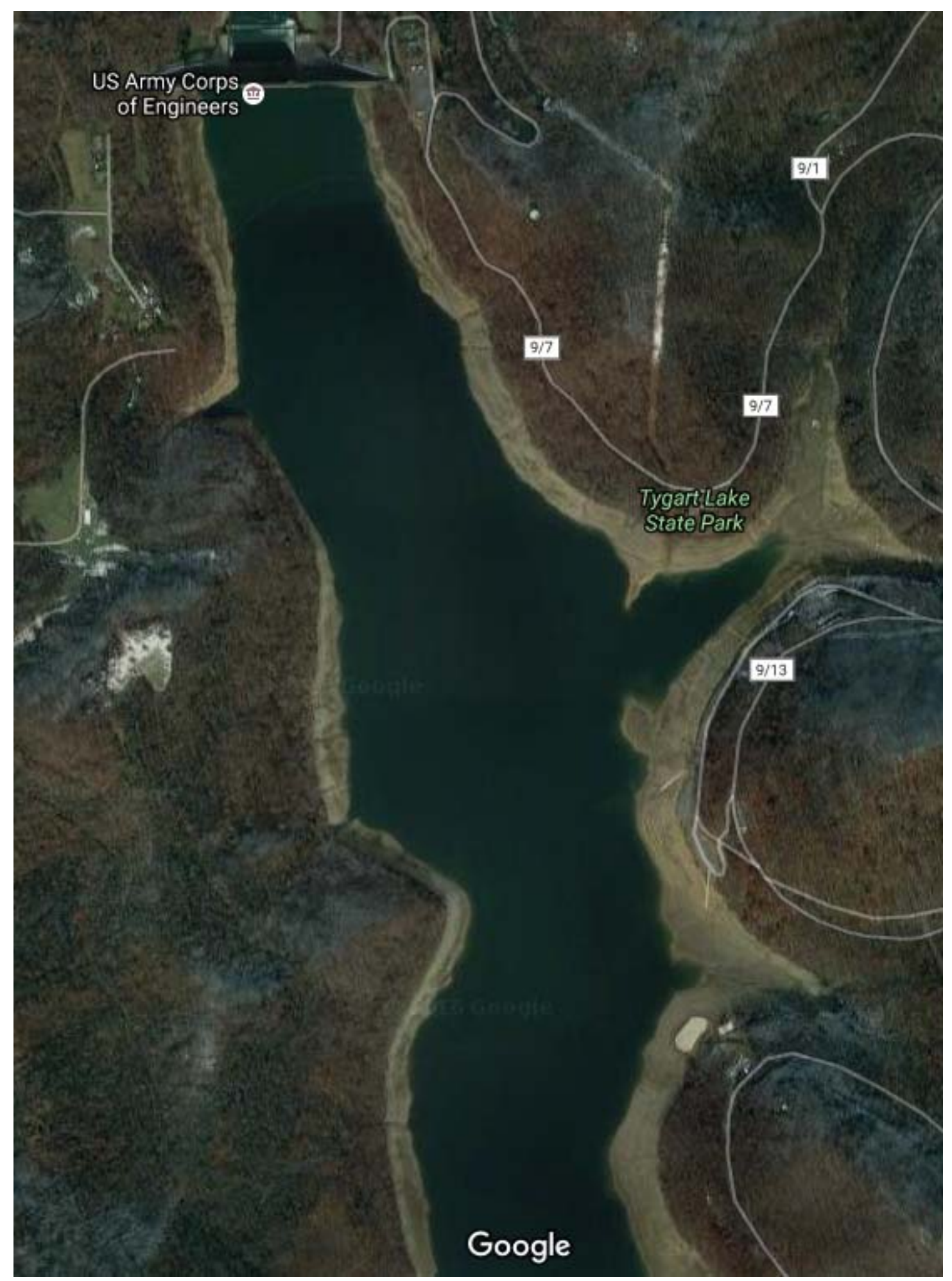

Figure 5.1: Tygart Lake located in Grafton, WV (Map Data: USDA Farm Service Agency, Google, 2016) 


\subsection{Mine Plan}

A 6,000 acre underground coal mine is located east of the Tygart Reservoir. The mine consists of longwall, and supporting room and pillar mining methods in the Lower Kittening seam (Permit \# U-2004-06, WVDEP, 2009).

Longwall panels will be approximately $1200 \mathrm{ft}$ wide. The longwall panel closest to the dam will be $1,000 \mathrm{ft}$ wide. The distance from the mine to the dam is estimated to be $3,600 \mathrm{ft}$ at surface EL $1340 \mathrm{ft}$ and approximate mine floor EL 830ft. Subsidence is expected to occur at a minimum 3300ft distance from Tygart Lake Dam.

The coal mining is to be performed by automatic longwall and the continuous mining room and pillar method. The longwall method will be full coal seam extraction. The room and pillar mining method will result in partial extraction of coal reserves leaving pillars to support the mine roof and prevent mine subsidence at the perimeter gate pillars. The mine location approximate to the reservoir is shown in Figure 5.2.

The average overburden depth for panels 2 and 3 are 582ft and 484ft respectively. This is the average for the full length of the panel. At the edge of the longwall panel closest to borehole T51-80 the approximate overburden depth is $318 \mathrm{ft}$.

The proposed mining offset distances from the mine to the reservoir and dam are presented in Table 5.1 and illustrated in Figure 5.3. The distance from the normal pool level of the lake (EL $1094 \mathrm{ft}$ ) to the closest longwall panel is $1627 \mathrm{ft}$. The closest distance to room and pillar mining is $1000 \mathrm{ft}$.

Table 5.1 lists the approximate water elevations for the Tygart reservoir for three perspectives illustrated in Figure 5.3. The first perspective is referenced from the mine permit as Cross Section C; the second perspective is referenced as Line 1 which is at the direct offset of the mine edge to the centerline of the reservoir channel; Line 2 is the shortest distance of the mine edge to the summer pool elevation of the reservoir; and Line 3 is the shortest distance of the mine edge to the full spillway elevation. 
The full pool level coincides with the spillway elevation of $1167 \mathrm{ft}$. The probable maximum flood (PMF) is approximately 30ft above the full pool elevation; however the normal expected conditions do not exceed $1100 \mathrm{ft}$.

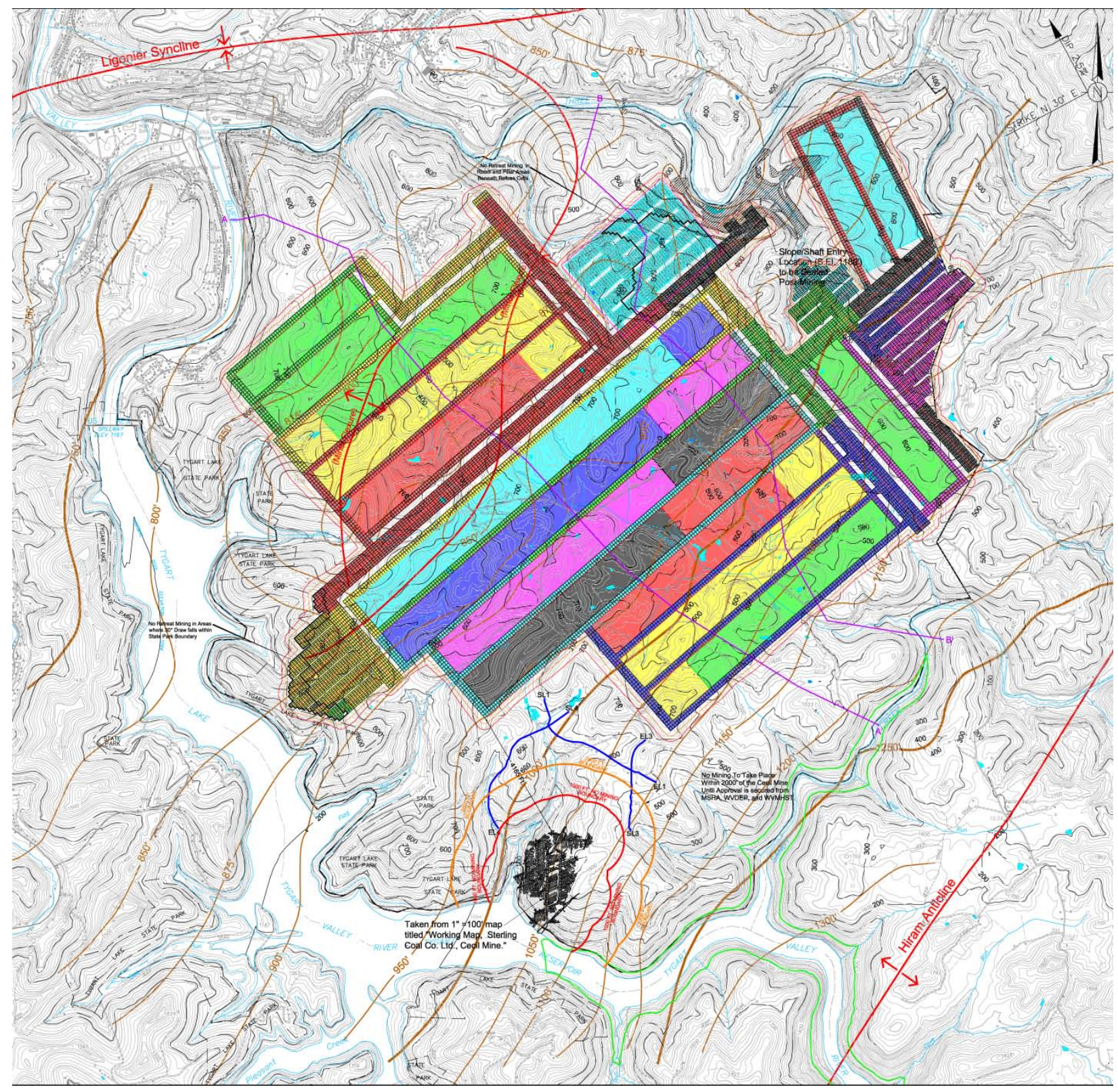

Figure 5.2: Mine plan at Tygart Lake (WVDEP permit \#U-2004-06, 2009) 
Table 5.1: Distances of reservoir pool levels with mine location

\begin{tabular}{|c|c|c|c|c|}
\hline Pool Level Condition & $\begin{array}{c}\text { Elevation } \\
\text { (ft) }\end{array}$ & $\begin{array}{c}\text { Cross Section C } \\
\text { (ft) }\end{array}$ & $\begin{array}{c}\text { Direct offset Distance Pool } \\
\text { to Mine (Line of Sight) (ft) } \\
\text { (shortest distance perpendicular } \\
\text { to mine) }\end{array}$ & $\begin{array}{c}\text { Figure 5.3 } \\
\text { Reference } \\
\text { Line }\end{array}$ \\
\hline $\begin{array}{c}\text { Minimum to } \\
\text { Center of channel }\end{array}$ & 1009.5 & 4,920 & 4,750 & (1) \\
\hline Winter & 1039.5 & Unknown bottom & Unknown bottom & N/A \\
\hline $\begin{array}{c}\text { Summer } \\
\text { Full (Spillway) }\end{array}$ & 1093.5 & 3,920 & 420 & (3) \\
\hline Probable Maximum Flood \\
(PMF)
\end{tabular}

N/A: not available

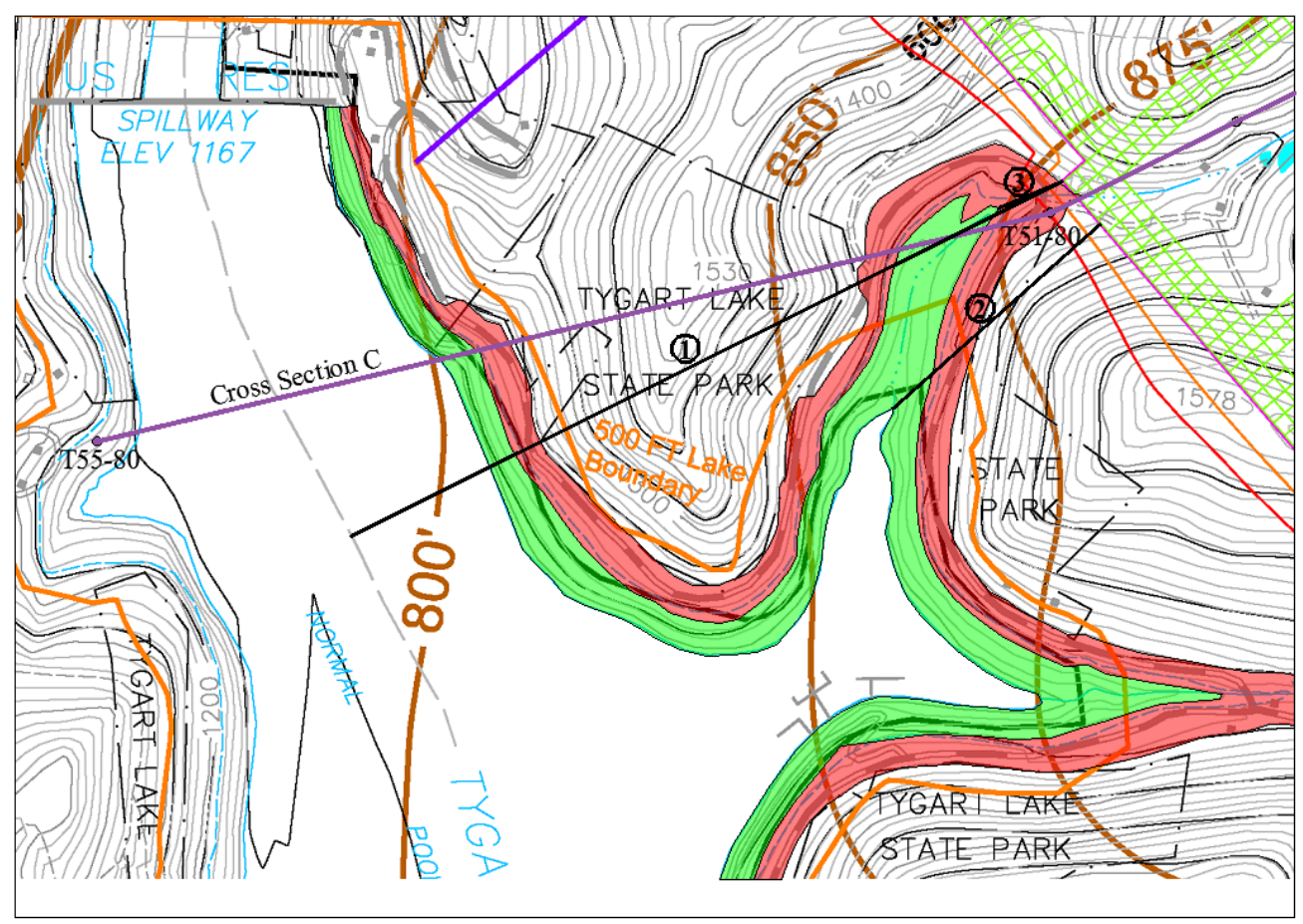

Figure 5.3: Mine location referenced to reservoir pool level conditions (After WVDEP, 2009) 


\subsection{Subsurface Geology}

Borehole T51-80 is the closest location to the longwall panels of interest (shown in Figure 5.3). The geologic profile around the gate road pillars are expected to be similar. The cross section of this location is shown in Figure 5.4 where Borehole T51-80 is located at the center.

Figure 5.4 illustrates the profile along Cross Section Line C. The most common rock types found near these coal seams are shale, limestone, and clays. The location of these layers is critical in determining the changes in hydraulic conductivity above a mine. Sandstone is a very hard rock with low transmissivity (thickness $\mathrm{x}$ hydraulic conductivity). However it is more susceptible to fracturing and is generally not self healing after fracturing.

The proposed mine seam is the Lower Kittanning located at an approximate elevation of $880 \mathrm{ft}$. The coal seam to be mined is approximately $4.4 \mathrm{ft}$ thick at this location. The actual extraction thickness is approximately $6.0 \mathrm{ft}$ due to the size of the longwall mining equipment (WVDEP, 2009). There are two large sandstone layers beginning approximately $120 \mathrm{ft}$ above the mine. These are the Upper Freeport and Mahoning sandstone layers. Neither sandstone layer is homogeneous with a thin layer of shale separating them.

The Johnstown limestone layer is located above the Lower Kittanning coal seam. This could potentially create condition for karsting to occur below the reservoir or dam. The karst is due to the dissolution of limestone due to increased seepage effects. 
The geologic material properties from WVDEP (2009) are presented in Tables 5.2, 5.3, 5.4, and 5.5 .

Table 5.2: Overburden characteristics

\begin{tabular}{|l|c|c|}
\hline \multicolumn{3}{|c|}{ Overburden Charactistics } \\
\hline Redbeds & \multicolumn{2}{|c|}{ Located sbove Location of Interest } \\
\hline Conemaugh Group & Above Sandstone & Clayey \\
\hline Mahoning Sandstone & $\begin{array}{c}\text { Begins } 160 \text { to } 200 \mathrm{ft} \text { above } \\
\text { Approximately } 50 \mathrm{ft} \text { thickness }\end{array}$ & $270 \mathrm{ft}$ below Surface at Minimum \\
\hline Shale Dominated Layer & $150-200 \mathrm{ft}$ & 24 to 30 times coal seam height \\
\hline Lower Kittanning Coal Seam & \multicolumn{2}{|c|}{ Mined Seam } \\
\hline
\end{tabular}

Table 5.3: Overburden rock competency

\begin{tabular}{|c|c|c|}
\hline Hard Rock in Overburden & $15 \%-39 \%$ & $\begin{array}{c}\text { Competent sandstone or limestone that has greater } \\
\text { resistance to effects of subsidence related } \\
\text { deformations }\end{array}$ \\
\hline
\end{tabular}

Table 5.4: Estimate Rock Strength

\begin{tabular}{|l|l|}
\hline Estimated Rock Strength \\
\hline Unit Weight of Sandstone & $160 \mathrm{pcf}$ \\
\hline Unit Weight of Shale & $160 \mathrm{pcf}$ \\
\hline Strength of Rock & $5000 \mathrm{psi}$ \\
\hline $\begin{array}{l}\text { Shear Strength of } \\
\text { Sandstone }\end{array}$ & $1000 \mathrm{psi}$ \\
\hline & $\begin{array}{l}45 \text { Degree } \\
\text { friction } \\
\text { Angle }\end{array}$ \\
\hline
\end{tabular}

Table 5.5: Rock Size:

\begin{tabular}{|l|l|}
\hline $\begin{array}{l}\text { Max particle size } \\
\text { assumed 4ft }\end{array}$ & $\begin{array}{l}\text { Little difference between } \\
\text { compacted and non-compacted } \\
\text { Material }\end{array}$ \\
\hline
\end{tabular}




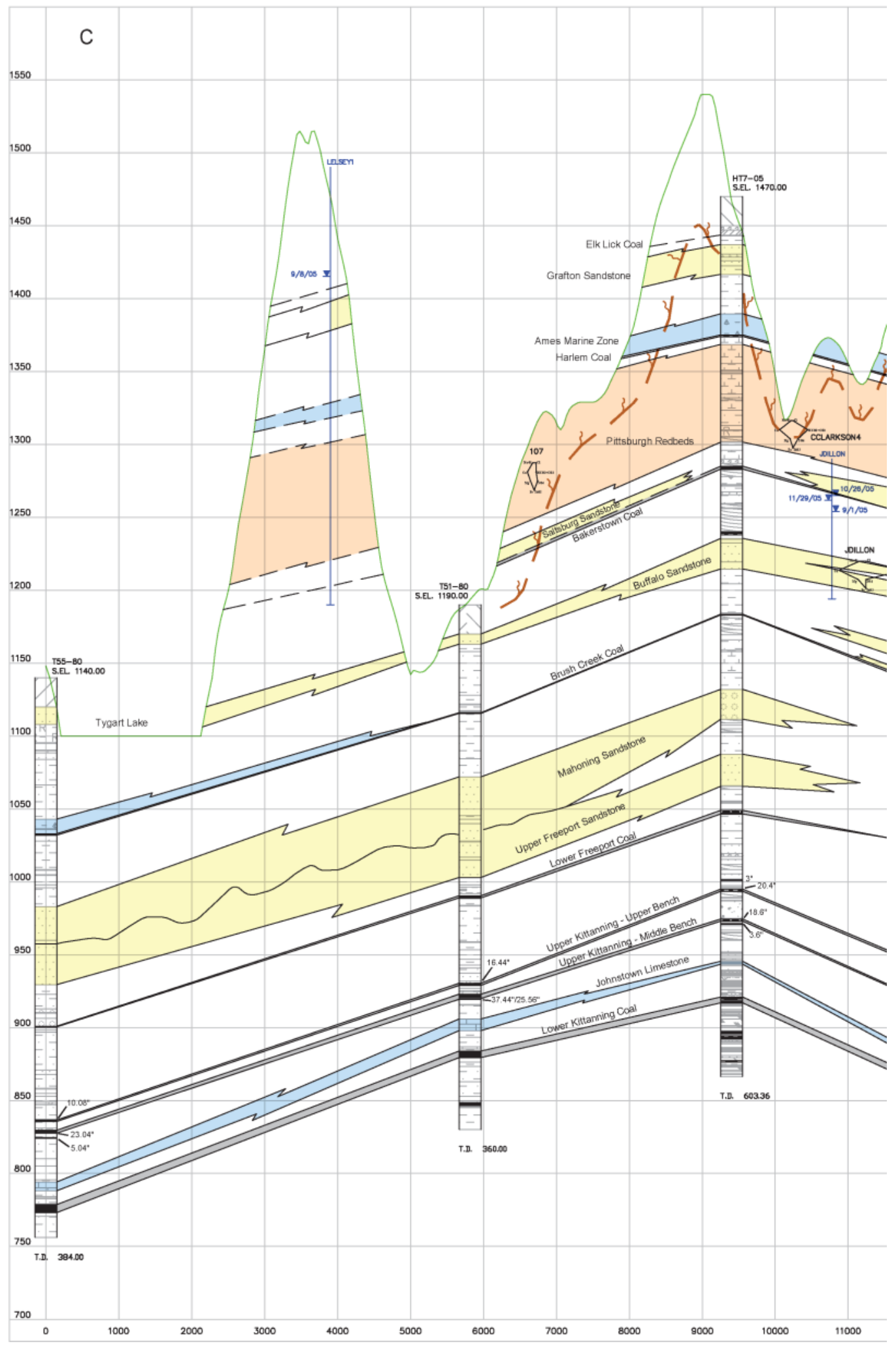

Figure 5.4: Cross-section C lithology (WVDEP, 2009) 


\subsection{Mine Subsidence Analysis}

Theories on mine subsidence include surface deformation, strain distribution, and effects on overburden permeability and groundwater seepage. Theories from North America and China have confirmed by case history studies that multiple subsurface zones can lead to either mine inundation by groundwater or to mines remaining dry. The North American approach identified that underground mining created five depth zones correlated to empirical relationships of the mine seam thickness being extracted. The Chinese methodology divided the subsurface into three distinct zones is a more empirical analysis.

This section examines these approaches to understand the subsurface effects due to subsidence and strain which may impact overburden rock and soil permeability leading to reductions or increases in material permeability effecting seepage.

\subsubsection{North American Subsidence Analysis \& Calculations}

Figure 5.5 illustrates the North American subsidence analysis divided the subsurface region located above a mine into the following five sections: i) Caved Zone (lowest), ii) Fractured Zone, iii) Dilated Zone, iv) Constrained Zone and v) Surface Fracture Zone (most upper) (Bai et al., 1995). Parameters are based on the seam thickness of $6 \mathrm{ft}$. This is the minimum thickness for the mining equipment to be used. The mine seam thickness requires practical modification prior to use in calculations in order to capture the minimum and maximum thickness reported in the mine permit. The coal seam varies in thickness across the mine face between $4.5 \mathrm{ft}$ to $6 \mathrm{ft}$, with local zones having thicker seams.

Determination of the five zone extents is presented below. The analysis is initiated with reference elevation (EL) from the floor of the extracted coal mine, EL= 879.46ft. Distance from the ground surface is $310.54 \mathrm{ft}$. 


\subsubsection{Caved Zone}

The material in this zone above the mine seam is in complete disruption. It is best described as broken and rubblized strata immediately above the caving roof. This zone ranges in extent from above the mine seam to $6 \mathrm{t}$ to $10 \mathrm{t}$. This range captures several rock layers including deposits of shale, limestone, sandstone, and coal.

The minimum zone range: $6 \mathrm{t}=6 * 6 \mathrm{ft}=36 \mathrm{ft}$ : Elevation range $883.56 \mathrm{ft}$ to $919.7 \mathrm{ft}$

Thickness above mine roof $=36.15 \mathrm{ft}$

The maximum zone range: $10 \mathrm{t}=10 * 6 \mathrm{ft}=60 \mathrm{ft}$

Elevation ranges 919.71ft to 942.83ft: Thickness above mine roof $=59.27 \mathrm{ft}$

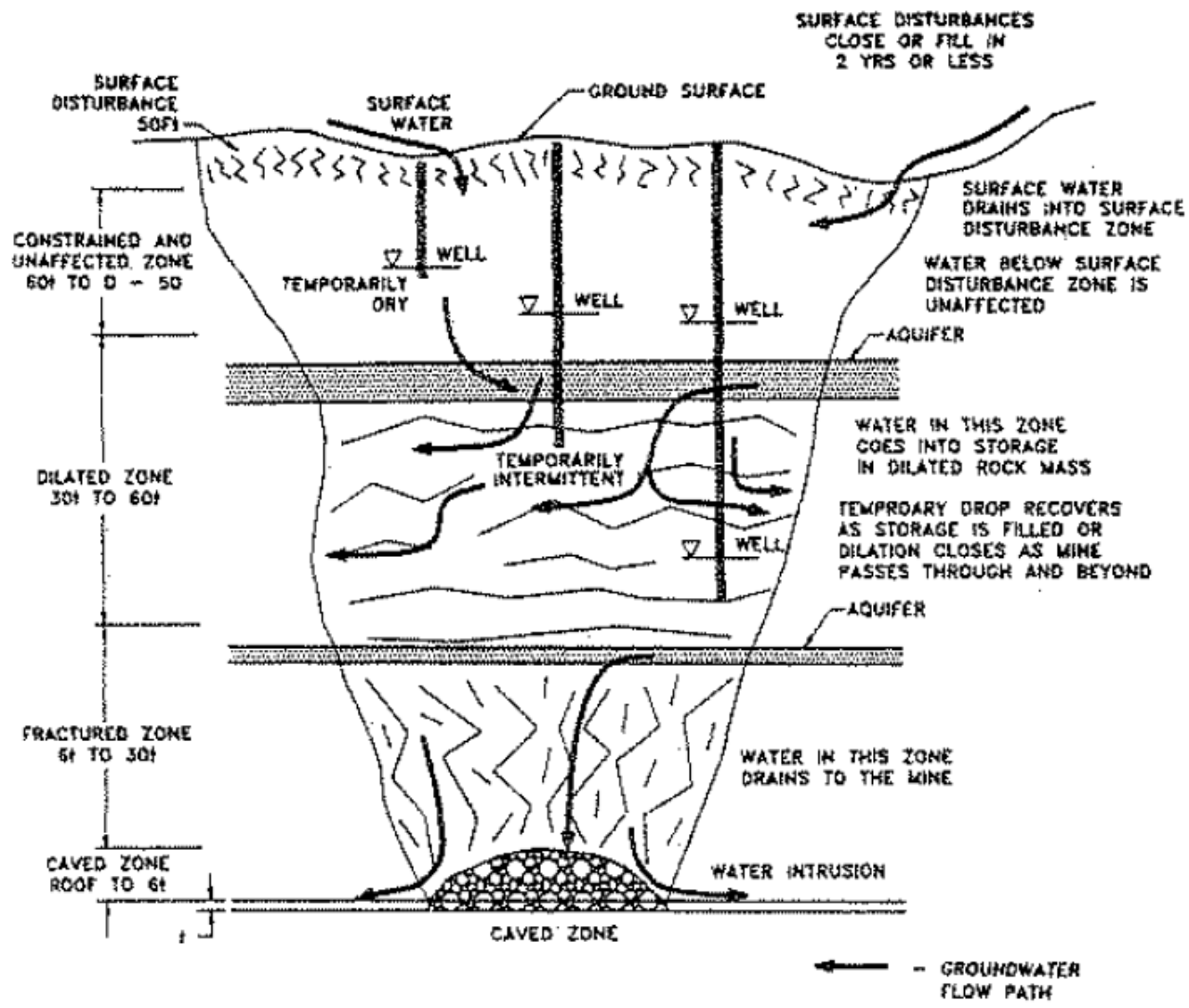

Figure 5.5: Subsidence zones (Kendorski, 1979) 


\subsubsection{Fractured Zone}

This zone is characterized as being vertically transmissive due to extensive fractures. The expected response of these strata is to crack and settle resulting in fractures extending through individual beds. Consequences of this effect are opening of bedding planes, shearing, and dislocation of the beds.

The range of extents based on the Fractured Zone below is calculated as follows:

Minimum extents of top of fractured zone: $24 \mathrm{t}=24 * 6 \mathrm{ft}=144 \mathrm{ft}$

Maximum extents of top of fractured zone: $30 \mathrm{t}=30 * 6 \mathrm{ft}=180 \mathrm{ft}$

\subsubsection{Dilated Zone}

This zone is positioned above the Fractured zone and is characterized has having increased groundwater storativity with little to no vertical transmissivity. The strata in this zone deform as a beam, with increased compression at the upper dimensions and exhibits surface subsidence deformation. The overburden formations would be expected to dilate followed by vertical strains which separate the lenticular bedding plans.

This zone extends vertically from the top of the fractured zone

Minimum potential extents to the top of the Dilated zone: $30 \mathrm{t}=180 \mathrm{ft}$

Maximum potential extents to the top of the Dilated zone: $60 \mathrm{t}=360 \mathrm{ft}$

Elevation ranges $942.83 \mathrm{ft}$ to surface. 


\subsubsection{Constrained Zone}

A Constrained Zone was not expected at this location because the Dilated Zone intersects the surface and Surface Fracture Zone.

\subsubsection{Surface Fracture Zone}

This zone is subjective. Kendorski (1993) lists the extent of surface subsidence to $50 \mathrm{ft}$. The actual depth is reliant on the material properties in the strata. Plastic type surface soils will show very little fracturing but will show subsidence. Rock layers in this zone will show fracturing but may be indiscernible from natural fractures already in this zone. The fractures in this zone are not expected to cause any additional water transfer into the fractured zone except where shallow mining occurs.

Using this method, the Dilated Zone would extend to the surface. However studies have shown the surface zone contains weathered rock which undergoes fracturing. The fractures are generally quickly filled in but can create surface water to seep into the lower zones. If the surface zone connects with the fractured zone, a direct link to the mine seam can be created.

For this case the Dilated Zone would extend from the Upper Freeport or Mahoning sandstone layer to the surface zone at 50ft below ground level. In this zone only localized vertical fracturing is expected. The layers of rock will experience strains and separation.

Figure 5.6 shows the final North American subsidence zone ranges and the approximate depth range for each layer above a mine represented with the borehole lithology from WVDEP (2009). Additional information includes the material's hydraulic conductivity values at the pre- and postmining conditions discussed in Section 5.6. 


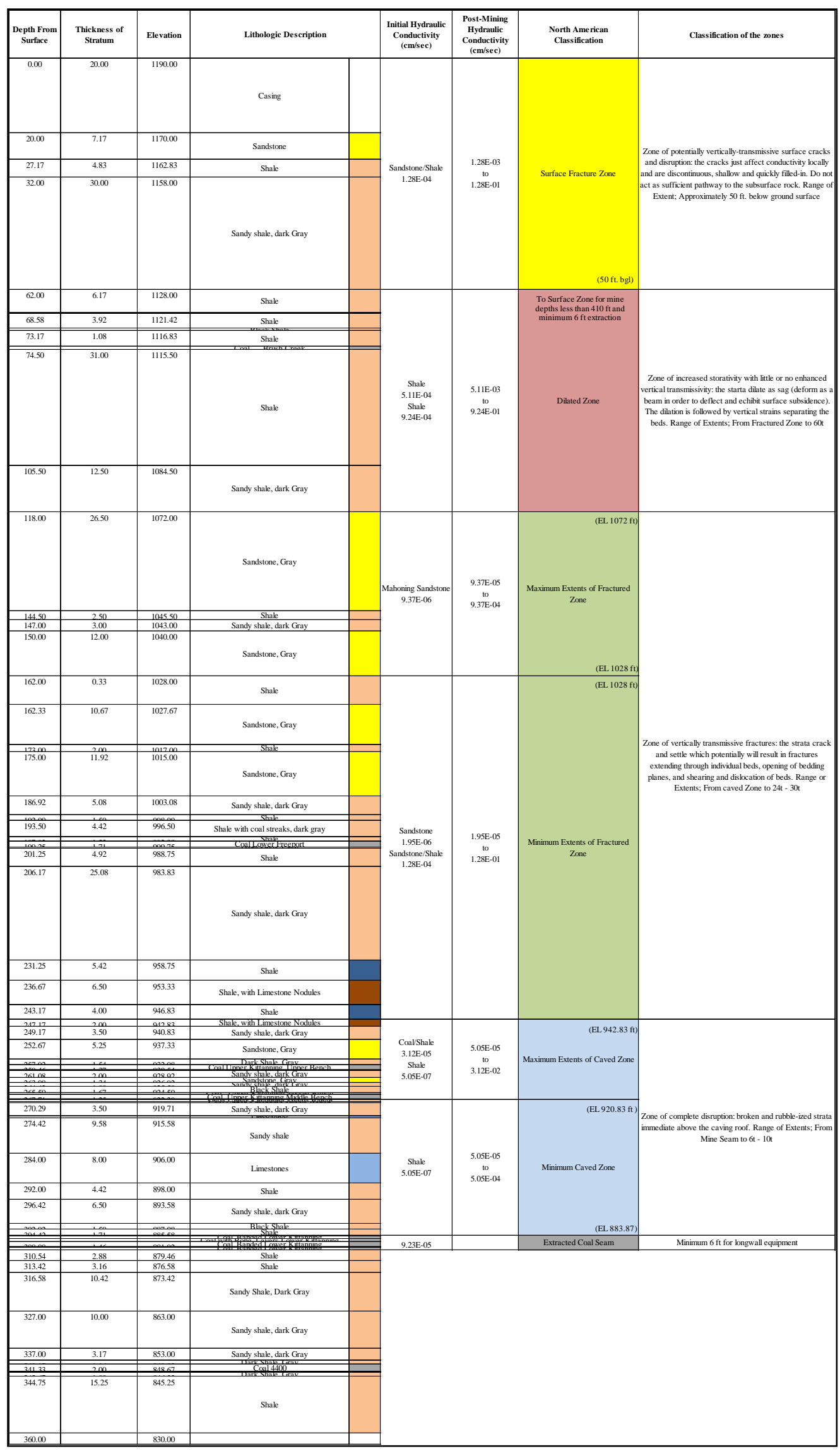

Figure 5.6: North American Analysis 


\subsubsection{Chinese Mine Subsidence Analysis}

The Chinese subsidence analysis is an analytical method incorporates strata lithology and strength parameters with coefficients to determine the ranges for each of the following zones: i) bending, ii) fractured, and iii) caving. Figure 5.7 illustrates the three zones with the mining depth.

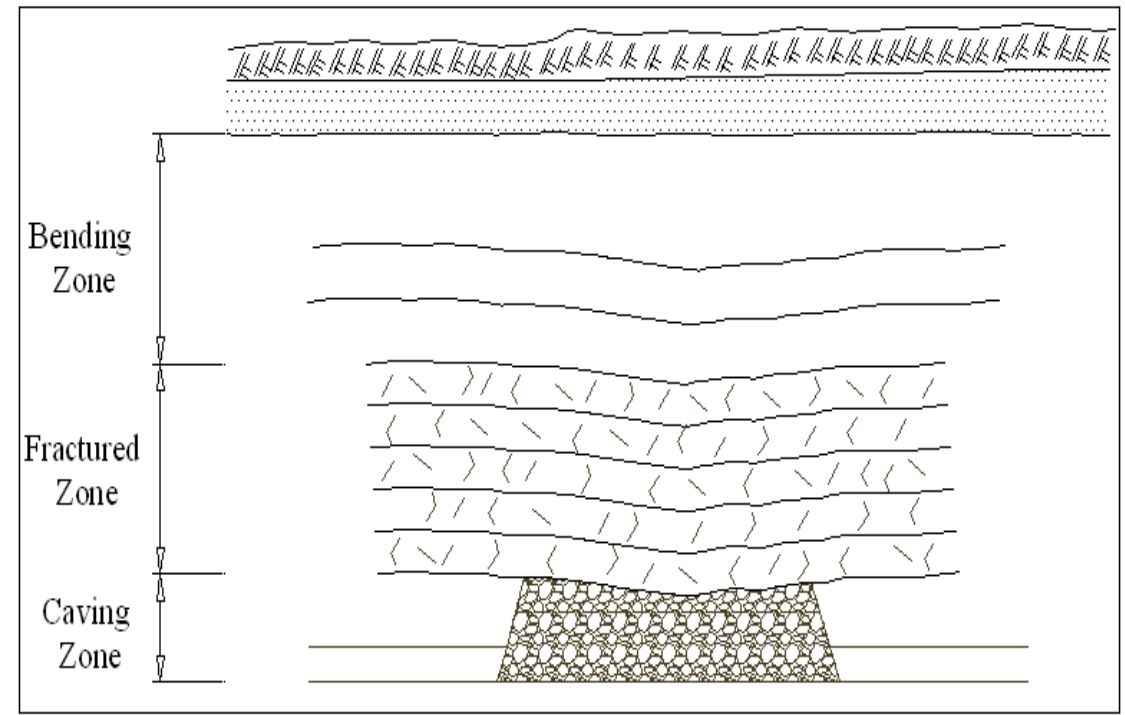

Figure 5.7: Subsidence zones based on Chinese literature (After Bai, et al.,1995)

\subsubsection{Caving Zone}

The amount of fracturing or caving in this zone is dependent on the rock dilation and differs depending on the type of rock present. The average coefficient for rock dilation is usually less than 1.5 (unconfined state) and decreases under multiple seams due to repeated compression. Bai, et al., (1995) lists approximate coefficients for use with Equations 1 through 5. 
The Chinese have developed a formula for determining the extent of this zone:

$$
H_{c} \text { or } H_{f}=\left(\frac{(\mathbf{1 0 0} \times \boldsymbol{M})}{(\boldsymbol{a} \times \boldsymbol{M}+\boldsymbol{b}))}+\mathrm{C}\right.
$$

$H_{c}$ or $H_{f}$ is the extent of the caving zone in total height

$\mathrm{M}$ is the coal seam thickness

a and $b$ are the coefficients of rock dilation (listed below)

$\mathrm{c}$ is the mean square deviation (listed below)

Equation 1 is used to determine the maximum heights of the caving and fractured zones.

Different coefficients are used for each zone and are listed in Tables 5.6 and 5.7.

Table 5.6: Strata lithology verses rock strength (Bai, et al., 1995)

\begin{tabular}{|l|c|}
\hline Strata Lithology & Uniaxial Compressive Strength \\
\hline Strong & $>40 \mathrm{Mpa}(5,800 \mathrm{psi})$ \\
\hline Medium Strong & 20 to $40 \mathrm{Mpa}(2,900$ to $5800 \mathrm{psi})$ \\
\hline Weak & $<20 \mathrm{Mpa}(2,900 \mathrm{psi})$ \\
\hline
\end{tabular}

Table 5.7: Coefficients for maximum height of Caving zone Hc (Bai, et al., 1995)

\begin{tabular}{|l|c|c|c|}
\hline Strata Lithology & $a$ & $b$ & $c$ \\
\hline Strong & 2.1 & 16 & 2.5 \\
\hline Medium Strong & 4.7 & 19 & 2.2 \\
\hline Weak & 6.2 & 32 & 1.5 \\
\hline Weathered & 7.0 & 63 & 1.2 \\
\hline
\end{tabular}

\subsubsection{Fractured Zone}

This zone does not remain constant, and will reconsolidate over time (Bai, et al., 1995). The length of time is also a function of the type of overburden. Stronger strata will remain constant 
for a least a month and remain up to 20 years before reconsolidation occurs. Weak strata will remain for only 6 months to 17 months. At this point the zone will decrease at an average rate of $0.4 \mathrm{~m}$ per month. Field experience has shown that the fractured zone will also from a saddle shape due to compaction.

Table 5.8: Coefficients for maxium height of Fractured Zone Hf (Bai et al., 1995)

\begin{tabular}{|l|c|c|c|}
\hline Strata Lithology & a & b & c \\
\hline Strong & 1.2 & 2.0 & 8.9 \\
\hline Medium Strong & 1.6 & 3.6 & 5.6 \\
\hline Weak & 3.1 & 5.0 & 4.0 \\
\hline Weathered & 5.0 & 8.0 & 3.0 \\
\hline
\end{tabular}

\subsubsection{Bending or Constrained Strata Zone}

This zone lies between the dilated and surface zones. It lies above an aquifer zone and does not allow additional water to flow into the fractured zone and ultimately into the mined area. According to Bai et al. (1995), this zone is a barrier that provides a measure of safety for the water bodies above.

This zone only exists when the mine lies deeper than the combination of the surface and fractured zones. It is characterized by having tensile strains less than $1 \mathrm{~mm} / \mathrm{m}$ where there is no increased permeability. However Bai, et al. (1995) expresses that localized excessive strains may occur in this zone. The report by Kendorski (1979) also determines that this zone should be comprised of shale to limit fracturing and become "self-healing”.

The Chinese have a similar aquiclude zone that allows for clays, shale, and crystalline rocks. This is located between the upper boundary of the fracture zone and an overlying aquifer. Their equation for the thickness of this zone is; 


$$
H_{p}=d\left(\frac{M}{n}\right)
$$

Where;

$\mathrm{M}$ is the seam thickness

$\mathrm{n}$ is the number of lifts (mined seams)

$\mathrm{d}$ is the coefficient for thickness of the protective layer

The coefficient is based on the presence of clay material (Figure 5.8) in the strata overlying and aquiclude layer. The amount present dictates the coefficient used.

Table 5.9: Coefficient $d$ for the thickness of the protective layer

\begin{tabular}{|l|c|c|c|c|}
\hline Strata Lithology & Case a & Case b & Case c & Case d \\
\hline Strong & 4 & 5 & 7 & 6 \\
\hline Medium & 3 & 4 & 6 & 5 \\
\hline Weak & 2 & 3 & 5 & 4 \\
\hline Weathered & 2 & 2 & 5 & 3 \\
\hline
\end{tabular}




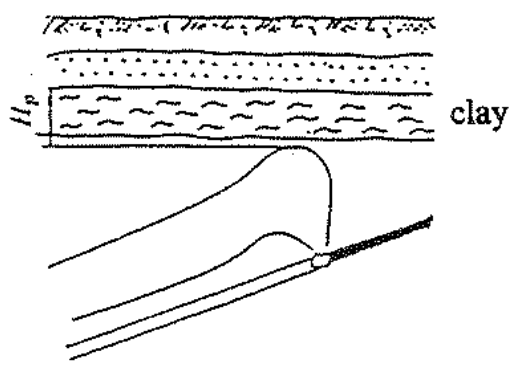

a: Thick Clay at Bottom of Unconsolidated Strata.

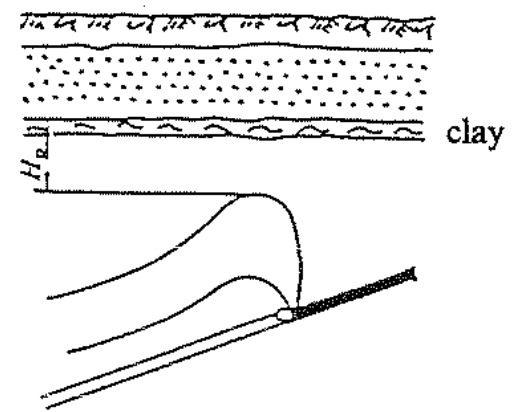

b: Thin Clay at Bottom of Unconsolidated Strata.

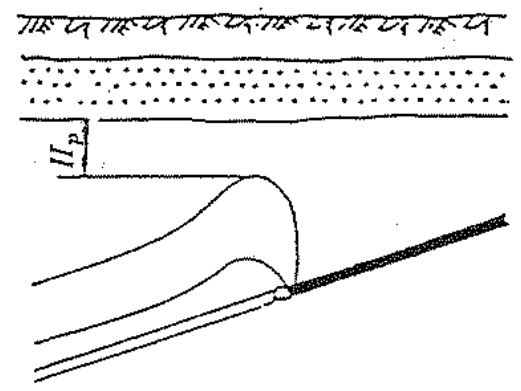

C: No Clay at Bottom of Unconsolidated Strata.

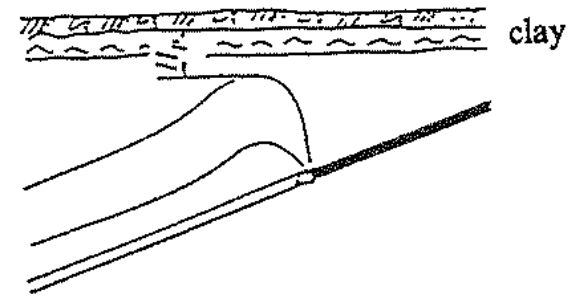

d; Uniform Clay Distribution in Unconsolidated Strata.

Figure 5.8: Type of protective coal layer (Bai et al., 1995) 
From the lithology, there appears to be minimal clay deposits above the Fractured Zone and the base of an overlying aquifer. Assuming medium strong strata, the coefficient from Table 5.9 for the clay material would be 6 .

$$
H_{p}=6\left(\frac{6}{\mathbf{1}}\right)=10.98 \mathrm{~m} \text { or } 36 \mathrm{ft}
$$

This protective layer is an aquiclude zone that is made up of shale, clays and crystalline rocks (Bai, et al.,1995). However it was not recognized in North American experience and was therefore not included in the Chinese Zone classification.

Table 5.10 represents rock strength values that were used for the Chinese method. The rock strength was used to generalize the type of strata around the location of interest. From this information the coefficients were determined for the Caved and Fractured Zones.

Table 5.10: Values determined for Chinese Method

\begin{tabular}{|c|c|}
\hline \multicolumn{2}{|c|}{ Estimated Rock Strength } \\
\hline Unit Weight of Sandstone & $160 \mathrm{pcf}$ \\
\hline Unit Weight of Shale & $160 \mathrm{pcf}$ \\
\hline Strength of Rock & $5000 \mathrm{psi}$ \\
\hline $\begin{array}{c}\text { Shear Strength of } \\
\text { Sandstone }\end{array}$ & $1000 \mathrm{psi}$ \\
\hline Shear Strength of \\
Fractured Shale & $\begin{array}{c}45 \text { Degree } \\
\text { friction } \\
\text { Angle }\end{array}$ \\
\hline
\end{tabular}


This formula was used for determining the Caved and Fractured zones:

$$
H_{c} \text { or } H_{f}=\left(\frac{(100 \times M)}{(a \times M+b))}+c\right.
$$

For Caving Zone;

Medium strong strata;

M (seam thickness) ; 1.83m (6ft)

Coefficients a, b, c; 4.7, 19, 2.2

$H_{c}=\left(\frac{(100 \times 1.83)}{(4.7 \times 1.83+19))}+2.2=8.83 \mathrm{~m}\right.$ or $28.96 \mathrm{ft}$

For Fractured Zone;

Medium strong strata;

M (seam thickness); 1.83m (6ft)

Coefficients a, b, c; 1.6, 3.6, 5.6

$H_{f}=\left(\frac{(100 \times 1.83)}{(1.6 \times 1.83+3.6))}+5.6=33.63 \mathrm{~m}\right.$ or $110.34 \mathrm{ft}$

From the equations above, the Caved Zone directly above the mine seam is approximately $29 \mathrm{ft}$. The Fractured Zone lies directly above the Zone and extends to a height approximately 110ft above the coal seam or $81 \mathrm{ft}$ above the extends of the Caved Zone. The remaining strata are considered in the Bending Zone as the Chinese Method does not identify this as a Zone. These zones are represented in Figure 5.9 alongside the lithology and elevations around borehole T5180 . 


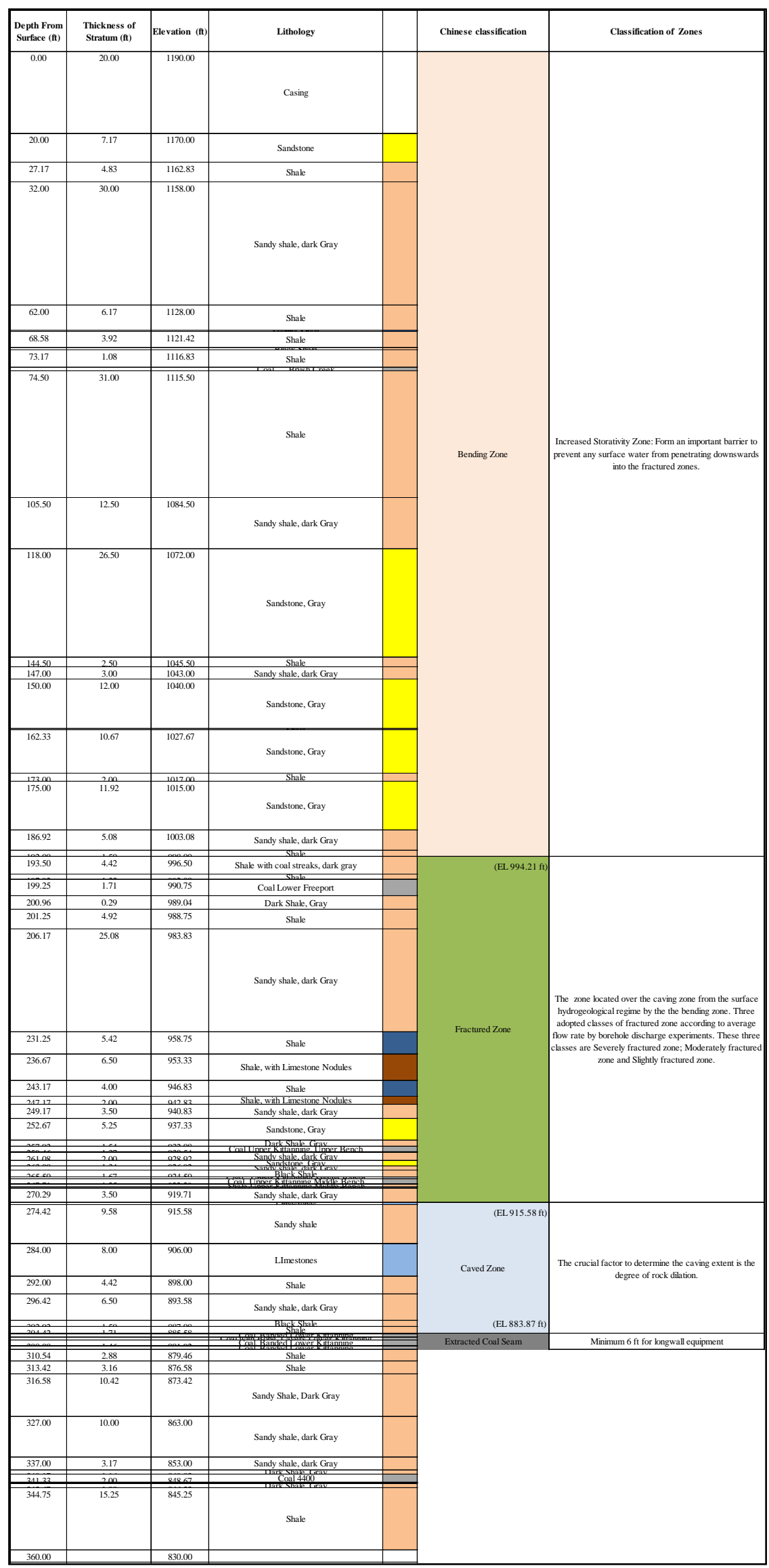

Figure 5.9: Chinese subsidence analysis 


\subsubsection{Tygart Mine Subsidence}

Comparisons of the North American to Chinese subsidence zone calculations are presented in Table 5.11. The respective zone thickness ranges are calculated and differences in the Caved and Fractured zones. The depths of the North American zones are larger than the Chinese zones and consequently reflect a worst case condition of permeability change; therefore the remainder of this SQRA analysis is based on the North American results.

Table 5.11: Subsidence Zone comparison

\begin{tabular}{|c|c|c|c|c|c|}
\hline \multicolumn{2}{|c|}{ North American zones (ft) } & & \multicolumn{2}{|c|}{ Chinese zones (ft) } & \multirow{2}{*}{$\begin{array}{c}\text { Thickness } \\
\text { (ft) }\end{array}$} \\
\hline Ground elevation & 1190.00 & \multirow{2}{*}{50.00} & Ground elevation & 1190.00 & \\
\hline Surface Fracture Zone & 1140.00 & & \multirow[b]{2}{*}{ Bending Zone } & \multirow{2}{*}{$\begin{array}{l}1190.00 \\
\text { to } \\
994.21\end{array}$} & \multirow[b]{2}{*}{195.79} \\
\hline Dilated Zone & $\begin{array}{c}1140.00 \text { to } \\
1072.00\end{array}$ & 68.00 & & & \\
\hline Fractured Zone & $\begin{array}{c}1072.00 \text { to } \\
942.83\end{array}$ & 129.17 & Fractured Zone & $\begin{array}{l}994.21 \\
\text { to } \\
915.58\end{array}$ & 78.63 \\
\hline Caved Zone & $\begin{array}{c}942.83 \text { to } \\
883.87\end{array}$ & 58.96 & Caved Zone & $\begin{array}{l}915.58 \\
\text { to } \\
883.87\end{array}$ & 31.71 \\
\hline Extracted Coal Seam & 879.46 & & Extracted Coal Seam & 879.46 & \\
\hline
\end{tabular}

Figure 5.10 shows the location of interest with the calculated subsidence distances at the Tygart Reservoir from the WV permit file information. The orange line closest to the mine boundary represents a subsidence angle of 15 degrees and the red line represents an angle of 30 degrees. At 30 degrees, the subsidence angle would cross the public water line of Tygart Lake where the feeder stream enters the reservoir.

The non-shaded region of the lake represents the summer pool elevation (1094ft). The light green shaded area is full pool level or spillway elevation (1166.5ft). The red zone is the extents of a probable maximum flood (PMF) at an elevation of $1197 \mathrm{ft}$. This represents a worst case scenario. At this location, the PMF would overtop the mine by approximately $100 \mathrm{ft}$.

The coal seam strikes in a northeast to southwest direction. The dip for the area varies from $2.0 \%$ to $3.3 \%$. In the northwestern section of the site, the dip is approximately $2 \%$. 


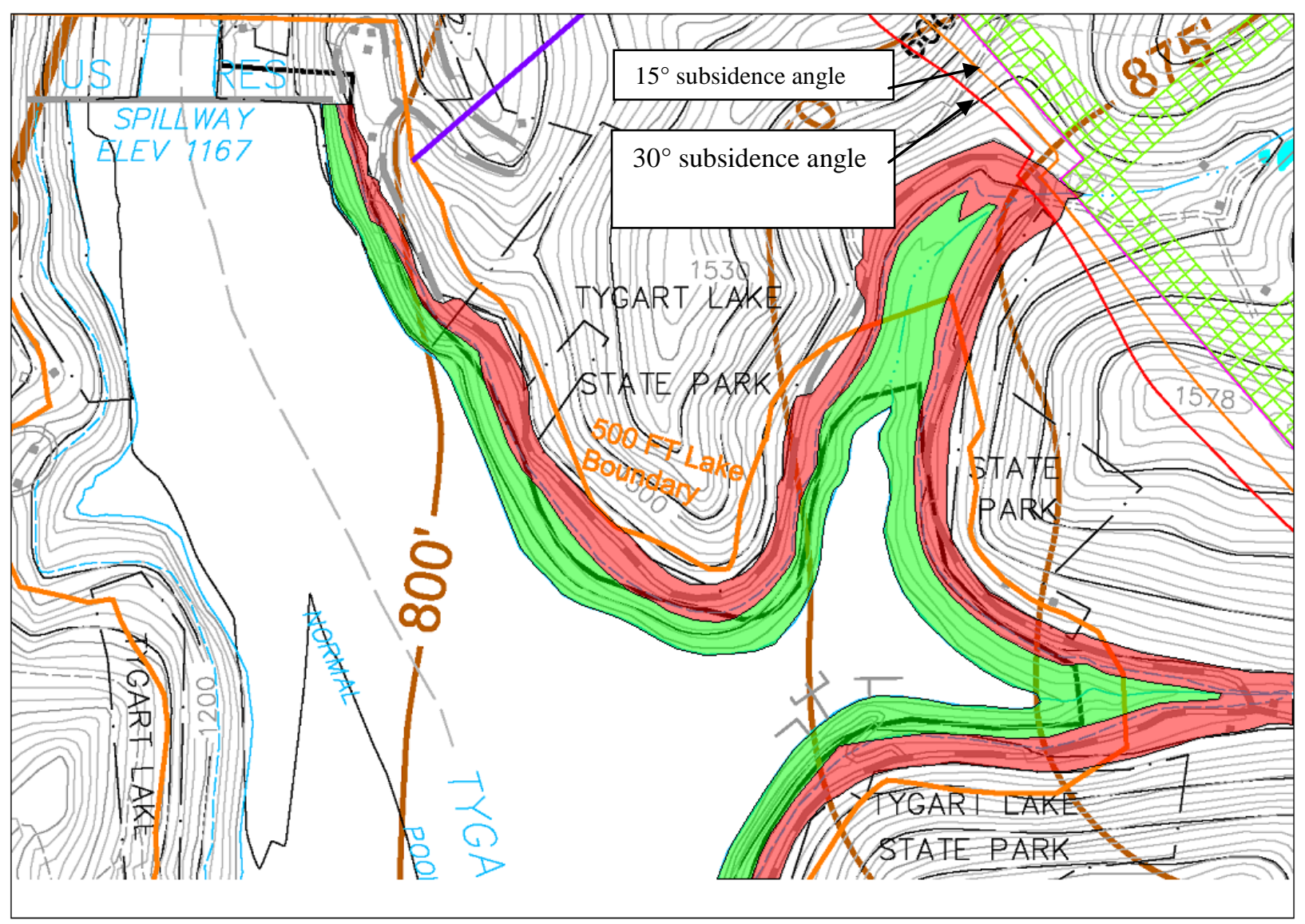

\section{Legend}

Full Pool Level (1166.5 ft)

Probable Maximum Flood

$(1197 \mathrm{ft})$

Figure 5.10: Mine subsidence angles (After WVDEP, 2009)

Figure 5.11 illustrates the correlation of the North American subsidence zones presented as depth elevations with the existing site lithology. The five zones with corresponding depth elevations illustrate the size of the subsurface area affected by subsidence at the $30^{\circ}$ angle referenced from the edge of the mine and extending to the edge of the reservoir. 


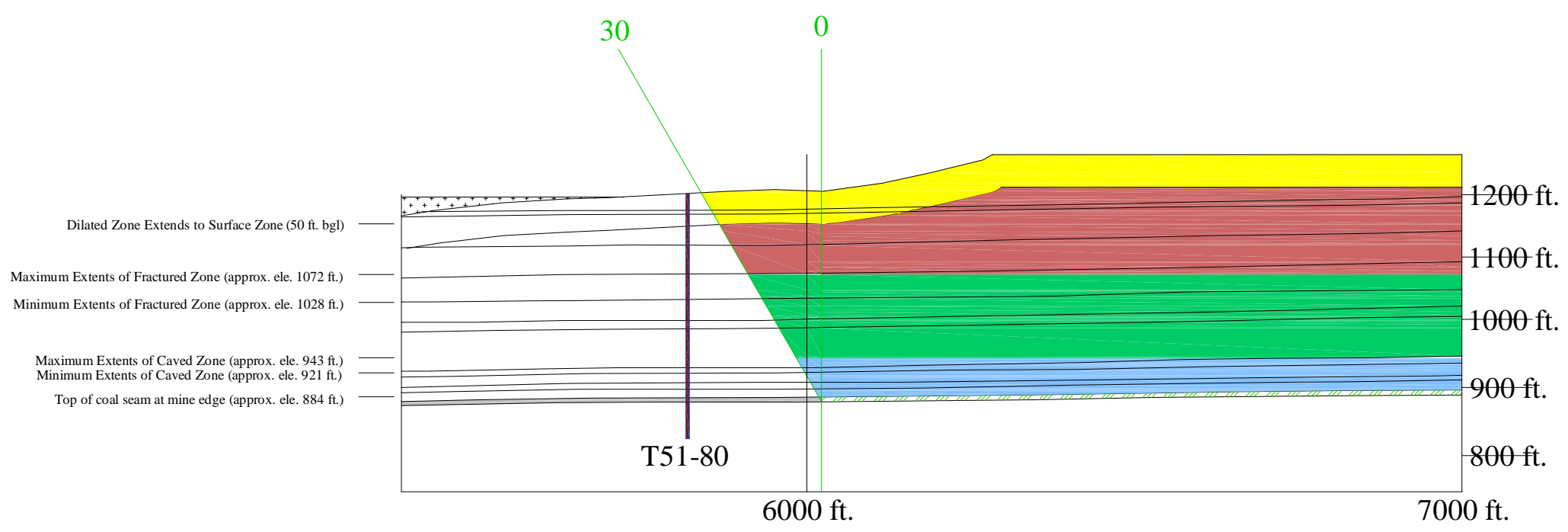

\begin{tabular}{|cc|}
\hline & Legend \\
$\square \quad$ Surface Fracture Zone \\
$\square$ \\
$\square \quad$ Dilated Zone \\
$\square \quad$ Fractured Zone \\
$\square \quad$ Caved Zone \\
$\square \quad$ Coal Seam \\
$\square \quad$ Mined Coal Seam \\
\hline
\end{tabular}

Figure 5.11: North American zones 


\subsection{Hydraulic Conductivity}

Hydraulic conductivity tests were not available for borehole T51-80. To estimate the permeability of the lithography near the location of interest a borehole similar in elevation was used: HT16-05. The borehole is located in the Northeast section of the mine site and was drilled in November 2005. The top elevation of this borehole is $1248 \mathrm{ft}$ while the elevation of borehole T51-80 is 1190ft. The actual hydraulic conductivities for the HT16-05 are shown in Table 5.12.

Table 5.12: Hydraulic conductivity for overburden layers at borehole HT16-05

\begin{tabular}{|c|c|c|c|c|}
\hline \multicolumn{5}{|c|}{ Borehole HT16-05 } \\
\hline Strata Layer & $\begin{array}{c}\text { Hydraulic Conductivity } \\
(\mathrm{ft} / \mathrm{s})\end{array}$ & $\begin{array}{c}\text { Hydraulic Conductivity } \\
(\mathrm{cm} / \mathrm{s})\end{array}$ & Top Depth (ft) & Bottom Depth (ft) \\
\hline Mahoning Sandstone & $2.92 \mathrm{E}-07$ & $8.89 \mathrm{E}-06$ & 43 & 58 \\
\hline Mahoning Sandstone & 0 & 0 & 55 & 70 \\
\hline Mahoning Sandstone & $3.08 \mathrm{E}-07$ & $9.37 \mathrm{E}-06$ & 70 & 85 \\
\hline Upper Freeport Coal & $1.76 \mathrm{E}-06$ & $5.36 \mathrm{E}-05$ & 85 & 92 \\
\hline Shale & $3.03 \mathrm{E}-05$ & $9.24 \mathrm{E}-04$ & 93 & 108 \\
\hline Shale & $1.68 \mathrm{E}-05$ & $5.11 \mathrm{E}-04$ & 108 & 123 \\
\hline Sandstone & $3.28 \mathrm{E}-07$ & $9.99 \mathrm{E}-06$ & 123 & 138 \\
\hline Shale & $3.90 \mathrm{E}-07$ & $1.19 \mathrm{E}-05$ & 138 & 153 \\
\hline Shale & 0 & 0 & 153 & 168 \\
\hline Sandy/Shale & 0 & 0 & 168 & 183 \\
\hline Sandstone/Shale & $4.20 \mathrm{E}-06$ & $1.28 \mathrm{E}-04$ & 183 & 198 \\
\hline Sandstone & $6.39 \mathrm{E}-08$ & $1.95 \mathrm{E}-06$ & 198 & 213 \\
\hline Coal/Shale Zone & $1.02 \mathrm{E}-06$ & $3.12 \mathrm{E}-05$ & 213 & 218 \\
\hline Shale & $2.81 \mathrm{E}-08$ & $8.56 \mathrm{E}-07$ & 219 & 234 \\
\hline Split of Kittanning Coal & & & & \\
\hline Shale & $1.34 \mathrm{E}-06$ & $4.09 \mathrm{E}-05$ & 236 & 241 \\
\hline Lower Kittanning Coal & $1.66 \mathrm{E}-08$ & $5.05 \mathrm{E}-07$ & 242 & 257 \\
\hline
\end{tabular}

The only layers identified by name are the Mahoning Sandstone and the coal seams. Therefore estimation was done based on similar elevation of layers between the boreholes to identify hydraulic conductivities near the location of interest. These are highlighted in Table 5.12. Given the locations, similar elevations, and low angle of dip between the test sites, it is reasonable to expect these values would be representative of actual field values found near borehole T51-80. 
Within the overburden there are many thin layers of rock. The actual permeability of each thin layer may differ slightly, but for analysis, generalizations were made within the lithography. Multiple layers of one rock type are considered a homogeneous layer within each zone. Table 5.13 shows the approximated field conditions at borehole T51-80. The existing hydraulic conductivities were determined using the aforementioned method. The final three columns represent the potential increase in hydraulic conductivity for each layer if mining were to occur; and are based on review of literature.

Literature discusses that within the Subsidence Angle of Draw, the sandstone layer permeability can increase up to two orders of magnitude while shale may increase in permeability up to three orders of magnitude (Booth, 2006). This dictates the expected post-mining hydraulic conductivity within each strata layer. Within the Subsidence Angle of Draw, the largest increase in permeability is possible due to fracturing, increased strain, and bedding separation. This is shown in Table 5.14 under the Subsidence Angle of Draw column. Past the Subsidence Angle of Draw there is potential for groundwater drawdown due to permeability changes within the Angle of Subsidence Draw. The extent of the potential drawdown is the Angle of Groundwater Influence. 
Table 5.13: Estimated pre-mining hydraulic conductivity at borehole T51-80

\begin{tabular}{|c|c|c|c|c|c|c|}
\hline \multicolumn{7}{|c|}{ Approximate Hydraulic Conductivities near Borehole T51-80 } \\
\hline Subsidence Zones & Strata Layer(s) & $\begin{array}{l}\text { Hydraulic Conductivity } \\
\text { (ft/s) }\end{array}$ & $\begin{array}{l}\text { Hydraulic Conductivity } \\
\text { (ft/d) }\end{array}$ & $\begin{array}{c}\text { Hydraulic } \\
\text { Conductivity } \\
(\mathrm{cm} / \mathrm{s})\end{array}$ & Top Depth (ft) & Bottom Depth (ft) \\
\hline Surface Fracture Zone & Sandstone/Shale & 4.20E-06 & 3.63E-01 & $1.28 \mathrm{E}-04$ & 0.00 & 50.00 \\
\hline \multirow{2}{*}{ Dilated Zone } & Shale & 1.68E-05 & $1.45 \mathrm{E}+00$ & 5.11E-04 & 50.00 & 118.00 \\
\hline & Shale & 3.03E-05 & $2.62 \mathrm{E}+00$ & $9.24 \mathrm{E}-04$ & & \\
\hline Maximum Fractured Zone & Mahoning Sandstone & $3.08 \mathrm{E}-07$ & 2.66E-02 & $9.37 \mathrm{E}-06$ & 118.00 & 162.00 \\
\hline \multirow{2}{*}{ Minimum Fractured Zone } & Sandstone & 6.39E-08 & 5.52E-03 & 1.95E-06 & 162.00 & 247.17 \\
\hline & Sandstone/Shale & 4.20E-06 & 3.63E-01 & 1.28E-04 & & \\
\hline \multirow{2}{*}{ Maximum Caved Zone } & Coal/Shale & $1.02 \mathrm{E}-06$ & 8.83E-02 & 3.12E-05 & 247.17 & 269.79 \\
\hline & Shale & $1.66 \mathrm{E}-08$ & 1.43E-03 & 5.05E-07 & & \\
\hline Minumum Caved Zone & Shale Zone & $1.66 \mathrm{E}-08$ & $1.43 \mathrm{E}-03$ & 5.05E-07 & 269.79 & 306.13 \\
\hline Mine Seam & Lower Kittanning Coal & 3.03E-06 & 2.62E-01 & $9.23 \mathrm{E}-05$ & 306.13 & 310.54 \\
\hline
\end{tabular}

Table 5.14: Approximate hydraulic conductivities pre- and post mining at borehole T51-80

\begin{tabular}{|c|c|c|c|c|c|c|}
\hline \multicolumn{7}{|c|}{ Approximate Hydraulic Conductivities near Borehole T51-80 } \\
\hline \multirow[b]{2}{*}{ Subsidence Zones } & \multirow[b]{2}{*}{ Strata Layer(s) } & \multicolumn{2}{|c|}{ Depth (ft) } & \multirow[b]{2}{*}{$\begin{array}{c}\text { Hydraulic Conductivity } \\
(\mathrm{cm} / \mathrm{s})\end{array}$} & \multicolumn{2}{|c|}{ Subsidence Angle of Draw } \\
\hline & & Top Depth & Bottom Depth & & $\begin{array}{l}\text { Minimum Increase in } \\
\text { Magnitude of Hydraulic } \\
\text { Conductivity }\end{array}$ & $\begin{array}{l}\text { Maximum Increase in } \\
\text { Magnitude of Hydraulic } \\
\text { Conductivity }\end{array}$ \\
\hline Surface Fracture Zone & Sandstone/Shale & 0.00 & 50.00 & $1.28 \mathrm{E}-04$ & 1 & 3 \\
\hline \multirow{2}{*}{ Dilated Zone } & Shale & 50.00 & 118.00 & 5.11E-04 & 1 & 3 \\
\hline & Shale & & & $9.24 \mathrm{E}-04$ & 1 & 3 \\
\hline Maximum Fractured Zone & Mahoning Sandstone & 118.00 & 162.00 & 9.37E-06 & 1 & 2 \\
\hline \multirow{2}{*}{ Minimum Fractured Zone } & Sandstone & 162.00 & 247.17 & 1.95E-06 & 1 & 2 \\
\hline & Sandstone/Shale & & & $1.28 \mathrm{E}-04$ & 2 & 3 \\
\hline \multirow{2}{*}{ Maximum Caved Zone } & Coal/Shale & 247.17 & 269.79 & 3.12E-05 & 2 & 3 \\
\hline & Shale & & & 5.05E-07 & 2 & 3 \\
\hline Minumum Caved Zone & Shale & 269.79 & 306.13 & 5.05E-07 & 2 & 3 \\
\hline Mine Seam & Lower Kittanning Coal & 306.13 & 310.54 & $9.23 \mathrm{E}-05$ & 2 & 3 \\
\hline
\end{tabular}




\subsection{Strain Locations and Values}

Generally subsidence creates zones of compression directly above the extracted coal seam with areas of tension beginning near edges and extending outwards. Heavy fracturing and compression occur directly above the mine where tensional strains occur past the inflection point outwards to the extent of where the rock is undisturbed. This correlates with the Angle of Subsidence Draw. The recommended tolerable strain for groundwater aquifers and surface bodies of water is 0.005 (Singh, 1992). However, research has shown that increased permeability can occur with extensional strains of 0.001 (Bai, et al., 1995). This is 5 times less than the recommended guidelines. IC 8741 recommends strains not to exceed 0.00875 which is far greater than both of these values.

\subsection{Groundwater and Permeability}

Subsidence can affect permeability in the subsurface in multiple ways. It can create an area of compression above the mine causing an area of pooling. In areas of tension located within the area of draw, strain values will increase permeability. Both of these instances will allow for changes on subsurface water flows outside the angle of draw. The area affected is termed in this document as the Angle of Groundwater Influence. Like the angle of draw this range develops at an angle extending outwards from the extents of the mine.

\subsubsection{Mine Flooding}

The flow rate into the mine was determined using equations based on mine discharges. These reflect lower rates than during active mining. Using the nearby Sentinel Mine to determine the accuracy of these equations, the estimate drainage into Tygart \#1 mine was estimated (Table 5.15). The expected flow rate is between 260 gallons per minute (gpm) and 466 gpm. At these rates it is estimated to take between 12 and 15 years to saturate the mine void to $85 \%-90 \%$. 
Table 5.15: Predicted and actual mine flow rate (WVDEP, 2009)

\begin{tabular}{|c|c|c|c|c|c|c|c|c|}
\hline & \multicolumn{2}{|c|}{$\begin{array}{c}\text { Sentinel, West Mains } \\
962.18 \mathrm{Ac} \\
31.63 \%>500 ' \text { cover } \\
\text { wtd Avg. } \\
\text { Overburden }=450 \text { ' }\end{array}$} & \multicolumn{2}{|c|}{$\begin{array}{c}\text { Sentinel, D-1 Pump } \\
4051.58 \text { Ac } \\
54.29 \%>500 \text { ' cover } \\
\text { wtd Avg. } \\
\text { Overburden }=530\end{array}$} & \multicolumn{2}{|c|}{$\begin{array}{c}\text { Tygart \#1, } \\
\text { During Mining } \\
6,000 \mathrm{Ac} * \\
65.97 \%>500 \text { ' cover } \\
\text { wtd Avg. } \\
\text { Overburden }=540 \text { ' }\end{array}$} & \multicolumn{2}{|c|}{$\begin{array}{c}\text { Tygart \#1, } \\
\text { Post Mining } \\
5,300 \mathrm{Ac} * \\
76.39 \%>500 \text { ' cover } \\
\text { wtd Avg. } \\
\text { Overburden }=565 \text { ' }\end{array}$} \\
\hline & $\mathrm{gpm} / \mathrm{ac}$ & $\begin{array}{l}\text { Total } \\
\text { gpm }\end{array}$ & $\mathrm{gpm} / \mathrm{ac}$ & $\begin{array}{l}\text { Total } \\
\text { gpm }\end{array}$ & $\mathrm{gpm} / \mathrm{ac}$ & $\begin{array}{l}\text { Total } \\
\text { gpm }\end{array}$ & $\mathrm{gpm} / \mathrm{ac}$ & $\begin{array}{l}\text { Total } \\
\text { gpm }\end{array}$ \\
\hline McCoy Eq. & 0.1375 & 132 & 0.08167 & 334 & 0.0627 & 374 & 0.049 & 260 \\
\hline Leavitt Eq. & 0.1474 & 142 & 0.103 & 597 & 0.0983 & 590 & 0.08787 & 466 \\
\hline $\begin{array}{c}\text { Actual, } \\
\text { During Mining }\end{array}$ & 0.3097 & 298 & 0.2204 & 893 & $\begin{array}{c}\text { (Assume } \\
0.20)\end{array}$ & $(1200)$ & N/A & N/A \\
\hline
\end{tabular}

"Approximately 6,000 acres are planned to be mined, but about 700 such acres lie where surface elevations are below 1360 feet. Afler complete flooding of the mine and overlying fractured zone, the hydraulic gradient will prevent further recharge in those areas. The final post-mining rechare area, then, will encompass approximately 5,300 acres, and the recharge rate will be reduced.

The estimated total water required to fill the mine is based on the void space minus the gob fill from subsidence. The required water for a 50\% fill due to subsidence is approximately 4.7 Billion gallons as shown in equation 6 (WVDEP, 2009). However this is based on the entire mine void being flooded.

$$
\begin{aligned}
\text { Mined Area } & =6,000 \text { acres }=261,360,000 \mathrm{ft}^{2} \\
\text { Avg. Mine Height } & =6 \mathrm{ft} \\
\text { Avg. Reserve Recovery (original void space created) } & =80 \%
\end{aligned}
$$$$
\text { Volume Reduction Factor (due to subsidence) }=50 \%
$$$$
\text { So that: Volume } \quad=261.36 \mathrm{MM} \mathrm{ft}^{2} \times 6 \mathrm{ft} \times 60 \% \times 50 \%=627,264,000 \mathrm{ft}^{3}
$$$$
=4.692 \text { Billion gal. }
$$

Figure 5.12 illustrates the mine flooding extents expected. The mine flooding is based on an infiltration rate of 260gpm and 466gpm. Discharge may occur if portals do no remain sealed. The only outcrop barrier is in the up-dip most part of the area, located where Sandy Creek joins the Tygart River Valley. 


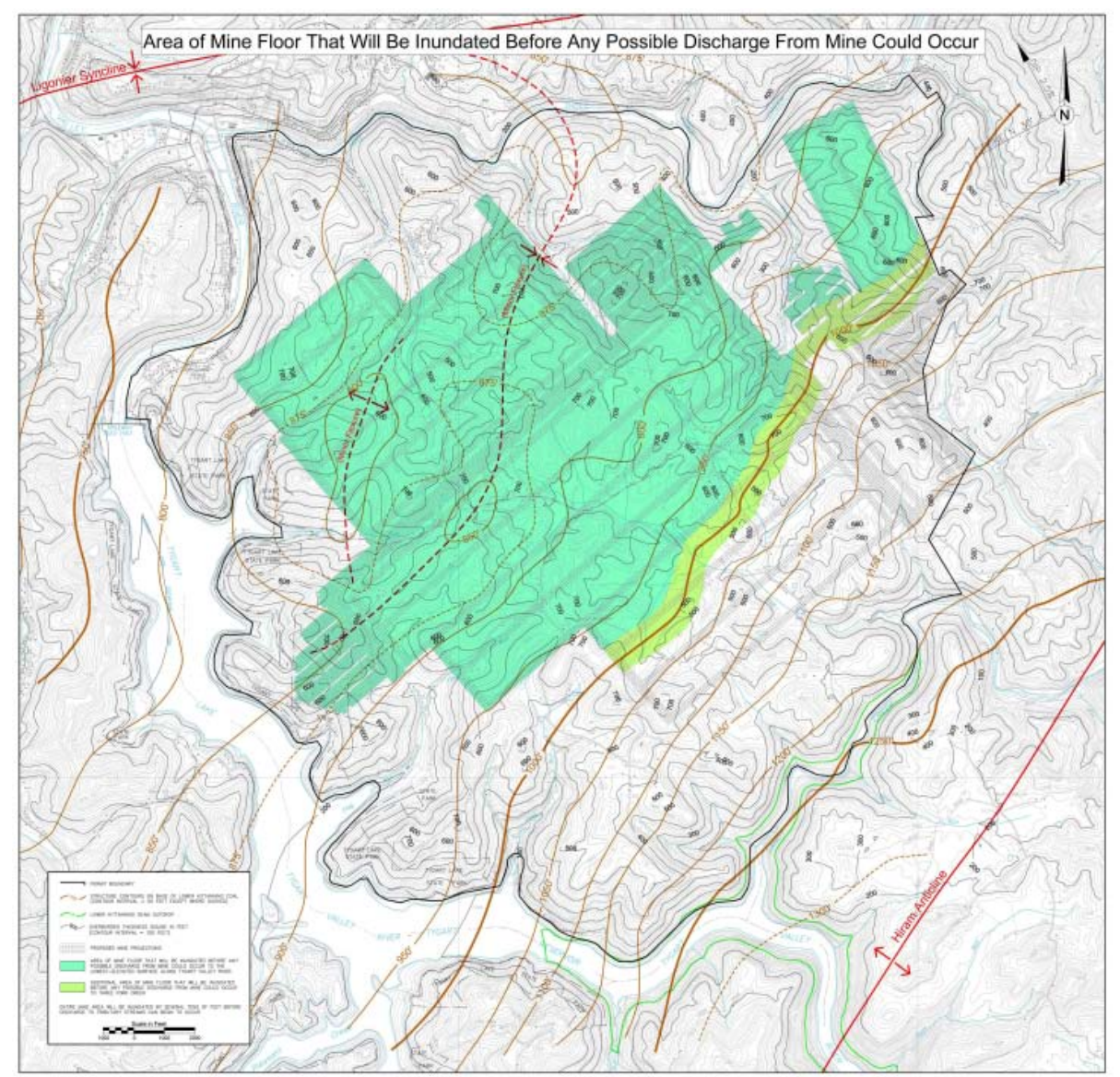

Figure 5.12: Flooded mine extents (WVDEP, 2009)

Figure 5.13 identifies the elevation outcrop locations where the flooded mine discharge is expected. The coal seam dip and corresponding planned discharge location is identified.

The mine is planned to flood and treatment systems for acid mine water are addressed in the permit file. 


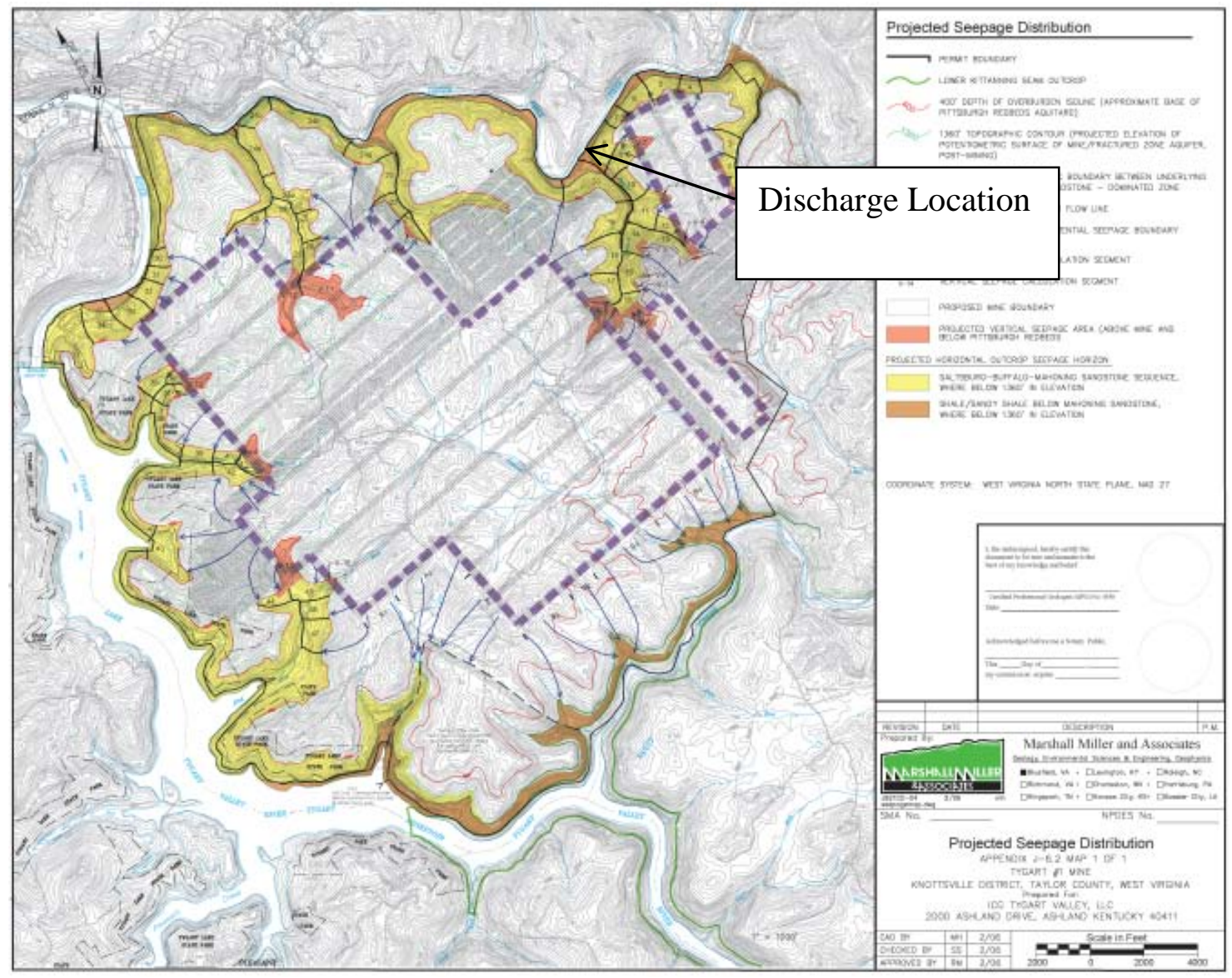

Figure 5.13: Projected seepage outcrop locations (WVDEP, 2009)

The location shown in Figure 5.10 shows two small tributaries that feed into Tygart Lake. These tributaries are potential locations for naturally occurring stress relief fracturing. The tributaries run perpendicular to the bedding plane angle of dip. As the surface water flow slowly erodes the soil and upper bedrock, the forces in the valley walls above will push into the streambed causing upheaval. If this occurs, the layers that lie below the streambed could be fractured. 


\subsection{Potential Failure Modes Analysis}

\subsubsection{Semi-Quantitative Risk Assessment}

The initiating event for these occurrences is subsidence due to mining which creates strain within the overburden affecting ground surface subsidence and groundwater seepage patterns. These strains cause fracturing as openings develop in rock joints and faults which increase in horizontal and vertical hydraulic permeability. This range of extension is considered to affect the permeability of the rock and soil foundation zone adjoining the reservoir at both locations and can extend several hundred feet from the edges of the mine voids.

The following narrative presents a potential failure mode description for a room and pillar, and longwall mining event near the rim of a USACE reservoir. It develops the structure of the event tree analysis due to subsurface seepage culminating with a loss of reservoir pool level control.

\subsubsection{Gate Road Pillar (Entries)}

Failure Mode Description: Installation of a longwall coal mine in the vicinity of boring T51-80. Subsidence will cause vertical and horizontal fracturing of overburden rock (FLAW). The potential ground subsidence will occur within longwall extraction zone.

Probability Level I - initiating event: At gate road pillars, it will experience stress and strain inflections near and at pillars as wave approaches; subsidence extending past gate road pillars at $15^{\circ}$ or $30^{\circ}$ Angle of Subsidence Draw (with an average of $23^{\circ}$ ); and, at perimeter gate road pillars, ground will be disturbed within the $15^{\circ}$ to $23^{\circ}$ offset Angle of Subsidence Draw. Over the gateway and gate road pillars, the ground surface disturbance zones would be expected as negative strains resulting in permeability increases 
The Failure Mode description for this condition is as follows:

The mine subsidence (Flaw) produces the caved, fractured, and dilated zones which are the initiating event triggering increased vertical and horizontal strains in the rock strata. A pool level rise increases the hydraulic gradient between the reservoir foundation and the subsidence zones increasing seepage. The seepage flowrate is increased and exceeds the critical gradient of the erodible foundation soil and internal erosion initiates (Initiation). The pool level rise has sufficient duration to maintain the gradient so that internal erosion develops and is supported by soil particle displacement (Progression). Detection and intervention are unsuccessful (Unsuccessful Detection and Intervention). As a result, gross enlargement of a sinkhole below the reservoir level develops and the pool level is unable to be controlled (Uncontrolled Reservoir Level).

These mining methods will cause mine subsidence of the overlying geologic strata. The subsidence may be manifested by development of zones of increased strains developed in the overburden rock. The strains will have various zones of influence, both vertical and horizontal.

Longwall panels 2 and 3 are approximately 1200ft wide and are illustrated in Figure 5.14. Longwall panel 1 is $1000 \mathrm{ft}$ wide. The average thickness of the coal seam for the mine is between $4.5 \mathrm{ft}$ and $5.5 \mathrm{ft}$ with local thicknesses exceeding $10 \mathrm{ft}$. Due to the size of the mining equipment, the expected thickness of the void created in this location is $6 \mathrm{ft}$. 


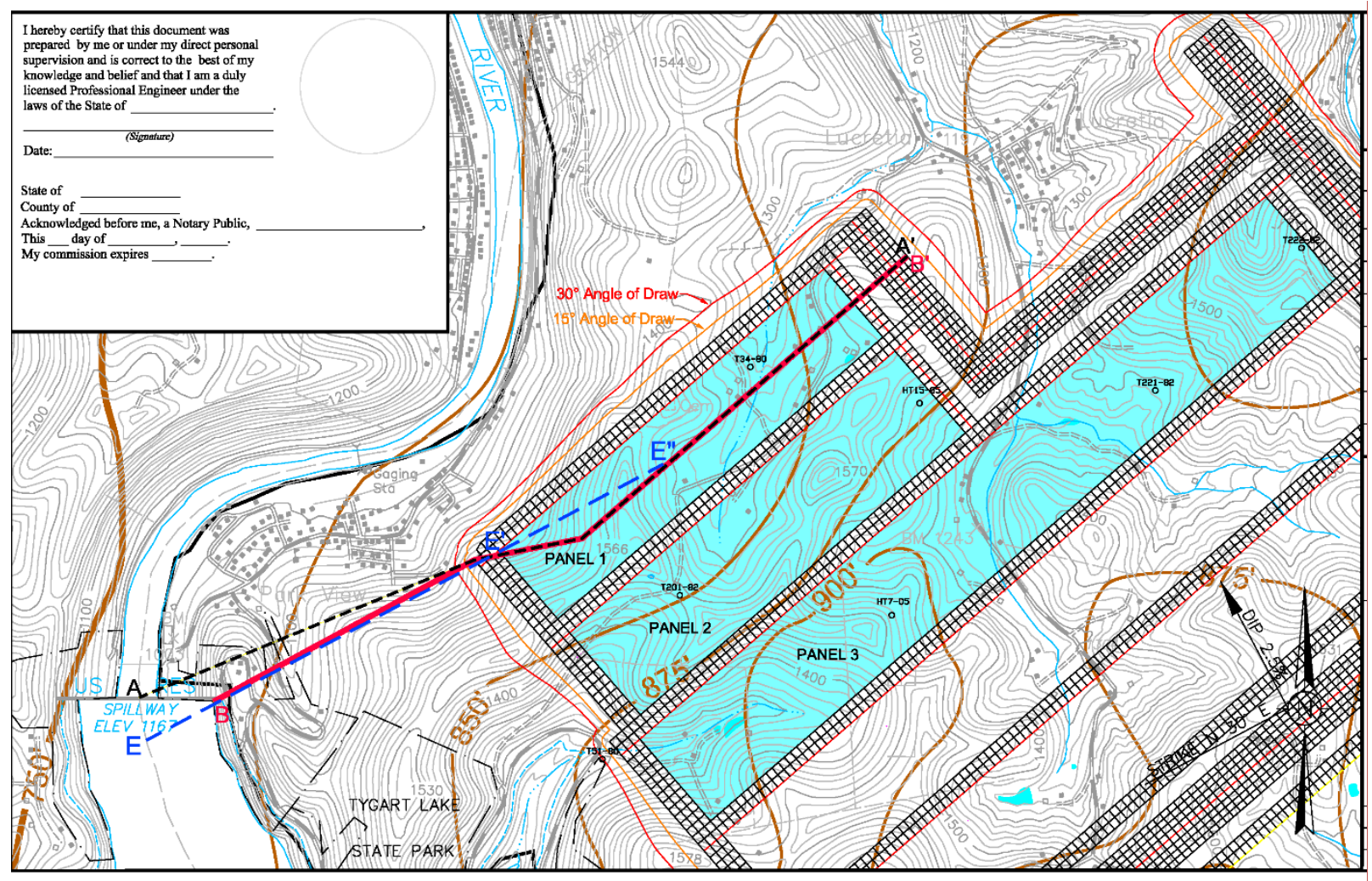

Figure 5.14: Longwall panels near borehole T51-80(WVDEP, 2009)

Groundwater and seepage changes due to mining near the perimeter rim of Tygart reservoir is analyzed at the approximate junction of panels \#2 and \#3. At this location a local stream feeds into the reservoir. The location of these longwall panels and perimeter appurtenant structures are the closest distance to the reservoir. This may cause the pool perimeter to intersect the overburden that has been fractured (flawed) by the longwall mining. 


\subsubsection{SQRA for Gate Road Pillars}

\subsubsection{Load Conditions}

Change in pool level: The pool level elevation determines the vertical and horizontal distance between the reservoir rim and the affected overburden from mining. The expected pool levels are shown in Table 5.16.

Table 5.16: Pool Level Elevations

\begin{tabular}{|l|r|}
\hline \multicolumn{2}{|c|}{ Pool Level (ft.) } \\
\hline Minimum & 1009.5 \\
\hline Winter & 1039.5 \\
\hline Summer & 1093.5 \\
\hline Full & 1166.5 \\
\hline PMF & 1196.3 \\
\hline
\end{tabular}

Table 5.17 shows the expectancy for certain pool levels. Given the location near borehole T5180, normal pool levels would not have a significant impact on seepage and potential subsurface erosion near the reservoir rim.

Table 5.17: Likelihood of conditions for pool levels

\begin{tabular}{|c|c|c|}
\hline Likely Event Conditions & $\begin{array}{l}\text { Somewhat Likely or } \\
\text { Neutral Event } \\
\text { Conditions }\end{array}$ & Unlikely Event Conditions \\
\hline $\begin{array}{l}\text { The normal Expected } \\
\text { pool levels for Tygart } \\
\text { Lake are the Winter } \\
\text { (1039.5ft) and Summer } \\
\text { pool (1093.5ft) }\end{array}$ & $\begin{array}{l}\text { Flood conditions that } \\
\text { cause pool elevation } \\
\text { changes leading to rim } \\
\text { extending above zone of } \\
\text { groundwater influence }\end{array}$ & $\begin{array}{l}\text { Full pool elevation or top of } \\
\text { spillway elevation (1166.5ft) } \\
\text { will cause reservoir rim to } \\
\text { extend above fractured zones } \\
\text { and above pillar extents }\end{array}$ \\
\hline
\end{tabular}

The closest approach of the mine to the summer pool level is $1670 \mathrm{ft}$. For unlikely conditions of pool levels reaching the spillway elevation the offset distance is $420 \mathrm{ft}$. In a worst case scenario of probable maximum flood, the pool level would overtop the mine at one location. 


\subsubsection{Flaw}

The subsidence trough may experience subsidence at - 4ft (pooling of water), fracturing, surface disturbance and dilation of overburden. At the pillars it will experience stress and strain inflections near and at pillars as wave approaches; subsidence extending past the pillars at $15^{\circ}$ or $30^{\circ}$ Angle of Subsidence Draw (with an average of $23^{\circ}$ ). At the perimeter pillars ground disturbance will occur within the $15^{\circ}$ to $23^{\circ}$ offset Angle of Subsidence Draw. The pillars will also have stress/strain inflection and fracture due to negative strain. Over the pillars the ground surface disturbance zones would be expected as negative strains, expanding fractures, resulting in permeability increases.

Table 5.18: Likelihood conditions for Subsidence Angle of Draw

\begin{tabular}{|l|l|l|}
\hline \multicolumn{1}{|c|}{$\begin{array}{c}\text { Likely Event } \\
\text { Conditions }\end{array}$} & $\begin{array}{c}\text { Somewhat Likely or Neutral } \\
\text { Event Conditions }\end{array}$ & \multicolumn{1}{c|}{$\begin{array}{c}\text { Unlikely Event } \\
\text { Conditions }\end{array}$} \\
\hline $\begin{array}{l}\text { The angle of draw } \\
\text { (subsidence) extends 15 } \\
\text { degrees from vertical. } \\
\text { The affected area extends } \\
\text { approximately 83ft } \\
\text { beyond pillars }\end{array}$ & $\begin{array}{l}\text { The angle of draw (subsidence) } \\
\text { extends 30 degrees from } \\
\text { vertical. The affected area } \\
\text { extends approximately 179ft } \\
\text { beyond pillars. }\end{array}$ & $\begin{array}{l}\text { Angle of draw (subsidence) } \\
\text { extends beyond 35 degrees. }\end{array}$ \\
\hline
\end{tabular}

The maximum angle of draw calculated for this event is 30 degrees. This is represented as the red line in Figure 5.10.

\subsubsection{Pathway}

Angle of Groundwater Influence: The Angle of Groundwater Influence represents the lateral extents for changes in groundwater flow. The Angle of Groundwater Influence is the region where drawdown or head changes occur due to subsidence affects. For this analysis the maximum extents of the angle of groundwater influence to be 60 degrees. The likelihood of seepage increases are presented in Table 5.19. 
Table 5.19: Likelihood conditions for Angle of Groundwater Influence

\begin{tabular}{|l|l|l|}
\hline \multicolumn{1}{|c|}{$\begin{array}{c}\text { Likely Event } \\
\text { Conditions }\end{array}$} & $\begin{array}{l}\text { Somewhat Likely or } \\
\text { Neutral Event Conditions }\end{array}$ & \multicolumn{1}{c|}{$\begin{array}{c}\text { Unlikely Event } \\
\text { Conditions }\end{array}$} \\
\hline $\begin{array}{l}\text { The angle of groundwater } \\
\text { influence extends 30 degrees } \\
\text { from vertical. The affected } \\
\text { area extends approximately } \\
\text { 179ft horizontally from mine } \\
\text { extents. }\end{array}$ & $\begin{array}{l}\text { The angle of groundwater } \\
\text { influence extends 40 } \\
\text { degrees from vertical. The } \\
\text { affected area extends } \\
\text { approximately 260ft } \\
\text { horizontally from mine } \\
\text { extents. }\end{array}$ & $\begin{array}{l}\text { The angle of groundwater } \\
\text { influence extends 60 degrees } \\
\text { from vertical. The affected } \\
\text { area extends approximately } \\
\text { 537ft horizontally from mine } \\
\text { extents. }\end{array}$ \\
\hline
\end{tabular}

\subsubsection{Initiation}

The initiation of increased seepage from the reservoir into the fractured voids is expected as a likely event. The seepage is expected to have a high gradient from the reservoir elevation

\subsubsection{Event tree analysis}

The event tree for this analysis is illustrated in Figure 5.15. Time frame is not shown when looking at long term effects. Specific details explaining the development of the conditional and risk categories are presented in Chapter 4. 


\begin{tabular}{|c|c|c|c|c|c|}
\hline $\begin{array}{c}\text { Phase } \\
\text { Condition }\end{array}$ & $\begin{array}{l}\text { Loading } \\
\text { Yes/No } \\
\text { Decision }\end{array}$ & $\begin{array}{c}\text { Flaw } \\
\\
\left(\mathbf{P}_{\mathrm{f}}\right) \\
\text { Initiating } \\
\text { Event }\end{array}$ & $\begin{array}{l}\text { Pathway } \\
\left(\mathrm{P}_{\mathrm{f}}\right) \\
\text { Initiating } \\
\text { Event }\end{array}$ & $\begin{array}{c}\text { Initiation of } \\
\text { Seepage } \\
\left(\mathbf{P}_{\mathbf{f}}\right) \\
\text { Initiating } \\
\text { Event }\end{array}$ & $\begin{array}{c}\text { Progression } \\
\text { Yes/No } \\
\text { Decision }\end{array}$ \\
\hline $\begin{array}{c}\text { Maximum } \\
\text { Subsidence } \\
\text { Occurs }\end{array}$ & $\begin{array}{c}\text { Pool Elevation } \\
\text { Changes due to } \\
\text { Seasonal Effects } \\
\text { (Seepage Forces / } \\
\text { Velocity) }\end{array}$ & $\begin{array}{c}\text { Subsidence Angle } \\
\text { of Draw } \\
\text { Strain }\end{array}$ & $\begin{array}{c}\text { Extent of } \\
\text { Groundwater Cone } \\
\text { of Depression }\end{array}$ & $\begin{array}{l}\text { Permeability } \\
\text { Increase Due to } \\
\text { Extension. } \\
\text { Dependent on } \\
\text { Strata type }\end{array}$ & $\begin{array}{l}\text { Increase in } \\
\text { Seepage Flowrate } \\
\text { and Velocity }\end{array}$ \\
\hline $\begin{array}{c}\text { Longwall } \\
\text { Mining } \\
\text { Near Tygart } \\
\text { Lake }\end{array}$ & $\begin{array}{l}\text { Winter Pool } \\
\text { Summer Pool } \\
\text { Full Pool } \\
\text { Probable } \\
\text { Max. Flood }\end{array}$ & \begin{tabular}{|l}
$0^{\circ}$ to $10^{\circ}$ \\
$10^{\circ}$ to $20^{\circ}$ \\
$20^{\circ}$ to $25^{\circ}$ \\
$25^{\circ}$ to $30^{\circ}$ \\
$30^{\circ}$ to $35^{\circ}$ \\
$>35^{\circ}$
\end{tabular} & $\begin{array}{l}0^{\circ} \text { to } 10^{\circ} \\
10^{\circ} \text { to } 20^{\circ} \\
20^{\circ} \text { to } 30^{\circ} \\
30^{\circ} \text { to } 40^{\circ} \\
40^{\circ} \text { to } 50^{\circ} \\
50^{\circ} \text { to } 60^{\circ} \\
>60^{\circ}\end{array}$ & $\begin{array}{l}\text { Perm. 10x } \\
\text { Perm. 100x } \\
\text { Perm. } 1000 \mathrm{x} \\
\text { Perm. }-100 \mathrm{x}\end{array}$ & No Erosion \\
\hline
\end{tabular}

Figure 5.15: Event tree for full extraction longwall mining (After Wachtel, 2012)

Figure 5.16 illustrates the one branch analyzed from Figure 5.15. The selected branch is based on a loading summer pool reservoir elevation, the flaw of $15^{\circ}$ angle of draw, the pathway of $40^{\circ}$ groundwater extent, and the initiation of uncontrolled seepage. 


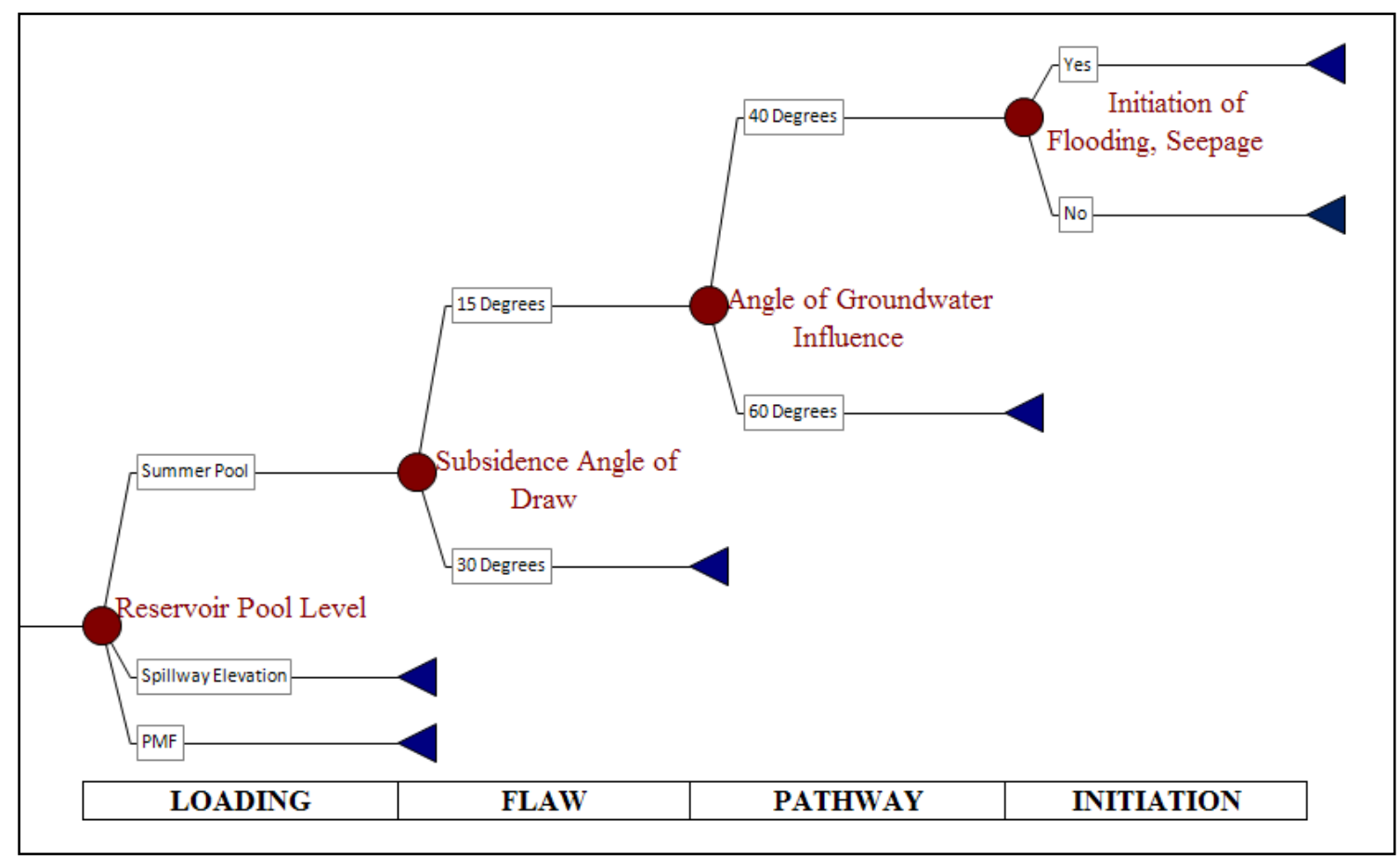

Figure 5.16: Event tree for seepage initiation

Table 5.20 presents the probability for the Angle of Groundwater Influence based on subsidence ranges based on literature showing an average range to be $20^{\circ}$ to $40^{\circ}$, with greater angles possible in areas of steep terrain (Booth, 2006). The method used for this analysis was a lognormal distribution using this range

Table 5.20: Probability of Angle of Groundwater Influence based on Subsidence Angle of Draw

\begin{tabular}{|c|l|l|l|l|l|l|}
\hline \multirow{2}{*}{$\begin{array}{c}\text { Angle of } \\
\begin{array}{c}\text { Groundwater } \\
\text { Influence }\end{array}\end{array}$} & $\begin{array}{l}\text { 0-10 } \\
\text { Degrees }\end{array}$ & $\begin{array}{l}10-20 \\
\text { Degrees }\end{array}$ & $\begin{array}{l}20-25 \\
\text { Degrees }\end{array}$ & $\begin{array}{l}\text { 25-30 } \\
\text { Degrees }\end{array}$ & $\begin{array}{l}\text { 30-35 } \\
\text { Degrees }\end{array}$ & $\begin{array}{l}35-40 \\
\text { Degrees }\end{array}$ \\
\hline 0-10 Degrees & 0.008 & 0.000 & 0.000 & 0.000 & 0.000 & 0.000 \\
\hline 10-20 Degrees & 0.549 & 0.185 & 0.000 & 0.000 & 0.000 & 0.000 \\
\hline 20-30 Degrees & 0.395 & 0.651 & 0.528 & 0.432 & 0.000 & 0.000 \\
\hline 30-40 Degrees & 0.048 & 0.164 & 0.422 & 0.508 & 0.894 & 0.722 \\
\hline 40-50 Degrees & 0.000 & 0.000 & 0.048 & 0.057 & 0.101 & 0.266 \\
\hline 50-60 Degrees & 0.000 & 0.000 & 0.002 & 0.003 & 0.004 & 0.011 \\
\hline$>60$ Degrees & 0.000 & 0.000 & 0.00 & 0.00 & 0.001 & 0.001 \\
\hline Total Probability & 1.000 & 1.000 & 1.000 & 1.000 & 1.000 & 1.000 \\
\hline
\end{tabular}




\subsubsection{Probability for increased hydraulic conductivity}

On the basis of the maximum subsidence angle presented in the permit file of $30^{\circ}$, the corresponding probability is 0.89 that the Angle of Groundwater Influence will extend between $30^{\circ}$ to $40^{\circ}$ and $10 \%$ between 40 and 50 degrees. The probabilities of the Angle of Groundwater Influence are reduced above $40^{\circ}$ as shown in Table 5.20 and illustrated in Figure 5.17.

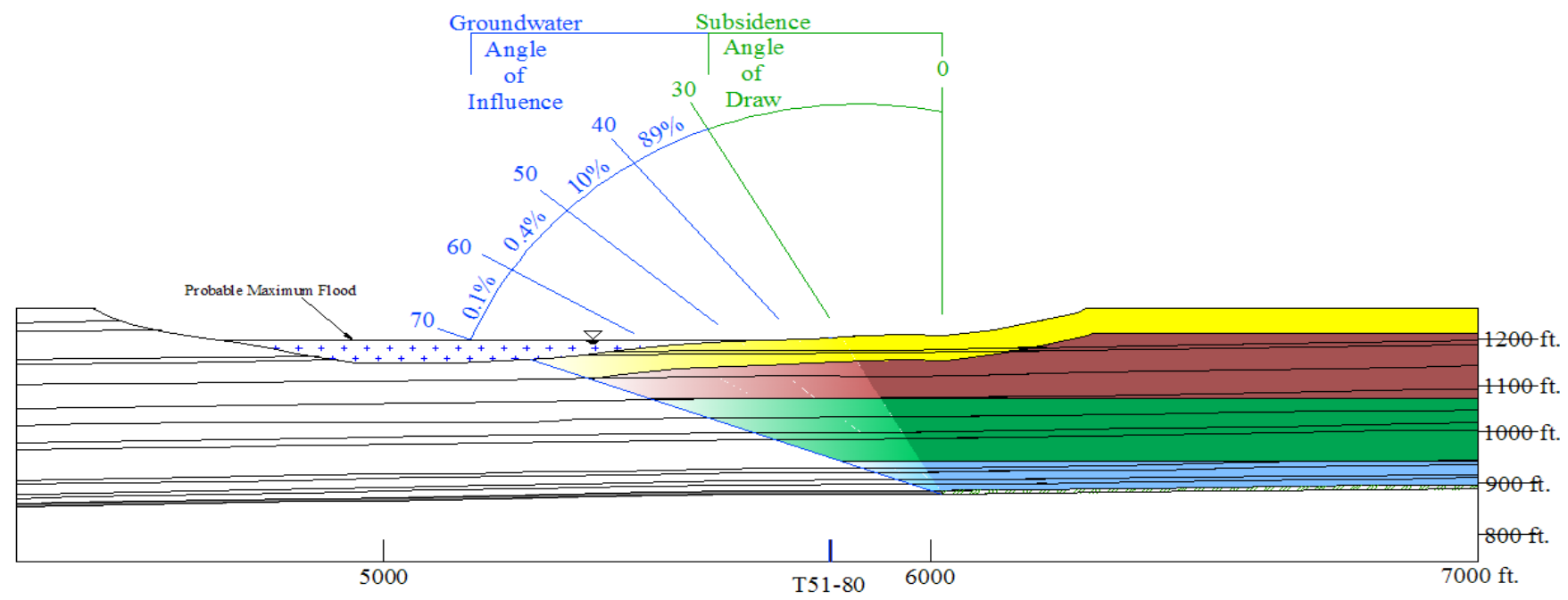

\begin{tabular}{|c|c|c|}
\hline $\begin{array}{c}\text { Gradient for } \\
\text { Zones of }\end{array}$ & \multicolumn{2}{|c|}{$\begin{array}{l}\text { Hydraulic Conductivity } \\
(\mathrm{cm} / \mathrm{s})\end{array}$} \\
\hline Groundwater Draw & Minimum & Maximum \\
\hline 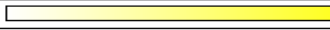 & $1.28 \mathrm{E}-03$ & $1.28 \mathrm{E}-02$ \\
\hline 도 & $5.11 \mathrm{E}-03$ & $9.24 \mathrm{E}-01$ \\
\hline & $1.95 \mathrm{E}-05$ & $1.28 \mathrm{E}-01$ \\
\hline & $5.05 \mathrm{E}-05$ & $3.12 \mathrm{E}-02$ \\
\hline
\end{tabular}

Figure 5.17: Probability of change in groundwater flow along cross section C-C

The values provided in Figure 5.17 represent the percent that increased groundwater flow changes may occur at specific angles. These angles are portrayed over Cross section C-C with the probable maximum flood elevation shown. In actuality the PMF would overtop the mine north-west of this cross section. 


\subsubsection{Probability based on offset distances}

The probabilities for Groundwater Angle of Influence described above are represented given a $30^{\circ}$ Subsidence Angle of Draw. These are shown from the edge of the mine along cross section C-C. A more generalized probability of increased hydraulic conductivity can be determined based on the lateral offset distance between the mine and the reservoir rim. Table 5.21 represents the total probability given $200 \mathrm{ft}$, $400 \mathrm{ft}$ and $600 \mathrm{ft}$ offset distances. These probabilities are for a mine approximately 350ft deep and using ranges of subsidence from Singh (1992).

Table 5.21: Probability for erosion to occur based on offset distance

\begin{tabular}{|c|c|c|c|c|c|c|c|}
\hline \multirow[b]{2}{*}{ Offset Distance } & \multicolumn{6}{|c|}{ Potential for Erosion Given Angle of Subsidence Draw } & \multirow{2}{*}{$\begin{array}{c}\text { Total } \\
\text { Probability }\end{array}$} \\
\hline & $\begin{array}{c}0-10 \\
\text { Degrees }\end{array}$ & $\begin{array}{c}10-20 \\
\text { Degrees }\end{array}$ & $\begin{array}{c}20-25 \\
\text { Degrees }\end{array}$ & $\begin{array}{c}25-30 \\
\text { Degrees }\end{array}$ & $\begin{array}{c}30-35 \\
\text { Degrees }\end{array}$ & $\begin{array}{c}35-40 \\
\text { Degrees }\end{array}$ & \\
\hline $200 \mathrm{ft}$ & 0.001 & 0.096 & 0.127 & 0.118 & 0.050 & 0.017 & 0.41 \\
\hline $400 \mathrm{ft}$ & 0.000 & 0.000 & 2.2E-03 & 2.3E-03 & $1.1 \mathrm{E}-03$ & 9.5E-04 & 6.6E-03 \\
\hline $600 \mathrm{ft}$ & 0.000 & 0.000 & 0.000 & 0.000 & $5.0 \mathrm{E}-5$ & $1.7 \mathrm{E}-05$ & $6.7 \mathrm{E}-05$ \\
\hline
\end{tabular}

As the horizontal distance between the mine and a reservoir increases, the likelihood that subsidence based changes in permeability (and groundwater flow) will have an impact decreases. The event tree analysis results, shown in Figure 5.18 and Table 5.22, show that there can be a significant reduction in the potential for changes in permeability as the offset distances increases from $200 \mathrm{ft}(40.96 \%), 400 \mathrm{ft}(0.0067 \%)$, to $600 \mathrm{ft}(0.000067 \%)$. 

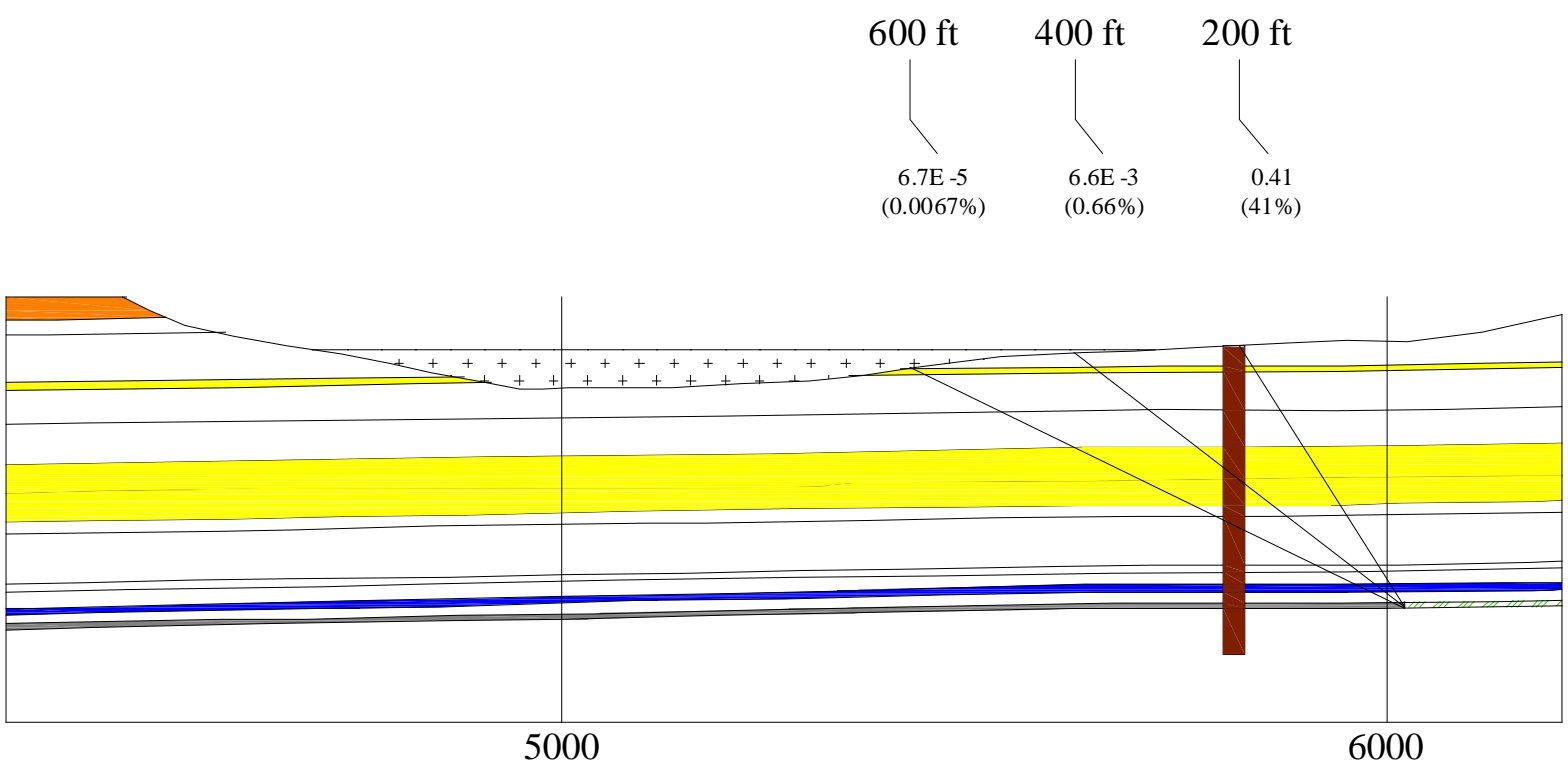

Figure 5.18: Offset distances to mine based on probability

\subsection{Conclusions}

The underground mine near Tygart Lake will create subsidence creating physical changes within the overburden. These changes will affect hydraulic conductivity and groundwater flow rate exceeding the $200 \mathrm{ft}$ offset guidelines recommended by IC8741. This Chapter details the method of event tree analysis to determine the potential for groundwater changes to intersect the reservoir at Tygart Lake given lateral distances based on pool level.

This analysis projected the likelihood of groundwater influence occurring beneath the reservoir rim based on a 30 degree angle of draw. Under PMF conditions the reservoir will overtop the barrier pillars of the mine, creating a strong likelihood that seepage from the reservoir will initiate. A full pool level (420 feet lateral offset) the potential for initiation of seepage from the reservoir is reduced to $0.5 \%$. At summer pool level (1670 feet), the offset distance was well beyond and potential impact to the reservoir. 


\section{CHAPTER 6: Computer Modeling Assessment}


Subsidence due to underground mining causes changes in the overburden including fracturing, bedding plan separation and increases in both vertical and lateral strain. As discussed in Chapter 1 , these changes increase the permeability of the overburden and potentially permanently alter the flow path of groundwater. As groundwater seeps into the mine vertically, the phreatic surface begins to drawdown in the area known as the Cone of Depression. The extent of the drawdown is based on the recharge rate and the magnitude of change in hydraulic conductivity within the bedding layers. If the increase in hydraulic conductivity connects to the mine or other outlet, such as an outcrop, the drawdown effect may be permanent. If the drawdown occurs near a surface body of water, the effect may create a pathway from the water body to the outlet (such as the mine void). Such a link may create head loss and the inability to properly maintain the pool elevation. Increased seepage from a reservoir due to changes in hydraulic conductivity may initiate erosion around the reservoir rim, potentially causing failure.

The purpose of this chapter is to show how computer modeling analysis can be performed to estimate the potential groundwater changes due to underground mining at an actual field site. The site chosen for this analysis was the Arch Coal's Leer mining complex adjacent to Tygart Lake in Grafton, WV. This site was chosen based on the initial parameter of longwall mining within proximity to a reservoir and the wealth of information available for this particular mining operation. This analysis was only able to be performed due to the thoroughness of preliminary research performed by the mining company and provided by the West Virginia Department of Environmental Protection.

The goal of the computer modeling is to determine if there is potential for failure of a reservoir based on offset distance, given property changes in the rock and soil due to underground mining (Figure 6.1). For the model examined in this chapter, the mine location was already determined. However, offset distance was altered based on pool level conditions. Potential failure was considered if flow rate changes above one order of magnitude below the reservoir rim were observed in the Fractured, Dilated or Surface zones. The caved zone was not considered for failure as the proximity and physical changes were unlikely to perpetrate to the surface. For example, the Caved Zone will undergo heavy fracturing and an expected large increase in hydraulic conductivity. This will affect the flow paths in the overlying zones but, unless significant flow rate changes in the overlying zones is observed, an increased flow rate in the 
caved zone would not directly cause drawdown of the reservoir. For this analysis, the threshold for failure was established at one order of magnitude change in flow rate beneath the reservoir rim. For dam and reservoir safety, any potential change in flow rate at or beneath the reservoir is of concern and considered a potential hazard to the integrity of a site. However, computer modeling is an estimate of changes based on various assumptions (i.e. homogeneous bedding layers). Therefore, for the model presented here, the threshold for a considered failure was set at a change in flow rate significant enough to eliminate differences based on the limitations of the model.

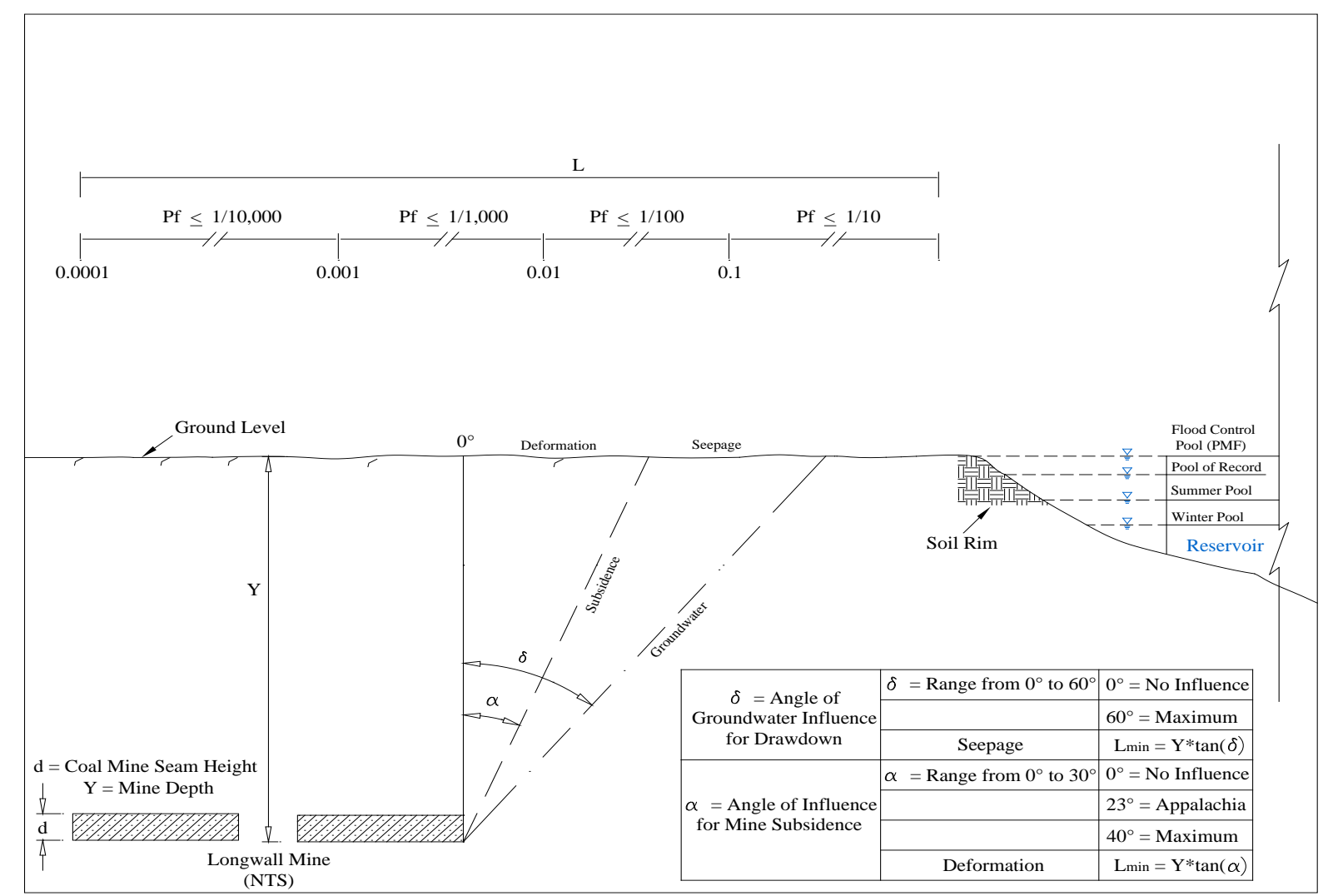

Figure 6.1: Probability of Failure at Reservoir Rim Based on Proximity to an Underground Mine

\subsection{Tygart Lake}

Tygart Lake is located in Appalachia approximately 2.25 miles south of Grafton, WV. It is impounded by a 1,921 ft long dam which rises $207 \mathrm{ft}$ above the river bed. The reservoir is approximately 3,430 acres in size and is used for flood control. On the eastern side of the 
reservoir a 6,000 acre coal mine currently being installed using longwall and the room and pillar methods The longwall method will be full coal seam extraction while the room and pillar mining method will result in partial extraction of coal reserves leaving pillars to support the mine roof and prevent mine subsidence at the perimeter gate pillars. The closest approach to the reservoir is shown in Figure 6.2. Line 1 shows the direct distance to the original streambed. At summer pool level (line 2), the mine is laterally 1,670 ft away from the barrier pillars at the edge of the longwall face. At full pool level (Line 3) the offset distance is 467 feet laterally from the pool to the mine edge. However, at probable maximum flood conditions, the reservoir may potentially overtop the barrier pillars, well within the expected Angle of Subsidence Draw. For the modeling approach the summer, full and PMF pool conditions were considered.
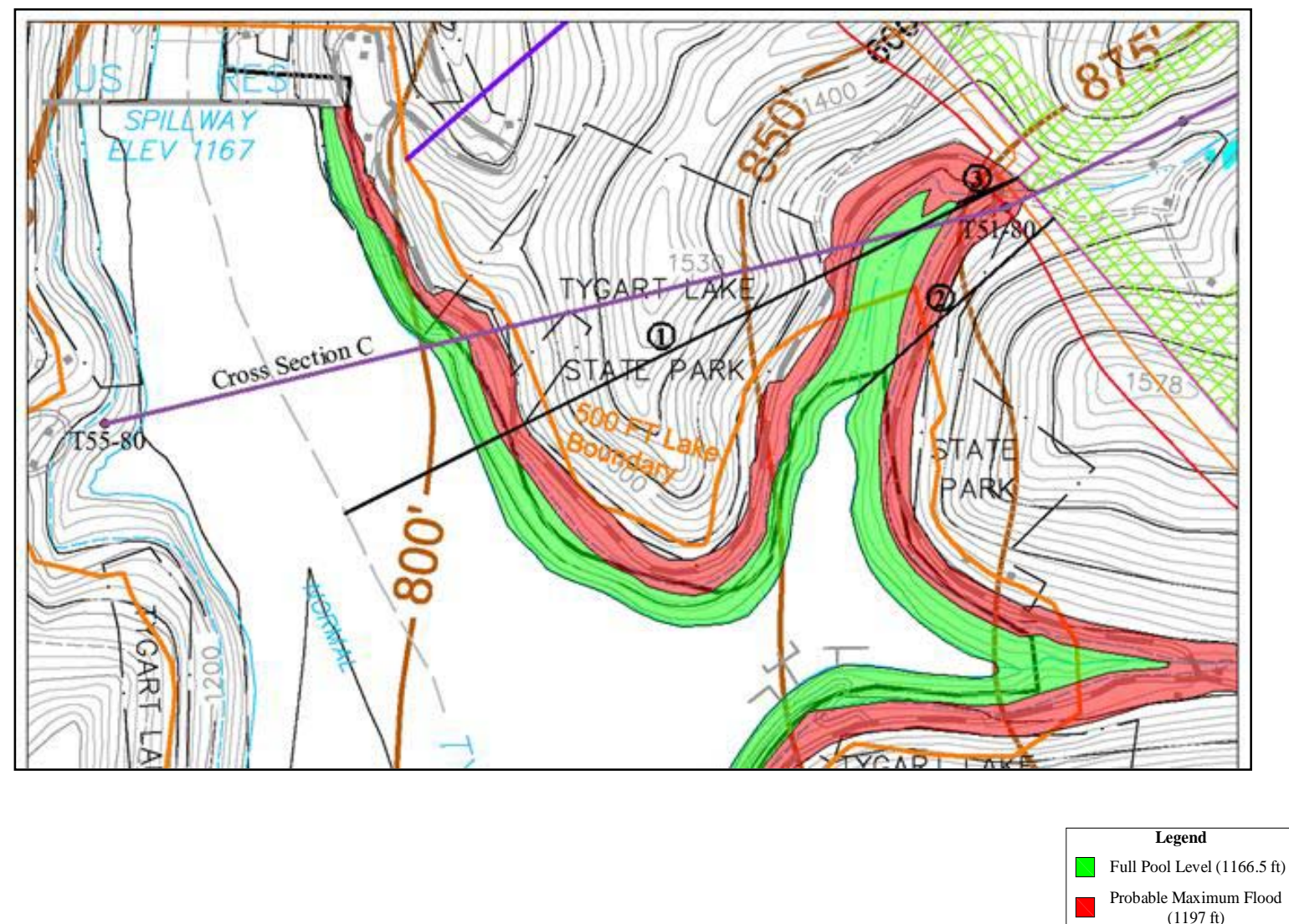

Figure 6.2: Pool Level inundation areas at Tygart Lake (After WVDEP, 2009) 


\subsection{Methods of Evaluation}

There are two major methods used by computer software for soil, rock and groundwater modeling analysis: the finite element method and the finite difference method. Both methods have benefits and drawbacks depending on the type of modeling performed. However, for detailed 2D analysis of a geologic cross-section, the finite element appears to be preferential in that it can more closely reflect the subtle changes within the overburden

\subsubsection{Finite Element Method}

The finite element method (FEM) is a practice of taking an object or location, such as a geologic cross section, and breaking it into smaller parts called elements. These elements are interconnected at points called nodes. In real world situations, it is difficult to create equations and boundary conditions for an entire region. By breaking the region into smaller sections, each element can be analyzed through triangulation and the effects of that element become a boundary condition for the adjacent element. The more elements used, the more accurate the results.

This method is very useful in estimating stress, strain and displacement in areas that can't be effectively tested. It is also useful in modeling the potential effects of these changes in a hypothetical analysis.

\subsubsection{Finite Difference Method}

The finite difference method (FDM) uses a similar method to approximate values at nodes. For determining values a grid is created over a region, such as a cross section. However, unlike the finite element method, each section of the grid must be a polynomial The FDM solves the partial differential equation matrix by replacing them with finite difference equations which are algebraic in form. It then approximates the differences between grid points via the Taylor series expansion. The finite difference method is limited in several facets. The difference equations must be linear which reduces the accuracy for real world problems. It is also limited in that it may produce errors if grid points are subjected to different boundary conditions or have anisotropic conditions. 


\subsubsection{Comparison of Methods}

Using the finite element method is the preferred method to determining deformation in overburden compared to the finite difference method. In finite difference, the grid is created in quadrilateral blocks. In finite element there are not these limitations as the mesh is triangulated through a matrix. The finite element method relates stresses, forces and strains creating equations and relating them in a matrix form. The finite difference method uses changes between grid points by simple formula of slope of a straight line by replacing the derivatives using first order expansion of the Taylors series of the function. While this is an effective method for handling simplistic models, it does not effectively detail the interaction of various differences within the model. The finite element can perform these interactions by preserving fluxes within the mesh. This is essential for both determining the stress-strain relationship in solid material and in changes in groundwater flow.

When analyzing soil and rock profiles, the lithology is not homogeneous. There are variations in rock quality and permeability. As deformation occurs, each point on the matrix will react differently based on the changes that occur around it. In finite difference, such as FLAC, similar material will react more like a solid rigid body between grid points. In finite element each node is triangulated, acting independently.

At Tygart Lake, the finite element method was used in similar fashion. The model was designed based on known static conditions in the field. The geologic conditions were built within a program creating the boundaries of the bedding layers that would be used to create a matrix of nodes within layers. A load (such as flood conditions) would be added or a void (such as a mine) would be implemented and the changes analyzed for each node. This is the most important aspect due to one section of a layer may react differently given its surroundings than the section adjacent to it. An example of the profile forms is shown in Figure 6.3. 


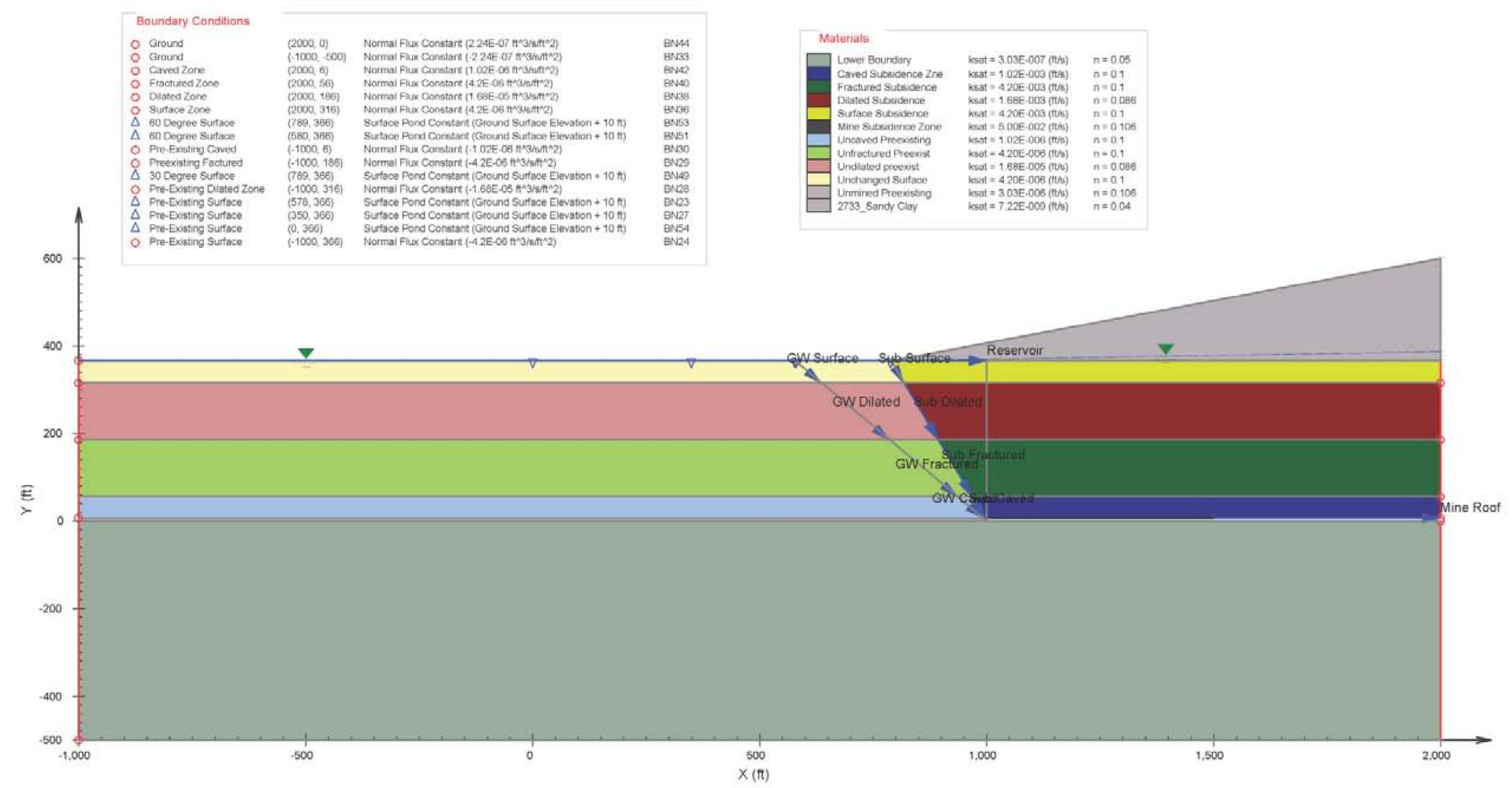

Figure 6.3: Basic model of cross-section a Tygart Lake 
For flux in groundwater flow due to subsurface changes there is a similar approach. The groundwater could flow following the path of least resistance. With the matrix capabilities of finite element, the fluxes in groundwater flow could be shown as flowing in, through and around the most permeable layers, giving an accurate representation of field conditions. An example of this is shown if Figure 6.4.

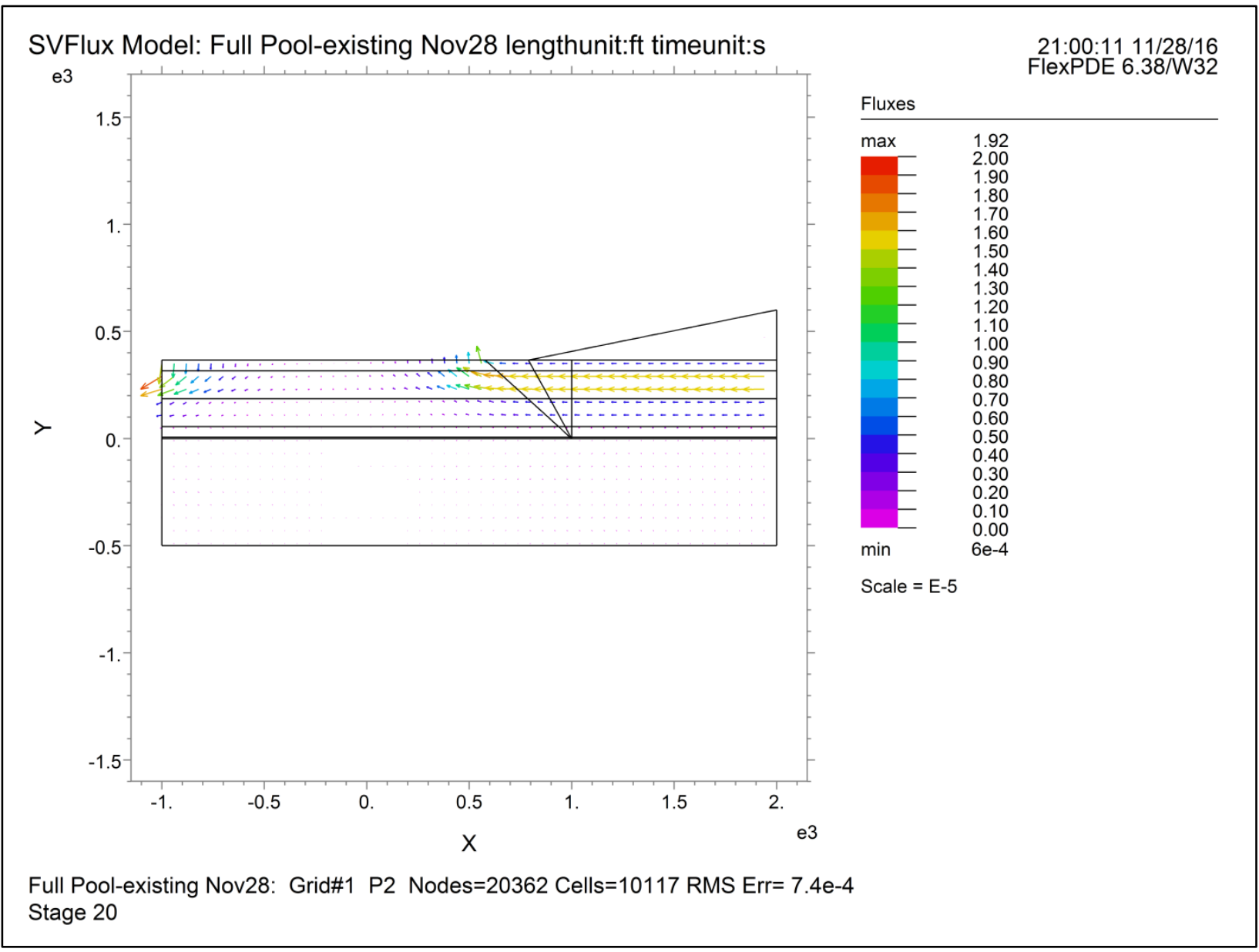

Figure 6.4: Flux model at Tygart Lake

\subsection{SoilVision ${ }^{\circledR}$}

Soil Vision uses a finite element method for its functions to determine component displacements, strains, and stresses under internal and external loads. Known geological and hydrological conditions are entered under static conditions. Once a load is applied, each node in the matrix is formulated to represent the changed conditions. The nodes are then evaluated based on the changes applied to the nodes around it. This is an estimation process that can be used to not only 
determine deformation and strains within a solid mass, but also the potential changes that occur in fluid transfer. Soil Vision has two software programs that can be coupled together based on stress and deformation.

SVFlux is a Soil Vision software designed to model seepage and groundwater in soils by calculating saturated and unsaturated groundwater flow (Thode, 2013). It is used in the estimation of:

- unsaturated hydraulic soil properties for seepage finite element modeling

- field capacity and capillary rise based on grainsize information

- $\quad$ soil-water characteristic curves

- $\quad$ saturated or unsaturated hydraulic conductivity curves

Soil Vision Flux, using the finite element method, can provide an estimate on the groundwater flow path given current field conditions. Soil Vision allows for the input of borehole samples and hydraulic conductivities for each rock type and depth into its database. If accurate field conditions are known, the potential flow path of groundwater can be modeled. While it can’t anticipate the location of specific fractures, it can detail which layers are the most transmissive locations and show the flux in flow rates along the Subsidence Angle of Draw. This in turn can provide the locations of the highly transmissive zones and the boundaries within which they lie. For Tygart Lake, the finite element modeling software would show the areas most potentially affected should a pathway from the reservoir to these locations be created.

\subsection{Modeling}

\subsubsection{Modeling Approach}

The modeling method consists of the geological cross section containing the five (5) basic rock subsidence layers based on Kendorski. The thickness of each layer was based on the maximum extents of these zones. For example, the thickness of the fractured zone maybe between 6 times the thickness of the coal seam and 24 times the thickness. For this model, 24 times the coal seam thickness was used to determine the Fractured Zone Layer thickness. The bedding planes were assumed to be horizontal homogeneous layers, using known field values. The approach was to establish steady state conditions prior to mining. A mine void was then introduced to quantify the 
extent of changes groundwater flow under summer pool, full pool and PMF conditions. This modeling method was performed to show the expected range of groundwater flow changes at a known field site based on set loading conditions (pool level). The data was then analyzed for extent (vertically and laterally) and flow rate change.

\subsubsection{Modeling Variables}

The modeling variables are the adjustments that were made from existing to post-mining conditions to determine the potential extent of seepage changes due to underground mining.

1.) Vary the lateral offset distance from mine to reservoir

2.) Identify the five (5) subsidence zone extents detailed by Kendorski

- Minimum to maximum ranges for each identified zone

3.) Hydraulic Conductivity Zones:

- Introduce increased hydraulic conductivity at bedding layers

- Pre and post mining velocity changes by order of magnitude

4.) Vary the reservoir pool elevations for summer, full pool and PMF under steady state and transient conditions

At the proposed site, models were created formulating changes in permeability in field conditions due to subsurface mining. The initial parameters were designed to imitate actual current rock and soil conditions found at the mine site. This was performed by importing borehole and laboratory data provided through studies in the region. Where direct information is not available, estimates based on similar conditions were used.

Two Borehole samples were used to aide in the development of the bedding layers for this location to provide information on the homogeneous hydraulic conductivity of bedrock layers. The closest borehole sample at the location of interest was T51-80 (See Figure 6.1). The lithology is shown in Figure 5.4. However, there were only two locations at the mine site that were tested for hydraulic conductivities: H13-05 and H16-05 (shown in Tables XX and XX or Section XX. 
Table 6.1: Hydraulic conductivity for Borehole H13-05

\begin{tabular}{|c|c|c|c|c|}
\hline \multicolumn{5}{|c|}{ Borehole H13-05 } \\
\hline Strata Layer & $\begin{array}{c}\text { Hydraulic Conductivity } \\
(\mathrm{ft} / \mathrm{s})\end{array}$ & $\begin{array}{c}\text { Hydraulic Conductivity } \\
(\mathrm{cm} / \mathrm{s})\end{array}$ & Top Depth (ft) & Bottom Depth (ft) \\
\hline Lower Kittanning Coal & $4.20 \mathrm{E}-06$ & $1.28 \mathrm{E}-04$ & 640 & 647 \\
\hline Upper Freeport Coal & $2.97 \mathrm{E}-07$ & $9.05 \mathrm{E}-06$ & 459 & 466 \\
\hline Harlem Coal & $3.04 \mathrm{E}-08$ & $9.27 \mathrm{E}-07$ & 172 & 179 \\
\hline Grafton Sandstone & $2.53 \mathrm{E}-06$ & $7.71 \mathrm{E}-05$ & 130 & 137 \\
\hline Mahoning Sandstone & $5.35 \mathrm{E}-08$ & $1.63 \mathrm{E}-06$ & 435 & 450 \\
\hline Mahoning Sandstone & $3.93 \mathrm{E}-08$ & $1.20 \mathrm{E}-06$ & 420 & 435 \\
\hline Mahoning Sandstone & $1.96 \mathrm{E}-08$ & $5.97 \mathrm{E}-07$ & 405 & 420 \\
\hline Shale & $1.64 \mathrm{E}-08$ & $5.00 \mathrm{E}-07$ & 390 & 405 \\
\hline Buffalo Sandstone/Brush & $4.72 \mathrm{E}-06$ & $1.44 \mathrm{E}-04$ & 375 & 390 \\
\hline Creek Coal & 0 & 0 & 360 & 375 \\
\hline Buffalo Sandstone & 0 & 0 & 345 & 360 \\
\hline Buffalo Sandstone & 0 & 0 & 330 & 345 \\
\hline Buffalo Sandstone & $6.65 \mathrm{E}-08$ & $2.03 \mathrm{E}-06$ & 315 & 330 \\
\hline Buffalo Sandstone & 0 & 0 & 230 & 245 \\
\hline Pittsburg Redbeds & 0 & 0 & 215 & 230 \\
\hline Pittsburg Redbeds & 0 & 0 & 200 & 215 \\
\hline Pittsburg Redbeds & 0 & 0 & 185 & 200 \\
\hline Pittsburg Redbeds & $1.13 \mathrm{E}-06$ & $3.44 \mathrm{E}-05$ & 65 & 80 \\
\hline Clarksburg Redbeds & 0 & 0 & 50 & 65 \\
\hline Clarksburg Redbeds & & & & \\
\hline
\end{tabular}

Table 6.2: Hydraulic conductivity for Borehole H16-05

\begin{tabular}{|c|c|c|c|c|}
\hline \multicolumn{5}{|c|}{ Borehole H16-05 } \\
\hline Strata Layer & $\begin{array}{c}\text { Hydraulic Conductivity } \\
(\mathrm{ft} / \mathrm{s})\end{array}$ & $\begin{array}{c}\text { Hydraulic Conductivity } \\
(\mathrm{cm} / \mathrm{s})\end{array}$ & Top Depth (ft) & Bottom Depth (ft) \\
\hline Lower Kittanning Coal & $3.03 \mathrm{E}-06$ & $9.23 \mathrm{E}-05$ & 259 & 266 \\
\hline Upper Freeport Coal & $1.76 \mathrm{E}-06$ & $5.36 \mathrm{E}-05$ & 85 & 92 \\
\hline Split of Kittanning Coal & $1.34 \mathrm{E}-06$ & $4.09 \mathrm{E}-05$ & 236 & 241 \\
\hline Coal/Shale Zone & $1.02 \mathrm{E}-06$ & $3.12 \mathrm{E}-05$ & 213 & 218 \\
\hline Shale & $1.66 \mathrm{E}-08$ & $5.05 \mathrm{E}-07$ & 242 & 257 \\
\hline Shale & $2.81 \mathrm{E}-08$ & $8.56 \mathrm{E}-07$ & 219 & 234 \\
\hline Sandstone & $6.39 \mathrm{E}-08$ & $1.95 \mathrm{E}-06$ & 198 & 213 \\
\hline Sandstone/Shale & $4.20 \mathrm{E}-06$ & $1.28 \mathrm{E}-04$ & 183 & 198 \\
\hline Sandy/Shale & 0 & 0 & 168 & 183 \\
\hline Shale & 0 & 0 & 153 & 168 \\
\hline Shale & $3.90 \mathrm{E}-07$ & $1.19 \mathrm{E}-05$ & 138 & 153 \\
\hline Sandstone & $3.28 \mathrm{E}-07$ & $9.99 \mathrm{E}-06$ & 123 & 138 \\
\hline Shale & $1.68 \mathrm{E}-05$ & $5.11 \mathrm{E}-04$ & 108 & 123 \\
\hline Shale & $3.03 \mathrm{E}-05$ & $9.24 \mathrm{E}-04$ & 93 & 108 \\
\hline Mahoning Sandstone & & & & 85 \\
\hline Mahoning Sandstone & $3.08 \mathrm{E}-07$ & $9.37 \mathrm{E}-06$ & 70 & 70 \\
\hline Mahoning Sandstone & $2.92 \mathrm{E}-07$ & $0.89 \mathrm{E}-06$ & 43 & 58 \\
\hline
\end{tabular}


The strata layer type and depth were cross referenced with borehole T51-80 to provide the best fit for hydraulic conductivity at the location of interest. The chosen results are highlighted in Table 6.2. For each of the five zones based on Kendorski (1993), the rock type that was present the most was evaluated to make each of the zones homogeneous. These are the initial conditions for groundwater flow.

Based on the rock type and known existing hydraulic conductivities, the estimated increase in hydraulic conductivity for the zones of Angle of Subsidence Draw Draw and Angle of Groundwater Influence were developed. The maximum potential increase for sandstone is between 1 to 2 orders of magnitude and for Shale, up to three orders of magnitude. These are shown in Table 6.3.

However, in the actual field, the highest increases in hydraulic conductivity would occur above the mine edges, where the highest impact from tensile strain would occur. The fractured and caved zones would experience larger increases than the dilated zone as vertical and horizontal cracking would occur, creating more voids for groundwater flow. The dilated zone would be expected to have less vertical fracturing but horizontal strain would increase flow potential laterally. The surface zone generally contains existing fractured and weathered rock and soil. Disturbance in this area due to subsidence would open voids for vertical and horizontal hydraulic conductivity with increases much like that of the fractured zone. These increases would dissipate outward along the subsidence zone. Table 6.3 shows the maximum potential increase within the Subsidence Zone. There is no vertical deformation or increase in horizontal strain within the Angle of Groundwater Influence; however, there will be temporary to permanent changes in the groundwater flow path due to the cone of depression, even though no actual increase in permeability occurs. 
Table 6.3: Approximate hydraulic conductivities at Tygart Lake

\begin{tabular}{|c|c|c|c|c|c|c|}
\hline \multicolumn{7}{|c|}{ Approximate Hydraulic Conductivities near Borehole T51-80 } \\
\hline \multirow[b]{2}{*}{ Subsidence Zones } & \multirow[b]{2}{*}{ Strata Layer(s) } & \multicolumn{2}{|c|}{ Depth (ft) } & \multirow[b]{2}{*}{$\begin{array}{l}\text { Hydraulic Conductivity } \\
\text { (cm/s) }\end{array}$} & \multicolumn{2}{|c|}{ Subsidence Angle of Draw } \\
\hline & & Top Depth & Bottom Depth & & $\begin{array}{c}\text { Minimum Increase in } \\
\text { Magnitude of Hydraulic } \\
\text { Conductivity }\end{array}$ & $\begin{array}{l}\text { Maximum Increase in } \\
\text { Magnitude of Hydraulic } \\
\text { Conductivity }\end{array}$ \\
\hline Surface Fracture Zone & Sandstone/Shale & 0.00 & 50.00 & $1.28 \mathrm{E}-04$ & 1 & 3 \\
\hline \multirow{2}{*}{ Dilated Zone } & Shale & 50.00 & 118.00 & $5.11 \mathrm{E}-04$ & 1 & 3 \\
\hline & Shale & & & 9.24E-04 & 1 & 3 \\
\hline Maximum Fractured Zone & Mahoning Sandstone & 118.00 & 162.00 & 9.37E-06 & 1 & 2 \\
\hline \multirow{2}{*}{ Minimum Fractured Zone } & Sandstone & 162.00 & 247.17 & 1.95E-06 & 1 & 2 \\
\hline & Sandstone/Shale & & & $1.28 \mathrm{E}-04$ & 2 & 3 \\
\hline \multirow{2}{*}{ Maximum Caved Zone } & Coal/Shale & 247.17 & 269.79 & 3.12E-05 & 2 & 3 \\
\hline & Shale & & & 5.05E-07 & 2 & 3 \\
\hline Minumum Caved Zone & Shale & 269.79 & 306.13 & 5.05E-07 & 2 & 3 \\
\hline Mine Seam & Lower Kittanning Coal & 306.13 & 310.54 & 9.23E-05 & 2 & 3 \\
\hline
\end{tabular}


Additional properties of the rock types required for the computer modeling analysis were not available in the 2009 WVDEP reports. The property values that were input into SoilVision ${ }^{\circledR}$ are shown in Table 6.4. The properties shown with an asterisk are determined by the computer program based on other input data. For example, the porosity is the same value as the saturated volumetric water content. The properties input to estimate the rock layers of the overburden were saturated volumetric water content (porosity), specific gravity and hydraulic conductivity. Hydraulic conductivity was based on existing field data . A hydraulic conductivity ratio of 1:1 $(\mathrm{H}: \mathrm{V})$ was assumed. The additional properties were estimated from literature. Of the rock types, the Upper Mahoning and Lower Mahoning sandstone layers were detailed in Relationship between Unconfined Compressive Strength and Degree of Saturation for Selected Sandstones (Shakoor and Barefield, 2009). As the Mahoning are sandstone layers found near Tygart Lake, these particular values were used. However, additional values are provided for verification. The saturated volumetric water content (porosity) for shale and coal were averaged for initial conditions.

The computer model was designed around depth and offset distances determined through WVDEP reports. The cross-section was then separated into the 5 zones (based on Kendorski) each for subsidence, groundwater draw and pre-existing conditions. Borehole T51-80 showed over 60 different bedding layers at the point of interest ranging from several inches to 31 feet in thickness. However, as with the hydraulic conductivity, the layer properties were consolidated into each of these zones so that each could be considered homogeneous. The same method was used for the lateral length of the model so it would act as one continuous layer during pre-mining conditions. 
Table 6.4: SoilVision ${ }^{\circledR}$ input parameters

\begin{tabular}{|c|c|c|c|c|c|c|c|}
\hline \multicolumn{7}{|c|}{ Soil Vision } & \\
\hline Saturated & & Coal & Limestone & Shale & \begin{tabular}{|l|} 
Sandstone \\
\end{tabular} & Mudstone & \\
\hline \multicolumn{7}{|l|}{ Volumetric Water Content } & \\
\hline Saturated Volumetric Water Content & & \multicolumn{5}{|c|}{ Same as Porosity for Saturated Conditions } & \\
\hline Coefficient of Compressibility (mv) & $1 / \mathrm{psf}$ & & & & & & \\
\hline & & & & & & & \\
\hline \multicolumn{7}{|l|}{ Hydraulic Conductivity } & \\
\hline Saturated Hydraulic Conductivity (ksat) & $\mathrm{ft} / \mathrm{s}$ & \multicolumn{5}{|c|}{ See PFMA } & \\
\hline Ky-ratio & & & & & $1.04 \mathrm{v} / \mathrm{h}$ & & \\
\hline \multirow[t]{4}{*}{$\alpha$} & degree & & & & $0.64-0.85$ & & \\
\hline & degree & $0.925,0.80$ & & & & & \\
\hline & degree & & & & $0.64-0.85$ & & \\
\hline & degree & & & 0.76 & & & \\
\hline \multicolumn{7}{|l|}{ Volume-Mass Parameters } & \\
\hline *Void Ratio (e) & & \multicolumn{5}{|c|}{ Varies } & \\
\hline \multirow[t]{4}{*}{ *Porosity (n) (Decimal) } & & & 0.01 to .30 & .05 to .15 & .05 to .15 & .5 to .15 & Jaeger, et al. , 2007 \\
\hline & & $.098-.113$ & & $.161-.242$ & & & Mastalerz, et al. , 2012 \\
\hline & & & & & $\begin{array}{c}.0931 \\
\text { Lower } \\
\text { Freeport } \\
\end{array}$ & & Shakoor and Barefield, 2009 \\
\hline & & & & & \begin{tabular}{|c|}
.08 \\
Lower \\
Mahoning \\
\end{tabular} & & \multirow[t]{3}{*}{ Shakoor and Barefield, 2009} \\
\hline *Degree of Saturation & & & Fixed at $1 \mathrm{fo}$ & or Saturated & Conditions & & \\
\hline *Degree of Saturation of Air & & & Fixed at $0 \mathrm{fo}$ & or Saturated & Conditions & & \\
\hline \multirow[t]{2}{*}{ Specific Gravity (Gs) } & & & & & $\begin{array}{c}2.17 \\
\text { Lower } \\
\end{array}$ & & \multirow[t]{2}{*}{ Shakoor and Barefield, 2009} \\
\hline & & & & & \begin{tabular}{|c|}
2.22 \\
Lower \\
Mahoning \\
\end{tabular} & & \\
\hline \multirow[t]{3}{*}{ *Dry Density (pd) } & $\mathrm{lb} / \mathrm{ft}^{3}$ & & & & $\begin{array}{l}134.3 \\
\text { Lower } \\
\end{array}$ & & \multirow[b]{2}{*}{ Shakoor and Barefield, 2009} \\
\hline & $\mathrm{lb} / \mathrm{ft}^{3}$ & & & & \begin{tabular}{|c|}
137.9 \\
Lower \\
Mahoning \\
\end{tabular} & & \\
\hline & $\mathrm{lb} / \mathrm{ft}^{3}$ & & & & & & \\
\hline *Total Density (pt) & $\mathrm{g} / \mathrm{cm}^{3}$ & $1.34-1.8$ & $1.93-2.90$ & $1.77-3.20$ & $1.61-2.76$ & & \\
\hline *Unit Weight (uwt) & $\mathrm{lb} / \mathrm{ft}^{3}$ & & & & & & \\
\hline *Gravimetric Water Content (gwc) & & \multicolumn{5}{|c|}{ Varies } & \\
\hline
\end{tabular}

The potentiometric surface was estimated based on private water well levels provided in the WVDEP investigation reports. The estimated hydraulic gradient above the area of interest is $0.022 \mathrm{ft} / \mathrm{ft}$. An arbitrary head constant of 10 feet was applied to simulate the reservoir pool level required lateral distances. 


\subsubsection{Boundary Conditions}

Boundary conditions for inflow and outflow of the model were designed for normal flux. This allowed for the flow to be unbounded in the lateral or vertical direction. The upslope was given properties similar to the aquitarding Pittsburgh Redbeds. This material has very low permeability and acts as a confining flow boundary.

\subsection{Calibration}

Once the initial conditions were implemented, the model was calibrated to match groundwater flow and phreatic surface levels. Ideally this is performed in SoilVision ${ }^{\circledR}$ using piezometer data. When input, the software can manipulate the rock and soil properties to reflect actual measured conditions (Figure 6.5). However, for Tygart Lake, piezometer data was not available for analysis.

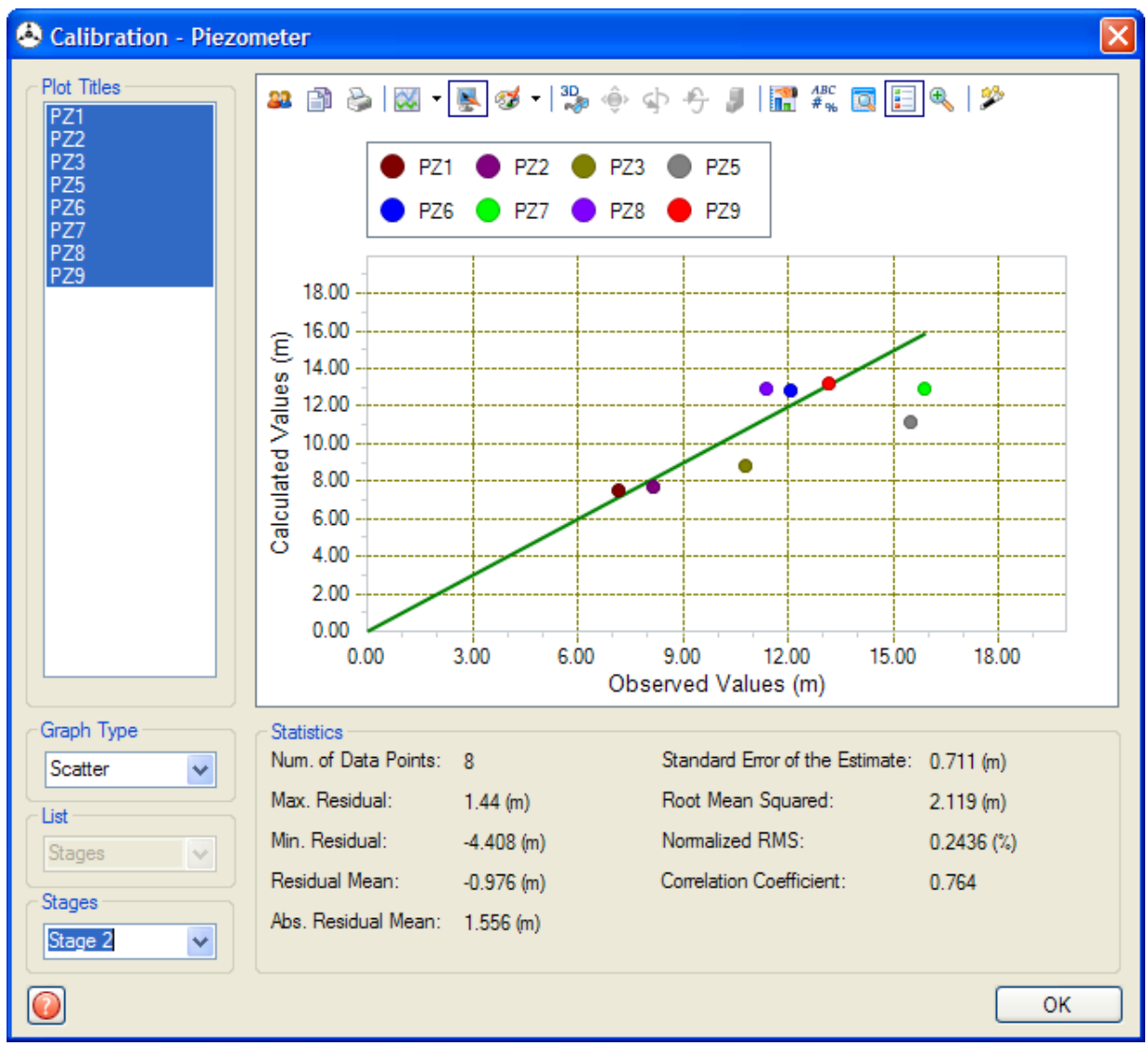

Figure 6.5: SoilVision ${ }^{\circledR}$ calibration method 
To calibrate the model, the existing flow path was followed as shown in Figure 6.6. This Figure is not to scale for visual purposes. Due to this, the angle of dip for the bedding layers appear to be greater than the actual $2 \%$ dip angle found in the location of interest. The groundwater recharges where the Pittsburgh redbeds are non-continuous. The model setup is shown in Figure 6.7. For this model, the $2 \%$ angle of dip was considered to have minimal impact on the material features of each horizontal layer, which has consistent initial properties laterally.

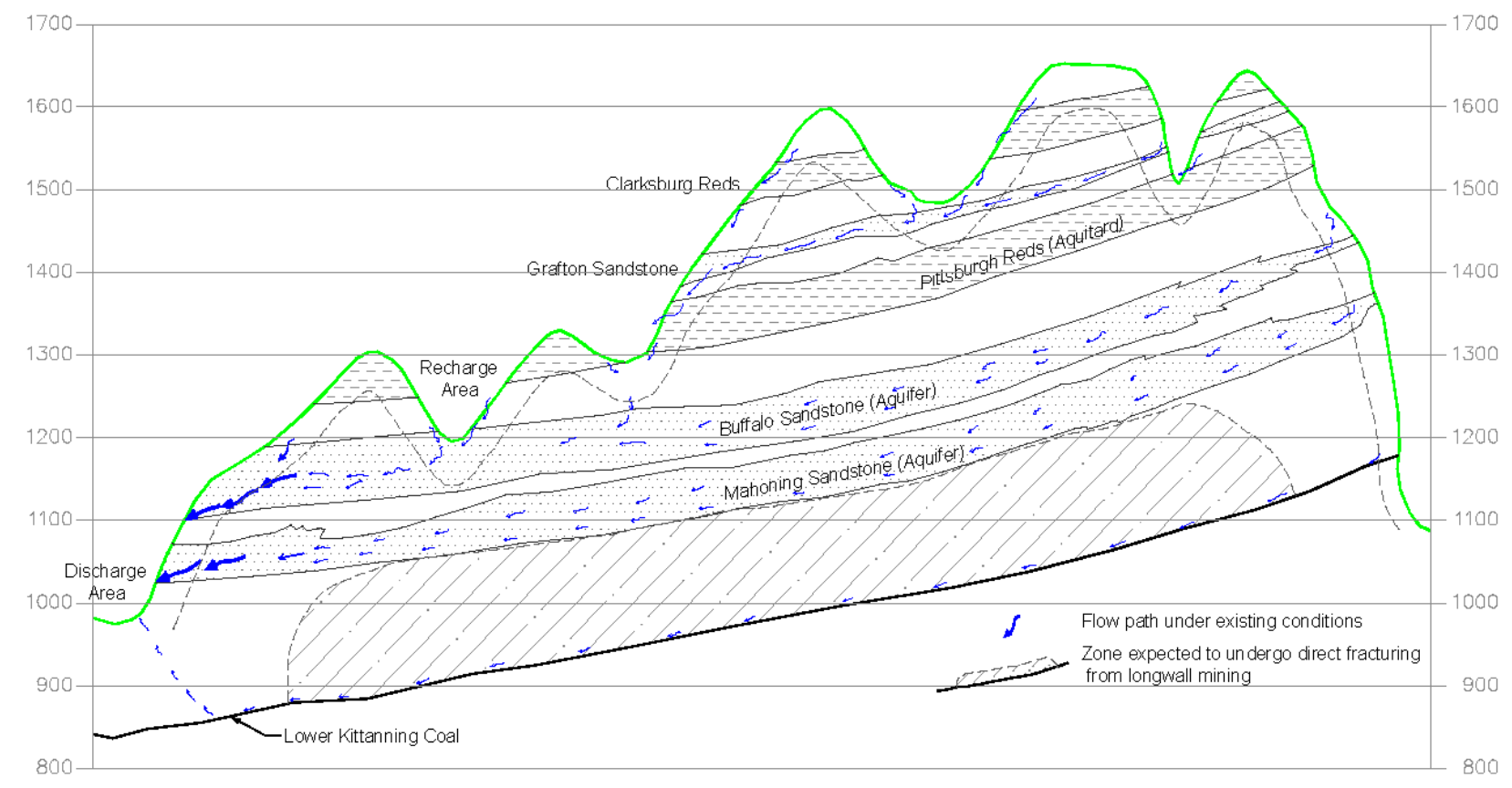

Figure 6.6: Groundwater flowpath adjacent to Tygart Lake (WVDEP, 2009) 


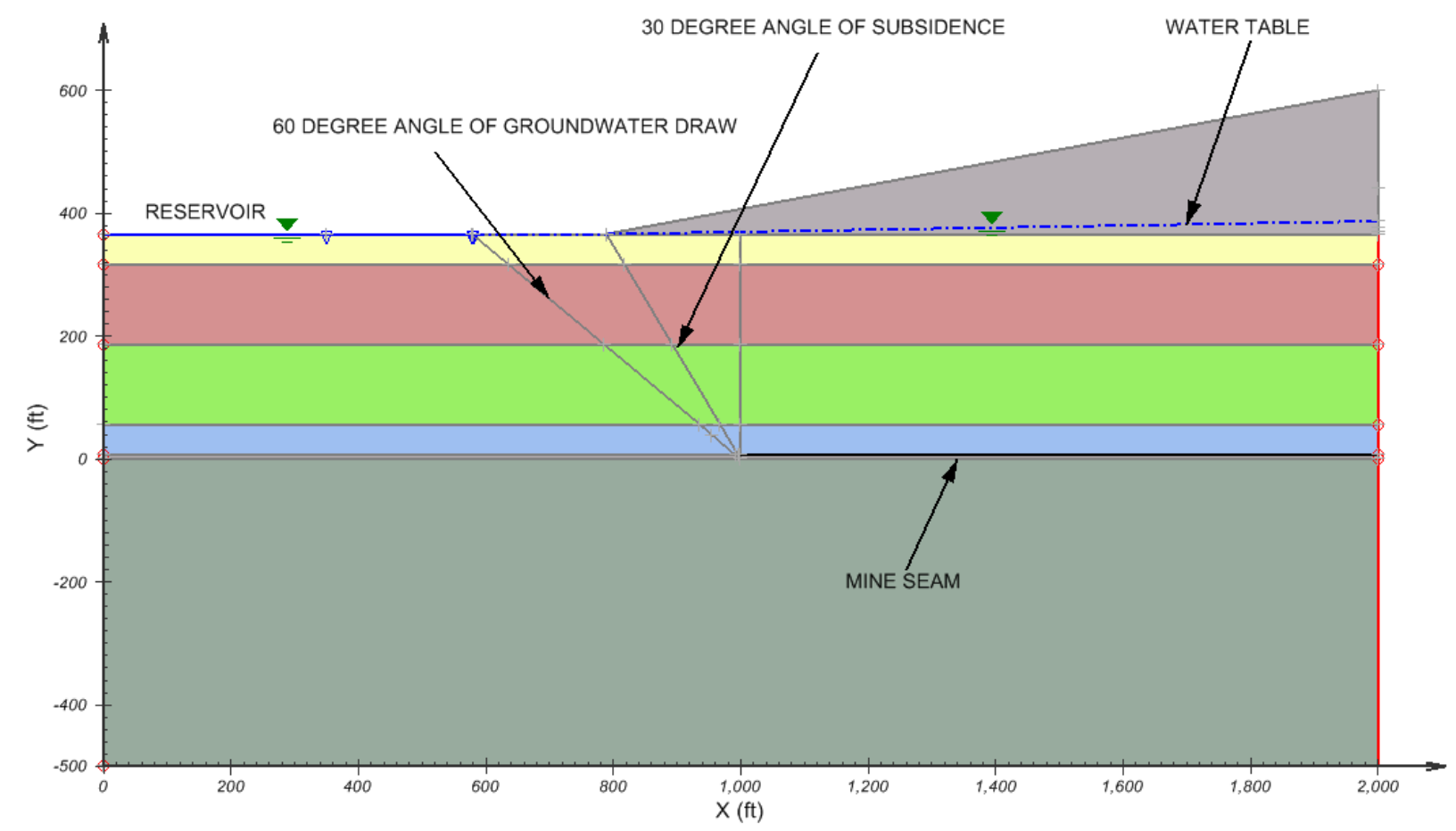

Figure 6.7: Basic model setup for Tygart Lake Cross-section

The boundary conditions for the model are shown in Table 6.5. There are seven total zones; five based on Kendorski (1993), a ground or base layer and a triangular layer representing the upslope from the reservoir. The Normal Flux constants represent the inflow (recharge) and outflow(discharge) from the model perimeter. The surface pond constant represents the reservoir and is divided into three sections at full pool level. Each surface pond section is given a head level. In this instance, the head is $10 \mathrm{ft}$.

Table 6.5: Boundary conditions

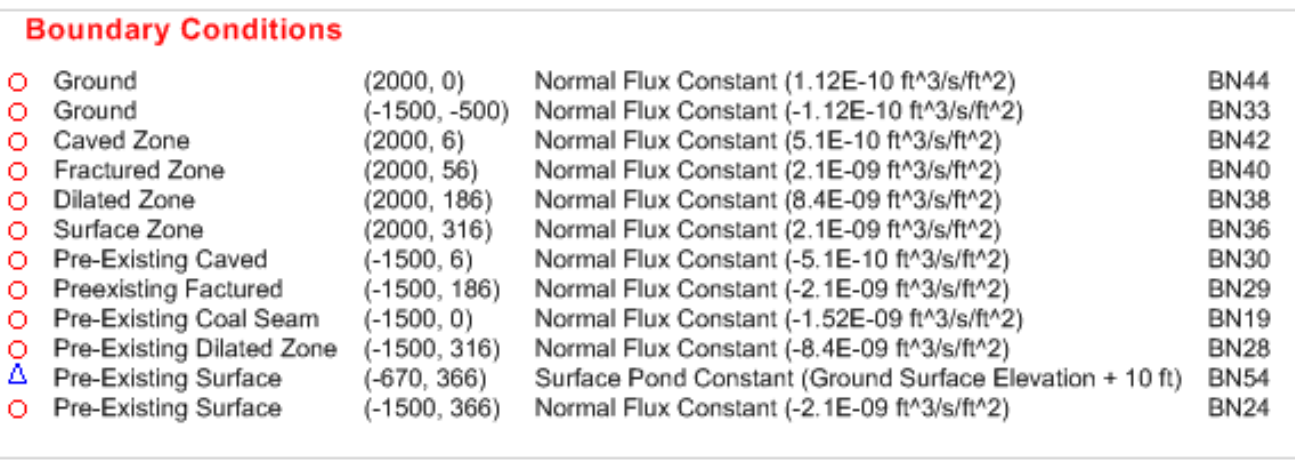


The materials used for the calibration model are shown in Table 6.6. This legend shows all of the materials currently assigned to the model with the associated hydraulic conductivity (as discussed in Section 6.5.2) and porosity. The porosity is shown as a decimal. For example, the lower boundary porosity is 0.05 or $5 \%$.

Table 6.6: Materials

\begin{tabular}{|c|c|c|}
\hline \multicolumn{3}{|l|}{ Materials } \\
\hline Lower Boundary & ksat $=3.03 \mathrm{E}-007(\mathrm{ft} / \mathrm{s})$ & $n=0.05$ \\
\hline Caved Subsidence Zne & $\mathrm{ksat}=1.02 \mathrm{E}-003(\mathrm{ft} / \mathrm{s})$ & $n=0.1$ \\
\hline Fractured Subsidence & ksat $=4.20 \mathrm{E}-003(\mathrm{ft} / \mathrm{s})$ & $n=0.1$ \\
\hline Dilated Subsidence & $\mathrm{ksat}=1.68 \mathrm{E}-003(\mathrm{ft} / \mathrm{s})$ & $n=0.086$ \\
\hline Surface Subsidence & $\mathrm{ksat}=4.20 \mathrm{E}-003(\mathrm{ft} / \mathrm{s})$ & $\mathrm{n}=0.1$ \\
\hline Mine Subsidence Zone & $\mathrm{ksat}=5.00 \mathrm{E}-002(\mathrm{ft} / \mathrm{s})$ & $\mathrm{n}=0.106$ \\
\hline Uncaved Preexisting & $k s a t=1.02 E-006(\mathrm{ft} / \mathrm{s})$ & $n=0.1$ \\
\hline Unfractured Preexist & ksat $=4.20 \mathrm{E}-006(\mathrm{ft} / \mathrm{s})$ & $n=0.1$ \\
\hline Undilated preexist & $\mathrm{ksat}=1.68 \mathrm{E}-005(\mathrm{ft} / \mathrm{s})$ & $n=0.086$ \\
\hline Unchanged Surface & $\mathrm{ksat}=4.20 \mathrm{E}-006(\mathrm{ft} / \mathrm{s})$ & $\mathrm{n}=0.1$ \\
\hline Unmined Preexisting & ksat $=3.03 \mathrm{E}-006(\mathrm{ft} / \mathrm{s})$ & $n=0.106$ \\
\hline 2733_Sandy Clay & $\mathrm{ksat}=7.22 \mathrm{E}-009(\mathrm{ft} / \mathrm{s})$ & $n=0.04$ \\
\hline
\end{tabular}

To calibrate, the inflow and outflow of the model was equalized to reach steady state conditions. This was compared to the initial hydraulic conductivities to verify that each flow path was consistent (Figure 6.8). The arrows show the flow path of the groundwater. The longer the arrows, the higher rate of flow is shown. From the image, the dilated zone, made of the Buffalo and Mahoning sandstone layers, is the aquifer controlling the groundwater flow. As the groundwater flow reached the reservoir. The equipotential lines intersect with the reservoir, as the reservoir pool elevation is the phreatic surface. The length of the reservoir is extended so the discharge boundary suction does not affect drawdown within the model parameters. 


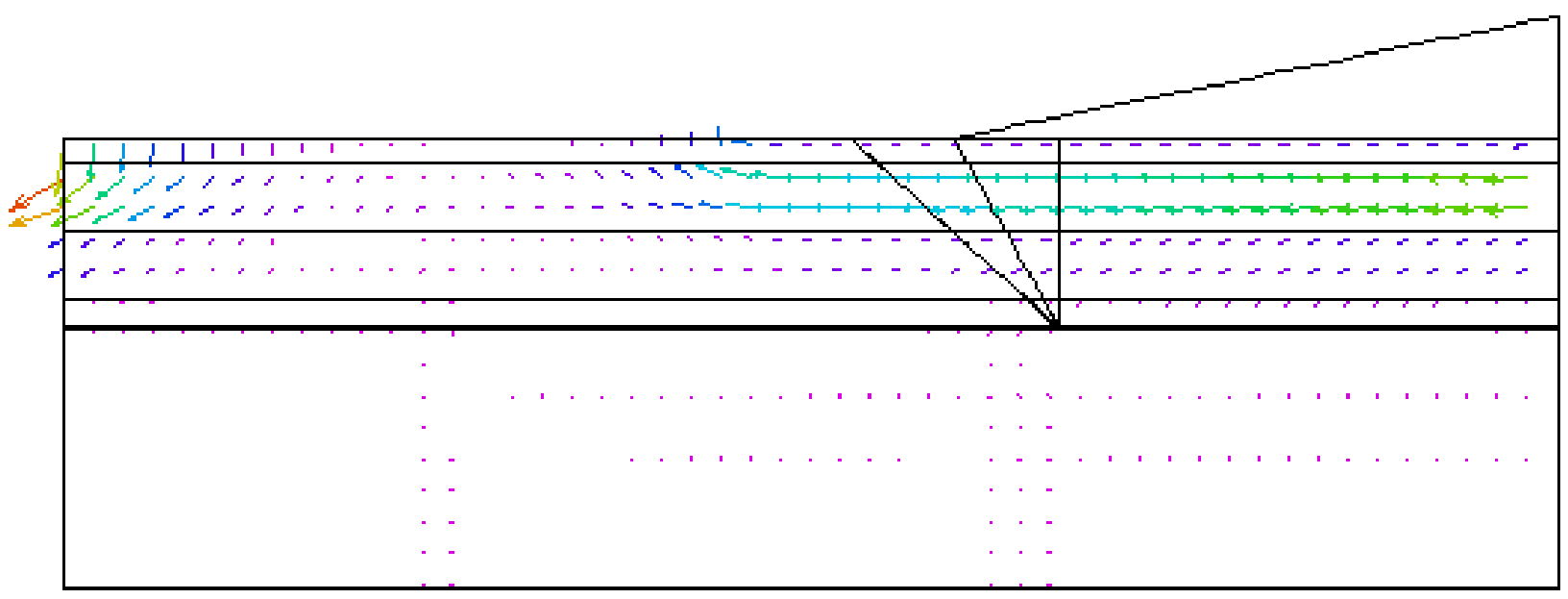

Figure 6.8: Existing groundwater flow path

\subsubsection{Introduction of Mine}

Hydraulic conductivity properties of the Subsidence and Groundwater zones were altered to reflect the changes due to mining. The hydraulic conductivity was increased in each zone based on material type and proximity to the mine subsidence. For instance, shale may increase upwards of three orders of magnitude within the subsided overburden. However, that magnitude is unlikely to extend into the Angle of Groundwater Influence. The extent of the effects in this region may only be one order of magnitude or may be negligible. For this model, a conservative approach (based on potential hazard to the reservoir) was of one order of magnitude was used for each layer.

In the subsidence zone directly above the mine, the caved and fractured zones were increased three orders of magnitude as these are dominated by shale and are the regions most directly affected by subsidence. In the dilated zone, represented by sandstone, the maximum potential increase of hydraulic conductivity is two orders of magnitude. However because this region will have localized fracturing and bedding plane separation but no complete fracturing, this region is likely to only have upper reaches of one order. The surface zone, being comprised mainly of weathered shale, would be expected to increase a maximum of two orders of magnitude for hydraulic conductivity. The existing, expected and worst case effects for each zone are shown in Table 6.7. 
Table 6.7: Hydraulic conductivities for model

\begin{tabular}{|l|l|c|c|c|}
\hline \multirow{2}{*}{\multicolumn{2}{|c|}{ Zone }} & \multicolumn{2}{c|}{ Hydraulic Conductivity (ft/s) } \\
\cline { 3 - 6 } & & Existing & Expected & Worst Case \\
\hline Within Mine Trough & Surface & $4.20 \mathrm{E}-06$ & $4.20 \mathrm{E}-04$ & $4.20 \mathrm{E}-03$ \\
\hline \multirow{4}{*}{ Angle of Subsidence } & Dilated & $1.68 \mathrm{E}-05$ & $1.68 \mathrm{E}-04$ & $1.68 \mathrm{E}-03$ \\
\cline { 2 - 5 } & Fractured & $4.20 \mathrm{E}-06$ & $4.20 \mathrm{E}-03$ & $4.20 \mathrm{E}-03$ \\
\cline { 2 - 5 } & Caved & $1.02 \mathrm{E}-06$ & $1.02 \mathrm{E}-03$ & $1.02 \mathrm{E}-03$ \\
\cline { 2 - 5 } & Coal & $3.03 \mathrm{E}-06$ & N/A & N/A \\
\hline & Surface & $4.20 \mathrm{E}-06$ & $4.20 \mathrm{E}-04$ & $4.20 \mathrm{E}-03$ \\
\cline { 2 - 5 } & Filated & $1.68 \mathrm{E}-05$ & $1.68 \mathrm{E}-04$ & $1.68 \mathrm{E}-03$ \\
\cline { 2 - 5 } & Cractured & $4.20 \mathrm{E}-06$ & $4.20 \mathrm{E}-04$ & $4.20 \mathrm{E}-03$ \\
\cline { 2 - 5 } & Coal & $1.02 \mathrm{E}-06$ & $1.02 \mathrm{E}-04$ & $1.02 \mathrm{E}-03$ \\
\cline { 2 - 5 } & $3.03 \mathrm{E}-06$ & $3.03 \mathrm{E}-04$ & $3.03 \mathrm{E}-03$ \\
\hline
\end{tabular}

For the mined coal seam, parameters needed to be created to replicate a mine void. Changing the hydraulic conductivity and porosity only would not adequately demonstrate a mine void as the bounding layers would counteract replication of free flow into the mine (flooding). Therefore the mine was mirrored to function as a drain. SoilVision ${ }^{\circledR}$ has a feature called Tunnel Line that acts like a mine shaft. It is "suited for the numerical modeling of pumping rates required in a mine shaft in order to keep the mine shaft de-watered if it happens to be below the groundwater table" (Fredlund, 2009). For the purpose of this model, a tunnel section was created along the roof of the coal seam to replicate the mine shaft. However, the pumping rate would be the same as the infiltration rate from the Caved zone above. Equalizing these rates reproduced the effect of flooding of the mine shaft (Figure 6.9).

\subsubsection{Recharge Calibration}

Calibration of the recharge rate into the model was based on the infiltration rate into the mine void after mining had occurred. The anticipated flow rate into the mine adjacent to Tygart Lake was 0.20 gallons per minute per acre (WVDEP, 2009) and shown in Table 5.15. This was correlated with the nearby Sentinel mine which showed infiltration rates of $0.31 \mathrm{gpm} / \mathrm{ac}$ and 0.22 gpm/ac during mining operations. For this model, the $0.20 \mathrm{gpm}$ was used as the expected rate of flow into the mine. The flow rate of $0.20 \mathrm{gpm} / \mathrm{ac}$ is equal to $1.02 \mathrm{E}-08 \mathrm{ft}^{3} / \mathrm{s}$ per foot.

To calibrate the recharge, the initial inflow was set at an arbitrary rate based on the initial hydraulic conductivities of each zone. The model was run under mined conditions and the flow 
rate from the Caved Zone into the mine was measured via a Flux line for summer pool level. The recharge was then uniformly adjusted until the influx into the mine approximately matched the desired infiltration rate of $1.02 \mathrm{E}-08 \mathrm{ft}^{3} / \mathrm{s}$ per square foot $\left(8.80 \mathrm{E}-04 \mathrm{ft}^{3} / \mathrm{d}\right.$ per square foot). The recharge values were correlated with the potential flow rate of the material layers using Darcy's Law. Give the initial hydraulic conductivities, gradient of the modeled location (dip 2\%) and the limited recharge due to overlying Pittsburgh redbeds, the flow rate values appear to be within acceptable parameters.

\subsubsection{Mine Drain}

Under these conditions, the recharge from the Caved Zone entered the mine void at the desired pumping rate. However, due to the bounded conditions without pumping, the flow was reintroduced into the groundwater system at the mine boundary. Under actual conditions, the infiltrated water would not be re-introduced until the mine shaft flooded. A tunnel line with a drain rate of $1.02 \mathrm{E}-08 \mathrm{ft}^{3} / \mathrm{s}$ per foot was added to the model, simulating the flow discharging into the mine.

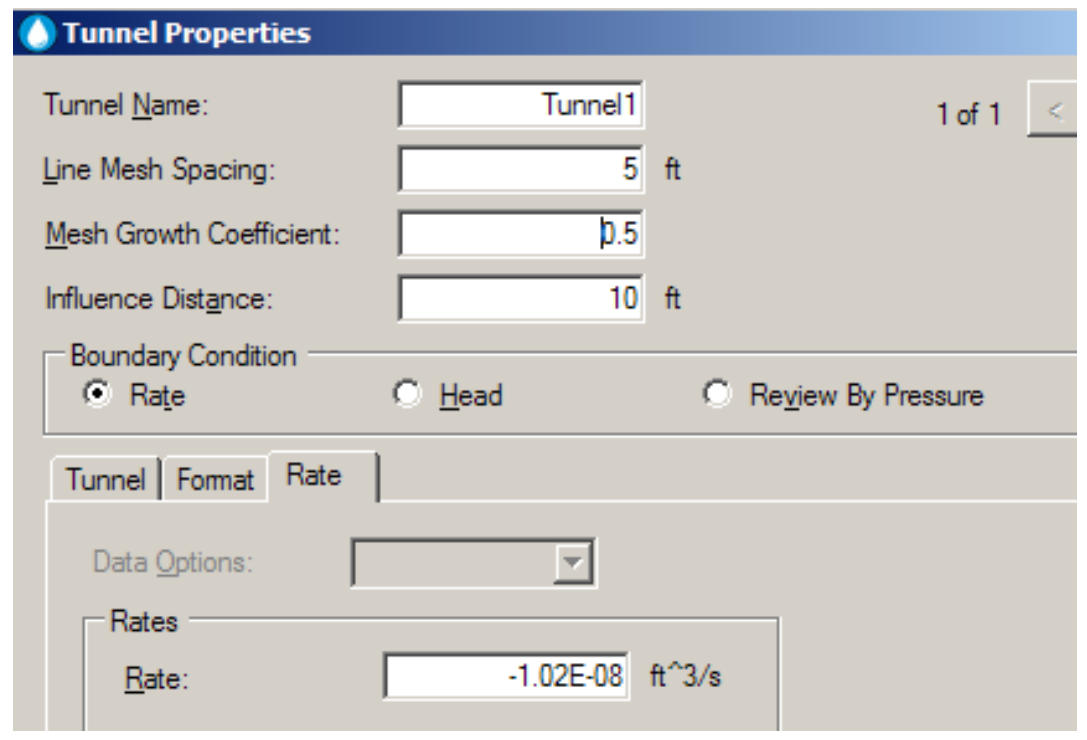

Figure 6.9: Tunnel line drain rate

The model with the flux lines used is shown in Figure 6.10. The flux lines run underneath the reservoir, on the mine roof and on the surface, dilated, fractured and caved layers along the extents of the Angle of Groundwater Influence and the Angle of Subsidence Draw. The reservoir flux line was located to on the first 50 feet of the reservoir rim. This was chosen so as to only 
detail the most crucial area where flow changes may occur. If the flux line was extended the length of the reservoir, the components would be an average over the length, giving it an inaccurate portrayal as changes are less likely to occur the greater lateral distance from the changes in rock properties.

The flow rates on each of the flux lines were measured for $\mathrm{X}, \mathrm{Y}$ and Normal components. These components were compared between pre- and post-mining conditions for full pool, summer pool and probable maximum flood reservoir offsets.

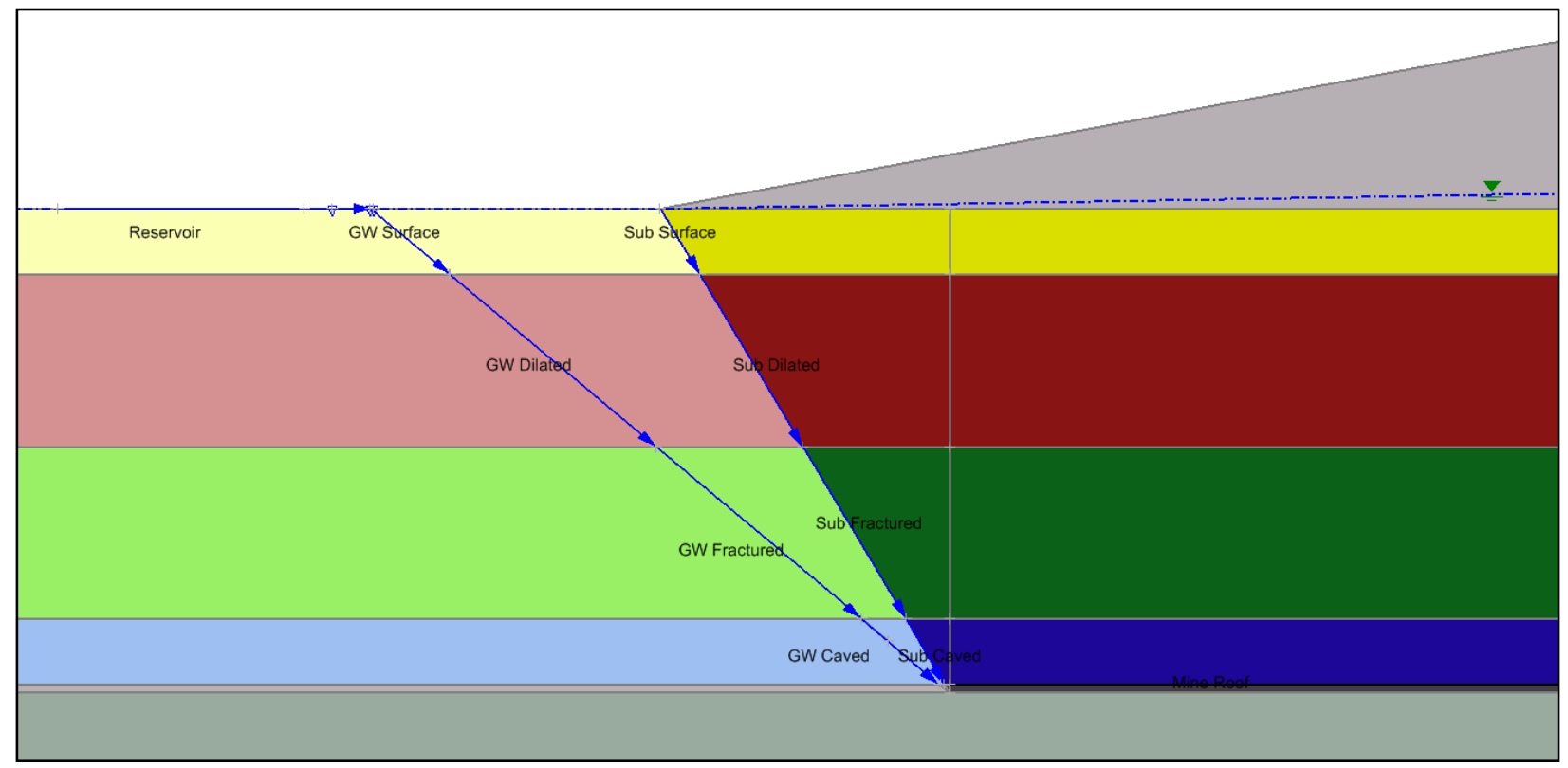

Figure 6.10: Flux line locations

An example of the readings produced for each flux line is shown in Figure 6.11. It provides the instantaneous flow rates $\left(\mathrm{ft}^{3} / \mathrm{s}\right)$ for $\mathrm{X}, \mathrm{Y}$, and normal flow. 


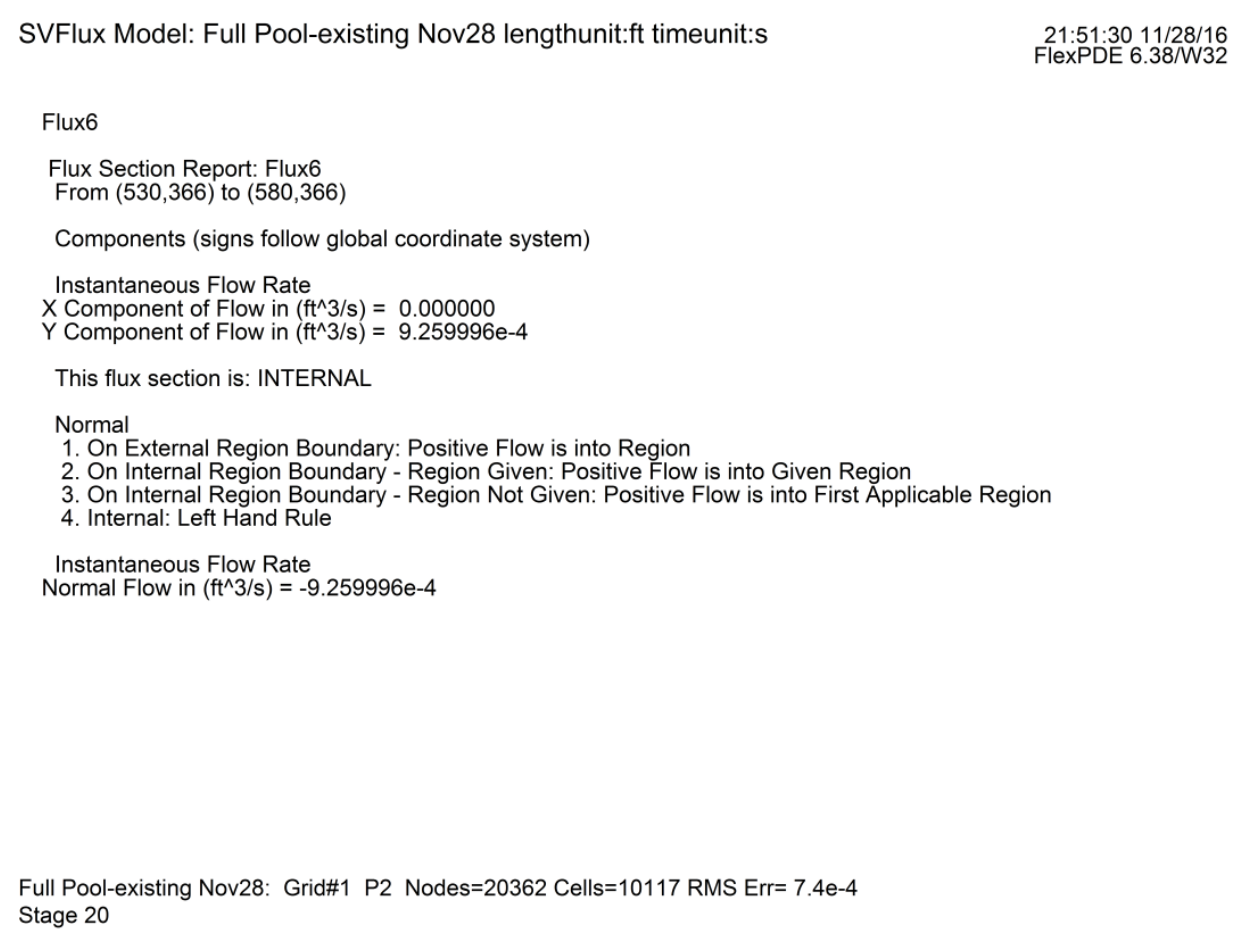

Figure 6.11: Flux line output

\subsection{Steady-State Solution Controls}

The finite element model uses triangulation to determine the variable outputs within the model. The finite element method options within SoilVision allow the user to control the solver for the modeling solution.

\subsubsection{Error limit}

There are two error limit control settings within Soil Vision; the accuracy control (ERRLIM) and the spatial accuracy control. These are an estimate of the relative error based on dependent variables (Fredlund, 2009). The model developed for the location of interest at Tygart Lake used the default setting of 0.002 for 2D modeling for the ERRLIM and 0.001 for the XERRLIM.

\subsubsection{Threshold}

The threshold is the value for which the modeling solution is set to maintain the error limit. For the design model for Tygart Lake, the primary solution variable was chosen as head (h), which was the default value. The minimum value the model was set to maintain for the head variable was 0.001 (default). 


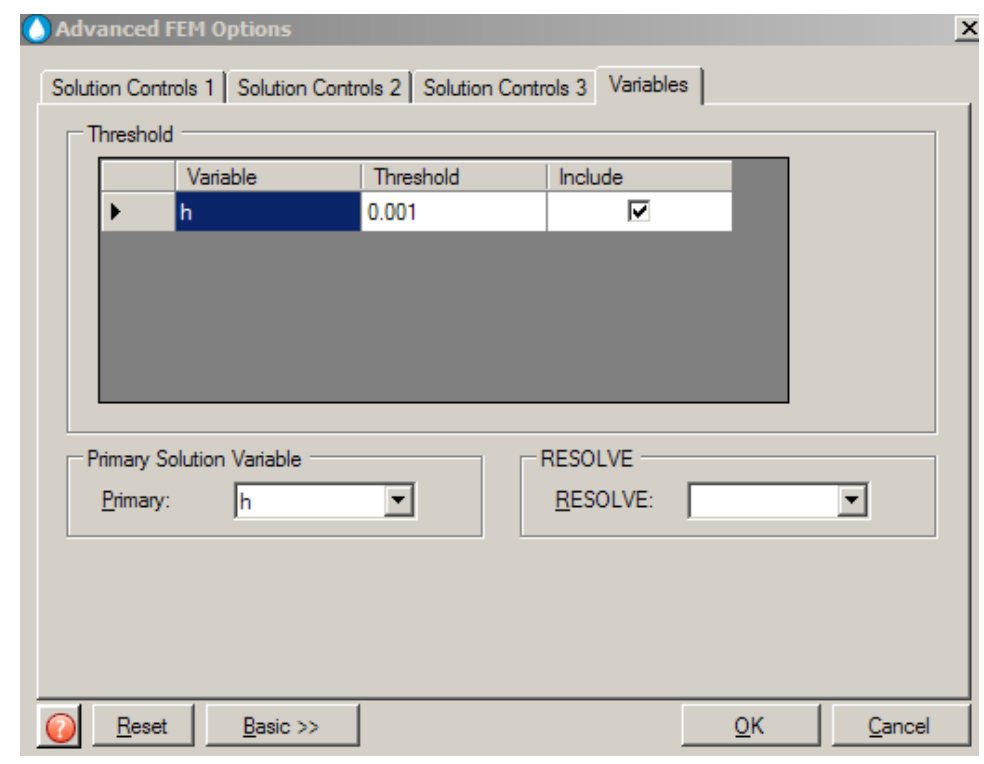

Figure 6.12: Variable threshold

\subsection{Mesh Refinement}

The mesh refinement intensified at two particular locations within the model. One was at the edge of the mined seam where the Angles of Subsidence and Groundwater Draw joined together. This was caused by the proximity of the three separate regions of material properties (Subsidence Caved, Groundwater Caved, and Coal Seam) and the tunnel drain. The second location was at the edge of the Angle of Groundwater Influence where it intersected the surface. The high mesh refinement was required for full pool conditions as the reservoir overtopped extended beyond this angle by approximately two feet laterally. The proximity of the reservoir flux line edge at full pool conditions and the regional nodes required refinement.

\subsection{Results}

Groundwater draw into the mine came via recharge from the Caved and the lower part of the Fractured Zones (Figure 6.13). The upper Fractured, Dilated and Surface zone groundwater recharge was drawn down above the mined seam. However, once the flow path reached the edge of the mine, the equipotential lines returned to that similar to pre-existing conditions. Figure 6.14 shows the flow path of the groundwater recharge under full pool conditions. Flow for the full pool and summer pool levels was similar with the exception that equipotential lines that flowed into the reservoir varied given the lateral differences in pool level. This shows that there is an 
initial drawdown of the groundwater flow above the mine. However, as it reaches material of the pre-existing conditions, the flow from the upper recharge layers continue to feed into the reservoir, rather than draw from the reservoir.

The flux lines were analyzed for the $\mathrm{X}, \mathrm{Y}$ and Normal components of flow rate $\left(\mathrm{ft}^{3} / \mathrm{s}\right)$ to show the rate of change at particular locations when a coal seam is mined. The pre-existing conditions were compared with the post-mining conditions at summer pool, full pool and PMF pool level once the model reached steady-state conditions. The only variable between the three models was the pool level extents. 


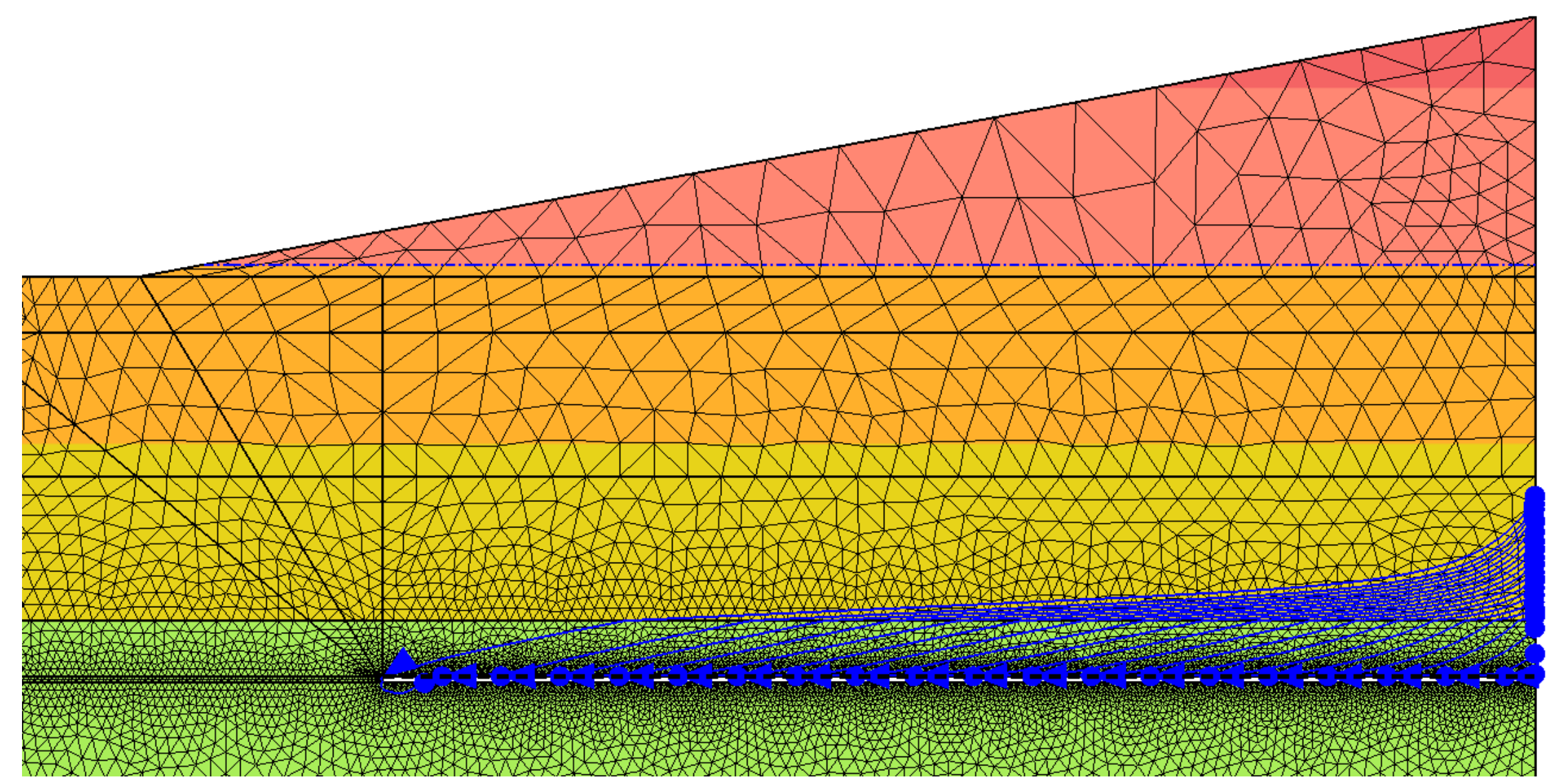

Figure 6.13: Flow path of groundwater into mine 


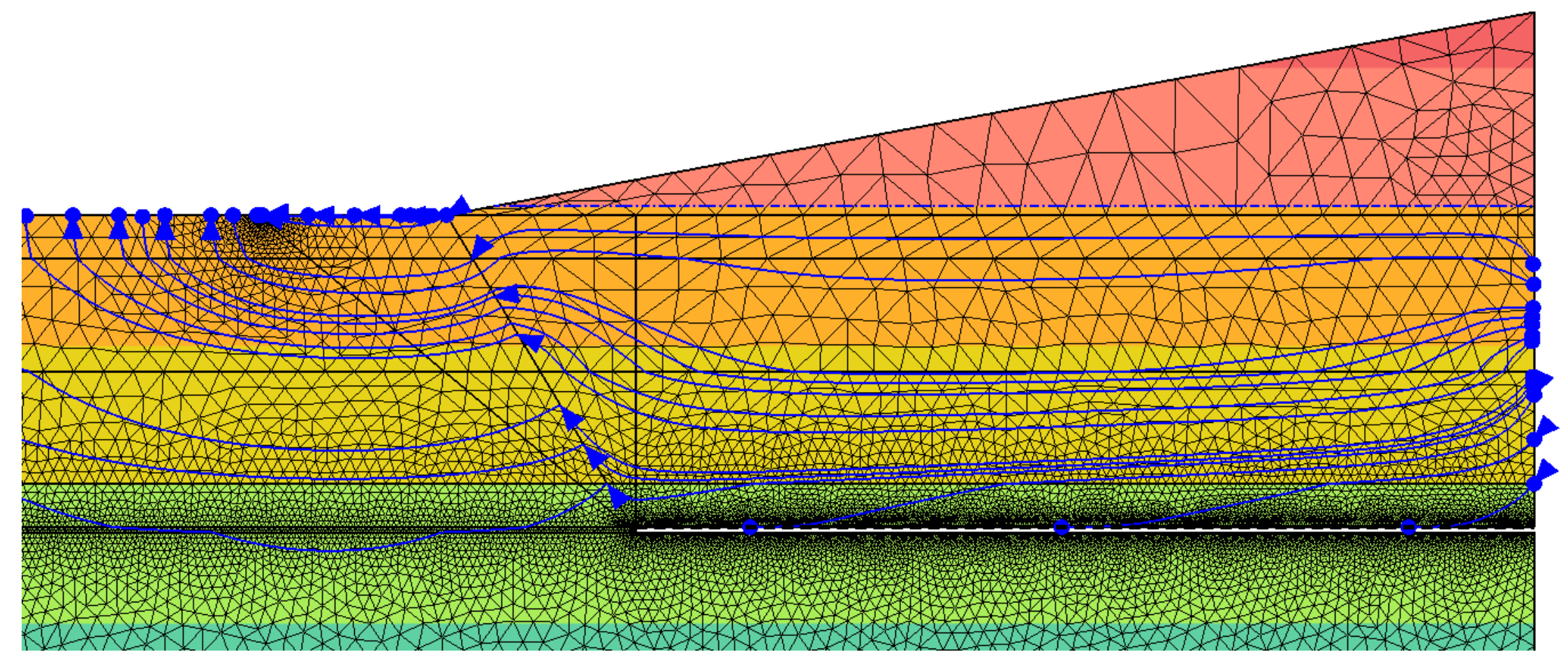

Figure 6.14: Recharge flow path for Full pool conditions 


\subsubsection{Flux Component}

The results from the X-component flow rate are shown in Table 6.8. The component's sign follows the global coordinate system. For the $\mathrm{X}$ components, a negative sign details a flow from the hillside (mine) towards the reservoir. This is to be expected as the recharge comes from the right of the model, flowing down gradient toward the reservoir. The reservoir and mine roof flux lines are zero as the flux is only measured in the $\mathrm{Y}$ direction for these components.

Table 6.8: $\mathrm{X}$ component flow rates

\begin{tabular}{|c|c|c|c|c|c|c|}
\hline \multirow[b]{2}{*}{ Flux Line } & \multicolumn{6}{|c|}{ X Component Flow Rate $\left(\mathrm{Ft}^{3} / \mathrm{s}\right)$} \\
\hline & $\begin{array}{c}\text { Pre-Existing at } \\
\text { Summer Pool } \\
\text { Level }\end{array}$ & $\mid \begin{array}{c}\text { Post-Mining at } \\
\text { SummerPool } \\
\text { Level }\end{array}$ & $\begin{array}{l}\text { Pre-Existing at } \\
\text { Full Pool Level }\end{array}$ & $\mid \begin{array}{c}\text { Post-Mining at } \\
\text { Full Pool } \\
\text { Level }\end{array}$ & $\begin{array}{c}\text { Pre-Existing at } \\
\text { PMF Pool } \\
\text { Level }\end{array}$ & $\begin{array}{l}\text { Post-Mining at } \\
\text { PMF Pool Level }\end{array}$ \\
\hline Reservoir & 0 & 0 & 0 & 0 & 0 & 0 \\
\hline GW Surface & $-1.03 \mathrm{E}-07$ & $-8.35 \mathrm{E}-08$ & $-2.67 \mathrm{E}-07$ & $-2.45 \mathrm{E}-07$ & $-1.80 \mathrm{E}-06$ & $-2.88 \mathrm{E}-06$ \\
\hline GW Dilated & $-1.07 \mathrm{E}-06$ & $-8.44 \mathrm{E}-07$ & $-1.12 \mathrm{E}-06$ & $-8.77 \mathrm{E}-07$ & $-6.58 \mathrm{E}-05$ & $-1.16 \mathrm{E}-04$ \\
\hline GW Fractured & $-2.68 \mathrm{E}-07$ & $-1.30 \mathrm{E}-07$ & $-2.68 \mathrm{E}-07$ & $-1.26 \mathrm{E}-07$ & $-1.84 \mathrm{E}-05$ & $-4.23 E-05$ \\
\hline GW Caved & $-2.50 \mathrm{E}-08$ & $-7.82 \mathrm{E}-09$ & $-2.49 \mathrm{E}-08$ & $-6.57 \mathrm{E}-09$ & $-1.16 \mathrm{E}-06$ & $-2.57 \mathrm{E}-06$ \\
\hline Sub Surface & $-1.03 \mathrm{E}-07$ & $-1.27 \mathrm{E}-07$ & $-1.07 \mathrm{E}-07$ & $-1.35 \mathrm{E}-07$ & $-2.06 \mathrm{E}-05$ & $-9.70 \mathrm{E}-06$ \\
\hline Sub Dilated & $-1.07 \mathrm{E}-06$ & $-7.50 \mathrm{E}-07$ & $-1.09 \mathrm{E}-06$ & $-7.67 \mathrm{E}-07$ & $-1.16 \mathrm{E}-04$ & $-1.12 \mathrm{E}-02$ \\
\hline Sub Fractured & $-2.68 \mathrm{E}-07$ & $-9.04 \mathrm{E}-08$ & $-2.69 \mathrm{E}-07$ & $-8.55 \mathrm{E}-08$ & $-1.61 \mathrm{E}-05$ & $-3.93 E-05$ \\
\hline Sub Caved & $-2.50 \mathrm{E}-08$ & $-8.52 \mathrm{E}-09$ & $-2.49 \mathrm{E}-08$ & $-6.81 \mathrm{E}-09$ & $-1.08 \mathrm{E}-06$ & $-2.65 \mathrm{E}-06$ \\
\hline Mine Roof & 0 & 0 & 0 & 0 & 0 & 0 \\
\hline
\end{tabular}

Overall, there was a general reduction in flow along the flux lines for summer and full pool levels. The most significant areas of reduction in the $\mathrm{X}$ direction occurred within the caved zones of Subsidence and Groundwater Draw. This is due to the mine draining the normal recharge along this zone, reducing the flow rate beyond the mine edge. The post-mining flow rates in this zone were between $26.4 \%$ and $34.1 \%$ of the pre-mining flow rates.

There was one zone that did see an increase in flow rates for summer and full pool conditions. The Surface Subsidence zone showed an increase in flow between pre- and post-mining flow. However, the increased flow rate was relatively minimal; 1.23 times and 1.26 times the premining flow rate respectively. 
The most prevalent increase in flow was within the Dilated Subsidence Zone at PMF conditions where there was an increase of over two orders of magnitude in the total flow from -1.16E-04 $\mathrm{ft}^{3} / \mathrm{s}$ ) to $-1.12 \mathrm{E}-02 \mathrm{ft}^{3} / \mathrm{s}$ down gradient. The Dilated Zone contains the sandstone aquifer and is the controlling zone for groundwater flow.

The results of the change in flow rate from pre- to post-mining for each load condition (pool level) are as follows:

\section{Summer Pool:}

- Reduction in flow rate within all zones of the Angle of Groundwater Influence. Most significant change was within the zone adjacent to the Caved Subsidence zone. The flow rate reduced from $-2.50 \mathrm{E}-08 \mathrm{ft}^{3} / \mathrm{s}$ to $-8.52 \mathrm{E}-09 \mathrm{ft}^{3} / \mathrm{s}$ or to approximately $34 \%$ of the initial flow rate.

- The Dilated, Fractured and Caved Subsidence zones showed reduced flow rates between $70.1 \%$ and $34.1 \%$ of the initial flow. The most significant was the Subsidence Caved zone with a reduction from $-2.50 \mathrm{E}-08 \mathrm{ft}^{3} / \mathrm{s}$ to $-8.52 \mathrm{E}-09 \mathrm{ft}^{3} / \mathrm{s}$.

- Increase in flow occurred within the Surface Subsidence zone. The increase in flow was 1.23 times greater than pre-mining conditions.

- No flow rate changes were greater than one order of magnitude.

\section{Full Pool:}

- Reduction in flow rate within all zones of the Angle of Groundwater Influence. The flow in the Caved Groundwater zone was 3.20 times greater under pre-mining conditions than post-mining. A reduction from $-2.49 \mathrm{E}-08 \mathrm{ft}^{3} / \mathrm{s}$ to $-6.57 \mathrm{E}-9 \mathrm{ft}^{3} / \mathrm{s}$.

- The subsided Dilated, Fractured and Caved zones showed flow rate reduction. The Caved and Fractured subsidence zones displaying a post-mining flow rates of $27.3 \%$ and $31.8 \%$ respectively of the pre-mining flow, respectively.

- The Surface Subsidence zone increased in flow rate by 1.26 times from pre- to postmining.

- No flow rate changes were greater than one order of magnitude.

\section{Probable Maximum Flood:}


- There was significant increase in flow rate in the $\mathrm{X}$ direction in all zones except for at the extents of the Surface Subsidence Zone, which decreased flow rate.

- The Dilated zone increased over two orders of magnitude from $-1.16 \mathrm{E}-04 \mathrm{ft}^{3} / \mathrm{s}$ ) to -1.12E$02 \mathrm{ft}^{3} / \mathrm{s}$.

The flow rate changes under summer and full pool load conditions were remarkably similar. This shows that the lateral offset distance of the load conditions was far enough that it did not have a significant influence in flow rate changes within areas potentially affected by underground mining. There was a general increase in flow under PMF conditions, with over two orders of magnitude within the Dilated Subsidence zone indicating that the Dilated zone (sandstone aquifer) is the controlling factor for flow.

\subsubsection{Y Flux Component}

At summer pool head level, there was a general negative (downward) flow in the Y component of the flux lines for both pre- and post-mining conditions (Table 6.9). There were, however, considerable increases in the flow rate. For summer pool level, two zones increased over three orders of magnitude; the Groundwater Dilated and Subsidence Surface zones. The Subsidence Surface zone increased from $-4.48 \mathrm{E}-12 \mathrm{ft}^{3} / \mathrm{s}$ to $-4.29 \mathrm{E}-08 \mathrm{ft}^{3} / \mathrm{s}$. The Groundwater Surface zone showed a change from minimal positive flow to negative flow $\left(7.06 \mathrm{E}-13 \mathrm{ft}^{3} / \mathrm{s}\right.$ to $\left.-6.46 \mathrm{E}-10 \mathrm{ft}^{3} / \mathrm{s}\right)$. While the equipotential lines show the flow in a downward direction within the Angles of Subsidence and Groundwater Draw, at the reservoir rim there is positive flow (recharge); albeit as a slightly diminished rate. This indicates that flow rate changes influenced by the underground mine do not have a significant effect on the reservoir, as it is 1670 feet laterally from the mine edge (1248 feet from Angle of Groundwater Influence). 
Table 6.9: Y component flow rates

\begin{tabular}{|c|c|c|c|c|c|c|}
\hline \multirow{3}{*}{ Flux Line } & \multicolumn{7}{|c|}{\begin{tabular}{c} 
Y Component Flow Rate (Ft $\left.{ }^{3} / \mathrm{s}\right)$ \\
\cline { 2 - 7 }
\end{tabular}} & $\begin{array}{c}\text { Pre-Existing at } \\
\text { Level }\end{array}$ & $\begin{array}{c}\text { Post-Mining at } \\
\text { SummerPool } \\
\text { Level }\end{array}$ & $\begin{array}{c}\text { Pre-Existing at } \\
\text { Full Pool Level }\end{array}$ & $\begin{array}{c}\text { Post-Mining at } \\
\text { Full Pool } \\
\text { Level }\end{array}$ & $\begin{array}{c}\text { Pre-Existing at } \\
\text { PMF Pool } \\
\text { Level }\end{array}$ & $\begin{array}{c}\text { Post-Mining at } \\
\text { PMF Pool Level }\end{array}$ \\
\hline Reservoir & $3.60 \mathrm{E}-07$ & $2.64 \mathrm{E}-07$ & $4.64 \mathrm{E}-07$ & $3.55 \mathrm{E}-07$ & $3.37 \mathrm{E}-08$ & $1.32 \mathrm{E}-08$ \\
\hline GW Surface & $7.06 \mathrm{E}-13$ & $-6.46 \mathrm{E}-10$ & $1.98 \mathrm{E}-07$ & $1.17 \mathrm{E}-07$ & $1.44 \mathrm{E}-05$ & $2.45 \mathrm{E}-05$ \\
\hline GW Dilated & $-2.38 \mathrm{E}-11$ & $-6.27 \mathrm{E}-08$ & $7.04 \mathrm{E}-08$ & $-1.20 \mathrm{E}-08$ & $2.81 \mathrm{E}-05$ & $5.89 \mathrm{E}-05$ \\
\hline GW Fractured & $-1.53 \mathrm{E}-10$ & $-5.67 \mathrm{E}-08$ & $1.02 \mathrm{E}-08$ & $-4.97 \mathrm{E}-08$ & $-8.87 \mathrm{E}-07$ & $1.68 \mathrm{E}-07$ \\
\hline GW Caved & $-9.86 \mathrm{E}-11$ & $-6.53 \mathrm{E}-09$ & $1.33 \mathrm{E}-09$ & $-5.07 \mathrm{E}-09$ & $-4.34 \mathrm{E}-07$ & $-1.71 \mathrm{E}-06$ \\
\hline Sub Surface & $-4.48 \mathrm{E}-12$ & $-4.29 \mathrm{E}-08$ & $3.93 \mathrm{E}-10$ & $-4.53 \mathrm{E}-08$ & $1.73 \mathrm{E}-05$ & $2.59 \mathrm{E}-05$ \\
\hline Sub Dilated & $-4.23 \mathrm{E}-11$ & $5.42 \mathrm{E}-08$ & $4.02 \mathrm{E}-09$ & $5.58 \mathrm{E}-08$ & $-7.24 \mathrm{E}-08$ & $1.17 \mathrm{E}-02$ \\
\hline Sub Fractured & $-1.09 \mathrm{E}-10$ & $-2.97 \mathrm{E}-08$ & $2.97 \mathrm{E}-09$ & $-2.80 \mathrm{E}-08$ & $-2.51 \mathrm{E}-06$ & $-8.80 \mathrm{E}-06$ \\
\hline Sub Caved & $-5.27 \mathrm{E}-11$ & $-2.67 \mathrm{E}-09$ & $6.04 \mathrm{E}-10$ & $-2.13 \mathrm{E}-09$ & $-2.29 \mathrm{E}-07$ & $-7.27 \mathrm{E}-07$ \\
\hline Mine Roof & $-2.61 \mathrm{E}-08$ & $-1.19 \mathrm{E}-08$ & $-1.96 \mathrm{E}-08$ & $-1.27 \mathrm{E}-08$ & $-2.49 \mathrm{E}-06$ & $-7.57 \mathrm{E}-07$ \\
\hline
\end{tabular}

For full pool level, the initial flow was positive (upwards) for all cases beyond flow into the existing coal seam. However, once the mine was introduced, the flow changed from an upwards flow to a downward flow along the Subsidence and Groundwater draw extents with a few exceptions. The Dilated Subsidence zone showed an increase in flow in the Y direction by $13.8 \mathrm{X}$ the pre-mining conditions. Additionally, at the Groundwater surface and Reservoir flux lines, the reservoir rim overlaps the extent of the Angle of Groundwater Influence at the surface. Positive flow in these two areas indicates that, while the groundwater flow path has changed, the reservoir is still receiving recharge. The reduction in recharge into the reservoir was limited to a difference of $1.09 \mathrm{E}-07 \mathrm{ft}^{3} / \mathrm{s}$. The flow path through the Angle of Groundwater Influence for full pool level is illustrated in Figure 6.15.

Under PMF conditions, the Dilated, and Groundwater Fractured zones changed flow in the positive (upwards) direction. The Dilated Subsidence zone flow changed flow significantly from $-7.24-08 \mathrm{ft}^{3} / \mathrm{s}$ to $1.17 \mathrm{E}-02 \mathrm{ft}^{3} / \mathrm{s}$. There was little change at the reservoir rim, which extends laterally to the edge of the mined seam, which decreased from $3.37 \mathrm{E}-08 \mathrm{ft}^{3} / \mathrm{s}$ to $1.32-08 \mathrm{ft}^{3} / \mathrm{s}$. At the Fractured and Caved Subsidence zones, the negative flow path increased after the mine was introduce and the flow entered the mine. 
The results of the change in flow rate from pre- to post-mining for each load condition (pool level) are as follows:

\section{Summer:}

- Downward flow rates increased significantly within the Angles of Subsidence and Groundwater Draw. The most prevalent was Subsidence Surface zone increased from $-4.48 \mathrm{E}-12 \mathrm{ft}^{3} / \mathrm{s}$ to $-4.29 \mathrm{E}-08 \mathrm{ft}^{3} / \mathrm{s}$ (3 orders of magnitude).

- Groundwater Surface Zone showed a change from minimal positive flow to negative flow (7.06E-13 $\mathrm{ft}^{3} / \mathrm{s}$ to $\left.-6.46 \mathrm{E}-10 \mathrm{ft}^{3} / \mathrm{s}\right)$.

- The affects on the reservoir rim were insignificant.

\section{Full Pool:}

- Flow path generally changed from a positive (upward) to negative (downward) flow postmining; with a few exceptions.

- The Dilated Subsidence Zone increased flow in the positive direction (13.9X ).

- The reservoir rim showed a minimal decrease in recharge from the groundwater.

\section{Probable Maximum Flood:}

- Downward flow in the Caved and Fractured Zones increased as flow entered the mine.

- The Dilated Subsidence zone flow changed flow significantly from $-7.24-08 \mathrm{ft}^{3} / \mathrm{s}$ to $1.17 \mathrm{E}-02 \mathrm{ft}^{3} / \mathrm{s}$.

- Flow in the Subsidence Fractured zone increased over two orders of magnitude. 


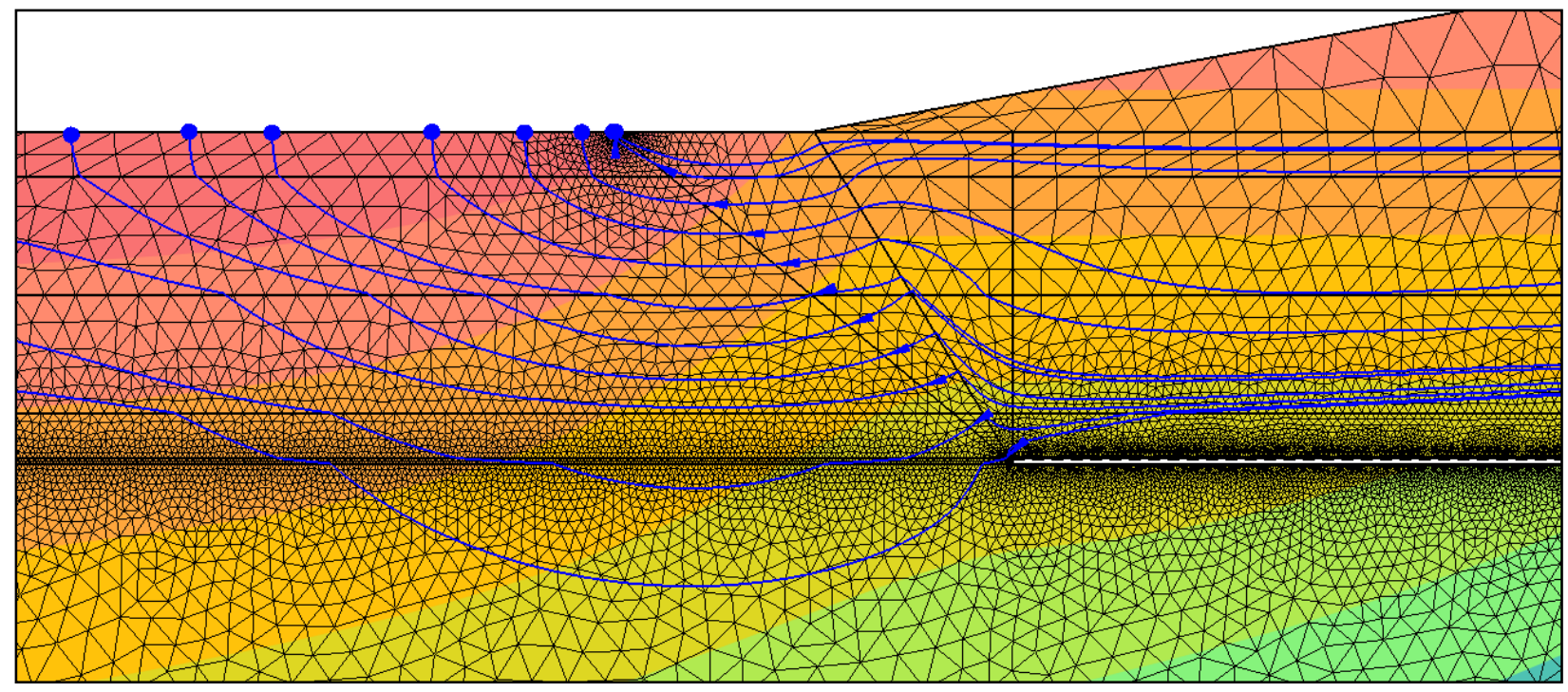

Figure 6.15: Groundwater flow through the Angle of Groundwater Influence at full pool level

\subsubsection{Normal Flow Rate}

The normal flow rate, shown in Table 6.10, is based on the left hand rule for internal boundaries. For external boundaries, positive flow is into the region, negative is out. At the reservoir rim, a positive value is flow from the reservoir into the surface zone. At the mine drain, negative flow represents the draw from the Caved Zone into the mine. For both of these instances the change in flow rate is the same as the $\mathrm{Y}$ components, as there is no $\mathrm{X}$ component considered at these locations for the model.

For summer and full pool load conditions, there were limited changes between pre- and postmining for each flux section. The range of changes at post-mining, excluding the mine roof as this change is due to the tunnel section, for summer pool was between 0.45 (Subsidence Fractured) and 1.65 (Surface Subsidence) times the pre-mining flow rates. For full pool level, the change ranged from 0.43 to 1.86 times, with the upper and lower limits the same zones the same as summer pool.

Full Pool and Summer Pool levels were remarkable similar in all of the regions, including reservoir flow rate and mine infiltration rate. This indicates that for these two cases, the pool level had a limited affect on the overall changes in groundwater flow. The most significant difference between the Full and Summer Pool levels was the flow rate at the reservoir rim, at a difference of 9.10-E-08 $\mathrm{ft}^{3} / \mathrm{s}$. 
Table 6.10: Normal flow rates

\begin{tabular}{|c|c|c|c|c|c|c|}
\hline \multirow{2}{*}{ Flux Line } & \multicolumn{7}{|c|}{\begin{tabular}{c} 
Normal Flow Rate (Ft $\left.{ }^{3} / \mathrm{s}\right)$ \\
\cline { 2 - 7 }
\end{tabular}} & $\begin{array}{c}\text { Pre-Existing at } \\
\text { Level }\end{array}$ & $\begin{array}{c}\text { Post-Mining at } \\
\text { SummerPool } \\
\text { Level }\end{array}$ & $\begin{array}{c}\text { Pre-Existing at } \\
\text { Full Pool Level }\end{array}$ & $\begin{array}{c}\text { Post-Mining at } \\
\text { Full Pool } \\
\text { Level }\end{array}$ & $\begin{array}{c}\text { Pre-Existing at } \\
\text { PMF Pool } \\
\text { Level }\end{array}$ & $\begin{array}{c}\text { Post-Mining at } \\
\text { PMF Pool Level }\end{array}$ \\
\hline Reservoir & $-3.60 \mathrm{E}-07$ & $-2.64 \mathrm{E}-07$ & $-4.64 \mathrm{E}-07$ & $-3.55 \mathrm{E}-07$ & $3.37 \mathrm{E}-08$ & $1.32 \mathrm{E}-08$ \\
\hline GW Surface & $-1.03 \mathrm{E}-07$ & $-8.42 \mathrm{E}-08$ & $-6.88 \mathrm{E}-08$ & $-1.28 \mathrm{E}-07$ & $1.26 \mathrm{E}-05$ & $2.17 \mathrm{E}-05$ \\
\hline GW Dilated & $1.07 \mathrm{E}-06$ & $9.06 \mathrm{E}-07$ & $1.05 \mathrm{E}-06$ & $8.89 \mathrm{E}-07$ & $3.78 \mathrm{E}-05$ & $5.68 \mathrm{E}-05$ \\
\hline GW Fractured & $-2.68 \mathrm{E}-07$ & $-1.87 \mathrm{E}-07$ & $-2.57 \mathrm{E}-07$ & $-1.76 \mathrm{E}-07$ & $-1.93 \mathrm{E}-05$ & $-4.22 \mathrm{E}-05$ \\
\hline GW Caved & $2.51 \mathrm{E}-08$ & $1.43 \mathrm{E}-08$ & $2.34 \mathrm{E}-08$ & $1.16 \mathrm{E}-08$ & $1.60 \mathrm{E}-06$ & $4.28 \mathrm{E}-06$ \\
\hline Sub Surface & $1.03 \mathrm{E}-07$ & $1.70 \mathrm{E}-07$ & $1.06 \mathrm{E}-07$ & $1.80 \mathrm{E}-07$ & $3.34 \mathrm{E}-06$ & $-1.62 \mathrm{E}-05$ \\
\hline Sub Dilated & $-1.07 \mathrm{E}-06$ & $-6.96 \mathrm{E}-07$ & $-1.09 \mathrm{E}-06$ & $-7.11 \mathrm{E}-07$ & $-1.16 \mathrm{E}-04$ & $1.47 \mathrm{E}-04$ \\
\hline Sub Fractured & $2.68 \mathrm{E}-07$ & $1.20 \mathrm{E}-07$ & $2.66 \mathrm{E}-07$ & $1.14 \mathrm{E}-07$ & $1.87 \mathrm{E}-05$ & $4.81 \mathrm{E}-05$ \\
\hline Sub Caved & $2.51 \mathrm{E}-08$ & $1.12 \mathrm{E}-08$ & $2.43 \mathrm{E}-08$ & $8.94 \mathrm{E}-09$ & $1.31 \mathrm{E}-06$ & $3.37 \mathrm{E}-06$ \\
\hline Mine Roof & $2.61 \mathrm{E}-08$ & $-1.19 \mathrm{E}-08$ & $1.96 \mathrm{E}-08$ & $-1.27 \mathrm{E}-08$ & $-2.49 \mathrm{E}-06$ & $-7.57 \mathrm{E}-07$ \\
\hline
\end{tabular}

At PMF conditions, post-mining flow rates were between $0.37 \mathrm{X}$ and $0.67 \mathrm{X}$ the pre-mining flow within the Angle of Groundwater Influence. In the Angle of Subsidence, the Dilated Subsidence zone changed flow from a downward gradient flow to an upward flow, from -1.16-E04 $\mathrm{ft}^{3} / \mathrm{s}$ to 1.47-E04 $\mathrm{ft}^{3} / \mathrm{s}$. At the PMF reservoir. The flow reduction is the same as the Y component, as there is no X component for this particular flux line (or Mine Roof flux line). The reduction in flow, and the overall lower initial flow rates as compared to the summer and full pool levels, shows that as the reservoir rim encroaches the mine edge, the head reduces the flow of the underlying rock layers.

\subsubsection{Increased Flow Rate}

The computer model was also run using highly increased flow rates based on Darcy's law. This was performed to compare the changes in flow paths between anticipated low recharge rates with heavier flow to determine what impact may occur. A summary of the results, shown in Tables 6.11 and 6.12, are: 


\section{Component}

\section{Summer Pool:}

- The Dilated, Fractured and Caved Subsidence zones showed reduced flow rates between $81.9 \%$ and $30.5 \%$ of the initial flow. The most significant was the Subsidence Caved zone with a reduction from $-5.01 \mathrm{E}-05 \mathrm{ft}^{3} / \mathrm{s}$ to $-1.53 \mathrm{E}-05 \mathrm{ft}^{3} / \mathrm{s}$.

- Increase in flow occurred within the Surface Subsidence zone. The increase in flow was 1.41 times greater than pre-mining conditions.

- No flow rate changes were greater than one order of magnitude.

\section{Full Pool:}

- Reduction in flow rate within all zones of the Angle of Groundwater Influence. The flow Caved Groundwater zone was 3.78 times greater under pre-mining conditions than post-mining. A reduction from $-4.95 \mathrm{E}-05 \mathrm{ft}^{3} / \mathrm{s}$ to $-1.31 \mathrm{E}-05 \mathrm{ft}^{3} / \mathrm{s}$.

- The subsided Dilated, Fractured and Caved zones showed flow rate reduction. The Caved and Fractured subsidence zones displaying a flow rates of $27.4 \%$ and $31.6 \%$ respectively.

- The Surface Subsidence zone increased in flow rate by 1.29 times from pre- to postmining.

- No flow rate changes were greater than one order of magnitude.

\section{Probable Maximum Flood:}

- There was significant reduction in flow rate in all zones except for the Dilated Subsidence zone; between $5.6 \%$ and $21.7 \%$ the rate post-mining compared to premining.

- The Dilated zone increased over one order of magnitude (11.5X) from -1.06E-03 $\mathrm{ft}^{3} / \mathrm{s}$ to $-1.22 \mathrm{E}-02 \mathrm{ft}^{3} / \mathrm{s}$. 
Table 6.11: $\mathrm{X}$ component flow rates

\begin{tabular}{|c|c|c|c|c|c|c|}
\hline \multirow{2}{*}{ Flux Line } & \multicolumn{7}{|c|}{\begin{tabular}{c} 
X Component Flow Rate (Ft $\left.{ }^{3} / \mathrm{s}\right)$ \\
\cline { 2 - 7 }
\end{tabular}} & $\begin{array}{c}\text { Pre-Existing at } \\
\text { Level }\end{array}$ & $\begin{array}{c}\text { Post-Mining at } \\
\text { SummerPool } \\
\text { Level }\end{array}$ & $\begin{array}{c}\text { Pre-Existing at } \\
\text { Full Pool Level }\end{array}$ & $\begin{array}{c}\text { Post-Mining at } \\
\text { Full Pool } \\
\text { Level }\end{array}$ & $\begin{array}{c}\text { Pre-Existing at } \\
\text { PMF Pool } \\
\text { Level }\end{array}$ & $\begin{array}{c}\text { Post-Mining at } \\
\text { PMF Pool Level }\end{array}$ \\
\hline Reservoir & 0 & 0 & 0 & 0 & 0 & 0 \\
\hline GW Surface & $-2.06 \mathrm{E}-04$ & $-1.81 \mathrm{E}-04$ & $-5.32 \mathrm{E}-04$ & $-4.27 \mathrm{E}-04$ & $-1.33 \mathrm{E}-05$ & $-2.79 \mathrm{E}-06$ \\
\hline GW Dilated & $-2.15 \mathrm{E}-03$ & $-1.82 \mathrm{E}-03$ & $-2.23 \mathrm{E}-03$ & $-1.76 \mathrm{E}-03$ & $-5.48 \mathrm{E}-04$ & $-1.19 \mathrm{E}-04$ \\
\hline GW Fractured & $-5.36 \mathrm{E}-04$ & $-2.79 \mathrm{E}-04$ & $-5.32 \mathrm{E}-04$ & $-2.52 \mathrm{E}-04$ & $-2.90 \mathrm{E}-04$ & $-4.39 \mathrm{E}-05$ \\
\hline GW Caved & $-5.01 \mathrm{E}-05$ & $-1.51 \mathrm{E}-05$ & $-4.95 \mathrm{E}-05$ & $-1.31 \mathrm{E}-05$ & $-3.59 \mathrm{E}-05$ & $-2.00 \mathrm{E}-06$ \\
\hline Sub Surface & $-2.06 \mathrm{E}-04$ & $-2.91 \mathrm{E}-04$ & $-2.12 \mathrm{E}-04$ & $-2.74 \mathrm{E}-04$ & $-4.96 \mathrm{E}-05$ & $-8.25 \mathrm{E}-06$ \\
\hline Sub Dilated & $-2.15 \mathrm{E}-03$ & $-1.76 \mathrm{E}-03$ & $-2.17 \mathrm{E}-03$ & $-1.65 \mathrm{E}-03$ & $-1.06 \mathrm{E}-03$ & $-1.22 \mathrm{E}-02$ \\
\hline Sub Fractured & $-5.36 \mathrm{E}-04$ & $-1.90 \mathrm{E}-04$ & $-5.35 \mathrm{E}-04$ & $-1.69 \mathrm{E}-04$ & $-3.62 \mathrm{E}-04$ & $-4.06 \mathrm{E}-05$ \\
\hline Sub Caved & $-5.01 \mathrm{E}-05$ & $-1.53 \mathrm{E}-05$ & $-4.96 \mathrm{E}-05$ & $-1.36 \mathrm{E}-05$ & $-3.73 \mathrm{E}-05$ & $-2.49 \mathrm{E}-06$ \\
\hline Mine Roof & 0 & 0 & \multicolumn{7}{c}{0} & 0 & 0 & 0 \\
\hline
\end{tabular}

\section{Y Component}

\section{Summer:}

- Downward flow rates increased significantly within the Angles of Subsidence and Groundwater Draw. The most prevalent was Subsidence Surface zone increased from --1.07E-08 $\mathrm{ft}^{3} / \mathrm{s}$ to $-9.80 \mathrm{E}-05 \mathrm{ft}^{3} / \mathrm{s}$ (almost 4 orders of magnitude).

- Groundwater Surface Zone showed a change from minimal positive flow to negative flow (1.38E-09 $\mathrm{ft}^{3} / \mathrm{s}$ to $\left.-2.61 \mathrm{E}-06 \mathrm{ft}^{3} / \mathrm{s}\right)$.

- The affects on the reservoir rim were insignificant.

\section{Full Pool:}

- Flow path generally changed from a positive (upward) to negative (downward) flow post-mining; with a few exceptions.

- The Dilated Subsidence Zone increased flow in the positive direction.

- The reservoir rim showed a minimal decrease in recharge from the groundwater. 


\section{Probable Maximum Flood:}

- Flow in the Caved and Fractured Zones changed from positive to negative as flow entered the mine.

- Flow at the reservoir rim decreased 5 orders of magnitude from $2.70 \mathrm{E}-04 \mathrm{ft}^{3} / \mathrm{s}$ to $9.81 \mathrm{E}-09 \mathrm{ft}^{3} / \mathrm{s}$.

- The Dilated Subsidence zone flow rate increased by a factor of 47 (over one order of magnitude) from $2.63 \mathrm{E}-04 \mathrm{ft}^{3} / \mathrm{s}$ to $1.24 \mathrm{E}-02 \mathrm{ft}^{3} / \mathrm{s}$.

- Flow in the groundwater Caved and Fractured zones changed over one order of magnitude.

Table 6.12: Y component flow rates

\begin{tabular}{|c|c|c|c|c|c|c|}
\hline \multirow[b]{2}{*}{ Flux Line } & \multicolumn{6}{|c|}{ Y Component Flow Rate $\left(\mathrm{Ft}^{3} / \mathrm{s}\right)$} \\
\hline & $\begin{array}{c}\text { Pre-Existing at } \\
\text { Summer Pool } \\
\text { Level }\end{array}$ & $\begin{array}{c}\text { Post-Mining at } \\
\text { SummerPool } \\
\text { Level }\end{array}$ & $\begin{array}{l}\text { Pre-Existing at } \\
\text { Full Pool Level }\end{array}$ & $\begin{array}{c}\text { Post-Mining at } \\
\text { Full Pool } \\
\text { Level }\end{array}$ & $\begin{array}{c}\text { Pre-Existing at } \\
\text { PMF Pool } \\
\text { Level }\end{array}$ & $\begin{array}{l}\text { Post-Mining at } \\
\text { PMF Pool Level }\end{array}$ \\
\hline Reservoir & 6.73E-04 & 5.66E-04 & $9.26 \mathrm{E}-04$ & 7.36E-04 & 2.70E-04 & 9.81E-09 \\
\hline GW Surface & 1.38E-09 & $-2.61 \mathrm{E}-06$ & 3.94E-04 & 3.11E-04 & $1.26 \mathrm{E}-04$ & $2.50 \mathrm{E}-05$ \\
\hline GW Dilated & $-5.08 \mathrm{E}-08$ & $-1.38 \mathrm{E}-04$ & $1.41 \mathrm{E}-04$ & $-2.05 E-05$ & 3.10E-04 & 6.19E-05 \\
\hline GW Fractured & $-3.10 \mathrm{E}-07$ & $-1.19 \mathrm{E}-04$ & 2.03E-05 & $-9.90 \mathrm{E}-05$ & $1.06 \mathrm{E}-04$ & $2.42 \mathrm{E}-06$ \\
\hline GW Caved & $-1.98 \mathrm{E}-07$ & $-1.16 \mathrm{E}-05$ & 2.63E-06 & $-1.02 \mathrm{E}-05$ & 1.12E-05 & $-1.10 \mathrm{E}-06$ \\
\hline Sub Surface & $-1.07 \mathrm{E}-08$ & $-9.80 \mathrm{E}-05$ & $8.14 \mathrm{E}-07$ & $-9.21 \mathrm{E}-05$ & $1.56 \mathrm{E}-04$ & $2.67 \mathrm{E}-05$ \\
\hline Sub Dilated & $-9.54 \mathrm{E}-08$ & $6.59 \mathrm{E}-05$ & $8.16 \mathrm{E}-06$ & $6.78 \mathrm{E}-05$ & $2.63 \mathrm{E}-04$ & $1.24 \mathrm{E}-02$ \\
\hline Sub Fractured & $-2.21 \mathrm{E}-07$ & $-6.24 \mathrm{E}-05$ & 5.90E-06 & $-5.55 E-05$ & 5.54E-05 & $-8.49 \mathrm{E}-06$ \\
\hline Sub Caved & $-1.06 \mathrm{E}-07$ & $-4.78 \mathrm{E}-06$ & 1.20E-06 & $-4.28 \mathrm{E}-06$ & $5.38 \mathrm{E}-06$ & $-6.63 E-07$ \\
\hline Mine Roof & $-4.78 \mathrm{E}-05$ & $-1.68 \mathrm{E}-05$ & $-4.52 \mathrm{E}-05$ & $-2.55 E-05$ & $-3.83 E-05$ & $-2.62 \mathrm{E}-05$ \\
\hline
\end{tabular}

The results show that under low and large recharge flow rates, the changes in groundwater flow paths above a mine and extending in the Angle of Groundwater Draw are remarkably similar under summer and full pool conditions. While the actual flow rates are dependent on the inflow, the degree of increase or decrease in flow is approximately the same.

However, under PMF conditions where the reservoir rim overlaps the Angle of Groundwater Draw, there are significant differences. Under the limited recharge scenario, the increased head was substantial enough to increase flow into the Caved and Fractured Subsidence Zones. Given high recharge rates, while drawdown does occur, the drainage into the mine is not enough to significantly draw flow from the reservoir into the Fractured and Caved Zones. 


\subsection{Analysis of Findings}

Based on the modeling results for summer, full and PMF pool conditions, with recharge based on infiltration, only the PMF pool met the requirement of change in flow below the reservoir greater than one order of magnitude. This occurred in the Dilated Subsidence Zone for the X and Y components. In the X direction of the Dilated Subsidence zone, flow increased 96.5X from pre- to post-mining.

At the reservoir rim for summer and full pool levels, there was minimal change from pre- to post-mining. This coincides with literature showing the maximum extents of drawdown at approximately 60 degrees, and generally within 40 degrees. The summer pool level is 1670 feet laterally from the mine edge and over 1200 feet beyond the maximum estimated extents of groundwater draw.

Although the full pool level encroaches the edge of the 60 degree potential Angle of Groundwater Influence, for this modeling scenario, the lateral distance from the mine was large enough that it did not have a distinguishable impact. The similarities between the full and summer pool levels indicate that, for significant changes in groundwater flow affecting a reservoir to occur, the reservoir pool level at Tygart Lake must, at minimum, be within 60 degrees of the mine edge.

While there were significant changes at full and summer pool levels, none met the threshold for failure (minimum one order of magnitude). In fact, the changes in the sub-surface were remarkably similar between the two, indicating that if the reservoir rim is beyond the Angle of Subsidence Draw, it has limited affect on the groundwater flow rates within the affected area.

Additionally, the results in this chapter are based on the maximum potential increase in hydraulic conductivity. Actual changes in the overburden would not exceed and likely be less than the conservative approach detailed here. For Full and PMF Pool conditions, there is also the consideration that the pool levels will rarely occur and only for a short timeframe whereas the reservoir will consistently reach summer pool level.

From the findings of the modeling analysis of Tygart Lake, there is a potential for erosion to occur below the reservoir rim at PMF pool levels due to changes in hydraulic conductivity greater than one order of magnitude within the overburden. At summer and full pool levels, the 
changes below the reservoir do not meet the required increase in flow rate and therefore would not be considered a potential risk for erosion to occur. The lateral offset distance and potential for erosion is shown in Figure 6.16.

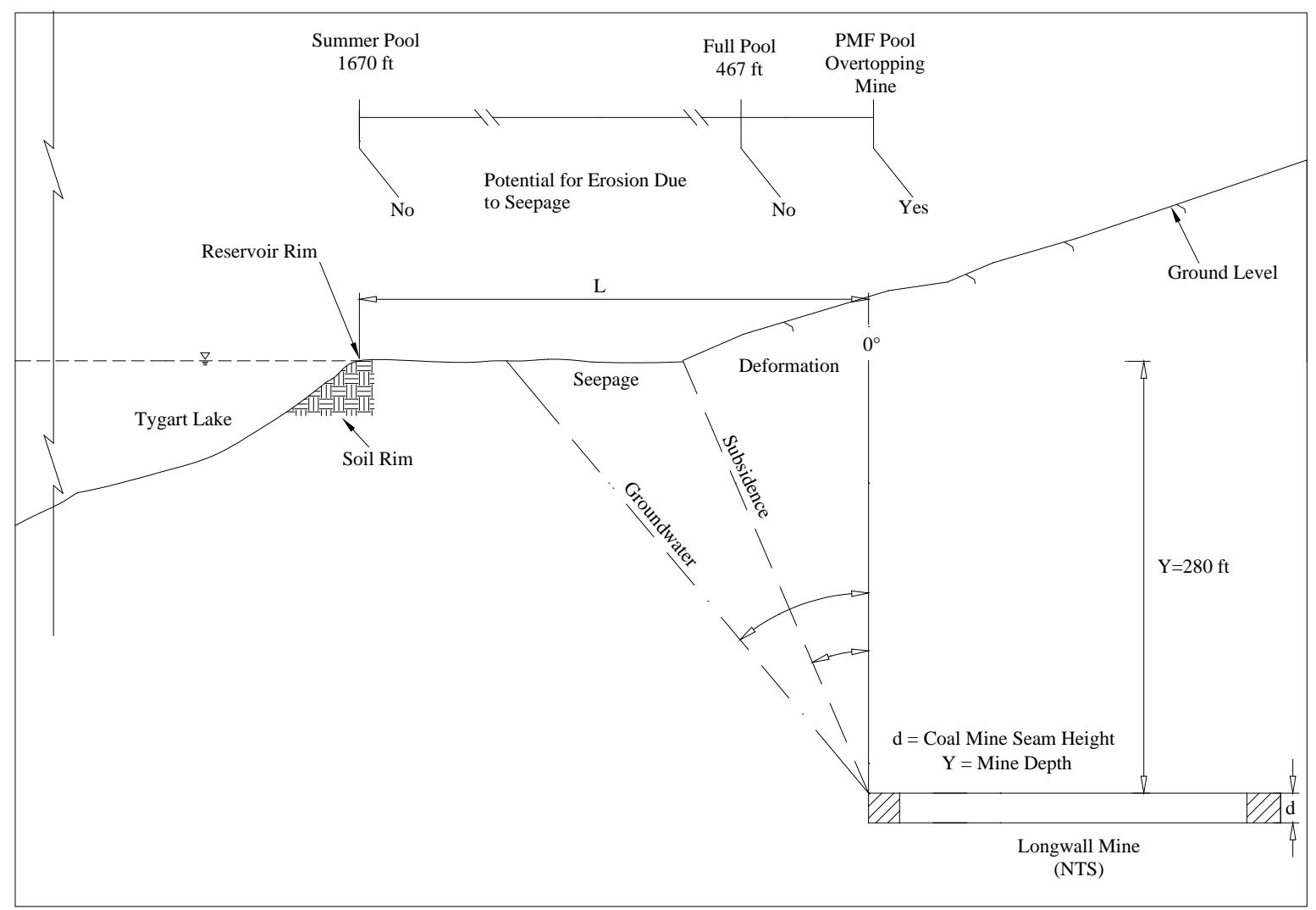

Figure 6.16: Potential for erosion at Tygart Lake based on lateral offset distance 


\section{CHAPTER 7: Summary of Findings}


The work provided in this research evaluates the potential failure modes for seepage to occur at a reservoir rim due to underground mining. The scope of the research was separated into four tasks: 1) a thorough literature review of mine subsidence prediction and empirical assessment, 2) semi-quantitative sensitivity analysis of risk based events for seepage mode failure near reservoirs, 3) numerical analysis assessing seepage at a field site and 4) a method to develop potential failure mode analysis of a mine site. The objective was to use event tree analysis through empirical and analytical methods, developing a methodology for a semi-quantitative seepage failure mode for underground mining near reservoirs. The methodology produced an event tree probability tool based on offset distance and an outline of defining parameters. This chapter summarizes the findings and details the benefits of the research.

\subsection{Task I: Literature Review}

The basis of this research began with Information Curricular (IC) 8741 . IC8741 is a set of offset guidelines developed in the late 1970's for underground mining near surface water bodies that was developed from two separate contracts with the former Bureau of Mines. However, the scope of the guidelines was based on protection of the mine workers during operation of the mine only. There was little discussion on the impacts mining would have on surface water bodies. The purpose of this literature review was to provide information from all facets to better understand the effects from underground mining as it pertains to groundwater flow and seepage. The Literature review in this research is separated into two chapters: Chapter 1 was dedicated to the geological and hydrological impacts of underground mining while Chapter 2 compared and contrasted the four publications on guidance for mining under water bodies.

Chapter 1 focuses on the geological and hydrological impacts of underground mining. The review details how a mine void, through subsidence, initiates changes in the overburden through fracturing, extensional strain and bedding plane separation. The changes alter the permeability of the rock layers, increasing the potential hydrologic conductivity beyond the extents of the mine. The affected groundwater flow may be temporally or permanently disrupted as pathways may extend into the mine void or differentiate from the original flow path, potentially creating drawdown from a surface water body. Increased hydraulic conductivity may initiate internal erosion which could create a pathway from a reservoir, leading to uncontrollable head loss. 
Chapter 2 is a concise comparison of IC8741 (Babcock and Hooker, 1977) with reports by Skelly and Loy (1976), Wardell (1976), and Kendorski and Singh (1979). The purpose was to show how each differentiated in regards to the methods and recommendations for offset based on lateral and vertical distance. Skelly and Loy presented two separate methods: one designed for maximum protection of miners with little or no subsurface exploration and one for evaluating specific conditions, allowing for the greatest potential coal extraction. Kendorski and Singh's objective was to determine how the water body size affects the potential hazard to the mine, potentially increasing mineral extraction. However, all four reports recommended a minimum offset distance of $200 \mathrm{ft}$ from a reservoir for mines up to 350 feet in depth.

Outcomes from the literature review include:

- The Angle of Subsidence Draw due to full extraction mining may extend up to 45 degrees from vertical outside a mined panel.

- Groundwater influence may extend beyond 60 degrees beyond a mined panel.

- Hydraulic conductivities may increase up to two orders of magnitude in sandstone and three orders of magnitude in shale within the subsidence zone.

Although the literature review presented in this research is a summary of existing work, it also provides a benefit as a standalone document for any research that pertains to changes in overburden due to mining. While the aim was to determine the impacts on surface water bodies, the same foundation of work may be applied to any areas where seepage or groundwater flow changes may be of concern due to mining. These can include head loss in wells, environmental risk to groundwater and flora, and erosion under developed areas. For research on surface water bodies, Chapter 2 provides a quick reference guide to the studies offset distances and parameters that were developed into the current federal guidelines.

\subsection{Task 2: Probabilistic Analysis Method}

For the probabilistic method analysis, an event tree failure mode was developed for Longwall (full extraction) and Room and Pillar mining (partial extraction). Comparison between the two types of mining showed differences in the length of time subsidence occurs within the overburden. For longwall mining, 95\% of subsidence occurs during the mining operation (active subsidence). However, for Room and Pillar mining, very little initial subsidence occurs as the 
weight of the strata is supported by the pillars. For partial (<70\%) extraction Room and Pillar mining, subsidence occurs gradually over decades to over one hundred years as pillars begin to fail. In the long term, Room and Pillar mining effects can be reviewed the same as Longwall mining in that, once total pillar failure occurs, the full effects of subsidence has occurred.

The event tree analysis of Longwall mining was developed based on five parameters leading to a conditional event: is erosion of the subsurface likely to occur (Figure 7.1): 1) pool elevation, 2) time interval, 1) Angle of Subsidence Draw, 4) Angle of Groundwater Influence and 5) permeability increase in the strata layers.

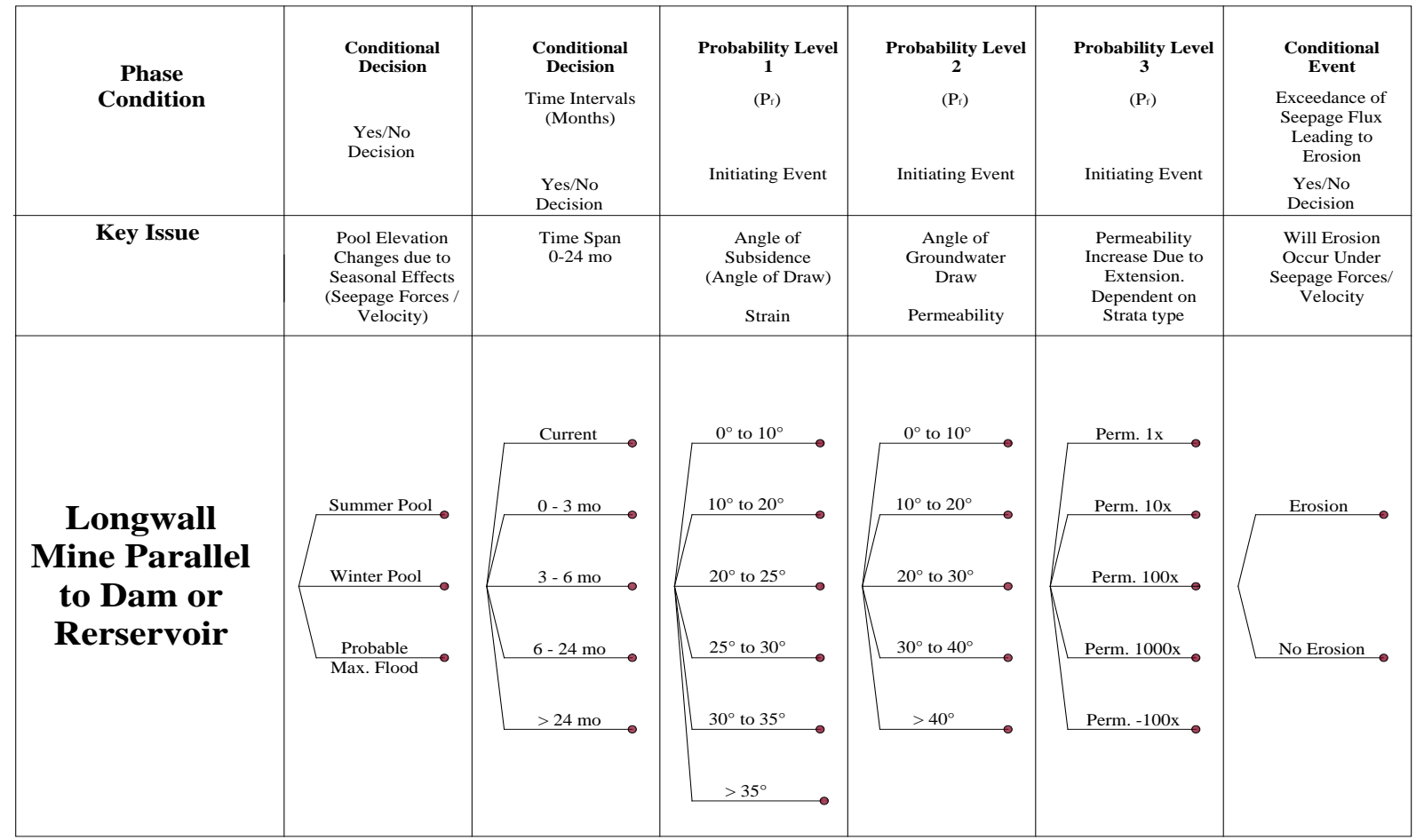

Figure 7.1: Event tree for longwall mining

Outcomes of this research are that the pool level, Angle of Subsidence Draw and Angle of Groundwater Influence all affect the lateral offset distance from a mine to a reservoir. The Angle of Groundwater Influence is dictated by terrain type and the Angle of Subsidence Draw in that, the extent of changes in groundwater flow is affected by gradient will extend beyond the Angle of Subsidence Draw. The permeability increase of the overburden layers is based on the highest potential increase determined by rock type and initial hydraulic conductivity. 
Numerical values and conditional decision values were applied to the Longwall (Full Extraction) event tree to evaluate the probability determined for each branch of the event tree. General analysis was applied to the Longwall mining event tree for offset distances of 200 feet, 400 feet, and 600 feet and showed that at a 200 foot offset, the potential for erosion at the reservoir rim was $41 \%$. At $400 \mathrm{ft}$ offset, the probability for initiation of erosion reduced to $0.66 \%$ and at 600 feet the probability is $0.0067 \%$.

Table 7.1: Probability for erosion given Angle of Subsidence Draw

\begin{tabular}{|c|c|c|c|c|c|c|c|}
\hline \multirow[b]{2}{*}{ Offset Distance } & \multicolumn{6}{|c|}{ Potential for Erosion Given Angle of Subsidence Draw } & \multirow{2}{*}{$\begin{array}{c}\text { Total } \\
\text { Probability }\end{array}$} \\
\hline & $\begin{array}{c}0-10 \\
\text { Degrees }\end{array}$ & $\begin{array}{c}10-20 \\
\text { Degrees }\end{array}$ & $\begin{array}{c}20-25 \\
\text { Degrees }\end{array}$ & $\begin{array}{c}25-30 \\
\text { Degrees }\end{array}$ & $\begin{array}{c}\text { 30-35 } \\
\text { Degrees }\end{array}$ & $\begin{array}{c}35-40 \\
\text { Degrees }\end{array}$ & \\
\hline $200 \mathrm{ft}$ & 0.001 & 0.096 & 0.127 & 0.118 & 0.050 & 0.017 & 0.41 \\
\hline $400 \mathrm{ft}$ & 0.000 & 0.000 & 2.3E-03 & $2.3 \mathrm{E}-03$ & $1.1 \mathrm{E}-03$ & $9.5 \mathrm{E}-04$ & $6.6 \mathrm{E}-03$ \\
\hline $600 \mathrm{ft}$ & 0.000 & 0.000 & 0.000 & 0.000 & $5.0 \mathrm{E}-05$ & $1.7 \mathrm{E}-05$ & 6.7E-05 \\
\hline
\end{tabular}

\subsection{Task 3: Semi-Quantitative Sensitivity Analysis}

The Semi-Quantitative Risk Assessment (SQRA) was developed to calculate the likelihood of seepage changes affecting a surface water body due to underground coal mining. This was based on U.S. Army Corps of Engineers' methodology and the event tree analysis described in Chapter 3. For the potential failure mode analysis (PFMA) presented in this research, there were four developed elements:

- Loading: Pool Elevation affecting the lateral offset distance between the reservoir and the mine

- Flaw: Underground mining creates subsidence extending outward known as the Subsidence Angle of Draw.

- Pathway: Changes in hydraulic conductivity and groundwater flow extending beyond the Subsidence Angle of Draw.

- Initiation: Conditional decision whether the changes in the overburden represent a potential to initiate seepage from the reservoir. 


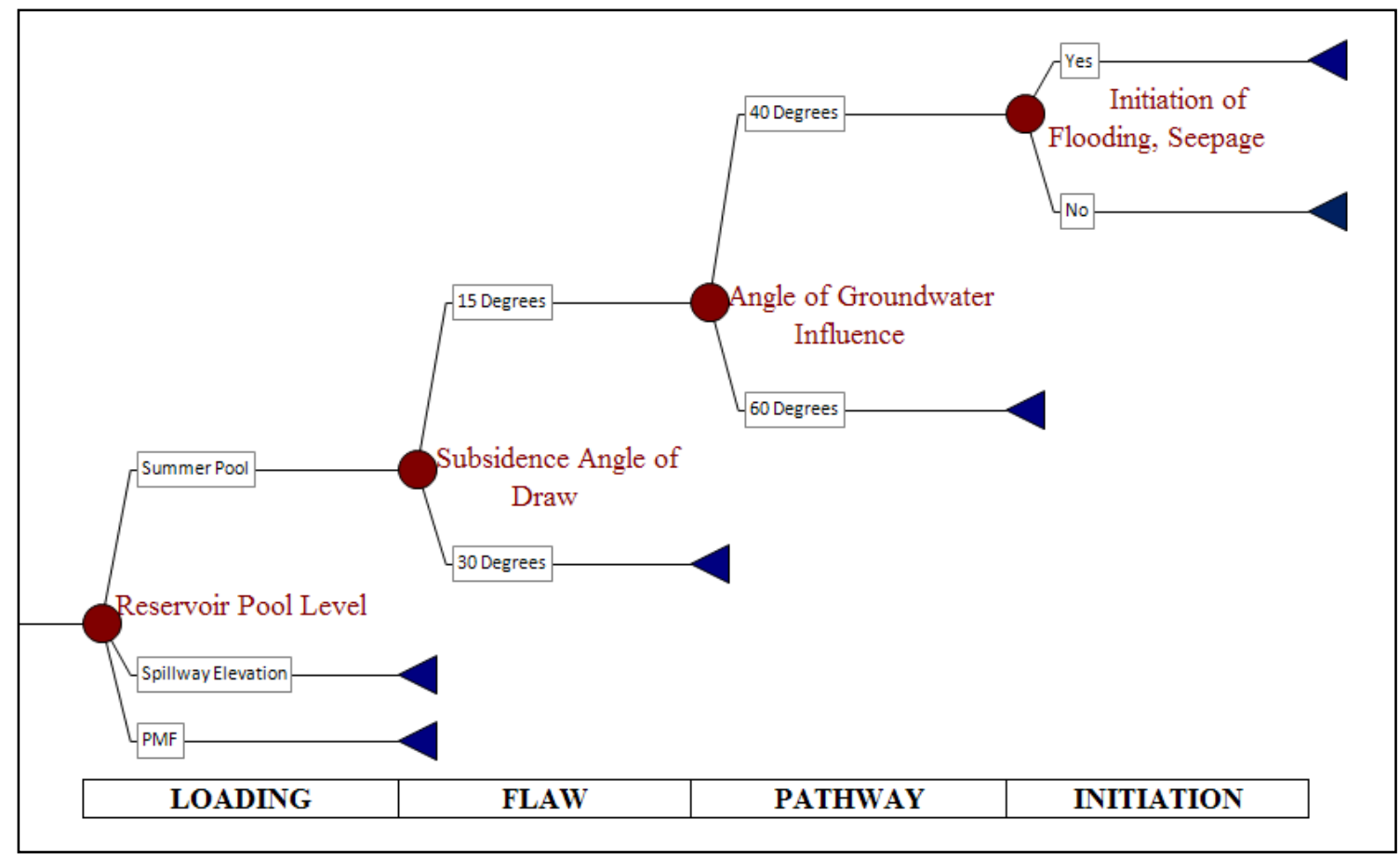

Figure 7.2: Example of PFMA event tree analysis

The four key elements would tie into the USACE methodology for intervention and the likelihood of failure by uncontrolled head loss in the reservoir.

For the PFMA, a planned mine near Tygart Lake in Grafton, WV was chosen solely based the available data from WVDEP. The PFMA was performed using given mine depth, rock properties and nearest lateral offset distances for various pool levels of the reservoir. The analysis was compared with probability of occurrence based on literature, with a potential failure mode considered to be intersection of the reservoir with the Angle of Groundwater Influence. At PMF level, the reservoir overtopped the barrier pillars of the mine, initiating a potential failure. At full pool level, 420 feet laterally from the mine, groundwater influence would have to extend outwards from the mine at an angle of 50.66 degrees. The probability of failure at this offset distance was $0.5 \%$. At summer pool level, the 1670 foot offset distance was well beyond any potential impact at the reservoir rim. 


\subsection{Task 4: Computer Modeling Assessment}

Finite Element Computer modeling analysis was performed on the same location of Tygart Lake as was in the SQFMA performed in Task 3 using SoilVision ${ }^{\circledR}$ software. The basic model approach used five homogeneous layers of overburden based on Kendorski (1993) for the zones of subsidence, groundwater draw and pre-existing conditions. Mine depth, offset distances and initial rock properties were developed using collected field data from the WVDEP. The model was calibrated and run for pre- and post-mining conditions for summer pool, full pool and probable maximum flood levels. The hydraulic conductivities of each layer for subsidence were changed based on rock type at intervals based on the literature. Flux lines were created at the extents of the Angle of Subsidence Draw, Angle of Groundwater Influence, the reservoir rim, and the mine roof. These were measured in the X, Y, and Normal directions.

The outcome showed that under PMF conditions, there were changes in the groundwater flow rate of greater than one order of magnitude in the X direction (96.5X) in the Dilated Subsidence zone beneath the reservoir rim and increased and significantly increased and changed flow direction in the $\mathrm{Y}$ direction. This constituted a potential failure as the degree of change within the Dilated Subsidence zone may initiate erosion and seepage from the reservoir. Flow paths show that there is drawdown from the reservoir into the Dilated Zone. Reservoir rim proximity and recharge rate appear to have a significant effect on drawdown from a reservoir.

At full pool and summer pool levels, there were significant changes in the groundwater flow within the Angles of Subsidence and Groundwater Draw. The most notable flux section changes were at the extents of the Surface and Dilated zones in the Y direction at summer pool level and the Surface Subsidence zone under full pool conditions. However, there were no significant changes at or beneath the reservoir rim for either of these scenarios for Tygart Lake that would constitute a potential failure. In fact, summer and full pool levels returned similar results, indicating that under these geological conditions, if the reservoir pool level does not intersect the Angle of Subsidence Draw, the mine has limited affect on the reservoir.

The findings from the computer modeling analysis showed that under PMF conditions, there is a potential for erosion to initiate beneath the reservoir rim at Tygart Lake given hydraulic conductivity increases within the overburden. The potential risk, determined by computer modeling analysis based on offset distance for Tygart Lake, is shown in Figure 7.3. 


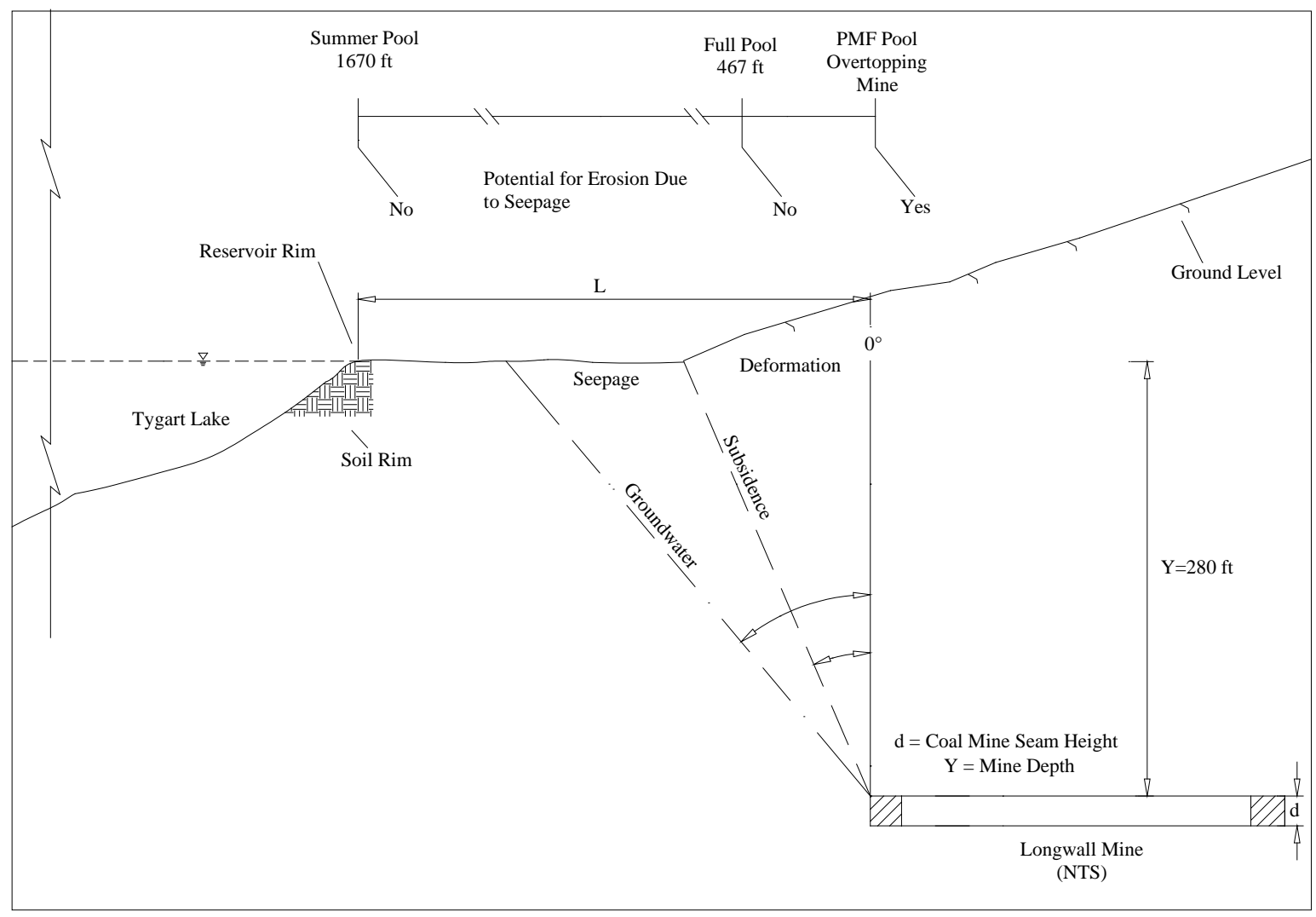

Figure 7.3: Potential for erosion at Tygart Lake based on lateral offset distance

\subsection{Conclusions}

IC8741 was developed to protect mine workers during the operation of the mine. The guidelines recommend a lateral offset distance of $200 \mathrm{ft}$ from PMF levels for mines up to 350 feet in depth and extending outward 25 degrees as depth increased. The outcome of the research presented in this study shows that changes in groundwater flow that may potentially affect surface water bodies extend beyond the offset guidelines provided in IC8741. Literature has shown that subsidence due to mining may extend greater than 40 degrees while groundwater flow may be affected above 60 degrees.

This research was performed to create a methodology for determining the potential hazard to a surface water body based on subsidence effects due to underground mineral extraction through event tree analysis. It shows that a risk based analysis method is possible for determining the extent of groundwater changes due to underground mining.

This research provides: 
- Developmental outline process detailing the factors that affect changes in groundwater flow due to underground mining and the parameters required to perform a risk based analysis including:

o Mine design and specifications

o Subsurface geology

o Subsidence extents and effects

- Development of event trees for partial (room and pillar) and full extraction (longwall) mining based on conditional and probabilistic criteria:

o Factors leading to maximum potential subsidence (conditional)

o Reservoir pool level ( conditional)

o Angle of Subsidence Draw (probabilistic)

o Angle of Groundwater Influence (probabilistic)

o Potential increase in hydraulic conductivity (probabilistic)

- Empirical and analytical analysis of a field site detailing the application of the methodology presented in this research depicting:

o Required initially known conditions

o utilization of known parameters

o application of event tree analysis

- Analytical analysis of a field site detailing:
o Model development and variables
o Boundary conditions
o Calibration using known and estimated initial hydraulic conductivities
o Evaluation of results

The developed technique was applied using probabilistic (empirical) and computer modeling (analytical) methods at a mine site near Tygart Lake in Grafton, WV to determine if the potential for failure due to erosion is significant. Both methods showed that at PMF pool level, conditions were sufficient to potentially initiate erosion.

The results of the SQRA and modeling analysis indicate that groundwater flow will be affected beyond the extent of permeability changes (Angle of Subsidence Draw) created due to underground mining. Drawdown, described as the cone of depression, will affect flow into and 
beneath the reservoir if it lies within the extent of the Angle of Groundwater Influence. If the change in flow is significant, it can initiate seepage leading to erosion. Erosion beneath the rim of a reservoir may inhibit the authorized purpose of the dam, potentially leading to failure.

The SQRA analysis at Tygart Lake showed that there was a $0.5 \%$ probability (empirical) that the Angle of Groundwater Influence would intersect the reservoir rim. Similarly, modeling analysis (analytical) determined that groundwater flow rates in the bedding layers beneath the reservoir rim increased over one order of magnitude under PMF conditions due to altered flow path created by the mine. Subsidence Draw due to underground mining may extend greater than 40 degrees while groundwater flow may be affected beyond 60 degrees. This can potentially initiate erosion beneath the reservoir rim. From the modeling analysis, it shows that the controlling factor is the rock layer above the Fractured Zone that has the highest initial hydraulic conductivity. For Tygart Lake, this was a sandstone layer within the Dilated Zone that acted as a buffer between the shallow flow and the mine.

The results of the analysis performed at Tygart Lake are limited by the criterion set in this research. The findings are based on changes in groundwater flow occurring at or beneath the reservoir. This occurred in both methods under PMF pool conditions. However, probable maximum flood conditions are an unlikely event. The potential for initiation of seepage leading to erosion detailed in this research would have to be correlated with the likelihood of a PMF to occur. Additionally, the timeframe for failure would require consideration as surface soils and bedding layers (such as shale) will self heal, returning permeabiltiy to near pre-mining conditions over time. These aspects would need to be applied by those authorized to maintain the integrity of the reservoir and used in determination of what changes constitute a potential failure.

This methodology and analysis provides a foundation for failure mode assessment of reservoirs adjacent to underground mines. Future research in the event tree notation may provide a more customized approach to determining potential risk factors. Increased 2D or 3D modeling, extending the layout and parameters of the mine and geological features, would provide additional details of the overall affect mining has on surface water bodies. 


\section{References}

Alexander, D.W. (2006). The Expected Value of Catastophies in Underground Coal Mines 19872001. Dissertation. West Virginia University. Morgantown, WV. 238pp.

Babcock, C.O., Hooker, V.E. (1977). Results of Research to Develop Guidelines for Mining Near Surface and Underground Bodies of Water, IC 8741. [Washington, D.C.] US Department of Interior, Bureau of Mines Information Circular.

Bai, M., Kendorski, F., Van Roosendaal, D. (1995). Chinese and North American HighExtraction Underground Coal Mining Strata Behavior and Water Protection Experience and Guidelines, Proc. 14th Conf. on Ground Control in Mining, West Virginia University, Morgantown, pp 209-217.

Booth, C. J. (1986). Strata-Movement Concepts and the Hydrogeological Impact of Underground Coal Mining. Groundwater, 24(4), 507-515.

Booth, C. J. and Spande, E. D. (1992), Potentiometric and Aquifer Property Changes Above Subsiding Longwall Mine Panels, Illinois Basin Coalfield. Ground Water, 30: 362-368.

Booth, C. J., A. M. Curtiss, Demaris, P.J., Bauer, R.A. (2000). "Site-specific variation in the potentiometric response to subsidence above active longwall mining." Environmental \& Engineering Geoscience 6(4): 383-394.

Booth, C. J. (2002). The effects of longwall coal mining on overlying aquifers. Mine Water Hydrogeology and Geochemistry. London, Geological Society. 198: 17-45.

Booth, C. J. (2006). Groundwater as an environmental constraint of longwall coal mining. Environmental Geology 49(6): 796-803.

Brown, A.J., Bridle, R.C. (2008). Progress in assessing internal erosion. Ensuring Reservoir Safety into the future. London, UK.

Craft, J. L. (1992) "Classification of Mine-Related Subsidence East of the Mississippi River, U.S.A.," 11th International Conference on Ground Control in Mining, The University of Wollongong, N.S.W.

Dolinar, D. R. (1999). Variation of Horizontal Stresses and Strains in Mines in Bedded Desposits in the Eastern and Midwestern United States. Pittsburgh, PA, National Institute for Occupational Safety and Health: 8pp.

Elsworth, D., \& Liu, J. (1995). Topographic Influence of Longwall Mining on Ground-Water Supplies. Groundwater, 33(5), 786-793. 
Farmer, I. (1992). Room and Pillar Mining. SME Mining Engineering Handbook. H. L. Hartman. Littleton, Colorado, Society for Mining, Metallurgy, and Exploration, Inc. Volume 2: p 1681-1701.

Federal Emergency Management Agency. (2004). Federal Guidelinesfor Dam Safety: Hazard Potential Classification System for Dams.

Fell, R., Bowles, D.S., Anderson, L.R., Bell, G. (2000). The status of methods for estimation of the probability of failure of dams for use in quantitative risk assessment. Proc. International Commission on Large Dams $20^{\text {th }}$ Congress, Beijing, China.

Fredlund, M. D. (1996). SoilVision users guide, Version 2.0.

Google. (2016). Tygart Lake. Map Data: USDA Farm Service Agency. Retrieved December 1, 2016

Guo, W., K. Morsy, Peng S. (2007). Relationship between Mining Subsidence and Mining Depth in Strip Pillar Mining. 26th International Conference on Ground Control in Mining. Morgantown, WV: 85-88.

Hopey, D. (1992), "Pennsylvania Says Mining destroyed lake dam in park Consol Energy sued for \$58 million to fix Greene Co. damage,” Pittsburgh Post-Gazette, Friday, February 01, 2008.

Jaegar, J., Cook, N., Zimmerman, R. (2007) Fundamentals of Rock Mechanics, $4^{\text {th }}$ Edition. Wiley-Blackwell. Hoboken, NJ. 488pp.

Karmis, M., Haycocks, C., Agioutantis, Z. (1992). The Prediction of Ground Movements caused by Mining. Proceedings, 3rd Workshop on Surface Subsidence due to Underground Mining, Morgantown, WV: 1-9.

Kelleher, J.T., Ven Roosendaal, D.J., Mehnert, B.B., Brutcher, D.F., Bauer, R.A. (1991), Overburden Deformation and Hydrologic Changes Due to Longwall Coal Mine Subsidence on the Illinois Basin. Land subsidence. Proc $4^{\text {th }}$ Int Symp Land subsidence, Houston, TX $12-$ 17 May. IAHS Publication No. 200, pp 1985-204.

Kendorski, F. S., Singh, M.M. (1979). Criteria for Determining When a Body of Surface Water Constitutes a Hazard to Mining. Downers Grove, Ill, Engineers International, INC: 364pp.

Kendorski, F.S. (1993), Effect of High-Extraction Coal Mining on Surface and Ground Waters, Proc. 12th Conf. on Ground Control in Mining, West Virginia University, Morgantown, p412-425pp. 
Mastalerz, M., He, L., Melnichenko, Y. B., \& Rupp, J. A. (2012). Porosity of coal and shale: insights from gas adsorption and SANS/USANS techniques. Energy \& Fuels, 26(8), 51095120.

Michael, P. R., Richmond, M. W., Superfesky, M. J., STUMP, D. E., \& Chavel, L. K. (2010). Potential of Breakthroughs of Impounded Coal Refuse Slurry into Underground Mines. Environmental \& Engineering Geoscience, 16(3), 299-314.

Mine Safety and Health Administration (MSHA) and Office of Surface Mining (OSM) (2003), "Report to Congress, Responses to Recommendations In the National Research Council's Report Coal Waste Impoundments: Risks, Responses, and Alternatives,” US Department of Labor and US Office of Department of Interior, Washington, D.C.

Office of Surface Mining, Reclamation, and Enforcement (OSM) (2006), "Slurry Impoundment Breakthroughs,” Charleston Field Office, US Department of Interior, Charleston, WV.

Peng, S. S., Cheng, S. L. (1980). Prediction of Surface Subsidence Profile Due to Underground Coal Mining. Department of Mining Engineering, College of Mineral and Energy Resources, West Virginia University.

Peng, S.S., Chiang, H.S. (1992). Longwall Mining. SME Mining Engineering Handbook. H. L. Hartman. Littleton, Colorado, Society for Mining, Metallurgy, and Exploration, Inc. Volume 2: $1780-1788$.

Peng, S. S., Luo, Y., \& Zhang, Z. M. (1995). Development of a subsidence database and determination of subsidence parameters. In Proceedings $14^{\text {th }}$ International Conference on Ground Control in Mining, Morgantown 226-235.

Reed, C., Rauch, H. (2001), Mining Induced Streamflow Loss for Spruce Laurel Fork in Boone County, West Virginia, Proc. 2001 National Association of Abandoned Mine Land Programs Annual Conference, Athens, Ohio, 24pp.

Roth, R., Randolph, J., Zipper, C. (1990). High-Extraction Mining, Subsidence and Virginia's Water Resources. Blacksburg: Virginia Center for Coal and Energy Reserarch, 87pp.

Scott, G. A. (2011). The practical application of risk assessment to dam safety. In GeoRisk 2011: Geotechnical Risk Assessment and Management. ASCE. 129-168.

Shakoor, A., \& Barefield, E. H. (2009). Relationship between unconfined compressive strength and degree of saturation for selected sandstones. Environmental \& Engineering Geoscience, 15(1), 29-40.

Singh, M. M. (1992). Mine Subsidence. SME Mining Engineering Handbook. H. L. Hartman. Littleton, Colorado, Society for Mining, Metallurgy, and Exploration, Inc. Volume 1: 939-97 
Skelly and Loy (1976). "Guidelines for Mining Near Water Bodies, Phase III - Final Report.” U.S. Department of Interior, Bureau of Mines, Project No. HO252083, Denver, CO.

Sydney Catchment Authority (2007). Literature review on longwall mining.

Thode, R. (2012). SVFLUX: Saturated/Unsaturated Finite Element 2D/3D Seepage Modeling Tutorial Manual, Theory Manual. SoilVision Systems LTD. Saskatoon, Saskatchewan, Canada. 110pp.

Unites States Department of Labor, Mine Safety and Health Administration (MSHA), (1999). “Dust- What you Can’t See CAN Hurt You.” National Mine Health and Safety Academy, 27pp.

United States Army Corps of Engineers (USACE) (1994). Authorized and Operating Purposes of Corps of Engineers Reservoirs, Hydraulics \& Hydrology Branch, PR-19, November 1994.

United States Army Corps of Engineers (USACE) (2008), Establishment of Risk Management Center (RMC) as an Expertise Center (CX) and Directory of Expertise (DX) at the U.S. Army Institute for Water Resources (CEIWR). Department of the Army, U.S. Army Corps of Engineers, Washington, D.C., November 20, 2008.

Van Roosendaal, D. J., Kendorski, F. S., Padgett, J.T. (1995). Application of Mechanical and Groundwater-Flow Models to Predict the Hydrogeologic Effects of Longwall Subsidence- A Case Study. 14th Conference on Ground Control in Mining. Morgantown, WV: 252-260.

Wachtel, T. (2012), Sensitivity Analysis of Risk Quidelines for Mining near Impounding Structures and Bodies of Water. Masters Thesis. West Virginia University, Morgantown

Wagner, H. (1980). Pillar design in coal mines. JS Afr Inst Min Metall, 80, 37-45.

Wardell, K., and Partners (1976). Guidelines For Mining Under Surface Water. Phase III and Final Report, U.S. Bureau of Mines - Contract No. HO.25201, K. Wardell \& Partners, Newcastle Staffs [England].

West Virginia Department of Environmental Protection (WVDEP), (2009). Permit ID U200406, Tygart \#1 Mine.

Wyrick, G. G., \& Borchers, J. W. (1981). Hydrologic effects of stress-relief fracturing in an Appalachian valley (No. 2177). GPO. 51pp.

Zimmerman, K., Fritschen, R. (2007). Study about the Dynamic Influences of Longwall Mining in the US on Surface Structures. 26 ${ }^{\text {th }}$ International Conference on Ground Control in Mining. Morgantown, WV: 79- 